\title{
Application Requinements for Wind Turbine Gearboxes
}

Robert Errichello

Jane Muller

GEARTECH

Albany, California

NREL technical monitor: Walt Musial

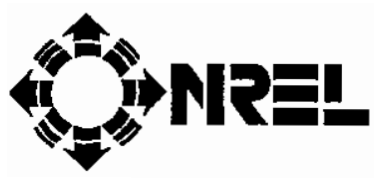

National Renewable Energy Laboratory 1617 Cole Boulevard Golden, Colorado 80401-3393

A national laboratory of the U.S. Department of Energy Managed by Midwest Research Institute for the U.S. Department of Energy under contract No. DE-AC36-83CH10093

Prepared under Subcontract No. AAO-3-13247-01

September 1994 


\section{NOTICE}

This report was prepared as an account of work sponsored by an agency of the United States government. Neither the United States government nor any agency thereof, nor any of their employees, makes any warranty, express or implied, or assumes any legal liability or responsibility for the accuracy, completeness, or usefulness of any information, apparatus, product, or process disclosed, or represents that its use would not infringe privately owned rights. Reference herein to any specific commercial product, process, or service by trade name, trademark, manufacturer, or othenwise does not necessarily constitute or imply its endorsement, recommendation, or favoring by the United States government or any agency thereof. The views and opinions of authors expressed herein do not necessarily state or reflect those of the United States government or any agency thereof.

Available to DOE and DOE contractors from:

Office of Scientific and Technical Information (OSTI)

P.O. Box 62

Oak Ridge, TN 37831

Prices available by calling (615) 576-8401

Available to the public from:

National Technical Information Service (NTIS)

U.S. Department of Commerce

5285 Port Royal Road

Springfield, VA 22161

(703) $487-4650$ 


\section{PREFACE}

A central component in every wind turbine design is the gearbox. Its reliability and cost are critical factors in the success of the overall design. Historically, the wind turbine industry has been plagued with gearbox failures, which have affected virtually every type of wind turbine configuration. In spite of the overall rise in productivity in the California wind farms, these failures have significantly hampered energy production and have placed a high maintenance burden on wind farm operators.

Many of these failures can be directly attributed to poor communication between the wind turbine engineer and the gearbox supplier. Successful wind turbine gearbox applications require a close working relationship between these two disciplines, with the active involvement of the wind turbine engineer during the design and procurement process. The wind turbine engineer must have enough knowledge to specify the application, environment, loads, gear life and quality, acceptance criteria, noise, and many other factors, and relate this information to the gearbox vendor. The reliability of the next generation of wind turbine gearboxes will depend on understanding the gearbox loads and proper design and specification of the gearbox components. Similarly, gearbox life expectancy will depend on the ability of wind turbine operators to make informed decisions about operation and maintenance.

This report was written by Robert Errichello and Jane Muller of GEARTECH in Albany, California. GEARTECH is a gear consulting firm that has investigated most of the problems common to wind turbine gearbox applications. Over the past decade, they have examined and analyzed numerous gearbox failures from a wide range of wind turbine configurations and sizes. This report is a compilation of their unique experience in the form of a technical guide. The objective is to help close the information gap among the gear industry, the wind turbine designers, and the wind turbine operators by providing a common information source for wind turbine gearbox applications. This report will assist in selecting, designing, manufacturing, procuring, operating and maintaining gearboxes for use on wind turbines.

Walt Musiàl

National Rë́newable Energy Laboratory

\section{Acknowledgements}

Many people have contributed to this document. The authors would like to thank the following people for their comments and suggestions: Walt Musial and Darrell Dodge, National Renewable Energy Laboratory; Brent Reardon, MSA; Brian McNiff, McNiff Light Industries; and John Westergard, Boreal Enterprises. The Department of Energy is credited for its funding of this document through the National Renewable Energy Laboratory under contract number DE-AC36-83CH10093. 


\section{Table of Contents}

Page

Preface $\ldots \ldots \ldots \ldots \ldots \ldots \ldots \ldots \ldots \ldots \ldots \ldots \ldots \ldots \ldots \ldots \ldots \ldots \ldots$ iii

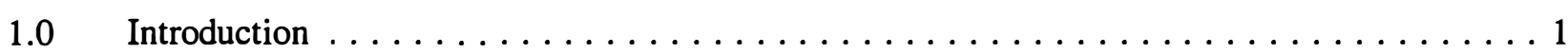

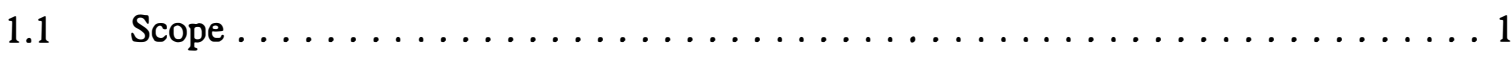

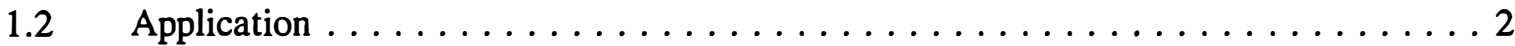

1.3 Wind Turbine Definitions and Symbols $\ldots \ldots \ldots \ldots \ldots \ldots \ldots \ldots \ldots \ldots \ldots$

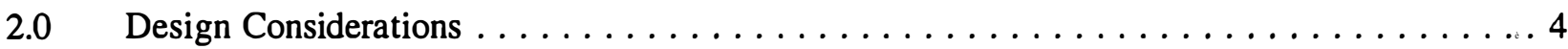

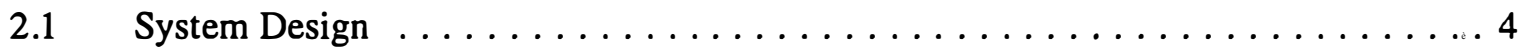

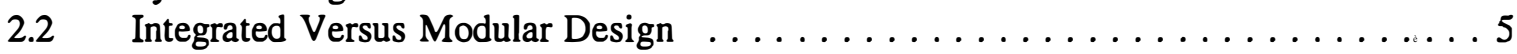

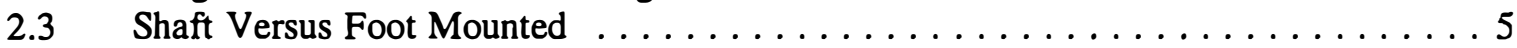

2.4 Epicyclic Versus Parallel Shaft Gearboxes $\ldots \ldots \ldots \ldots \ldots \ldots \ldots \ldots \ldots \ldots \ldots$

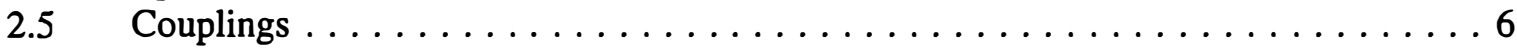

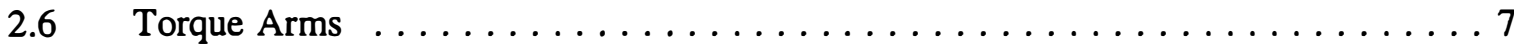

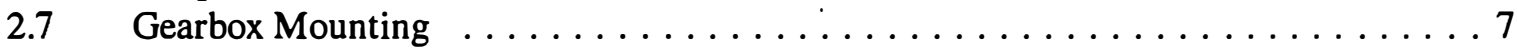

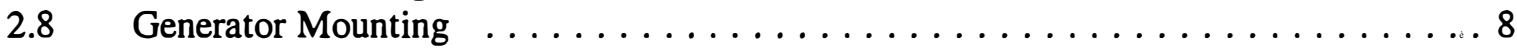

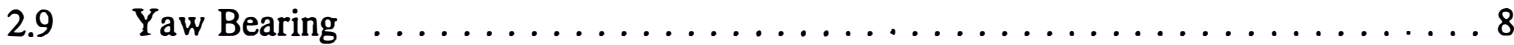

2.10 Maintenance Design $\ldots \ldots \ldots \ldots \ldots \ldots \ldots \ldots \ldots \ldots \ldots \ldots \ldots$

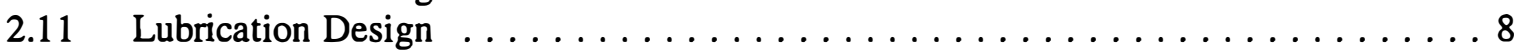

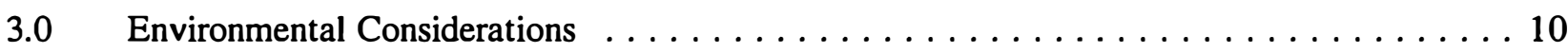

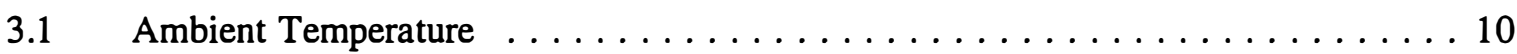

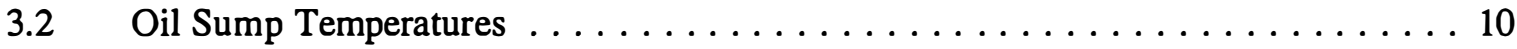

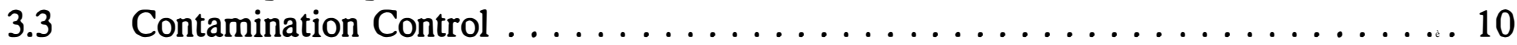

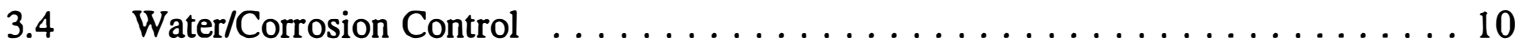

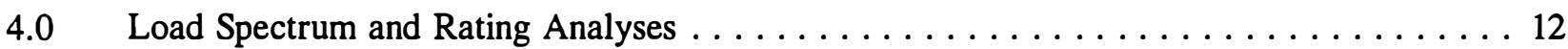

$4.1 \quad$ Design Load Spectrum . . . . . . . . . . . . . . . . . . 12

4.2 Methods for Determining Load Spectra . . . . . . . . . . . . . . . 12

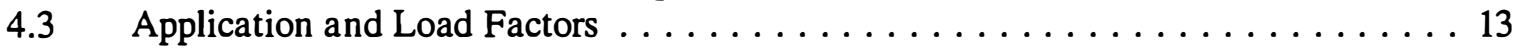

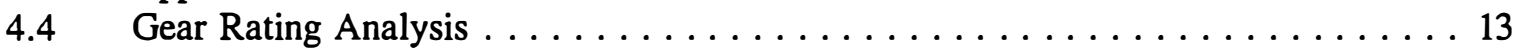

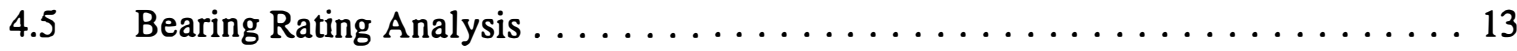

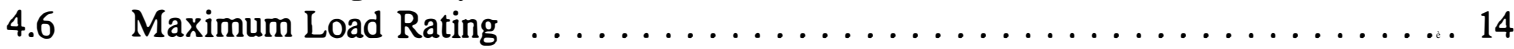

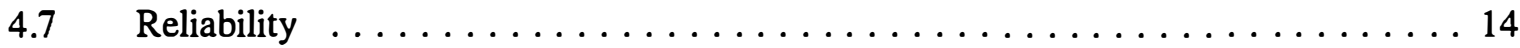




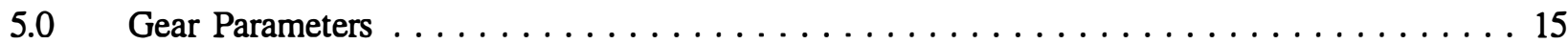

$5.1 \quad$ Gear Type $($ spur, single helical, double helical) $\ldots \ldots \ldots \ldots \ldots \ldots$

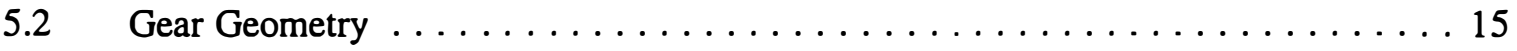

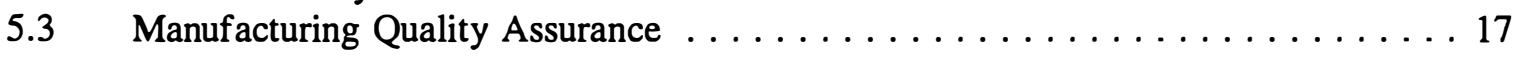

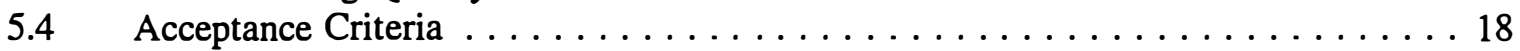

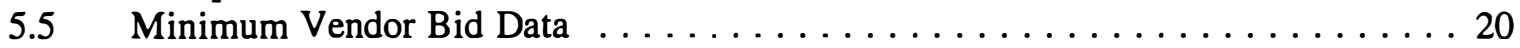

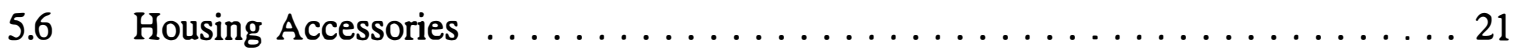

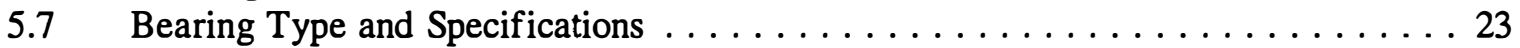

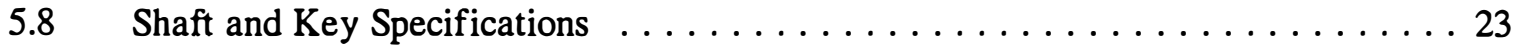

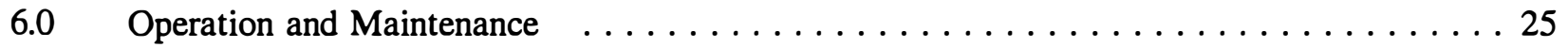

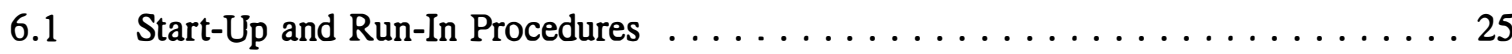

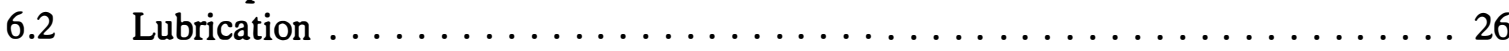

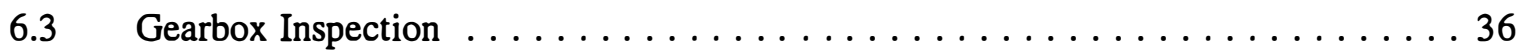

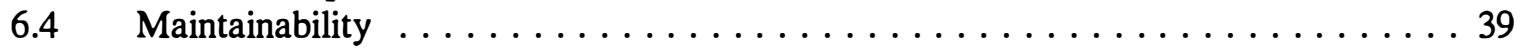

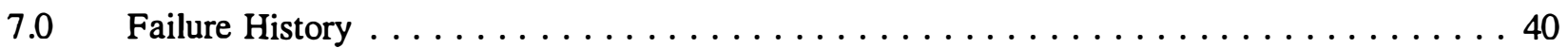

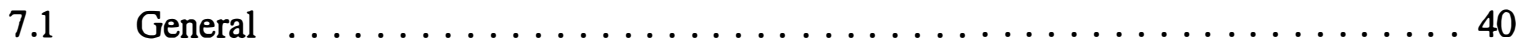

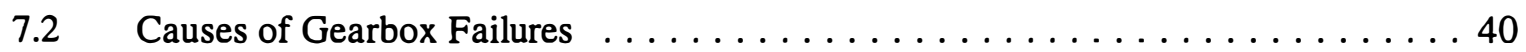

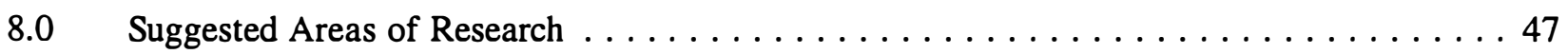

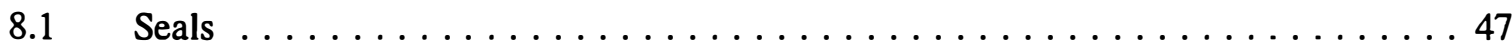

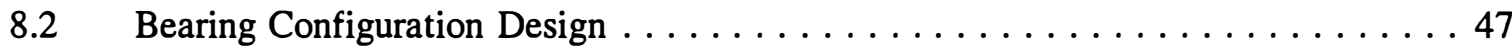

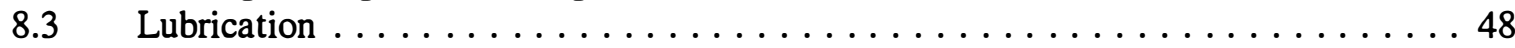

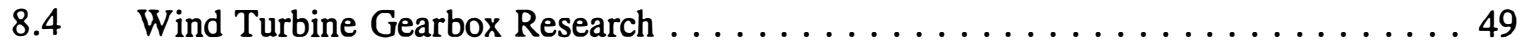

9.0 Recommended Procurement Procedure for Wind Turbine Gearboxes . . . . . . . . 50

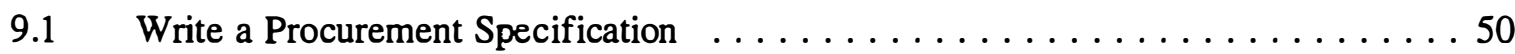

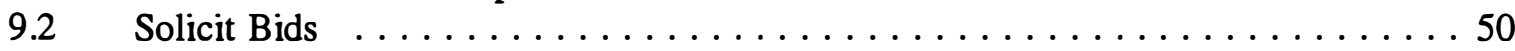

9.3 Evaluation of Proposals/Selection of Final Bidders $\ldots \ldots \ldots \ldots \ldots \ldots \ldots$

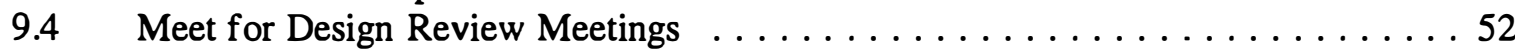

9.5 Selection of Vendor/Audit Design/Contract Award . . . . . . . . . . . 52

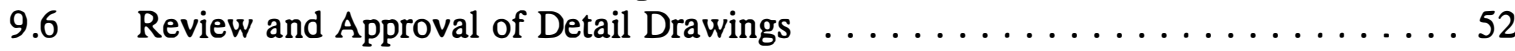

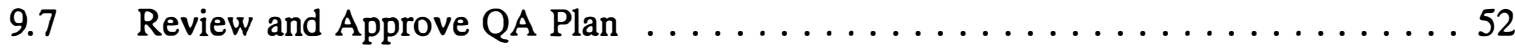

9.8 Meet to Approve Start of Manufacturing $\ldots \ldots \ldots \ldots \ldots \ldots \ldots \ldots \ldots \ldots \ldots \ldots \ldots$

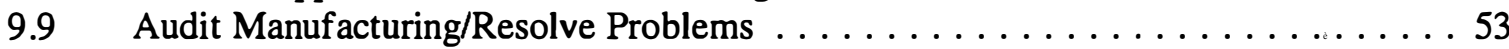

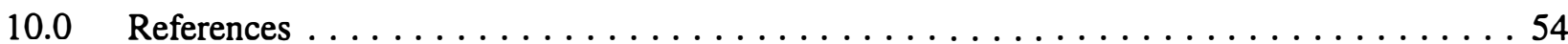


Appendix A: ANSI/AGMA 1012-F90 Gear Nomenclature and Definitions

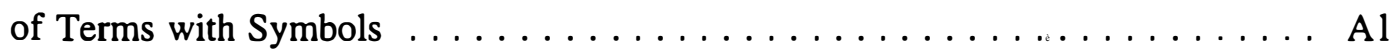

Appendix B: Gear Failure Modes and Prevention $\ldots \ldots \ldots \ldots \ldots \ldots \ldots \ldots \ldots \ldots$

Appendix $\mathrm{C}: \quad$ Introduction to Gear Failure Analysis $\ldots \ldots \ldots \ldots \ldots \ldots \ldots \ldots \ldots$

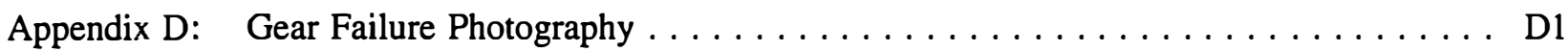




\section{List of Tables}

$\underline{\text { Page }}$

Table $5.2 .1 \quad$ Typical Single Stage Gear Ratio Ranges $\ldots \ldots \ldots \ldots \ldots \ldots$

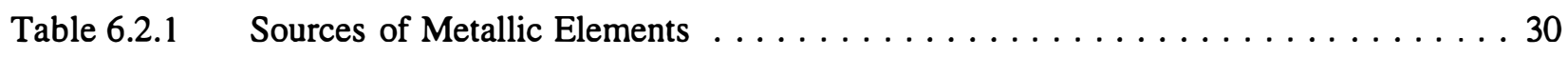

Table 6.2.2 Metallic Elements in a Typical Synthetic Gear Lubricant . . . . . . . . . 31

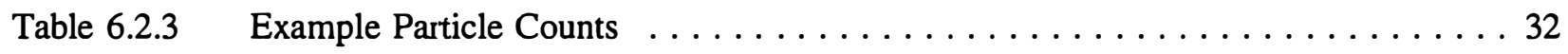

Table 6.2 .4 ISO Range Number Table $\ldots \ldots \ldots \ldots \ldots \ldots \ldots \ldots \ldots \ldots \ldots \ldots$

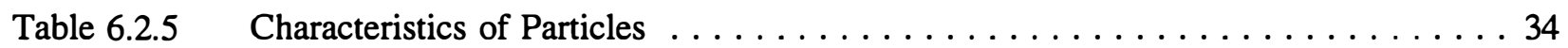

Table 6.2.6 Analysis Limits for Wind Turbine Gearbox Lubricants . . . . . . . . . 36 


\section{List of Figures}

$\underline{\text { Page }}$

Figure $\mathrm{B} 1 \quad$ Brittle fracture due to overload $\ldots \ldots \ldots \ldots \ldots \ldots \ldots \ldots \ldots$

Figure B2 Ductile fracture with significant plastic deformation $\ldots \ldots \ldots \ldots \ldots \ldots$

Figure B3 Mixed-mode fracture showing brittle and ductile fractures $\ldots \ldots \ldots \ldots \ldots$

Figure B4 Plastic deformation $\ldots \ldots \ldots \ldots \ldots \ldots \ldots \ldots \ldots \ldots \ldots \ldots \ldots \ldots \ldots$

Figure B5 Indentation caused by debris running through the mesh $\ldots \ldots \ldots \ldots \ldots \ldots$. . . . 22

Figure B6 Rippling due to boundary lubrication conditions $\ldots \ldots \ldots \ldots \ldots \ldots \ldots$

Figure B7 Tip-to-root interference due to inadequate profile modification $\ldots \ldots \ldots \ldots$ B23

Figure B8 Bending fatigue due to a manufacturing defect $\ldots \ldots \ldots \ldots \ldots \ldots \ldots \ldots$

Figure B9 Bending fatigue root fillet crack due to material defect $\ldots \ldots \ldots \ldots \ldots \ldots$

Figure B10 Bending fatigue crack on profile near pitchline $\ldots \ldots \ldots \ldots \ldots \ldots \ldots \ldots$

Figure B11 Macropits due to gear tooth misalignment $\ldots \ldots \ldots \ldots \ldots \ldots \ldots$

Figure B 12 Characteristic triangular-shaped flake macropits $\ldots \ldots \ldots \ldots \ldots \ldots$

Figure B $13 \quad$ Micropitting due to inadequate lubricant viscosity $\ldots \ldots \ldots \ldots \ldots \ldots \ldots \ldots$

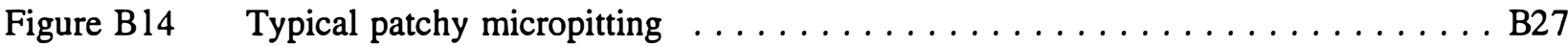

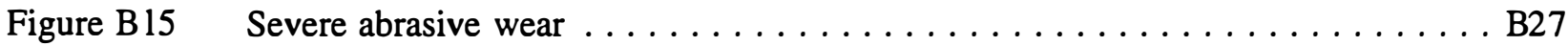

Figure $\mathrm{B} 16 \quad$ Corrosion in the form of rust deposits $\ldots \ldots \ldots \ldots \ldots \ldots \ldots \ldots$

Figure $\mathrm{B} 17$ Fretting corrosion due to vibration of a parked turbine $\ldots \ldots \ldots \ldots \ldots$

Figure B18 Severe polishing wear that has removed original grinding marks . . . . . . . . B29

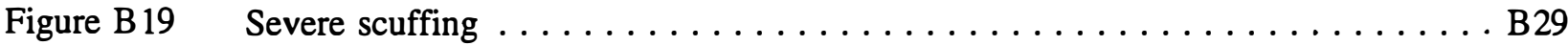




\subsection{INTRODUCTION}

\subsection{Scope}

GEARTECH has worked as gear consultants to the wind turbine industry for more than 11 years. Most of the work has involved inspection of wind turbine gearboxes, and performance of over sixty gearbox failure analyses. Based on that experience and 30 years in the gear industry, GEARTECH has developed recommended requirements for wind turbine gearbox applications. These requirements are the basis of this document.

Sections 1 through 6 describe these requirements and discuss design considerations, environmental considerations, load spectra, gear parameters, and operation and maintenance. These sections should not be construed as the basis for a design specification; rather, they are recommended requirements based on the authors' experience in the wind turbine industry.

Section 7 includes wind turbine gearbox failure case histories investigated by GEARTECH. Most of the investigations involved full disassembly and inspection of all components in the gearboxes. In most cases the gearboxes were considered failed. Some of the failures were isolated cases involving one or two gearboxes, but most failures were representative of a larger problem.

Section 8 includes suggestions for future research projects. Many advancements have been made in the procurement, design, and maintenance of wind turbine gearboxes, but experience has shown that some persistent problems require additional research. Also, the demand for increased power capacity, higher efficiency, and lighter compact gearboxes will require refinement of existing configurations and development of new designs.

Section 9 gives recommended procedures for purchasing reliable wind turbine gearboxes. In the past, most gearboxes were purchased as off-the-shelf items without adequate procurement specifications. Wind turbines are a relatively new application that requires a comprehensive procurement specification to purchase reliable wind turbine gearboxes.

Section 10 includes a list that references industry standards and technical papers relevant to wind turbine gearboxes.

Appendix A includes American National Standards Institute (ANSI) and American Gear Manufacturers Association (AGMA) 1012-F90 Gear Nomenclature, Definitions of Terms with Symbols, reproduced in part with the permission of AGMA. This standard defines the gear terminology used in this document.

Appendix B includes the technical paper titled "Gear Failure Modes and Prevention" and describes all the failure modes GEARTECH has observed in wind turbine gearboxes. The paper includes photographs of most of the failure modes and an extensive list of references.

Appendix C includes the technical paper titled "Introduction to Gear Failure Analysis," explaining the procedures used by GEARTECH in failure analyses.

Appendix D includes the technical paper titled "Gear Failure Photography." 


\subsection{Application}

A wind turbine is an energy conversion system that harnesses wind as a power source for the production of electricity. Wind turbines operate in winds up to about $27 \mathrm{~m} / \mathrm{s}(60.4 \mathrm{mph})$. Changes in wind speed and direction, and the dynamics of the rotor, result in loads on the gearbox that are very unsteady.

There are two turbine configurations: horizontal axis wind turbines (HAWT) and vertical axis wind turbines (VAWT). HAWTs are the most common turbines. They usually have towers 18 to 40 meters or more in height and rotors with 2 or 3 blades that rotate around a horizontal axis. The gearbox and generator are located at the top of the tower. The most common VAWT is called the Darrieus turbine. Its rotor rotates about a vertical axis with the blades bowed about a vertical, central tube or column. The gearbox and generator are located at the base of the turbine at ground level.

A wind turbine gearbox is a speed increaser that increases the relatively slow speed of the rotor to the speed of the generator. The application is a demanding one that requires careful consideration of the load spectrum to ensure that the gearbox has adequate load capacity and is within design constraints on size and weight. Gearboxes must be designed to maximize efficiency while minimizing sound level. Because wind power plants usually involve a large number of wind turbines which have limited accessibility for maintenance; reliability and maintainability are important considerations. The operational environment requires wind turbine gearboxes that are resistant to temperature extremes, contamination, and corrosion.

\subsection{Wind Turbine Definitions and Symbols}

The gear nomenclature used in this document is defined in Appendix A, which is extracted from AGMA 1012-F90, "Gear Nomenclature, Definitions of Terms with Symbols." Wind turbine nomenclature used in this document is defined here.

High-speed shaft: The high-speed shaft is the output shaft and is used to drive the generator.

Low-speed shaft: The low-speed shaft is the input shaft, main shaft, or rotor shaft.

Rotor speed: Rotor speed is the speed of the wind turbine rotor in revolutions per minute.

Upwind turbine: An upwind wind turbine is configured so the wind passes through the rotor before it passes through the tower.

Downwind turbine: A do wnwind wind turbine is configured so the wind passes through the tower before passing through the rotor.

Rotor: The hub and blade assembly.

Nacelle: The nacelle is the turbine head assembly which includes the drive train components.

Nacelle cover: The nacelle cover is the housing that covers the drive train components.

Horizontal axis: The axis of rotation is parallel to the ground.

Vertical axis: The axis of rotation is perpendicular to the ground.

Driven yaw: A motor actively positions the wind turbine relative to the wind. 
Free yaw: Wind turbine freely rotates on the tower to track the changing direction of the wind using its natural forces.

Damped yaw: Yaw motion is passively controlled by a device to prevent high yaw rates.

Rated output: The electrical output capacity of the wind turbine in kilo watts.

Rated wind speed: The lowest wind speed at which the rated output occurs.

Rotor diameter (horizontal axis): Diameter of the disk area swept by the rotation of the blades.

Rotor diameter (vertical axis): The equatorial diameter swept by the rotor in the horizontal plane.

Cut-in speed: The minimum wind speed at which the turbine generates power.

Cut-out speed: The maximum wind speed at which the turbine generates power.

Fixed pitch: Fixed pitch rotors have blades that do not change pitch and depend on aerodynamic stall to control peak power.

Variable pitch: Variable pitch rotors have adjustable pitch blades, which are usually controlled by a computer and used to actively limit peak power. 


\subsection{DESIGN CONSIDERATIONS}

The architecture of a wind turbine influences the design of its gearbox. Wind turbine architecture can be divided into two categories: integrated and modular. An integrated system consists of a gearbox with a housing that provides the bearing supports for the rotor and in some cases the support for the generator(s), as well as interfaces for other components, such as yaw drives. A modular system consists of a rotor shaft assembly, gearbox, generator, and possibly a yaw drive, each separately mounted to a common bed plate. The following sections discuss the characteristics of integrated and modular systems that should be considered when designing the gearbox.

\subsection{System Design}

The gearbox must be integrated into the wind turbine system such that all loads are accommodated without excessive stresses or deflections. Load paths should be designed to transmit the rotor loads to the tower without severe stress concentrations. Because integrated gearboxes provide support for the rotor, their housings must be carefully designed in order to minimize stresses and deflections. It is especially important to avoid deflections that cause gear mesh misalignment. Base plates for modular systems must be sufficiently rigid to maintain adequate alignment between the shafts of the rotor, gearbox, and generator.

The responsibility for the analysis of the dynamic response of the system should be clearly defined at the design stage. The analysis should include the total system of rotor, rotor shaft, rotor shaft bearings, gearbox, generator, couplings, mounting conditions, and all sources of excitation. System natural frequencies, mode shapes, and dynamic response amplitudes should be calculated. Because the excitation frequencies of the rotor are low (typically $0.5 \mathrm{~Hz}$ to $4 \mathrm{~Hz}$ ), it is especially important to avoid torsional resonance of the drive train.

The air flow through the nacelle and around the gearbox should be sufficient to provide adequate cooling for the gearbox. Ideally, the temperature distribution over the gearbox housing should be uniform to avoid thermal distortion. In some cases, compact gearboxes such as epicyclic types may require oil coolers or fans to maintain a safe operating temperature.

The work space on top of a wind turbine tower is often very limited and hazardous. It is therefore important to consider accessibility and maintainability when choosing the placement of gearbox inspection ports, breathers, oil level indicators, drain valves, and other components requiring maintenance. Inspection ports should be large enough to allow complete inspection of the gears, but small enough to minimize exposure to the environment when they are opened. Also, the inspection covers should be light and small enough to be easily handled by the technician.

The need for transducers to monitor temperature, vibration, oil pressure, or oil flow should be planned for in the design stage. 


\subsection{Integrated Versus Modular Design}

\subsubsection{Characteristics of Integrated Design}

Generally, integrated gearbox designs offer advantages that are important for large turbines. They are typically more compact and lighter weight, but each particular design should be evaluated. In some cases less weight and fewer parts may mean lower costs. Integrated designs can reduce misalignment between the rotor, gearbox, and generator, and allow the gearbox lubricant to be used to lubricate the enclosed couplings.

The most obvious disadvantage to an integrated design is maintainability. Retrofits of integrated systems can be difficult and require disassembly of the gearbox from the generator and rotor. However, overall maintenance may be reduced in such a system because the shaft couplings may not need to be aligned or lubricated.

Because the gearbox and rotor are integral, the rotor creates high loads on the gearbox housing, causing housing deflections that may misalign the gears. Extensive analysis is required to determine the housing deflections and to ensure that loads are properly accommodated.

With an integrated system there is a chance that gearbox lubricant may leak into the generator or generator debris may get into the gearbox. For example, corrosion or wear debris from the generator rotor or generator bearings may enter the gearbox undetected.

\subsubsection{Characteristics of Modular Design}

In a modular design the gearbox is easier to retrofit or maintain because it can be removed without disturbing the generator or rotor. There are lighter loads on the housing with a modular design because the rotor loads are transmitted directly to the tower through the bed plate.

\subsection{Shaft-Mounted Versus Foot-Mounted}

\subsubsection{Characteristics of Shaft-Mounted Gearboxes}

Shaft-mounted gearboxes are fixed to the rotor shaft with a rigid coupling or shrink ring rather than a flexible coupling. This eliminates the need for aligning and lubricating the low-speed coupling and saves space. Both parallel shaft gearboxes and epicyclic gearboxes can be shaft mounted. The gearbox housing is restrained by a torque arm to prevent the housing from rotating.

Shaft-mounted gearboxes subject the rotor shaft to a shear force and a bending moment when a single torque arm is used. The torque arm may twist the gearbox, causing the low-speed gear mesh to misalign. The gearbox should be located close to the rotor shaft bearing to minimize the bending moment. However, sufficient clearance should be provided between the gearbox and rotor shaft bearing to allow maintenance of bolts and seals. Two torque arms, $180^{\circ}$ apart, may be used to cancel the shear force and bending moment, but this adds cost and weight. Shaft mounts that use shrink rings are susceptible to fretting corrosion and require maintenance to ensure the mounting bolts remain tight.

\subsubsection{Characteristics of Foot-Mounted Gearboxes}

Foot-mounted gearboxes are rigidly connected to the bed plate. They can use a compliant coupling on the rotor shaft that damps the rotor loads before they reach the gearbox, and therefore reduce the loads 
on the gear teeth. Stresses on the low-speed shaft are reduced because there is no bending moment from a torque arm.

Foot-mounted gearboxes require an accurately machined and rigid bed plate to maintain alignment of the high-speed and low-speed couplings. They also require periodic maintenance to align the low-speed coupling. They may not be as compact as shaft-mounted gearboxes.

\subsection{Epicyclic Versus Parallel Shaft Gearboxes}

The demand for increased power capacity, higher efficiency and lighter weight compact gearboxes has prompted the investigation of epicyclic versus parallel shaft gear arrangements.

\subsubsection{Characteristics of Epicyclic Gearboxes}

Epicyclic gear arrangements share loads through two or more paths; therefore they are more compact than parallel shaft drives and offer significant savings in size and weight. The load sharing also gives them a large capacity for absorbing overloads.

Epicyclic gearboxes have concentric input and output shafts that save space by allowing the rotor and generator shafts to be coaxial.

Epicyclic gears are more efficient than parallel shaft gears because the conformal action of the planet to annulus gear mesh has less sliding.

The relatively small size of epicyclic gears gives lower pitchline velocity and decreased noise. However, because of the arrangement of epicyclic gearing, the annulus gear tends to trap any loose parts in the mesh, which can result in catastrophic damage. For this reason it is important to design internal fasteners so that they remain tight. Visual access is limited, making field inspections difficult or impossible.

Spur gears are often used in epicyclic gearboxes because helical gears tend to misalign the planet gears and interfere with a floating sun gear. This tends to make epicyclic gearboxes noisy because spur gears are not as quiet as helical gears, especially at high pitchline velocity. Generally, the lower pitchline velocity of epicyclic gears is not enough to offset the noise disadvantage of spur gears. However, gearboxes with an epicyclic low-speed spur gearset, combined with a parallel shaft helical gearset, tend to be compact and quiet.

To achieve equal load sharing, epicyclic gearboxes require tighter manufacturing and accuracy controls than parallel shaft arrangements. There are more parts in an epicyclic gearbox that must meet quality control requirements. This usually means higher cost.

Because epicyclic gearboxes are compact, a relatively high power density is produced, and they are more likely to require supplementary cooling to maintain an acceptable sump temperature.

\subsection{Couplings}

Shaft-mounted gearboxes are mounted rigidly to the rotor shaft with either a bolted flange or a shrink ring. Foot-mounted modular gearboxes are connected to the rotor shaft with a flexible coupling. The rotor has separate bearing supports (usually pillow blocks) that are directly connected to the bed plate. Shaftmounted and foot-mounted modular gearboxes are connected to the generator with a flexible coupling. 
Flexible couplings utilize mechanical, elastomeric, or metallic elements to accommodate parallel or angular misalignment between the gearbox shafts, rotor shaft, and generator shaft. Mechanical couplings include gear, chain, grid, and universal joints. Elastomeric couplings include rubber tire, compression jaw, pin and bushing, and donut lug. Metallic couplings include shims and diaphragms.

All couplings influence the dynamic properties of the drive train. The following characteristics should be considered when selecting couplings:

- System natural frequencies.

- Mass of rotor, couplings, gears, and generator rotor.

- Stiffness of shafts and couplings.

- Damping of bearings and couplings.

- Backlash of gears and couplings.

- Misalignment capacity of couplings.

- Lubrication of couplings.

- Unbalance of couplings.

- Shear forces transmitted by couplings.

Beñing moments transmitted by couplings.

- Axial fórces transmitted by couplings.

\subsection{Torqùe Arms}

The torque arm for a shaft-mounted gearbox should be mounted as specified by the gearbox vendor. The preferred position for the tie rod is perpendicular to a line through the rotor shaft center and the point of attachment to the gearbox housing. The foundation end of the tie rod should be located so that the tie rod is perpendicular to the axis of the rotor shaft. The tie rod should have spherical rod end bearings and should be mounted so that it is subjected to tension only.

Because the low-speed gear of a shaft-mounted gearbox is located by the rotor shaft, whereas the lowspeed pinion is carried by the gear housing, relative motion between the gear housing and rotor shaft causes misalignment of the low-speed gearset. Therefore, the relative motion should be minimized by using small clearances in the low-speed gear bearings and locating the torque arm so that it does not tend to tip the gearbox housing.

\subsection{Gearbox Mounting}

Foot-mounted gearboxes should be bolted to the base plate with shims under the feet of the gearbox to align the low-speed shaft to the rotor shaft. All feet should be supported so that the housing will not distort when the mounting bolts are tightened. After the gearbox is properly aligned, dowel pins should be installed to prevent movement and to ensure realignment if the gearbox is removed. 
Shaft-mounted gearboxes are mounted to the rotor shaft with either a rigid flange or a shrink ring. If a shrink ring is used the gearbox vendor's instructions for installation should be followed. All locking bolts should be gradually tightened to the specified torque and in the proper sequence. The locking collars must be parallel.

\subsection{Generator Mounting}

In an integrated system the generator is mounted directly to a flange on the gearbox housing. With a modular system the foot-mounted generator should be bolted to the base plate with shims under the feet of the generator to align the high-speed coupling that connects the generator shaft to the gearbox highspeed shaft. After the generator is properly aligned, dowel pins should be installed to prevent movement and to ensure realignment if the generator is removed.

\subsection{Yaw Bearing}

In modular systems the yaw bearing mounts between the base plate and the tower. With integrated systems the yaw bearing may mount directly to the gearbox housing. The yaw bearing must have adequate capacity to support shear forces (for example, rotor thrust), axial forces (for example, turbine weight), and bending moments (for example, dynamic rotor loads). It is especially important that bolted connections to the yaw bearing have adequate fatigue resistance. Integrated systems must have a gearbox housing that is rigid enough to transmit the rotor loads to the yaw bearing without excessive stresses or deflections.

\subsection{Maintenance Design}

Because work space around a wind turbine gearbox is limited, it is important to locate components so they are easily accessible for maintenance. All components such as breathers should be sturdy so that they will not be damaged if stepped on. Sharp comers or hazardous edges should be eliminated to minimize risk of injury to technicians when they climb over the gearboxes.

Because a wind plant may have many turbines (some have several thousand), the gearbox ease of maintenance is very important. Changing the oil in a gearbox is difficult and time consuming. Typically, the technician climbs the tower with a tag line that is used to hoist a drain line leading to a waste drum. The gearbox may hold over 40 liters (9.6 gallons) of oil. The drain time can be lengthy, especially if the drain hole is small and the oil is cold. After the oil has drained, the fill line is hoisted, and the oil is pumped up to the gearbox. This process generally requires two technicians.

To facilitate maintenance, devices for filling and draining oil and checking the oil level should be provided and located in convenient places. The drain should be at the bottom of a sloped sump so the oil can be completely drained. The drain valve should be a minimum of 1 inch national pipe thread (NPT) to allow the oil to be drained in a reasonable time.

\subsection{Lubrication Design}

Because the wind turbine environment is severe, the procurement specification should describe the application sufficiently to enable the gearbox manufacturer to specify an appropriate lubricant and lubrication system (see Section 3, Environmental Considerations). The choice of a lubricant and lubrication system should be the joint responsibility of the gearbox manufacturer and the gearbox purchaser. 


\subsubsection{Lubricant Type and Viscosity}

Wind turbine gears have relatively low pitchline velocity and high gear tooth loads. These conditions require either a synthetic or mineral gear oil with antiscuff additives and the highest viscosity that is practical. Too low a viscosity can cause micropitting, macropitting, adhesive wear and scuffing.

The choice of a lubricant depends on many factors, including viscosity, viscosity index, pour point, additives, and costs.

Synthetics have a low pour point. This means that a gearbox using a synthetic oil can be started at a lower ambient temperature than one using a mineral oil of comparable viscosity. Also, synthetics have high viscosity indices, which means the viscosity change with temperature is less than with mineral oils. However, mineral oils have the advantage of being less expensive. If a mineral oil is used, one with a viscosity grade a step higher can match the viscosity of the synthetic at higher operating temperatures and the lubricant can be preheated for cold start-ups.

Synthetic lubricants may improve gearbox efficiency and operate cooler than mineral oils because they have better lubricity. In general it is desirable to decrease the operating temperature of a gearbox lubricant. Lower lubricant temperatures increase the gear and bearing lives by increasing lubricant film thickness and increase lubricant life by reducing oxidation.

\subsubsection{Method of Lubricant Application}

The method of applying the lubricant to the gear teeth depends primarily on the pitchline velocity. Wind turbine gearbox pitchline velocities range from about $1 \mathrm{~m} / \mathrm{s}(3.28 \mathrm{ft} / \mathrm{s})$ to $10 \mathrm{~m} / \mathrm{s}(32.81 \mathrm{ft} / \mathrm{s})$. Splash lubrication systems are limited to about $15 \mathrm{~m} / \mathrm{s}(49.2 \mathrm{ft} / \mathrm{s})$. Above $25 \mathrm{~m} / \mathrm{s}(82.02 \mathrm{ft} / \mathrm{s})$ most gears are lubricated by a pressure-fed system. Therefore, pressure-fed systems are not mandatory for wind turbine gearboxes.

Splash lubrication is the simplest, most reliable system. The low-speed gear should dip into the oil bath to at least twice the tooth depth to provide adequate splash for gears and bearings. The high-speed gear should be above the oil level or provided with oil baffles to reduce losses caused by churning. The gear housing should have troughs to capture the oil flowing down the housing walls and channel it to the bearings.

While not generally required for wind turbine gearboxes, pressure-fed systems have the advantage of being able to use a filter to clean the oil and a heat exchanger to cool the oil. In contrast, the lubricant in splash lubricated gearboxes must be replaced or processed to remove contamination, and cooling is limited to convection and radiation heat transfer to the surrounding air. To ensure adequate lubrication and cooling, a pressure-fed system must be properly designed, including consideration of the flow rate, feed pressure, and the size, number, and placement of the jets. There are some general guidelines, based on experience, for specifying these parameters [28, 29], but each application must be evaluated independently, based on operating conditions and requirements. 


\subsection{ENVIRONMENTAL CONSIDERATIONS}

\subsection{Ambient Temperature}

Wind turbine gearboxes may be exposed to an ambient temperature range of $-29^{\circ} \mathrm{C}\left(-20^{\circ} \mathrm{F}\right)$ to $+50^{\circ} \mathrm{C}$ $\left(122^{\circ} \mathrm{F}\right)$. The ambient temperature is defined as the dry bulb air temperature within the nacelle in the immediate vicinity of the gearbox.

\subsection{Oil Sump Temperature}

The maximum oil sump temperature should be limited to $95^{\circ} \mathrm{C}\left(203^{\circ} \mathrm{F}\right)$ for mineral oils and $121^{\circ} \mathrm{C}\left(250^{\circ} \mathrm{F}\right)$ for synthetic oils. Temperatures above these limits can result in oxidation and decomposition of the lubricant additives. High temperatures may require special materials for nonmetallic components, such as seals.

The minimum oil sump temperature should be at least $5^{\circ} \mathrm{C}\left(41^{\circ} \mathrm{F}\right)$ higher than the pour point of the lubricant. Lower temperatures may prevent the oil from circulating freely and result in high starting torques.

\subsubsection{Temperature Control}

Adequate heat transfer from the gearbox should be provided, and the volume of oil should be sufficient to maintain the maximum oil temperature specified in Section 2.3.2. There should be a free flow of air within the nacelle and over the gearbox housing. Cooling fins on the gearbox housing or a circulating oil system with a heat exchanger may be necessary to control the operating temperature of the lubricant.

If the ambient temperature is lower than $5^{\circ} \mathrm{C}\left(41^{\circ} \mathrm{F}\right)$ below the pour point of the lubricant, a sump heater should be provided to heat the oil to a temperature at which it will circulate freely during starting.

\subsection{Contamination Control}

A large capacity, filtered breather should be provided to minimize contamination from dust and dirt.

The high-speed and low-speed shaft should have a positive external seal, such as a V-ring or felt wiper, to prevent contamination from dust, dirt, and moisture.

Magnetic plugs should be provided to collect ferrous debris and prevent it from running through and damaging gear teeth and bearings.

\subsection{Water/Corrosion Control}

Contamination by water is a common problem in wind turbine gearboxes. Water can enter gearboxes in a number of ways. Airborne water can enter a gearbox through breathers,, seals or any opening not properly sealed. Some wind turbines operate in an environment that may be moist during periods of wide temperature fluctuations, and this can create condensation inside the gearbox. A desiccant-type breather can help minimize contamination by water in damp environments. Input and output shafts should have V-rings to help exclude moisture (see Section 5.6.2.3). Water may be introduced if the lubricant is contaminated with water as a result of improper storage. Oil drums should be stored indoors, preferably at a constant temperature. Water may enter a gearbox during routine maintenance if inspection ports or covers are left off. Therefore, ports and covers should not be removed for long periods of time. Whereas 
dirt and debris can be filtered, once water enters a gearbox it is very difficult to remove without changing the oil. There are portable processing units that remove water from oil by either centrifuging or vacuum dehydration. See Section 6.2.4.3 for methods for determining water content and its effects. 


\subsection{LOAD SPECTRUM}

The loads on a wind turbine gearbox vary constantly as a result of the following:

- Turbulent wind fluctuations caused by terrain, boundary layer and atmospheric effects, and wakes from other turbines.

- Vertical and horizontal wind shear.

- Blade mass imbalance, blade pitch differences, and changes in gravity loads with blade rotation.

- Yawing motion of the rotor and off-axis operation.

- Unsteady loading caused by the blades passing through the tower "shadow."

- Transient starting loads caused by the generator.

- Transient braking loads from both aerodynamic and mechanical brakes.

\subsection{Design Load Spectrum}

The design load spectrum for a gearbox must be supplied by the wind turbine designer to the gearbox vendor. It should be presented in tabular form, listing torque level and percent time at each torque level. This is the form most familiar to gearbox vendors. The load spectrum should include all the torque that the gearbox will experience during its design life using a representative wind regime. These loads must include a full range of operating, transient, and extreme loads. For integrated housing designs which contain the low-speed shaft bearings, it is necessary to specify the load spectrum at all of the critical housing interfaces. These loads should include but not be limited to:

- Rotor torques caused by normal operation.

- Transient rotor torques caused by starting and stopping the turbine.

- Shear, moment, and axial loads from the rotor (integrated systems only).

\subsection{Methods for Determining Load Spectra}

Determining the load spectrum is a difficult task because there is still a great amount of uncertainty associated with predicting transient loads and with extrapolating relatively small amounts of data to predict inf requent high-load events [31, 32, 34, 40].

First, the wind turbine designer must define the gearbox operational environment. This will depend on the severity of the design wind site and the specific operational characteristics of the wind turbine. Guidance is given for determining operational, extreme, and transient load cases in the IEC Design Standard [23]. The approach used in the International Electrotechnical Commission (IEC) document is commonly used to establish the design loads for developing the load spectrum. However, the IEC document is in draft form and its inclusion should not be construed as an official recommendation.

Ideally, the design load spectrum should be determined from measurements of shaft strain on wind turbines operating at the specific site. The data should be collected over sufficient time and with adequate 
resolution to obtain a true representation of the long-term loads, including transient loads caused by starting and stopping the turbine.

With the loads identified, empirical or analytical methods can be used to develop a load spectrum. In most cases some analytic predictions will be necessary. For new gearbox designs, measurements from similar wind turbines can be used to predict the load spectrum, but extreme caution should be used to scale data and to account for any differences in the turbine's operation that would change the load distribution. Several analytical codes are available to assist designers in developing load spectra, but a full discussion of this topic is beyond the scope of this document. In lieu of measured shaft strain or data from similar wind turbines, the operating load spectrum can be synthesized from the site's wind speed distribution and the analytically determined power curve for the wind turbine.

Synthesized load spectra should include estimated transient loads that will result from starting and stopping the turbine. Often, transient loads are the highest and most difficult to predict. Gearboxes with brakes on the high-speed shaft may be subjected to very high transient loads during stopping [34]. These loads must be accounted for in the load spectrum.

\subsection{Application and Load Factors}

Traditionally, the gear industry $[15,16,17]$ has used the terms "application factor" and "service factor" to describe multipliers that relate the calculated load capacity of a gearbox to the applied load. The term "factor of safety" or "safety factor" is commonly used by machine designers to define the ratio of allowable stress to applied stress. Unfortunately, there is no universally accepted definition for application factor, service factor, or safety factor, and one must have a clear understanding of the meaning and significance of these terms when comparing gear load capacity using different industrial standards. Most of these factors work best when they are empirically determined from long experience with a particular application where the loads are well defined and do not vary significantly.

There has not been sufficient experience with wind turbines to warrant the use of a single multiplier, such as a service factor, to design a gearbox. Wind turbine loads vary significantly and are specific to a particular wind site and a particular turbine. Therefore, gear performance must be calculated based on an accurate load spectrum and a cumulative damage criterion, such as Miner's Rule.

\subsection{Gear Rating Analysis}

Pitting resistance and bending fatigue resistance should be rated in accordance with ANSI/AGMA 2001B88. Miner's Rule should be used to calculate gear life using a load spectrum supplied by the gearbox purchaser. Gear life calculations should be based on a reliability of $99 \%$ and the lower curves for life factor from Figures 16-1 and 16-2 of ANSI/AGMA 2001-B88. The gear pitting and bending fatigue lives should be a minimum number of hours specified by the purchaser. Scuffing resistance should be rated in accordance with Appendix A of ANSI/AGMA 2001-B88. The risk of scuffing should be less than 5\%.

\subsection{Bearing Rating Analysis}

Bearing life should be rated in accordance with ANSI/AFBMA Std 11-1990. Miner's Rule should be used to calculate bearing life using the load spectrum supplied by the gearbox purchaser. Bearing life calculations should be based on a reliability of $90 \%$. Life adjustment factors for reliability, material, and environment should be taken as unity (1.0) for rating calculations. The bearing life should be a minimum number of hours specified by the purchaser. 


\subsection{Maximum Load Rating}

The gearbox should be designed to withstand a momentary, maximum low-speed shaft torque, as specified by the purchaser. All major components of the gearbox, including gears, keys, shafts, bearings, housing, and fasteners should be capable of withstanding the maximum load without incurring excessive deflection or permanent deformation. The maximum load capacity should be calculated in accordance with AGMA 6010-E88 and ANSI/AGMA 6001-C88.

\subsection{Reliability}

Industrial standards for gears such as ANSI/AGMA 2001-B88, and bearings such as ANSI/AFBMA Std 11-1990, include reliability factors that account for the statistical variation of failures found in components testing. The overall reliability of a gearbox can be calculated from the reliability of the individual components. 


\subsection{GEAR PARAMETERS}

\subsection{Gear Type}

Three types of gears-spur, single helical, and double helical-are commonly used in wind turbine gearboxes.

\subsubsection{Characteristics of Spur Gears}

The gear teeth are parallel to the gear axis. They impose mainly radial loads on bearings, but misalignment of the gear mesh may cause thrust loads. Spur gears are usually noisier than helical gears because fewer teeth are in contact. The dynamic loads on the gear teeth may also be greater. Size for size, spur gears have less load capacity than helical gears.

\subsubsection{Characteristics of Single Helical Gears}

Helical gear teeth are inclined to the gear axis like a helical screw. Single helical gears impose both radial and thrust loads on bearings, so bearings and housing must be designed accordingly. They are usually quieter than spur gears because there are more teeth in contact. Dynamic loads on the gear teeth may be lower than on spur gears. Size for size, single helical gears have more load capacity than spur gears.

\subsubsection{Characteristics of Double Helical Gears}

Double helical gears share all the advantages of single helical gears, plus they may balance internally generated thrust loads. One member of the gearset must be free to float axially to share tooth loads between the two helices and balance the internally generated thrust loads. Because the two helices cannot be perfectly matched, the floating member will vibrate axially in response to unequal thrust loads, causing high dynamic loads and noise if the tooth geometric errors are excessive. External thrust loads on the floating member unload one helix and overload the other helix. Shaft couplings must be properly designed and maintained to limit external thrust loads.

The gap between the helices must be wide enough because gear cutting and finishing machines require space between the helices for runout of the tool. If the gap is too small the tool will run into the opposite helix when it runs out at the apex of the helix. Depending on the gear arrangement, the gap may add weight and length to the gearbox.

\subsection{Gear Geometry}

The gear geometry influences both the load capacity and the sound level emissions of a gearbox. With properly designed gear geometry, gears operate smoothly and quietly and have adequate load capacity to transmit the required power for the design life. See ANSI/AGMA 1012-F90 for gear nomenclature.

\subsubsection{Preferred Number of Pinion Teeth}

There is a preferred number of teeth for the pinion which can provide a good balance between pitting resistance, bending strength, and scuffing resistance. See AGMA 901-A92 for an algorithm to calculate the preferred number of teeth. Some designers recommend using tooth numbers for the pinion which equal the minimum required to avoid undercut. However, this method gives gearsets with less than 
optimum load capacity that are prone to scuffing. The number of teeth in the pinion should not be less than twenty (20) for wind turbine gearboxes.

\subsubsection{Gear Ratio}

The overall gear ratio of the gearbox is set by the requirements for rotor speed and generator speed. However, if there is more than one stage of gears, the gear designer can select optimum gear ratios for each stage. This maximizes load capacity and minimizes the weight and cost of the gearbox (see AGMA 901-A92).

Table 5.2.1 Typical Gear Ratio Ranges for Single Stage Gearing

\begin{tabular}{c|c}
\hline Gear Ratio & Gear Type \\
\hline $1-4$ & parallel shaft \\
\hline $3-6$ & star gear epicyclic \\
\hline $4-7$ & planetary epicyclic \\
\hline
\end{tabular}

When gear ratios exceed those shown in the table, it is generally more economical to add additional stages of gearing.

\subsubsection{Aspect Ratio}

The aspect ratio is the ratio of pinion face width to pinion diameter. It is an indicator of how sensitive a gearset is to misalignment. To achieve good load distribution, the aspect ratio should be less than 1.25 and preferably less than 1.0 (see AGMA 901-A92). The lower limit on face width is set by requirements for face contact ratio (see Section 5.2.4).

\subsubsection{Face Contact Ratio}

The face contact ratio is the ratio of the face width to axial pitch (see Appendix A). It is a measure of the number of teeth in contact and the smoothness of gear tooth meshing. A conventional helical gear has a face contact ratio greater than 1.0. Helical gears with face contact ratios less than 1.0 perform in a manner similar to spur gears and are rated the same.

\subsubsection{Transverse Contact Ratio}

The transverse contact ratio is the ratio of the angle of action to the angular pitch. It is a measure of the number of teeth in contact and the smoothness of gear tooth meshing. The preferred minimum transverse contact ratio is 1.4 (see Appendix A).

\subsubsection{Total Contact Ratio}

The total contact ratio is the sum of the transverse contact ratio and the face contact ratio. The preferred minimum total contact ratio is 1.4 for spur gears, and 2.4 for helical gears. 


\subsubsection{Profile Shift}

Profile shift is a design refinement of gear teeth that results in shifting of the tooth profile inward or outward radially to enhance the performance of a gearset.

Profile shift is used to:

- Prevent undercut.

- Balance specific sliding.

- Balance flash temperature.

- Balance bending fatigue life.

- Avoid narrow toplands.

The profile shift should be large enough to avoid undercut and small enough to avoid narrow toplands. In general, the profile shifts for balanced specific sliding, balanced flash temperature, and balanced bending fatigue life are different, but nearly the same for well designed gears (see AGMA 901-A92). For wind turbine gears, which are speed increasers, it is usually best to design the profile shift for balanced specific sliding.

\subsubsection{Profile Modification}

Profile modification, also called tip and/or root relief, is used to minimize the detrimental effects of tooth deflections, assembly tolerances, and tooth variations. It helps to avoid hard contact at the tip and root under a particular load. Proper profile modification increases load capacity and reduces noise. Because the loads on wind turbine gears are variable, the design point for the profile modification must be chosen carefully because the profile modification can be designed for only one load and over-modification is detrimental.

\subsubsection{Helix Modification}

Helix modification is the modification of the tooth face along the face width. Its purpose is to increase the amount of contact between gear teeth and to avoid hard contact at the ends of the face width under full load. Helix modification is used to minimize the detrimental effects of bending and torsional deflections of the pinion shaft, assembly tolerances, and tooth variations. Proper helix modification increases load capacity and reduces noise. Because the loads on wind turbine gears are variable, the design point for the helix modification must be chosen carefully because the helix modification can be designed for only one load and over-modification is detrimental.

\subsection{Manufacturing Quality Assurance}

\subsubsection{General}

In order to ensure a good quality assurance (QA) plan and reasonable acceptance criteria, a comprehensive procurement specification should be written. The gearbox purchaser should supply the procurement specification. Personnel experienced with wind turbines, gearboxes, and QA should be 
involved in writing the specification. The vendor should provide a comprehensive QA plan that controls manufacturing, inspection and testing.

5.3.1.1 Procurement Specification: The procurement specification defines how the gearbox should perform. It specifies the required life, reliability, efficiency, and sound level. It also defines the application, basic design, accessories, QA, and acceptance tests, and a method for comparing competing proposals.

It is best to tailor the specification so that it defines performance rather than design and allows vendors the creative freedom to meet contract requirements by applying their engineering expertise. Based on experience, the purchaser may wish to control some design details, but these constraints should be minimized. The objective is to focus vendor attention on performance requirements while allowing them the freedom to use their technical expertise most effectively.

5.3.1.2 Quality Assurance Tests: Tests and documentation are a significant part of production costs. The vendor should submit detailed plans for QA and gearbox testing. The time for negotiating these items is before a contract is awarded, not after. As many of the tests as possible should be carried out at the vendor's plant so that discrepancies are corrected before shipping. Specify which production processes and tests the purchaser wishes to witness. Shop inspections should include gear cutting and finishing, gear tooth accuracy measurement, gearbox assembly, and testing.

Ideally, tests verify that the gearboxes meet service load and speed requirements. As a minimum, all gearboxes should be no-load, spin tested. This detects certain assembly problems, oil leaks, and excessively noisy gears. But the test does not reveal how loads affect shaft alignment and tooth contact, and it is relatively ineffective at catching design errors or quality control (QC) problems.

\subsubsection{Responsibilities}

5.3.2.1 Purchaser Responsibilities: The purchaser is responsible for and must control the procurement documents, including the purchase order and the procurement specification.

5.3.2.2 Vendor Responsibilities: The gear vendor is responsible for and must control the QA plan, including the inspection and test plan.

It is imperative that there be a meeting between representatives of the purchaser and gear vendor at which the procurement documents and QA plan are reviewed line by line to ensure that all parties understand all requirements.

The gear drawings and QA plan should be approved by the purchaser before the vendor proceeds with manufacturing the gears. It is imperative that the purchaser is convinced that the vendor understands the requirements of the procurement specification before the purchase order is awarded. The best criteria for judging vendor competence are design review meetings with the vendor, evaluations of their QA plan and visits to their manufacturing facilities.

\subsection{Acceptance Criteria}

\subsubsection{Gear Materials}

Typical values of stresses on wind turbine gearboxes range from 1034 to $2068 \mathrm{MPa}(150,000$ to 300,000 psi) for Hertzian stresses, and 345 to $483 \mathrm{MPa}(50,000$ to 70,000 psi) for bending stresses. Peak stresses 
such as brake loads have been reported to be four to ten times greater than nominal stresses. These stresses require Grade Two materials per ANSI/AGMA 2001-B88. New designs with greater power demands will increase these stresses and make the requirements of high quality, accurate gearing more critical.

All gears should be made from carburizing grade alloy steels with sufficient hardenability to obtain case and core properties that meet the requirements for Grade Two material in accordance with ANSI/AGMA 2001-B88. The steel alloy should be selected and the carburizing process should be controlled to obtain a microstructure that has strength and fracture toughness meeting these requirements. Alloys such as (but not limited to) AISI 8620 or 4620 are not acceptable for large teeth with normal modules coarser than 5 because they do not have sufficient hardenability. The larger (coarser normal modules) the gear teeth, the more difficult it is to achieve sufficient hardening during carburizing. All gears should meet the QC requirements for grade 2 carburized and hardened gears in accordance with ANSI/AGMA 2001-B88. GEARTECH's experience has shown that the following exceptions to ANSI/AGMA 2001-B88 are necessary to tailor the specification for wind turbine gears:

- Core hardness should be 30-45 HRC, assuming a reasonable tolerance. The optimum core hardness for fatigue strength is $35 \mathrm{HRC}$.

- Certification in accordance with AMS 2301 or ASTM A 534 should be required. These standards specify the required cleanliness for steel alloys. Cleanliness is an indication of the amount of inclusions in steel. \% Inclusions may act as stress concentrations in gear teeth and have been the source of bending fatigue failures in wind turbine gearboxes.

- The first and last gears from each production run should be surface temper etch inspected in accordance with ANSI/AGMA 2007-B92, class B, level 2 (AGMA 2007 FB2). Surface temper etching determines if gear teeth have been tempered during the grinding process. Tempering may result in decreased surface hardness or cracking.

- Shot peening may be used to correct manufacturing errors such as root notches and minor surface cracks. It may also be used to increase the strength of gear teeth beyond what is achieved during manufacturing by inducing compressive residual stresses. If shot peening is specified, it should be the last step in the manufacturing process.

\subsubsection{Case Depth}

The effective case depth in case hardened gears should be designed to avoid subcase fatigue failures. The effective case depth should be in accordance with ANSI/AGMA 2001-B88.

\subsubsection{Gear Accuracy}

All wind turbine gears should meet the accuracy requirements for AGMA quality No. Q11 in accordance with ANSI/AGMA 2000-A88. The gear quality is an indication of geometric accuracy of the gear. The higher the quality, the higher the load capacity and the lower the noise level. Q11 should be easily achievable with carburized and ground gears.

\subsubsection{Gear Tooth Cutting}

All gear teeth should be cut with protuberance cutters with full fillet radii to help avoid root notches. Bending stresses are highest in the gear tooth roots, and notches may act as stress concentrations increasing the possibility of a bending fatigue failure. 


\subsubsection{Gear Tooth Grinding}

All gear teeth should be ground on the flanks only. Grinding notches in the tooth flanks or the root fillets are not acceptable because they act as stress concentrations.

\subsubsection{Gear Tooth Chamfering}

All gear teeth should have radii or chamfers at the tips of the teeth and over the full contour of the edges of the teeth. Shock loads or misalignment may subject gear teeth to hard contact at the tips, roots, or edges. Chamfers may help to avoid hard contact and tooth damage.

\subsubsection{Gear Tooth Surface Roughness}

All loaded gear tooth surfaces should have a maximum surface roughness of 0.8 micrometers (32 microinches) rms.

\subsection{Minimum Vendor Data}

\subsubsection{Proposal Data}

At a minimum, all bidders should submit detailed drawings and the following data with their proposal. These data are necessary to determine if vendors' proposals meet the requirements of the procurement specification. This must be completed before a final vendor is chosen.

- An outline dimension drawing of the gearbox that fully describes the overall dimensions of the gearbox, shaft/key sizes, mounting dimensions, directions of rotation, lubricant capacity, and net weight.

- An assembly drawing of the gearbox that gives the part numbers of all components and the catalog numbers of all bearings.

- Detailed drawings of all gears with the following data should be supplied as a minimum:

Number of teeth.

Net face width.

Outside diameter.

Normal module.

Normal pressure angle.

Helix angle.

Hand of helix.

Operating center distance.

Addendum modification coefficient.

Tooth thickness (or pin or span measurement).

Finish stock allowance.

Gear cutting method.

Gear finishing method.

Cutting tool normal tooth thickness.

Cutting tool addendum.

Cutting tool tip radius.

Tip/root relief. 
Helix modification.

Tip chamfer, edge round, end round.

Tooth surface roughness.

Geometric quality.

Metallurgical quality.

Material alloy and grade.

Heat treatment method.

Tooth surface and core hardness.

Effective case depth to $50 \mathrm{HRC}$.

\subsubsection{Contract Data}

5.5.2.1 Drawings: In the inquiry or the purchase order the purchaser should state the number of prints required and the schedule within which they should be submitted by the vendor.

5.5.2.2 Drawing Approval: The vendor should not proceed with manufacturing until the drawings have been approved by the purchaser in writing. Approval of the drawings should not constitute permission to deviate from any requirements in the procurement specification or the purchase order unless specifically agreed upon separately in writing.

5.5.2.3 Certified Drawings: After the drawings have been approved, the vendor should furnish certified copies in the quantity specified.

5.5.2.4 Instruction Manuals: The vendor should furnish the required number of instruction manuals for the gearbox. The manuals should include instructions for installation, start-up, operation and maintenance. The manuals should also include recommendations for lubrication and storage.

\subsection{Housing and Accessories}

\subsubsection{General}

All gears should be totally enclosed in a cast ductile iron or cast steel housing.

5.6.1.1 Housing Distortion: The housing should be designed and constructed to prevent excessive distortions resulting from thermal variations, mechanical loading, or both.

5.6.1.2 Housing Accuracy: The housing bores and flanges should be machined to an accuracy which ensures that all gearsets, bearings and component interfaces contact correctly.

5.6.1.3 Inspection Covers: Removable, gasketed inspection cover(s) should be provided for field inspection of the full face width of all gear meshes. The inspection opening should be a minimum of three-quarters of the gear face width. Tapped holes for inspection cover bolts should be blind. Because of the configuration of epicyclic gearboxes it may be difficult to inspect the gears, even with a large inspection port. Borescopes using fiber optics can be used to inspect hard to reach gears. If borescope inspection is necessary, adequate access should be determined at the design stage.

5.6.1.4 Dipstick/Sight Gauge: A dipstick with a positive seal or a sight gauge should be provided for field inspection of the oil level. 
5.6.1.5 Bore Covers: All bore covers, bearing retainer caps or seal retainer caps should be sealed with suitable sealing compound and should be provided with threaded holes to permit removal with jackscrews.

5.6.1.6 Housing Joint: If the housing has a split plane for gear removal, it should employ a flat metalto-metal joint maintained oil tight with suitable sealing compound. Gaskets should not be used. Hardened, tapered dowel pins should be provided to maintain alignment of the housing halves.

5.6.1.7 Lifting Holes: The housing should have lifting holes or eye bolts to facilitate lifting of the complete gearbox, and disassembly and reassembly of the housing.

5.6.1.8 Brake Mounting Pads: If a high-speed shaft brake is mounted on the housing, pads should be provided for mounting the brake.

5.6.1.9 Torque Arm Mounting Lugs: If the gearbox is a shaft mount, the housing should have mounting lugs for the torque arm.

5.6.1.10 Internal Fasteners: No staking, set screws, bolts, nuts, or pins should be used inside the housing. Wind turbines are subjected to high vibrations which may loosen internal parts that can fall into the gear mesh and cause damage.

\subsubsection{Seals}

5.6.2.1 General: The input and output shafts should have seals to retain lubricant, and V-rings to exclude dust and moisture.

5.6.2.2 Oil Seal Materials: If elastomeric material is used in seals it should be a high temperature material.

5.6.2.3 V-Rings: External V-rings should be provided to prevent contaminants from entering the oil seals.

\subsubsection{Hardware}

5.6.3.1 General: All fasteners should be metric Grade 8.8 or better. Fastener size, tightening torque and engagement length should be in accordance with ANSI/AGMA 6001-C88. Dimensions and locations of hardware should be in accordance with the outline dimension drawing.

5.6.3.2 Magnetic Plugs: Magnetic plugs should be provided for field inspection of wear particles. Dimensions and location of the magnetic plugs should be in accordance with the outline dimension drawing.

5.6.3.3 Drain Valve: A ball valve should be provided for draining the lubricant in the field. A nylon plug should be provided to seal the drain valve. The drain valve should be a minimum of $25.4 \mathrm{~mm}$ ( 1 inch) NPT to allow the oil to be drained in a reasonable amount of time. The drain should be located at the bottom of a sloped sump to facilitate drainage.

\subsubsection{Breathers}

5.6.4.1 General: The gear housing should have a large capacity, filtered breather. Dimensions and locations of the breather should be in accordance with the outline dimension drawing. 
5.6.4.2 Breather Type: The breather should be a throwaway, spin-on type with a $19.1 \mathrm{~mm}$ ( $3 / 4 \mathrm{inch})$ NPT nipple or equivalent. If the turbine operates in an extremely corrosive atmosphere, a closed system such as a bladder-type breather might be necessary.

\subsection{Bearings Types and Specifications}

\subsubsection{General}

All gears should be straddle-mounted in rolling element bearings.

\subsubsection{Bearing Arrangement}

Each gear shaft should be supported by one fixed bearing and one floating bearing. The fixed bearing should support both radial and thrust forces. The floating bearing should support only radial forces and be free to absorb any axial growth caused by thermal expansion (see Section 6.3 .4 for bearing endplay).

\subsubsection{Bearing Type}

All bearings should be spherical-roller, double-row tapered-roller, cylindrical roller or ball. Single-row tapered-roller bearings should not be used unless endplay can be maintained within acceptable limits under full load (see Section 6.3.4, Bearing Endplay).

\subsubsection{Shaft/Housing Fits}

All bearings should be tightly fit into the housing and onto shafts, or adequate means should be provided to prevent spinning of the inner or outer bearing races. All inner raceways should be constrained by heavy duty snap rings or clamping plates. There have been many instances of outer bearing races spinning in wind turbine gearboxes. All outer races should be constrained by a tight fit, pinning, or any other appropriate method.

\subsection{Shaft and Key Specifications}

\subsubsection{General}

All shafts should be designed in accordance with ANSI/AGMA 6001-C88.

5.8.1.1 Shaft Materials: The low-speed shaft should be a through-hardened alloy steel.

5.8.1.2 Shaft Hardness: All shafts should have a surface hardness of $286 \mathrm{BHN}$ minimum.

5.8.1.3 Magnetic Particle Inspection: All shafts should be $100 \%$ magnetic particle inspected. Cracks are not acceptable.

5.8.1.4 Shrink Fits: All gears should be shrink fitted to their shafts. The interference should be designed to transmit a minimum specified torque (such as maximum brake load). No benefit from keys should be considered when calculating the torque capacity.

5.8.1.5 Lifting Holes: All shaft ends should have threaded holes designed to accept eye bolts for lifting. 


\subsubsection{Keys}

\subsubsection{General}

All keys should be designed in accordance with ANSI/AGMA 6001-C88.

5.8.2.2 Key Materials: All keys should be through-hardened alloy steel.

5.8.2.3 Key Hardness: All keys should have a hardness of $286 \mathrm{BHN}$ minimum.

5.8.2.4 Key Geometry: All keys should have chamfers on all edges and ends.

5.8.2.5 Key/Shaft Fit: All keys should be fitted to their keyways with an interference fit. 


\subsection{OPERATION AND MAINTENANCE}

The operation and maintenance of a wind turbine gearbox is as important as designing, manufacturing and procuring the gearbox, and should be fully defined prior to purchasing the gearbox. Start-up, operating, and maintenance plans should be formalized before the gearbox is placed in service and should be the joint responsibility of the gearbox purchaser and vendor.

\subsection{Start-Up and Run-In Procedures}

The bed plate, mounting surfaces, shims, and shaft couplings must be accurately aligned for proper, overall performance and maximum bearing and coupling life. Load variations and temperature changes cause the alignment to change. Therefore it is best to carefully align couplings to ensure that they have adequate capacity to accommodate increases in misalignment. In some cases it is necessary to bias the cold alignment to minimize shaft misalignment at the operating temperature. For shaft-mounted gearboxes, the torque arm should be properly located and mounted without excessive clearance in the mounting points to ensure that the gearbox housing is not twisted and the high-speed coupling is not misaligned.

Before initiating start up of the wind turbine check:

- Oil level and type.

- Pipe connections.

- Electrical connections.

- Torque on mounting and gearbox bolts.

- Operation of automatic shutdowns and alarms.

- Coupling installation and alignment.

- Inspection cover installation.

- Heater, cooler, and fan operation.

During initial start-up, these procedures are helpful:

- Pre-oil the unit to lubricate gears, bearings and lip seals.

- For cold environment start-ups, preheat the lubricant.

- Load should not be applied until the oil has attained operating temperature.

- Start the gearbox slowly under light load. Check for proper rotation direction. Check system oil pressure.

- After oil circulates, stop the unit, check oil level, and add as necessary.

- Monitor continuously for excessive noise, vibration, and temperature. If any problems are detected, shut down immediately and take corrective action. 
- If possible, operate the first 10 hours at one-half load for a final tooth surface run-in.

- After the first 50 hours, drain the oil and flush with SAE 10 mineral flushing oil containing no additives. Drain the flushing oil completely, refill with recommended lubricant, and install a new oil filter.

- Check coupling alignments and retorque all bolts. Check all piping connections and tighten as necessary.

Finally, to confirm that the requirements of the procurement specification have been met, gearbox performance should be monitored under actual service conditions. Because the first few weeks after startup are critical, data on load, vibration, and performance should be collected. Not every application warrants full telemetry and strain gaging; however, power, temperature and noise level should be recorded for every gearbox and the lubricant should be analyzed for contamination. These actions will check the purchasing process and involve the vendor in corrections as necessary.

\subsection{Lubrication}

\subsubsection{Change Interval}

Depending on the type of lubricant and system, the lubricant should be changed every year or two. Monitoring and testing the lubricant for viscosity, water content, acid number, solid contaminants, and additive depletion will help determine the proper change interval.

\subsubsection{Lubricant Sampling}

The effectiveness of lubricant analysis depends on proper sampling techniques. The sample should be representative of the operating lubricant.

6.2.2.1 Sampling Techniques: Whenever samples are taken, it is important that the same procedures be followed so that consistent samples are obtained. Once the monitoring program has begun, do not change sampling procedures or sampling points. Some helpful suggestions are given below. Always use clean, plastic sample bottles, and keep all sampling equipment scrupulously clean. Prior to sampling, fill out the label completely and attach it to the sample bottle. Be sure to record the sample point and the date. Thoroughly clean the area around the sampling port or valve before opening the port or valve.

6.2.2.2 Sampling from Oil Drums: For monitoring the quality of the lubricant, the sample should be taken from the lubricant drum. If the objective is to test the general condition of the oil in the drum, the sample should be a mixture of oil taken from the top, middle and near the bottom of the drum. If the objective is to test for water contamination, sludge or sedimentation, the sample should be taken from the lowest point of the drum.

Use a manual suction pump to draw the oil sample into the sample bottle.

Sample from the top, middle, and near the bottom of the drum in order to obtain a representative sample and avoid stratification. Use a sampling rod and attach the sampling tube to the rod with plastic ties. Position the sampling tube a few inches from the bottom of the rod to prevent the end of the tube from touching the sides and bottom of the drum. Take one-third of the sample with the rod touching the bottom of the drum. Take another one-third of the sample with the rod raised to mid-height of the oil 
level. Take the final third of the sample with the rod raised so that the sampling tube is just below the surface of the oil.

Discard the sampling tube to avoid contaminating subsequent oil samples.

6.2.2.3 Sampling from the Gearbox Drain Valve: For monitoring gearbox health, the sample should be taken from the gearbox drain valve. Discard any oil that may have been stagnant in the drain valve. Do this by tuming on the valve, capturing the oil to be discarded in a separate bottle, and without touching the valve, obtain the sample to be analyzed in a fresh sample bottle.

\subsubsection{On-Site Monitoring}

There are several simple tests that can be performed on-site and at low cost to check for contamination or oxidation of the lubricant. The tests should be performed by the same person each time, because the tests require experience to accurately judge the results. The tests can be run as often as necessary, but they should be done every time samples are taken for laboratory analysis.

6.2.3.I Appearance Test: The simplest test is visual appearance. Often, this test will disclose problems such as gross contamination or oxidation.

Look at the lubricant in a clean, glass bottle. A narrow, tall vessel is best. Compare the sample with a sample of new, unused lubricant. The oil should look clear and bright. If the sample looks hazy and cloudy, or has a milky appearance, there may be water present. The color should be similar to that of the new oil sample. A darkened color may indicate oxidation or contamination with fine wear particles. Tilt the bottle and observe whether the used oil appears more or less viscous than the new oil. A change in viscosity may indicate oxidation or contamination. Look for sediment at the bottom of the bottle. If any is present, run the sedimentation test.

6.2.3.2 Odor Test: Carefully sniff the oil sample. Compare the smell of the used oil sample with that of new oil. The used oil should smell the same as new oil; that is, it should have a bland, oily odor. Oils that have oxidized have a "bumt" odor, or smell acrid, sour, or pungent.

6.2.3.3 Sedimentation Test: If any sediment is visible during the appearance test, a simple test for contamination can be performed on site as follows: place a sample of oil in a clean, white, plastic cup and allow it to stand for 2 days. Carefully pour off all but a few milliliters of oil. If any particles are visible at the bottom of the cup, contaminants are present. Resolution of the unaided eye is about $40 \mu \mathrm{m}$. If particles respond to a magnet under the cup, iron or magnetite wear fragments are present; if they don't respond to the magnet, and the solids feel gritty between the fingers, they are probably sand. If another liquid phase is visible, or the oil appears milky, water is probably present.

6.2.3.4 Crackle Test: If you suspect there may be water present in an oil sample, you should perform a simple test for water contamination that can be performed on site as follows: drop a small drop of oil onto a hot plate at $135^{\circ} \mathrm{C}\left(275^{\circ}\right)$. If the sample bubbles, water is above $0.05 \%$. If the sample bubbles and crackles, water is above $0.1 \%$. 


\subsubsection{Laboratory Analysis}

6.2.4.1 Viscosity: The ASTM D 445 test is an accurate, universal method for determining kinematic viscosities of lubricants. It measures the time for a fixed volume of oil to flow through a capillary viscometer under accurately reproducible head at closely controlled temperatures. Viscosities are then calculated from the measured flow time and the calibration constant of the viscometer. Units for kinematic viscosity are centistoke (cSt).

Viscosity is usually measured at $40^{\circ} \mathrm{C}\left(104^{\circ} \mathrm{F}\right)$ and $100^{\circ} \mathrm{C}\left(212^{\circ} \mathrm{F}\right)$. Viscosities at other temperatures can be determined by plotting the two points on special graph paper (ASTM Chart D 341). Viscosity index, or VI, is a means of expressing the variation of viscosity with temperature. VI is calculated from the measured viscosity at $40^{\circ} \mathrm{C}$ and $100^{\circ} \mathrm{C}$ using ASTM Method D 2270.

An increase in viscosity over that of fresh oil can be caused by oxidation or by contamination from dirt or water. A decrease in viscosity is unusual, but it can be caused by contamination with a solvent or with a lower viscosity fluid.

6.2.4.2 Total Acid Number: The standard test for Total Acid Number (TAN) is ASTM D 664, "Neutralization Number by Potentiometric Titration." The test uses potassium hydroxide to neutralize the acidic constituents in the oil. It yields a single number that represents the amount of potassium hydroxide used for a given sample of oil in units of $\mathrm{mgKOH} / \mathrm{g}$.

When tested, most new unused oils will have an acid number because the potassium hydroxide reacts with additives in the oil. Therefore, new, unused oil should be tested to establish a baseline TAN. Depending on the amount of additives, the new oil baseline TAN can range from 0.01 to 2.5 . With the new oil baseline TAN known, you can monitor any change in acidity from the new oil baseline.

The TAN is a measure of the acidity of an oil sample. The higher the TAN, the more acidic constituents are present. The acids usually form when high temperatures cause the oil to oxidize. The oxidation may be promoted by contaminants such as water, or wear debris such as iron and copper, that act as catalysts.

Oil oxidation is detrimental because it may increase viscosity, change color and odor, cause residues and sludge, and create acids that promote corrosion.

6.2.4.3 Water Content: The effects of water contamination are many. Water degrades the lubricant and precipitates additives. It also promotes oxidation and impairs the lubricant film. In nonmetallic components, water causes seal hardening and paint peeling.

Water causes corrosion by combining with sulfur to form sulfuric acid. It creates rust particles that lead to abrasive wear and act as a catalyst to oxidation. Water leads to rust etch pits that can promote metal fatigue and cause hydrogen embrittlement.

There are several tests for determining water content in lubricants. They are listed below in order of increasing accuracy:

Crackle Test: A simple test for water contamination is performed as follows: drop a small drop of oil onto a hot plate at $135^{\circ} \mathrm{C}\left(275^{\circ} \mathrm{F}\right)$. If the sample bubbles, water is above $0.05 \%$. If the sample bubbles and crackles, water is above $0.1 \%$.

Distillation (ASTM D 95): The distillation test is usually used on oils that prove to be positive by the crackle test and require a more accurate determination of water content. The test is a simple distillation 
of the oil and separation of the water. It detects water at levels of $0.1 \%$ (1000 ppm) or greater with reasonable precision.

Infrared Analysis: Infrared spectroscopy is usually used when water is present at levels above $0.05 \%$ (500 ppm).

Karl Fischer (ASTM D 1744): The Karl Fischer Titration test determines water content from the chemical reaction between a reagent and the water in the oil sample. It detects water as low as $0.001 \%$ (10 ppm). It is commonly used because it is accurate and relatively inexpensive.

\subsubsection{Spectrochemical Analysis}

This test detects microscopic metal particles in an oil sample. The typical spectrometer is capable of identifying about 20 metals, the source of which may be wear debris, contaminants or inorganic additives in the lubricant. Knowing the type and quantity of metals can help diagnose wear problems or disclose sources of contamination. For example, a high concentration of iron, chromium, manganese, molybdenum or nickel could indicate wear debris from gear teeth or bearings.

Spectrochemical analysis is rapid and inexpensive. The oil sample is burned and the light emitted is separated by diffraction into distinct wavelengths. Because each metal has its own characteristic wavelength, specific metals in the oil sample can be identified.

Table 6.2.1 is a general list of metallic elements that may be detected by spectrochemical analysis. It lists typical sources for each element. 
Table 6.2.1. Sources of Metallic Elements

\begin{tabular}{l|c|l}
\hline \multicolumn{1}{c|}{ Element } & Symbol & \multicolumn{1}{|c}{ Typical Source } \\
\hline Aluminum & $\mathrm{Al}$ & Dirt, labyrinth seals \\
Antimony & $\mathrm{Sb}$ & Bearings, grease \\
Arsenic & $\mathrm{As}$ & Bearings \\
Barium & $\mathrm{Ba}$ & Water, grease \\
Bismuth & $\mathrm{Bi}$ & Bearings \\
Boron & $\mathrm{B}$ & Additives \\
Cadmium & $\mathrm{Cd}$ & Bearings, plating \\
Calcium & $\mathrm{Ca}$ & Additives, water, grease, dirt \\
Chromium & $\mathrm{Cr}$ & Gears, shafts \\
Cobalt & $\mathrm{Co}$ & \\
Copper & $\mathrm{Cu}$ & Bearings \\
Indium & $\mathrm{In}$ & Solder \\
Iron & $\mathrm{Fe}$ & Gears, shafts, rust, water \\
Lead & $\mathrm{Pb}$ & Bearings, grease, paint \\
Magnesium & $\mathrm{Mg}$ & Dirt \\
Manganese & $\mathrm{Mn}$ & Gears, shafts \\
Molybdenum & $\mathrm{Mo}$ & Gears, shafts \\
Nickel & $\mathrm{Ni}$ & Gears, shafts \\
Phosphorus & $\mathrm{P}$ & Additives \\
Potassium & $\mathrm{K}$ & Dirt \\
Silicon & $\mathrm{Si}$ & Additives, dirt, sealants \\
Sodium & $\mathrm{Na}$ & Additives, dirt \\
Tin & $\mathrm{Sn}$ & Bearings, solder, coolers \\
Titanium & $\mathrm{Ti}$ & Paint, dirt \\
Vanadium & $\mathrm{V}$ & \\
Zinc & $\mathrm{Zn}$ & Additives \\
\hline
\end{tabular}

There are limitations to spectrochemical analysis. Emission spectroscopy works well for detecting metal particles up to 5-10 microns $(\mu \mathrm{m})$, but it will not detect particles greater than about $10 \mu \mathrm{m}$ because it is incapable of completely and consistently burning large particles. Therefore, it readily detects particles from mild adhesive wear, polishing, and micropitting because wear debris from these wear modes are within the detectable range. However, failure modes such as severe abrasion, macropitting, or scuffing usually generate particles that are larger than $10 \mu \mathrm{m}$. In such situations, ferrography, particle counting or analysis with the Wear Particle Analyzer may be superior monitoring techniques.

Spectroscopy does not distinguish between particles of free metal and particles of metal oxides or other compounds of metal. For example, rust particles may show up as increased iron content, but spectroscopy cannot identify whether the iron is in the form of wear debris, iron oxide, iron sulfide or rust. High concentrations of silicon or aluminum may indicate contaminants such as sand, dust or dirt. However, there are other sources for silicon, such as silicone antifoam additives or silicone gasket sealants. It is therefore important to analyze samples of fresh oil from new oil drums to establish a baseline level of silicon to help distinguish between contaminants and lubricant additives.

Table 6.2.2 shows the metallic elements in a typical synthetic gear lubricant. The concentrations of the additive elements were determined from spectrochemical analyses of samples of fresh lubricant. A table such as that shown in 6.2.2 serves as a baseline for additive concentrations. If analysis of used lubricant shows additive levels departing $\pm 30 \%$ from the baseline, depletion of the lubricant additives or contamination of the lubricant could be indicated, and the cause should be investigated. 
Table 6.2.2. Metallic Elements in a Typical Synthetic Gear Lubricant

\begin{tabular}{l|c|c|l|}
\hline Element & Symbol & $\begin{array}{c}\text { Average } \\
\text { Content (ppm) }\end{array}$ & $\begin{array}{c}\text { Additive } \\
\text { Description }\end{array}$ \\
\hline $\begin{array}{l}\text { Phosphorus } \\
\text { Sulfur }\end{array}$ & $\mathrm{P}$ & 315 & Antiscuff, antiwear \\
Silicon & $\mathrm{S}$ & 4600 & Antiscuff \\
Zinc & $\mathrm{Si}$ & 19 & Antifoam \\
& $\mathrm{Zn}$ & 4 & $\begin{array}{l}\text { Antiwear, } \\
\text { antioxidant, } \\
\text { anticorrosion }\end{array}$ \\
\hline
\end{tabular}

Note: $\mathrm{ppm}=$ parts per million $(1 \mathrm{ppm}=0.0001 \%)$

Sulfur, a common antiscuff additive in gear oils, is not detected by spectroscopy, and sulfur content must be determined by a separate test.

It is helpful to plot the results of spectrochemical analyses over time. The graphs will indicate the normal test variability and help you follow any trends in test results. An accelerating wear problem is most easily predicted from a trend line that is increasing.

6.2.4.5 Automatic Particle Counting: Particle counters monitor the number of particles of a given size range in a given volume of oil sample. This method for determining lubricant cleanliness detects all particles regardless of their composition and is capable of detecting particles in the range of 0.5 microns to greater than 100 microns.

Particle counters are either of the light-interruption type or the laser-scanning type. Either method provides analyses that are rapid and inexpensive.

Light-intermuption particle counters flow the lubricant through a small passage while a light beam scans the oil through a window. Particles in the oil that are within a set size range momentarily interrupt the light beam. The output from a detector that senses the interruption of the light beam is related to the time of interruption and hence the size of the particle.

Laser-scanning particle counters operate on a principle that is similar to that of the light-interruption type, except the oil sample remains stationary in a clear glass container while it is scanned by a revolving laser beam. The particle size range is selectable, as it is with the light-interruption method.

There are limitations to automatic particle counting. While particle counting detects all particles, it gives no information on the shape or composition of the particles. It is susceptible to incorrect counts caused by mistakenly counting bubbles of air or water. The oil sample must not be opaque. For accurate results, the oil sample should be well agitated to produce a uniform suspension of particulates, and the concentration of particles should be low enough to avoid counting two or more particles as one. 
6.2.4.6 ISO Solid Contamination Code: The International Standards Organization (ISO) Solid Contamination Code ISO/DIS 4406 has been universally accepted as the simplest and best means for expressing cleanliness levels. It has been adopted by the Society of Automotive Engineers (SAE J1165).

The ISO contamination code consists of the two range numbers $x / y$, and where $x$ represents the range number for particles greater than $5 \mu \mathrm{m}$ and y represents the range number for particles greater than $15 \mu \mathrm{m}$.

There are two ways to assign the ISO code. In the first method, the range numbers are selected from a table of range numbers versus particle concentration (see Table 6.2.4) for the number of particles greater than 5 and $15 \mu \mathrm{m}$ per milliliter. If a particle count falls between adjacent particle concentrations, the ISO range number is found opposite the higher concentration. In the second method the particle counts are plotted on graph paper (see Figure 1) and the range numbers are determined where the line crosses the 5 and $15 \mu \mathrm{m}$ vertical lines.

As an example, suppose the particle counts shown in Table 6.2.3 are obtained:

Table 6.2.3. Example Particle Counts

\begin{tabular}{c|c}
\hline Particle Size & Particles per 100 milliliters \\
\hline$>5$ & 161,700 \\
$>15$ & 7,800 \\
$>25$ & 1,680 \\
$>50$ & 268 \\
$>100$ & 20
\end{tabular}

Because there are 1617 particles/ml greater than $5 \mu \mathrm{m}$, the first range number given by Table 6.2 .4 is 18 . The $78 \mathrm{particles} / \mathrm{ml}$ greater than $15 \mu \mathrm{m}$ gives a range number of 13 . Therefore, the ISO code number for the sample is $18 / 13$.

Table 6.2.4 is a tabular presentation of typical ISO codes and corresponding particle concentrations.

6.2.4.7 Ferrographic Analysis: Ferrographic analysis separates wear debris and contaminants from a lubricant sample by magnetic precipitation. It is capable of precipitating particles that range from less than $1 \mu \mathrm{m}$ to greater than $200 \mu \mathrm{m}$. Ferrography provides two types of analysis, a relatively inexpensive directreading ferrograph and a more expensive analytical ferrograph. 
Table 6.2.4. ISO Range Number Table

\begin{tabular}{|c|c|}
\hline $\begin{array}{l}\text { Particle Concentration } \\
\text { (particles per milliliter) }\end{array}$ & Range \\
\hline $10,000,000$ & 30 \\
\hline $5,000,000$ & 29 \\
\hline $2,500,000$ & 28 \\
\hline $1,300,000$ & 27 \\
\hline 640,000 & 26 \\
\hline 320,000 & 25 \\
\hline 160,000 & 24 \\
\hline 80,000 & 23 \\
\hline 40,000 & 22 \\
\hline 20,000 & 21 \\
\hline 10,000 & 20 \\
\hline 5,000 & 19 \\
\hline 2,500 & 18 \\
\hline 1,300 & 17 \\
\hline 640 & 16 \\
\hline 320 & 15 \\
\hline 160 & 14 \\
\hline 80 & 13 \\
\hline 40 & 12 \\
\hline 20 & 11 \\
\hline 10 & 10 \\
\hline 5 & 9 \\
\hline 2.5 & 8 \\
\hline 1.3 & 7 \\
\hline 0.64 & 6 \\
\hline 0.32 & 5 \\
\hline 0.16 & 4 \\
\hline
\end{tabular}


In the direct-reading ferrograph, a diluted sample of lubricant is syphoned through a precipitation tube that resides in a powerful magnetic field. The combination of magnetic force and the viscous forces exerted by the lubricant causes the particles to be separated according to size. The large particles $(>5 \mu \mathrm{m})$ are deposited first, near the entry of the tube. Smaller particles $(1-2 \mu \mathrm{m})$ deposit farther down the tube. Two light beams pass through the precipitation tube, one at the entry deposit and one several millimeters farther down the tube where small particles deposit. Light attenuation at the two locations along the tube is used to quantify the relative amount of large to small particles. The results are reported as two scalar reading, "direct large" (DL), and "direct small" (DS).

In the analytical ferrograph, a diluted sample of lubricant is pumped across a microscope slide that is mounted at an angle above a magnet so that the field varies along the length of the slide. The particles are subjected to a continuously increasing magnetic force as they flow along the slide. Consequently, the particles precipitate and distribute according to size along a narrow band about $50 \mathrm{~mm}$ (1.97 inches) long. Ferrous particles line up in strings that follow the magnetic lines. Nonferrous particles and contaminants travel down the field in a random pattern. The slide is washed with a fixative that washes away the oil, locks the particles in place, and floats away other material.

The ferrogram (a slide upon which particles have been deposited) is examined in a bichromatic microscope equipped with a camera. The microscope uses both transmitted green light projected from the bottom of the ferrogram and red light reflected from the top of the ferrogram to distinguish the size, shape, texture, and composition of both metallic and nonmetallic particles. The particles have characteristics which help determine the wear mechanism and identify their sources. The following table classifies the types of particles.

Table 6.2.5. Characteristics of Particles

\section{Wear Particles}

Rubbing: Flat platelets $<15 \mu \mathrm{m}$ long, $<1 \mu \mathrm{m}$ thick. These are found in the lubricants of all machines and are indicators of normal wear.

Sliding: Generally $>15 \mu \mathrm{m}$ with a length/thickness ratio between 5 and 30 . Surfaces have parallel striations and may have temper colors. These particles are indicators of severe sliding.

Cutting: Long, curled chips resembling lathe cuttings are evidence of abrasive wear. May be caused by contamination of lubricant by hard, sharp-edged particles.

Fatigue: Generally $>5 \mu \mathrm{m}$ with a length/thickness ratio $<5$. Surfaces are rough and particles are shaped like chunks of coal rather than platelets.

Laminar: Thin, bright particles, often with holes in their surfaces and split edges. Length/thickness ratio $>30$. Typical of gear and rolling-bearing wear particles that pass between contacting surfaces.

Spherical: Generally $<5 \mu \mathrm{m}$ diameter with smooth surfaces. They are a sign of impending rolling-bearing fatigue failure.

\section{Ferrous Oxides}

Red oxide: Red/orange particles that align magnetically. These oxidized particles appear thick, rounded, and translucent, and indicate severe sliding wear. 
Dark metallo-oxide: Resemble red oxide sliding wear particles, except they are not translucent. Often show flecks of free metal on their surfaces. They are caused by heat and may be evidence of lubricant starvation or severe wear.

Black Oxide: Dark gray/black particles magnetically aligned and shaped like pebbles. These are evidence of inadequate lubrication. They represent a more severe condition than do red oxide particles.

Corrosion: Fine deposit of $<1 \mu \mathrm{m}$-size particles at the exit of the ferrogram. They are formed by a corrosive attack on metal surfaces and depletion of lubricant additives.

\section{Contaminants}

Friction Polymer: Amorphous, translucent material of no particular size. Indicates lubricant polymerization under extreme conditions.

Sand/Dirt: Generally $>5 \mu \mathrm{m}$ crystalline particles, not magnetically aligned.

Fibers: Translucent, fibrous particles, not magnetically aligned. Typical fibers include hair, cotton, wood, glass, minerals, nylon, and cellulose.

Spheres: Generally $>5 \mu \mathrm{m}$ with rough surfaces. May be contaminants from grinding, weiding, or shot blasting.

Other: Conitaminants such as paper, paint, varnish, glue, gasket or seal materials, or lubricant additives such as molybdenum disulfide or graphite.

6.2.4.8 Wear Particle Analyzer: In the Wear Particle Analyzer a diluted sample of lubricant is drawn through a filter that is in a strong magnetic field. The filter has a matrix of fine, ferromagnetic fibers that become magnetized in the magnetic field. The fibers capture small particles magnetically and physically capture particles larger than the spacing between the fibers.

A flux sensor determines the change in the magnetic field caused by the presence of the particles, and displays the magnetic equivalent of the captured particles in micrograms of iron metal. The reading, known as the magnetic iron content (MIC), is independent of particle size.

The Wear Particle Analyzer is capable of capturing particles $1 \mu \mathrm{m}$ and larger with an efficiency of $95 \%$ or greater.

The filter can be backwashed with solvent to recover the particles for microscopic examination and other diagnostic analyses.

\subsubsection{Recommended Analysis Limits}

Table 6.2.6 gives recommended limits for analysis parameters and typical contaminants for wind turbine gearboxes. 
Table 6.2.6. Analysis Limits for Wind Turbine Gearbox Lubricants

\begin{tabular}{l|c|c}
\multicolumn{1}{c|}{ Analysis Parameter } & Borderline & Unsatisfactory \\
\hline Water (Karl Fischer) & $0.05 \%$ & $>0.10 \%$ \\
\hline Sediment (see 6.2.3.3) & & visible \\
\hline TAN $^{1}$ increase over fresh oil & $40 \%$ & $>75 \%$ \\
\hline Viscosity change from ISO limits & $10 \%$ & $>20 \%$ \\
\hline
\end{tabular}

\begin{tabular}{l|c|c}
\hline \multicolumn{3}{|c|}{ Wear Metals (ppm) } \\
\hline Iron $(\mathrm{Fe})$ & $75-100$ & $>100$ \\
\hline Copper $(\mathrm{Cu})$ & $50-75$ & $>75$ \\
\hline Silicon $(\mathrm{Si})$ & $15-20$ & $>20$ \\
\hline
\end{tabular}

\begin{tabular}{l|c|l} 
& \multicolumn{3}{|c|}{ Typical contaminants in fresh oil (ppm) } \\
\hline Water & $100-300(0.01-0.03 \%)$ & \\
\hline Iron $(\mathrm{Fe})$ & $1-2$ & \\
\hline Silicon $(\mathrm{Si})$ & $2-3$ &
\end{tabular}

Notes: ${ }^{\text {-TAN }}=$ total acid number.

\subsubsection{Storage Procedures}

Drums of spare lubricant should be properly stored to avoid contamination. Drums should be stored indoors on their sides.

\subsection{Gearbox Inspection}

Several inspections can be performed by wind farm technicians to monitor the condition of wind turbine gearboxes. Some should be performed periodically as part of a maintenance program. Other inspections may be performed only at start-up or annually. The gear vendor's recommendations for gearbox installation, start-up, and maintenance should be followed.

\subsubsection{Gear Tooth Contact Patterns}

The way in which maing gear teeth contact is an indicator of how well they are aligned. Tooth contact patterns can be recorded under loaded or unloaded conditions. For no-load tests, the teeth of one gear are painted with soft marking compound, such as Prussian blue. Then, the teeth are rolled through mesh so the compound transfers the pattern to the unpainted gear. The pattern is lifted from the gear with scotch tape and mounted on paper to form a permanent record.

For loaded tests, several teeth on one or both gears are painted with machinist's layout lacquer. The gears are run under load for a sufficient time to wear off the lacquer and establish the contact patterns. The patterns are photographed to obtain a permanent record. 
No-load contact patterns are not as reliable as loaded contact patterns for showing how well gear teeth are aligned because the marking compound is relatively thick and no-load tests do not show distortion and misalignment caused by load, speed, or temperature. Therefore, no-load tests are usually done as preliminary checks and are followed by loaded tests.

Loaded contact patterns are best obtained under different loads ranging, for example, from $25 \%$ to $50 \%$ and $75 \%$ to $100 \%$ The contact patterns are inspected after running for a short time at each load to monitor how the contact patterns change with load. The ideal contact pattern covers $100 \%$ of the active face of the gear teeth under full load, except at the extremes of the teeth near the tips, roots, and ends, where the contact should be lighter, as evidenced by traces of lacquer.

\subsubsection{Sound and Vibration}

Sound and vibration measurements are useful diagnostics of the condition and geometric quality of a gearbox.

Noise emissions have historically been responsible for limiting the development of wind energy. Strict regulations have been enacted to limit the sound from wind turbines both in the United States and Europe. Pure tone frequencies from gearboxes have been targeted in many areas because they are perceived to be more annoying. Therefore, it is very important to control gearbox noise at the design stage, and the procurement specification should specify acceptance criteria for sound and vibration tests performed at the factory. The gear vendor's test plan should describe the test procedures and acceptance criteria.

A sound meter can be used to measure overall sound level, either in the turbine nacelle or at ground level. An accelerometer is preferred for measuring vibration on the gearbox housing because an accelerometer is small and rugged and has a large frequency response and large dynamic range. Housing vibration should be measured on a rigid part of the housing, such as a bearing block. To avoid attenuation of the vibration signal, the accelerometer should be mounted to the housing with a screw or stud rather than with a magnet:or adhesive.

The output from the sound meter and accelerometer can be read by a computer to calculate the frequency components of the data by fast Fourier transform (FFT). Analysis of the frequencies helps identify which components of the gearbox are major contributors to sound and vibration.

For monitoring the condition of gears it is best to analyze the vibration data in the time domain. By trending the averaged time domain signature, gear tooth problems can be detected from changes in the images of gear tooth meshing.

Time domain averaging requires a shaft encoder to accurately measure shaft speed so the data is synchronously averaged to obtain a time representation of the vibration generated over one rotation of each gear.

The shock pulse method can be used for monitoring the condition of rolling element bearings. It uses a piezoelectric transducer with a well defined mechanical resonant frequency to measure ultrasonic shock pulses or stress waves generated by the rolling elements and the raceways. By trending the data, bearing problems can be detected from changes in the shock pulse patterns.

\subsubsection{Temperature}

A maximum allowable oil sump temperature of $95^{\circ} \mathrm{C}\left(203^{\circ} \mathrm{F}\right)$ is recommended by AGMA 6010-E88. Sustained sump temperature in excess of $95^{\circ} \mathrm{C}\left(203^{\circ} \mathrm{F}\right)$ may result in accelerated degradation of the 
lubricant and elastomeric seals. Generally, sump temperatures should be less than $80^{\circ} \mathrm{C}\left(176^{\circ} \mathrm{F}\right)$ to obtain adequate life for the lubricant and seals.

The oil sump temperature can be measured with thermometers, thermocouples, or resistance temperature detectors (RTD) installed in the gear housing. The output from thermocouples or RTDs may be monitored by a computer to shut down the turbine in the event of overheating.

The exterior of the gearbox housing should be visually inspected periodically for evidence of overheating, such as discoloration or blistering of the paint. Sand or dust should be removed from the gearbox housing because it impedes heat transfer.

Wind turbines should not be operated with the nacelle cover removed or left open. Exposure to direct sunlight will cause the gearbox to run hotter, and air flow over the gearbox may be disrupted, resulting in less heat transfer and higher gearbox temperature.

\subsubsection{Bearing Endplay}

Endplay with spherical-roller, cylindrical-roller, and ball bearings is not critical as long as there is some clearance. In contrast, the endplay with tapered-roller bearings is critical. Excessive endplay misaligns the gears and may result in gear failure, while inadequate endplay may cause the bearings to overheat, resulting in failure.

For maximum load capacity, single-row, tapered-roller bearings should have zero endplay or a slight preload when they are at operating temperature and under full load. The gear vendor should set the cold, no-load endplay based on tests of thermal expansion and elastic deflections. If the gear housing is especially flexible, it may be necessary to set the bearings with a preload to compensate for deflections of the housing that increase endplay.

The bearing endplay can be checked in the field with a dial indicator installed as close as possible to the axis of the shaft. The endplay is measured by moving the shaft axially with a pry bar or special fixture. It is best to rotate the shaft slowly while applying pressure to ensure that the bearing rollers are properly seated. With pressure applied, the dial indicator is set to zero, the pressure is released, and applied in the opposite direction. The shaft is rotated to seat the rollers, and the endplay is read from the dial indicator.

\subsubsection{Shaft Alignment}

For maximum bearing and coupling life, shaft misalignment should be minimized. The cold, no-load alignment should be set so that the shafts are aligned when the drive system is at operating temperature and under full load.

The shaft alignment can be checked in the field with dial indicators or lasers. To measure the alignment with dial indicators, the reverse indicator method should be used to take two readings- - one with an indicator attached to the driving shaft and another with an indicator attached to the driven shaft. Laseroptic alignment devices are commercially available. These are more accurate and easier to use than dial indicators. These systems emit a beam from a semiconductor laser, refract the beam through a prism, and capture it with a detector. A computer uses the data from the detector to calculate the horizontal and vertical adjustments needed to correct the alignment. 


\subsection{Maintainability}

The general maintainability of wind turbine gearboxes is a very important issue which should be addressed at the design stage. Technicians must have safe access to equipment that requires maintenance. The work space on top of a wind turbine tower is often very limited and hazardous; therefore, some planning is needed when choosing the placement of breather, magnetic plugs, drain lines, fill plugs, filters, inspection ports and sight gauges or dip sticks.

Breathers should be placed where they are not likely to be stepped on. Magnetic plugs and all drain plugs should be placed on the bottom of the gearbox in an area that is easily accessible to technicians. Inspection ports should be large enough to allow inspection of the gearing, but small enough to minimize exposure to the environment when they are opened. Also, the inspection covers should be light and small enough to be easily handled by the technician. Some gearboxes have removable top covers that are unwieldy. When removed they expose the entire gearbox to the environment. This increases the probability of contamination by airbome particles and the possibility of technicians inadvertently dropping tools or rags into the gearbox. Site gauges and dipsticks should be placed where they will give an accurate reading, but are not likely to be damaged during routine maintenance.

Lubricant change-out and filtering procedures should also be determined during the design stage. The wind turbine operator and the gearbox designer should consider the following:

- Will the lubricant be changed in the tower or in the shop?

- Will the gearbox be flushed before adding new lubricant, and will this be done at the tower or in the shop?

- If a pressure-fed, filtered lubrication system is to be used, are the filters accessible for changing?

- If a portable filtering system is to be used, will it be done at the tower or in the shop? 


\subsection{FAILURE HISTORY}

\subsection{General}

During the past 11 years GEARTECH has inspected over sixty wind turbine gearboxes. Most inspections involved full disassembly and inspection of all components in the gearboxes. In most cases the gearboxes were considered failed. Some of the failures were isolated cases involving one or two gearboxes, but most failures were representative of larger problems, some involving hundreds of gearboxes. Based on investigations and interviews with dozens of wind farm personnel, it is estimated that there have been thousands of gearbox failures.

Gearbox failure analysis is a controversial subject because the defmition of "failure" can be subjective. GEARTECH considers a gearbox failed in the following circumstances:

- It does not survive the required lifetime.

- It exceeds the sound level or vibration limits.

- It has substantial oil leakage.

- It requires unusual maintenance.

Most of the failures that were investigated were considered to be catastrophic, meaning the gearbox required either major repair or total replacement.

Many catastrophic failures have been eliminated. Off-the-shelf, poorly designed, under-rated gearboxes that are inadequate for wind turbine applications are no longer the norm. Manufacturers and purchasers of gearboxes have learned through trial and error that the wind turbine application is severe. It is well known that peak loads, especially those caused by brake loads, are greater than originally thought. Operators have learned the importance of good maintenance and are now making sure that gearboxes are provided with an adequate amount of cool, dry, clean lubricant with adequate viscosity. Improved designs and better maintenance have improved the reliability of wind turbine gearboxes, but new designs with increased power create demands that should be addressed at the design stage. New turbines ranging from $300 \mathrm{~kW}$ to $750 \mathrm{~kW}$ require more complex configurations, such as epicyclic and split-power-path gearboxes, and integrated drive trains require more sophisticated design techniques to accommodate higher loads.

Significant ongoing problems with wind turbine gearboxes persist because of the manner in which they are purchased. To improve gearbox reliability it is essential that wind turbine gearboxes be purchased with a comprehensive procurement specification (see Section 9). GEARTECH has been involved in the purchase of new gearboxes for wind turbine and other industries over the past few years, and experience has shown that even with a good procurement specification, QC auditing, and testing, there may be errors or omissions that can cause gearbox failures. Nevertheless, purchasers must remain diligent in their efforts to purchase reliable gearboxes and carefully maintain and operate their equipment.

\subsection{Causes of Gearbox Failures}

The causes of gear failures are classified in the following six categories:

- Improper design (selection of geometry/materials/heat treatment/manufacturing methods/lubrication). 
- Improper manufacturing (processing/assembly/testing).

- Improper installation (mounting/couplings/alignment).

- Harmful environment (physical/chemical/electrical).

- Improper operation (testing/start-up/operation/maintenance).

- Incorrect design parameters, such as load spectrum and environment.

The following sections will discuss some of the problems and case histories we have witnessed in these categories.

\subsubsection{Improper Design}

A designer makes many decisions that determine the success or failure of the gearbox (see Section 5, Gear Parameters). The gear designer must be experienced and have a good understanding of the application. Following are some of the design flaws GEARTECH has discovered in wind turbine gearboxes:

- Gears too small.

- Bearings too small.

- Bearing fits too loose.

- Shaft seals inadequate.

- Too féw teeth in the pinion.

- Profile shift incorrect.

- Profile modification incorrect.

- Helix modification incorrect.

- Insufficient hardness of gears or shafts.

- Material flaws.

- Incorrect lubricant.

- Gear housing too flexible.

7.2.1.1 Case History: In a HAWT wind farm, 24 gearboxes were used to transmit $250 \mathrm{~kW}$ and increase the rotor speed from $55 \mathrm{rpm}$ to the generator speed of $1200 \mathrm{rpm}$. The gears were parallel-shaft, single helical, carburized and ground. The splash lubrication system used a mineral oil without antiscuff additives with viscosity of ISO 100 .

After about 250 hours of operation, two gearboxes failed by tooth bending fatigue. The gear tooth profiles were so badly wom that determination of the primary failure mode was impossible. Three other gearboxes with less service were selected for inspection. One had logged 15 hours, while the other two 
had operated for 65 hours each. Upon disassembly no broken teeth were found, but all three gearboxes had scuffed gear teeth. The primary failure mode was scuffing, and the earlier bending fatigue failures were caused by the dynamic loads generated by the worn gear teeth. Subsequent inspection of the remaining gearboxes revealed that all had scuffing damage which probably occurred immediately upon start-up because the loads were not reduced during run-in.

Fortunately, a prototype gearbox had been run at one-half load for about 50 hours. Upon inspection of these gears we obtained enough data to rate the gears. Referring to AGMA 250.04, the recommended viscosity for the gears under operating conditions was ISO 220. It was apparent that the viscosity originally supplied (ISO VG 100) was too low.

The lubricant film thickness was calculated with a computer program showing that the gears operated in the boundary lubrication regime. This program predicted the probability of wear at greater than $95 \%$.

The contact temperature was also calculated and the program predicted the probability of scuffing at $63 \%$. This is a high risk of scuffing. A high temperature peak near the tip of the pinion tooth was caused by the geometry of the gears. The designer selected a long addendum tooth for the pinion. Long addendum pinions perform well in speed reducers where they increase the amount of recess action and decrease the amount of approach action of the gear mesh. Because recess action is much smoother than approach action, long addendum pinions give speed reducers smooth meshing characteristics. When operated as a speed increaser, however, the approach and recess portions of the gear mesh reverse, making a long addendum pinion run rough and with greater vulnerability to scuffing.

To reduce the scuffing risk, a new gear tooth geometry was proposed with the pinion and gear addenda designed to minimize the flash temperature rise. The new gearset was analyzed under the assumption that the lubricant was a mineral oil with antiscuff additives and with a viscosity of ISO 220 . The calculations showed that the gears still operated in the boundary lubrication regime. However, the probability of wear fell to $94 \%$ and the optimized gear geometry greatly reduced the maximum contact temperature. The combination of reduced contact temperature and the increased scuffing resistance provided by higher viscosity mineral oil with antiscuff additives reduced the scuffing probability to $<5 \%$.

As is typical of many gear failures, this case history showed several factors contributing to the failures:

- The lubricant viscosity was too low.

- No antiscuff additives were used.

- A gearbox designed as a speed reducer was used as a speed increaser.

- The gear teeth were not provided with a coating or plating to ease run-in.

- The gears were not run-in under reduced loads.

As exemplified by this case history, gear failures can be avoided if designers and operators recognize that the lubricant is an important component of a gearbox, and appreciate that the tribology of gearing requires the consideration and control of many interrelated factors.

7.2.1.2 Case History: Helix modification is used to increase the amount of contact between gear teeth and to avoid hard contact at the end of the teeth (see Section 5.2.9, Helix Modification). 
During field tests of several prototype gearboxes, it was discovered that the helix modification had been ground on the pinion teeth backwards. Consequently, rather than improving the load distribution, a very high load intensity was created at one end of the teeth and the teeth failed by macropitting.

This case history shows the importance of witnessing QA tests at the manufacturer and inspecting operating prototype gearboxes before beginning full production. If the QA tests were observed the gears would never have been put into service. If prototype gearboxes were not tested in the field, all of the gearboxes would have been manufactured with the improper helix modification and the cost and down time would have been great.

7.2.1.3 Case History: Insufficient hardness can result from selection of an alloy with insufficient hardenability or by improper heat treatment. Four failed gearboxes were inspected and surface cracking was exhibited. It was determined that the gears were flame hardened, and this resulted in an inconsistent hardening pattem and extreme distortion that led to low strength, low accuracy, increased noise and poor load distribution. Unfortunately, there were hundreds of these gearboxes in service. Eventually they all failed prematurely.

\subsubsection{Improper Manufacturing}

The best way to avoid manufacturing errors is to specify quality tests and documentation. The vendor should submit detailed plans for QA and gearbox testing. The purchaser should verify that the QA plan is adhered to.

Following are some of the manufacturing errors witnessed by GEARTECH in wind turbine gearboxes:

- Debris left in gearbox.

- Grinding notches in the root of the gear teeth.

- Bearings installed backwards.

- Bearings not seated properly.

- Bearing endplay incorrect.

- Incorrect helix modification.

- Inadequate heat treatment.

- Incorrect plating.

7.2.2.1 Case History: Two years after a wind farm with 24 turbines went into operation it was reported that six of the gearboxes were noisy and a seventh had jammed and would not rotate. With the exception of the six troublesome gearboxes the turbines seemed to operate smoothly and quietly.

After interviewing the owner and the technicians and reviewing the service histories of the wind turbines, GEARTECH recommended that the six suspect gearboxes and two of the quiet units be inspected. Inspection of the exterior of the gearboxes did not disclose any oil leaks, signs of overheating, or unusual contamination. When the inspection ports were opened, the six noisy gearboxes were found to have broken teeth on the low-speed pinions. The jammed gearbox had broken teeth on both the low-speed pinion and gear. The two gearboxes that had operated quietly did not have any apparent damage. Contact 
patterns, taken with marking compound, showed no evidence of gear mesh misalignment. All eight gearboxes were disassembled and all components were thoroughly inspected, documented, and photographed.

Broken teeth were found in the oil sump of each of the damaged gearboxes. These were removed for later inspection. The jammed gearbox was damaged too severely to reveal the primary mode of failure, so the inspection concentrated on the five damaged gearboxes. All five low-speed pinions had bending fatigue fractures on two adjacent teeth. Teeth adjacent to the fractures had extensive macropitting. Other teeth further away from the fractures were undamaged except for mild abrasion. Beach marks on the fracture surfaces showed that the fatigue cracks had originated at the extreme end of the teeth in the root fillets on the tension side of the teeth.

Upon reviewing all the data, several facts were noted:

- All fractures were similar and exhibited features of bending fatigue. In each instance the crack origin was at the end of the tooth.

- On each of the pinions with fractures, the leading tooth (first to be loaded) had a very smooth fracture surface characteristic of slow crack growth, whereas the trailing tooth had a rougher surface characteristic of faster crack propagation.

- Teeth adjacent to the fracture had extensive macropitting, whereas teeth further away from the fractures were relatively undamaged.

- The working surfaces of the teeth rerrieved from the oil sumps showed no macropitting or other damage.

- On all six failed, low-speed pinions there was copper plating on the ends of the teeth and in the grinding relief for the adjacent bearing joumal. The copper plating was at the same end of the teeth where the bending fatigue cracks had originated. It extended about $2 \mathrm{~mm}$ along the tooth. On the two undamaged, low-speed pinions, the copper plating was in the grinding relief, but it stopped short of the ends of the teeth.

- The working surfaces of undamaged teeth and the contact patterns taken on the undamaged gearboxes showed that the gear teeth were in good alignment.

Based on these facts, the following conclusions and hypotheses were drawn:

- The primary mode of failure was bending fatigue originating at the tooth ends that were copper plated.

- The lead tooth was the first to fail by slow crack growth. As the tooth cracked it shed load to the adjacent tooth, which cracked more rapidly because it was overloaded due to lack of load sharing with the leading tooth.

- The macropitting on teeth adjacent to the fractures was a secondary failure mode that was caused by overloading resulting from loss of load sharing. This conclusion was substantiated by the undamaged teeth away from the fractures and the undamaged working surfaces of the teeth retrieved from the oil sumps. 
- The gear teeth were properly aligned. Normally misalignment is suspected when gear tooth fractures originate at the ends of the teeth. However, the wear patterns, tooth contact patterns, and condition of the bearings indicated that the tooth alignment had been good. Therefore, misalignment was ruled out as the cause of failure.

- It was hypothesized that the failure occurred because the ends of the pinion teeth were not hardened. Copper plating is used to mask areas that are to remain unhardened. The copper prevents diffusion of carbon during the carburizing heat treatment, and these areas develop relatively low hardness during subsequent quenching. It was likely that the bearing journals of the pinions were copper plated to ease machining. The plating was probably done by hanging the pinions over the plating tank and lowering the pinion shaft journals into the solution. Apparently some of the pinions were lowered too far into the solution and the ends of the teeth were inadvertently copper plated.

It was decided that laboratory tests should be performed to confirm or disprove the hypotheses. Therefore, several broken teeth with copper plating and two pinions without copper plating on the tooth ends were sent to a metallurgical laboratory for tests. The broken teeth were viewed in a scanning electron microscope equipped with an energy dispersive X-Ray (EDX). Striations found on the fracture surfaces proved that the fractures were caused by fatigue. The copper plating was confirmed by EDX analysis.

Metallurgical sections were prepared by cutting and polishing the ends of the teeth from both the fractured teeth and the undamaged pinions. Microhardness surveys on the metallurgical sections showed that the copper plating had prevented carburization of the ends of the fractured teeth. The hardness was 40 HRC across the entire tooth section. On the undamaged pinions, however, the metallurgical sections showed a proper hardness gradient that was $60 \mathrm{HRC}$ at the surface and decreased to a core hardness of $40 \mathrm{HRC}$.

It was concluded that the failures were caused by improper heat treatment due to the copper plating on the ends of the teeth. The low hardness and low strength were responsible for the bending fatigue failures. We recommended that the owner of the wind turbines inspect all the gearboxes and remove from service all those that had copper plating on the ends of the teeth. The owner found that four other gearboxes had copper plating on the tooth ends. After removing these gearboxes and replacing the low-speed pinions no other failures occurred.

\subsubsection{Improper Installation}

Installation is usually a joint responsibility that includes but is not limited to the gearbox manufacturer, generator manufacturer, turbine owner, and operator. Good communication between these parties ensures that items such as bearing endplay and alignment are properly set.

Following are some of the installation problems that have been discovered:

- Improper bearing endplay.

- Coupling misalignment.

- Torque arm incorrectly installed.

- Gearbox housing twisted due to incorrect shimming.

7.2.3.1 Case History: Improperly installed single-row tapered roller bearings can lead to gear misalignment if the endplay is excessive. Many wind turbine gearboxes using single-row tapered roller bearings have experienced misalignment problems that have led to major repairs or complete failure. 
If the cones or cups are not properly seated during assembly, there may be a gap that allows movement when the load is applied, resulting in excessive endplay. In a helical gearbox the thrust load pushes the cone tightly into one cup. With excessive endplay, the other bearing is loose enough that its cone shifts laterally away from the load, leaving the gear misaligned.

The misalignment concentrates the load at the ends of the gear teeth and causes them to pit. We have observed this in many gearboxes, most of which required repair or total replacement.

\subsubsection{Harmful Environment}

Many wind turbine sites are susceptible to contamination. The Palm Springs site is particularly severe because of contamination by sand. Wind plant environments may be harmful for the following reasons:

- Extreme temperature changes.

- Airborne contaminants.

- Inadequate seals and breather.

On many occasions GEARTECH has found abrasives such as sand, and contaminants such as water inside wind turbine gearboxes. These contaminants have caused abrasive wear and polishing that reduced gear accuracy and increased the noise level of the gearbox.

\subsubsection{Improper Operation}

There are a variety of problems with the operation of wind turbine gearboxes, but the most common problem encountered by GEARTECH is related to lubrication and contamination.

Some additional problems we encountered included:

- Mixing of incompatible lubricants.

- Improper lubricant storage.

- Poor housekeeping during maintenance.

- Insufficient lubricant or lack of lubricant.

- Operation of the turbine without the nacelle cover.

7.2.5.1 Case History: Micropitting is epidemic in wind turbine gearboxes. While micropitting does not always lead to catastrophic failure, it generally reduces gear accuracy and can progress to full scale macropitting and gear failure.

In several instances GEARTECH has solved micropitting problems by increasing the specific film thickness of the operating lubricant. This was accomplished by using higher viscosity lubricants, lowering the operating temperatures by adding supplementary cooling, using synthetic lubricants with higher viscosity indices, or using gears with smooth tooth surfaces. 


\subsection{SUGGESTED AREAS OF RESEARCH}

Many advancements have been made in the procurement, design, and maintenance of wind turbine gearboxes. However, in GEAR'TECH's experience some problems have been persistent enough to justify additional research. Also, the demand for increased power capacity, higher efficiency, and lighter, compact gearboxes will require refinement of existing configurations and development of new designs.

Following are a few of the areas in which GEAR'IECH believes additional research is justified.

\subsection{Seals}

Seal design has been problematic in wind turbine gearboxes and should be researched. Nearly every gearbox inspected by GEARTECH exhibited some seal leakage, ranging in degree from minor to severe.

Double-lip seals have been used, but in some instances the outer lip did not receive adequate lubrication and the seal failed by overheating. In other cases tandem double-lip seals failed in the same manner, and more quickly. Labyrinth seals have also been used. Certain designs have allowed contaminants in while permitting oil to leak out. To compound the problem, some wind turbine operators have reported success with a particular seal design while others have experienced failures with the same design. One design that has been successful for certain wind plants uses a single-lip seal to retain oil and an external V-ring to help minimize ingested contaminants.

The most serious consequence of seal leakage is loss of lubricant, leading to gearbox failure. Less severe leakage can result in increased maintenance and increased costs due to replacement of the lubricant. Also, if oil leaks out of a gearbox it is likely that contaminants are being ingested into the unit.

A less obvious consequence of oil leakage relates to environmental concems. If the ground surrounding the turbine is contaminated with an unacceptable amount of oil, state and local environmental laws may require that the topsoil be disposed of properly and replaced.

Existing seal designs should be investigated to determine which work, which fail, and why. Some suggestions for research include:

- Performance of seal designs currently used.

- Applicability of seal designs not currently used in wind turbines.

- Characteristics and performance of seal materials.

- Seal and lubricant compatibility.

- Maintenance and replacement of seals.

- Advantages and disadvantages of internal and external seals.

\subsection{Bearing Configuration Design}

Many of the gearboxes examined by GEAR'IECH have exhibited bearing problems that range from abrasive wear to catastrophic failure. One common problem is spinning of the outer bearing races. Wind turbines are not a typical industrial application for gearboxes, and GEAR'TECH's experience has shown 
that the usual design practices for bearing fits are not sufficient. Therefore, special design techniques are required and all inner races should be constrained by heavy duty snap rings or clamping plates. Outer races should be constrained by a tight fit, pinning, or other appropriate means. Some gearbox purchasers have addressed this issue by discussing new design configurations with gearbox manufacturers and bearing vendors.

Some bearing configurations, such as angular contact ball bearings and full-complement, cylindrical-roller bearings, have overheated and failed by scuffing.

Excessive endplay with tapered-roller bearings leads to gear misalignment and gear tooth failure. Such failures have been common in wind turbines.

Bearing configuration design is obviously an area that could benefit from research. Ideally this research should be a cooperative effort between purchasers, gearbox manufacturers, and bearing vendors. Existing configurations should be investigated to determine which work, which fail, and why.

Some suggestions for research include:

- Characteristics and performance of different types of bearings.

- Bearing retainer material: metallic versus non-metallic.

- Characteristics of full complement cylindrical-roller bearings.

- Determination and maintenance of proper bearing endplay.

- Means of constraining raceways.

\subsection{Lubrication}

Lubrication has become an increasingly important issue for wind turbine operators. Advances have been made in wind turbine lubrication, but there are areas that would benefit from further research. One area that should be addressed is the correct amount of lubricant for a wind turbine gearbox. Research has shown that there is an optimum amount of lubricant that supplies sufficient oil to the components, minimizing churning and increasing efficiency for a given gearbox. Reduction in the amount of lubricant can reduce costs and increase gear efficiency, therefore increasing the power produced.

The best way to determine the optimum amount of lubricant for a particular gearbox is by conducting in situ testing. This has been done in the past by wind turbine operators with promising results and merits further research.

Another problem common in wind turbine gearboxes is micropitting, which is strongly influenced by lubrication. Micropitting can reduce the accuracy of gear teeth. Reduced accuracy can result in increased noise and decreased efficiency.

In an industry where the ratio of cents per kilowatt hour of power produced is critical, the efficiency of gearboxes is crucial. All factors affecting efficiency, including lubrication, should be optimized. Some suggestions for research in this area include: 
- Amount of lubricant.

- Type of lubricant.

- Lubricant viscosity.

- Influence of lubricant type and additives on micropitting.

- Influence of lubricant type and additives on efficiency.

- Influence of lubricant type and additives on costs.

- Effects of contaminants on lubricant effectiveness.

- Cost effective monitoring of lubricants.

- Change-out interval.

\subsection{Wind Turbine Gearbox Research}

Wind turbine operators, engineers, windsmiths, and other personnel possess a wealth of information about wind turbine gearboxes which should be shared. Too often the same mistakes have been made and the same problems surfacing in different wind plants. If the talents and experiences of personnel in the wind turbine industry were pooled the benefits could be enormous.

People directly involved in the wind industry should be invited to suggest research projects. Such research should be directed to allow participation by any interested party, and the work, cost, and benefits should be shared by all. If information had been shared previously in an organized manner, perhaps many of today's problems would have been solved and there would have been fewer gearbox failures. 


\subsection{RECOMMENDED PROCUREMENT PROCEDURES FOR WIND TURBINE GEARBOXES}

Problems with gearboxes which resulted in repair costs, lost energy production, and legal expense could have been avoided if purchases had been planned properly. In the past, most gearboxes were purchased off the shelf on a "handshake" and without an adequate procurement specification. A detailed procurement specification based on field experience will help prevent many deficiencies in the design, manufacture, operation, and maintenance of wind turbine gearboxes.

The following is a plan for procuring reliable gearboxes. It describes how gearbox purchasers should select a vendor from among a number of bidders. It is strongly recommended that an experienced gearbox specialist be involved with the procurement process.

\subsection{Write a Procurement Specification}

With the help of a gearbox specialist, the purchaser should prepare a procurement specification for wind turbine gearboxes which fully describes the application and defines the gearbox performance. It should specify minimum requirements for design, manufacturing, QA, and testing. It should specify performance rather than design, and allow vendors the creative freedom to meet contract requirements. The specification should allow judging of all bidders on a equal basis.

The following items should be included as a minimum:

- Description of the application.

- Description of loads.

- Specification of the methodology for rating gears and bearings.

- Specification of gear and bearing design lives.

- Specification of gear metallurgical and geometric quality.

- Specification of the minimum data required from bidders.

- Specification of minimum design requirements.

- Specification of manufacturing and QA procedures.

- Specification of inspections, tests, and acceptance criteria.

\subsection{Solicit Bids}

The purchaser should solicit bids from gearbox manufacturers. Bidders should have experience and the capabilities necessary to produce gearboxes that conform to the requirements of the procurement specification.

The procurement specification should include a questionnaire that determines whether the bidder understands the procurement specification and whether the bidder has the experience and capabilities to produce reliable gearboxes. 
The procurement specification should define all data that bidders are required to submit with their proposals, including but not limited to:

- A completed questionnaire.

- A completed proposal form, including pricing and warranty.

- A list of exceptions to procurement specification.

- A preliminary QA plan.

- A preliminary manufacturing schedule.

- A layout (assembly) drawing of the gearbox.

- An outline dimension drawing of the gearbox.

- Gear data.

- Bearing data.

- Load/Life calculations.

- Lubrication data.

\subsection{Evaluation of Proposals/Selection of Final Bidders}

With the help of a gearbox specialist, the purchaser evaluates bidder proposals for completeness and conformance to the requirements of the procurement specification. The proposals are compared and the two or three bidders with the best proposals are selected for design review meetings.

Bidders must demonstrate that they meet the following minimum requirements prior to attending the design review meeting:

- Minimum required vendor data as specified in the procurement specification should be supplied.

- Bidder must have the experience and capabilities to produce reliable gearboxes.

- The bidder's pricing and warranty must be acceptable.

- Exceptions to the procurement specification must be acceptable.

- The preliminary QA plan and manufacturing schedule must be acceptable.

- The preliminary design must meet the rating requirements of the procurement specification.

- The preliminary design must meet the minimum design requirements of the procurement specification. 


\subsection{Meet for Design Review Meetings}

Design review meetings are conducted with the two or three bidders that submit the best proposals. A gear specialist consultant prepares a written evaluation based on the evaluations of the proposals and on the bidder presentations at the design review meetings. The evaluation discusses the relative merits of each proposal to provide the purchaser with sufficient information to select a vendor. At a minimum the following factors should be reviewed and discussed:

- Bidder experience and capabilities.

- Conformance to procurement specification.

- Quality assurance.

- Negotiation of exceptions to the procurement specification.

- Warranty.

\subsection{Selection of Vendor/Audit Design/Contract Award}

After considering the relative merits of each proposal, the purchaser should select the vendor and a gear specialist should audit the vendor's proposal. The final design audit includes the following as a minimum:

- Audit for conformance to the procurement specification.

- Gear rating for pitting resistance and bending strength per AGMA standards.

- Gear rating for scuffing and wear resistance per AGMA standards.

- Bearing life rating.

- Audit lubrication system.

A gear specialist should prepare a report summarizing the final design audit. The purchaser then awards the contract. Manufacturing should not commence until the purchaser approves the detail drawings and the QA plan.

\subsection{Review and Approval of Detail Drawings}

When the vendor submits final detail drawings, a gear specialist should review the drawings and provides written comments to the purchaser. After the drawings meet the requirements of the procurement specification, the purchaser approves the detail drawings.

\subsection{Review and Approve QA Plan}

When the vendor submits the final QA plan, the gear specialist should review the QA plan and provides written comments to the purchaser. After the QA plan meets the requirements of the procurement specification for manufacturing, QA, and testing, the purchaser approves the QA plan. 


\subsection{Meet to Approve Start of Manufacturing}

After the final detail drawings and the final QA plan are approved, a meeting should be arranged at the vendor's facility to ensure that all questions are answered prior to the commencement of manufacturing. This meeting is attended by the purchaser, vendor contact person, project manager, and the managers of sales, engineering, manufacturing, and QA. If the results of the meeting are satisfactory, the purchaser approves the start of manufacturing.

\subsection{Audit Manufacturing/Resolve Problems}

A gear specialist should audit manufacturing of the gearbox components for at least one gearbox. The audit should include visits to the vendor and consultation with the vendor and purchaser to resolve manufacturing problems and ensure compliance with the procurement specification.

Audit Inspections: A gear specialist should audit the inspections of the gearbox components. The audit should include visits to the vendor to witness all significant QA inspections, tests, and procedures for at least one gearbox to ensure compliance with the procurement specification.

Audit Assembly: A gear specialist should audit the assembly of the gearbox components. The audit should include visits to the vendor to witness the assembly of at least one gearbox to ensure compliance with the procurement specification.

Audit Tests: A gear specialist should audit the testing of at least one gearbox. The audit should include visits to the vendor to witness all tests to ensure compliance with the procurement specification.

Monitor Start-Up: A gear specialist should monitor the installation and start-up of the gearboxes. The monitoring includes visits to the wind farm to witness installation and start-up of at least one gearbox.

Monitoring start-up includes, but need not be limited to, the following:

- Providing a pre-start check list.

- Providing initial start-up procedures.

- Providing service condition monitoring procedures.

- Confinnation that gear tooth contact patterns are acceptable.

- Confinnation that abnornal wear or distress is not occurring. 


\subsection{REFERENCES}

1. AGMA 250.04 specification: Lubrication of Industrial Enclosed Gear Drives

2. AGMA 299.01 Gear Sound Manual

3. AGMA 904-A92 A Rational Procedure for Preliminary Design of Minimum Volume Gears

4. AGMA 908-B89 Geometry Factors for Determining the Pitting Resistance and Bending Strength of Spur, Helical, and Herringbone Gear Teeth

5. AMS 2301 Aircraft Quality Steel Cleanliness, Magnetic Particle Inspection Procedure

6. ANSI/AGMA 110.04 Nomenclature of Gear Tooth Failure Modes

7. ANSI/AGMA 115.01 Information Sheet: Basic Gear Geometry

8. ANSI/AGMA 1012-F90 Gear Nomenclature, Definitions of Terms with Symbols

9. ANSI/AGMA 2000-A88 Gear Classification and Inspection Handbook: Tolerances and Measuring Methods for Unassembled Spur and Helical Gears (Including Metric Equivalents)

10. ANSI/AGMA 2001-B88 Fundamental Rating Factors and Calculation Methods for Involute Spur and Helical Gear Teeth

11. ANSI/AGMA 2004-B89 Gear Materials and Heat Treatment Manual

12. ANSI/AGMA 2007-B92 Surface Temper Etch Inspection After Grinding

13. ANSI/AGMA 6000-A88 Specification: Measurement of Linear Vibration on Gear Units

14. ANSI/AGMA 6001-C88 Design and Selection of Components for Enclosed Gear Drives

15. ANSI/AGMA 6010-E88 Standard for Spur, Helical, Herringbone, and Bevel Enclosed Drives

16. ANSI/AGMA 6021-G89 Shaft Mounted and Screw Conveyor Drives Using Spur, Helical, and Herringbone Gears

17. ANSI/AGMA 6023-A88 Design Manual for Enclosed Epicyclic Gear Drives

18. ANSI/AGMA 6025-C90 Sound for Enclosed Helical, Herringbone, and Spiral Bevel Gear Drives

19. ASTM A 534 Standard Specification: Estimating the Average Grain Size of Metals

20. ASTM E 112 Standard Specification: Estimating the Average Grain Size of Metals

21. ASTM E 709 Standard Specification: Magnetic Particle Inspection

22. SAE J 406 Methods of Determining Hardenability of Steels 
23. Bakker, D. (December 1993). "Wind Turbine Generator Systems (WTGS)." Technical Committee 88, Wind Turbine Systems, International Electrotechnical Commission, standard IEC/TC 88. Draft version.

24. Errichello, R.L. (July 1988). "Buying the Best Gearbox." Machine Design, Vol. 60, No. 16; pp. 87-91.

25. Errichello, R.L. (1989). "A Rational Procedure for Designing Minimum-Weight Gears." Presented at the Power Transmission and Gearing Conference, Chicago 1989, ASME, Vol. 1; pp. 111-114 (Also published in GEAR TECHNOLOGY, Vol. 8, No. 6. November-December 1991).

26. Errichello, R.L. (January-April 1990). "Lubrication of Gears." Lubrication Engineering, Vol. 46, No. 1-4, parts 1-4. (Also published in GEAR TECHNOLOGY, Vol. 8, No. 2-4, parts 1-3. March-July 1991).

27. Errichello, R.L. (1991). "Gear Tooth Calculations." Dudley’s Gear Handbook, Chap. 6, McGraw-Hill.

28. Errichello, R.L. (May-June 1992). "The Top Ten Books for Gear Engineers." Gear Technology, Vol. 9, No. 3.

29. Errichello, R.L. (October 1992). "Friction, Lubrication, and Wear of Gears." ASM Handbook, Vol. 18; pp. 535-545.

30. Errichello, R.L. (July 1993). "Choosing the Right Gear Lube." Lubricants World; p. 12.

31. Jackson, K.L. (January 1994). "Scaling Wind Turbine Fatigue Occurrence Curves." Proceedings of the Energy Sources and Technology Conference, SED-Vol. 15, New Orleans, LA. Jan. 23-26, 1994.

32. Kelley, N.D. (January 1994). "The Identification of Inflow Fluid Dynamics Parameters That Can Be Used to Scale Fatigue Loading Spectra of Wind Turbine Structural Components." Proceedings of the Energy Sources and Technology Conference, SED-Vol 15, New Orleans, LA. Jan. 23-26, 1994.

33. Errichello, R.L. and Muller, J. (March 1994). "How to Analyze Gear Failures." Power Transmission Design, Vol. 36, No. 3; pp. 35-40.

34. McNiff, B.P., Musial, W.D. and Errichello, R.L. (September 1990). "Variations in Gear Fatigue Life for Different Wind Turbine Braking Srategies." Paper presented at the American Wind Energy Association (AWEA) National Conference in Washington, D.C.

35. McVittie, D.R. and Errichello, R.L. (1988). "The Application of Miner's Rule to Industrial Gear Drives." AGMA Paper No. 88 FTM 9.

36. McVittie, D.R. and Errichello, R.L. (March 1989). "Predicting Gear Life with Miner's Rule." Power Transmission Design, Vol. 31, No. 3; pp. 33-38.

37. Milburn, A., Godfrey, D. and Errichello, R.L. (1990). "Polishing Wear." AGMA paper No. 90 FTM 5.

38. Muller, J. and Errichello, R.L. (September 1991). "Buying Reliable Gearboxes for Wind Turbines." Paper presented at the American Wind Energy Association (AWEA) National Conference in Palm Springs, CA. 
39. Muller, J.R. (November 1993). "The Lubrication of Wind Turbine Gearboxes." Paper presented at the Annual Meeting of the Society of Tribologist and Lubrication Engineers, Calgary, Alberta, Canada, May 17-20, 1993. Lubrication Engineering, Vol. 49, No. 11; pp. 839-843.

40. Sutherland, H.J. (January 1993). "Frequency-Domain Stress Prediction Algorithm for the Life2 Fatigue Analysis Code." Proceedings of the Energy Sources and Technology Conference, SEDVol. 12, Houston, TX. Jan. 26-30, 1993. 


\section{Appendix A}

\section{Gear Nomenclature}

The following material has been extracted from AGMA 1012-F90,

"Gear Nomenclature, Definitions of

Terms with Symbols," with the

permission of the publisher,

American Gear Manufacturers Association,

1500 King Street, Suite 201,

Alexandria, Virginia 22314 


\section{Table Of Contents}

Section Title

Figures

Fig 3-1

Fig 3-2

Fig 3-3

Fig 3-4

Fig 3-5

Fig 3-6

Fig 3-7

Fig 3-8

Fig 3-9

Fig $3-10$

Fig 3-11

Fig 3-12

Fig 3-13

Fig 3-14

Fig 3-15

Fig 3-16

Fig 3-17

Fig 3-18

Fig 3-19

Fig 3-20

Fig 3-21

Fig 3-22

Fig 3-23

Fig 3-24

Fig 3-25

Fig 3-26

Fig 3-27

Fig 3-28

Fig 3-29

Fig $3-30$

Fig 3-31

Fig 3-32

Fig 3-33

Fig 3-34

Fig 3-35

Fig 3-36

Fig 3-37

Fig 3-38

Fig 3-39

Fig $3-40$

Fig 3-41

Fig 3-42

Fig 3-43

Fig 3-44

Fig 3-45

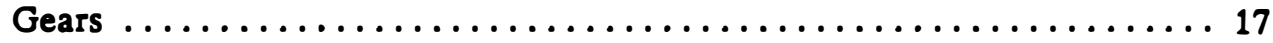

Basic Rack in Normal Plane ......................... 17

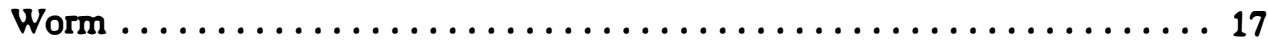

Spur Gears .................................. 18

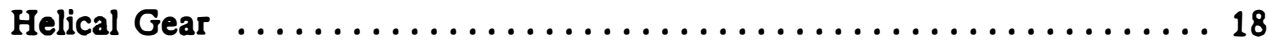

Parallel Helical Gears $\ldots \ldots \ldots \ldots \ldots \ldots \ldots \ldots \ldots \ldots \ldots \ldots \ldots \ldots \ldots$

Crossed Helical Gears .............................. 18

Single \& Double Helical . ........................... 19

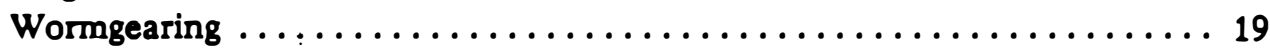

Double-Enveloping Wormgearing ...................... 19

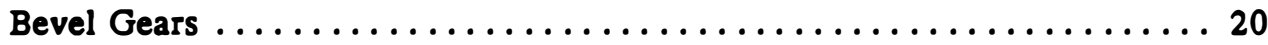

Angular Bevel Gears ............................ 20

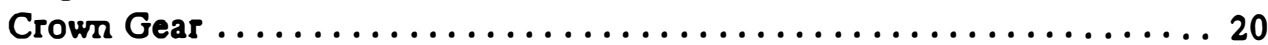

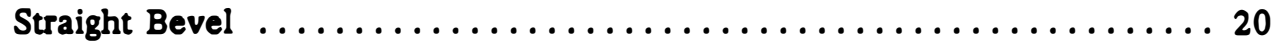

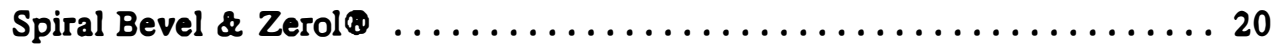

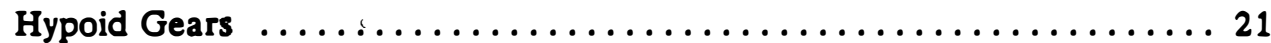

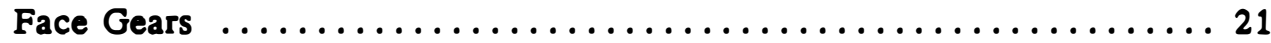

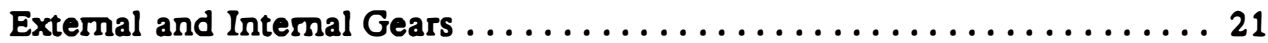

Helical \& Worm Hand ............................ 21

Spiral Bevel Hand ............................. 22

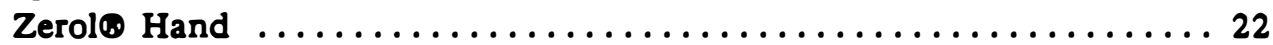

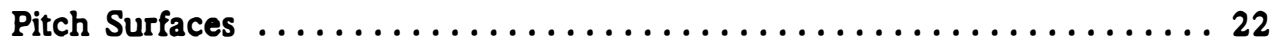

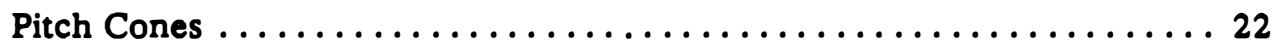

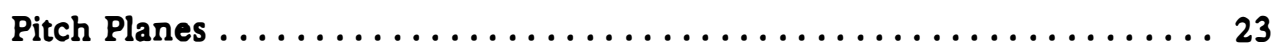

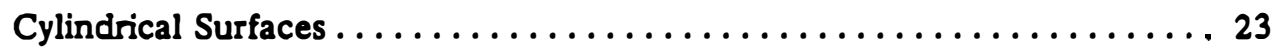

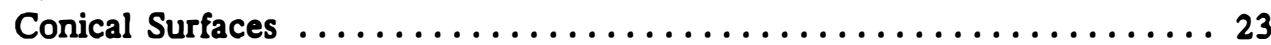

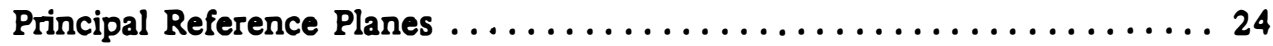

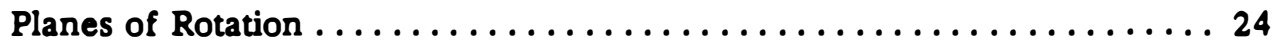

Planes at a Point on a Helical Tooth .................... 24

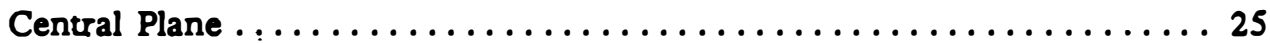

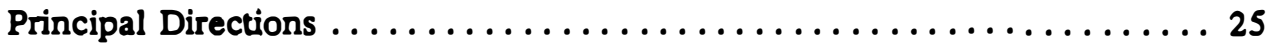

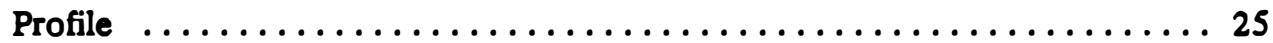

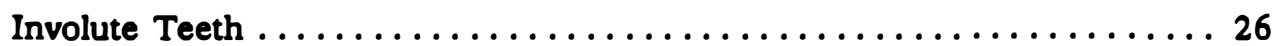

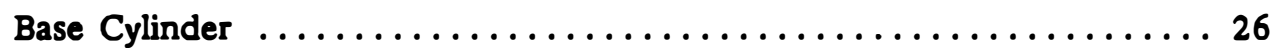

Pitch Circles and Line .......................... 26

Root Circle ................................... 26

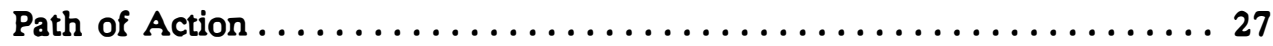

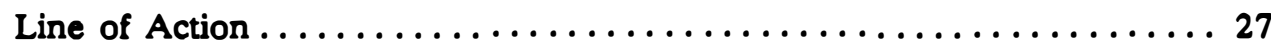

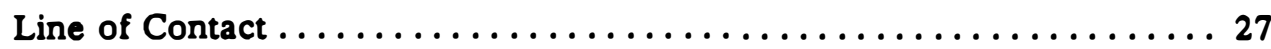

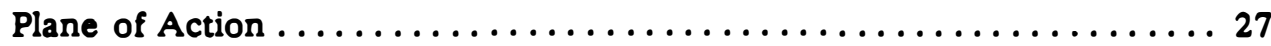

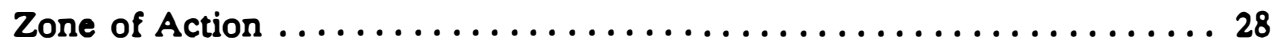

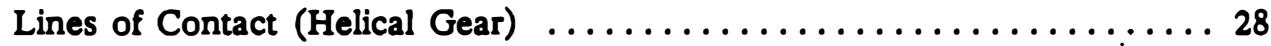

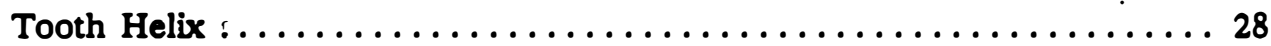

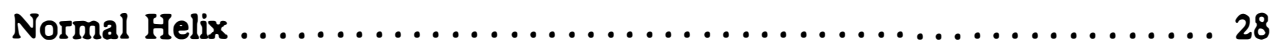

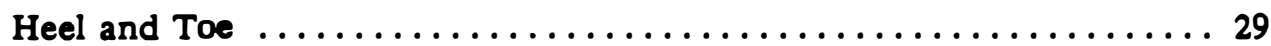




\section{Table Of Contents}

Section Title

Figures (cont)

Fig 3-46

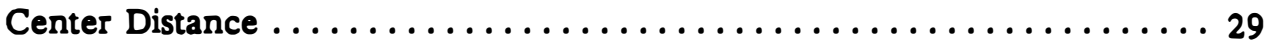

Fig 3-47

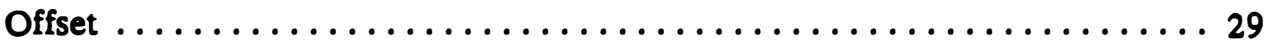

Fig 3-48

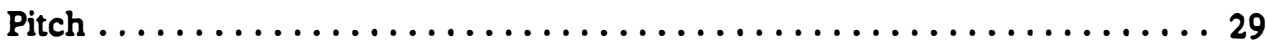

Fig 3-49

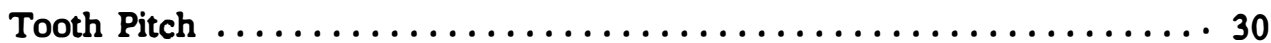

Fig 3-50

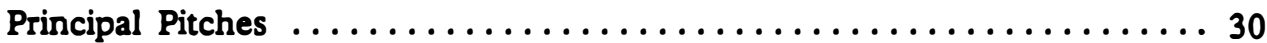

Fig 3-51

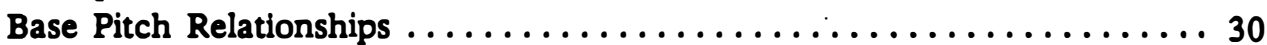

Fig 3-52

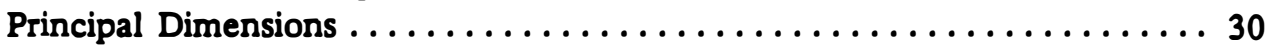

Fig 3-53

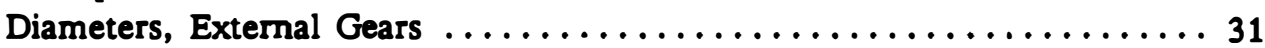

Fig 3-54

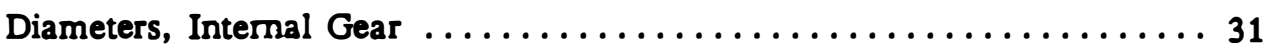

Fig 3-55

Fig 3-56

Fig 3-57

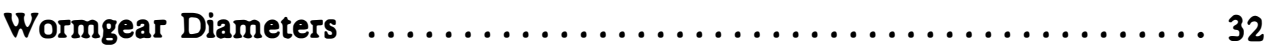

Fig 3-58

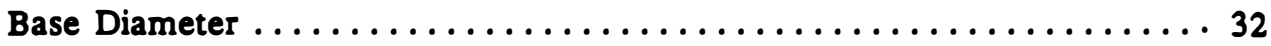

Fig 3-59

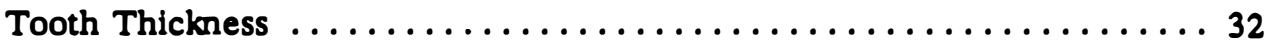

Fig 3-60

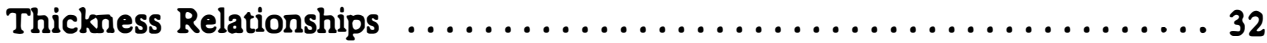

Fig 3-61

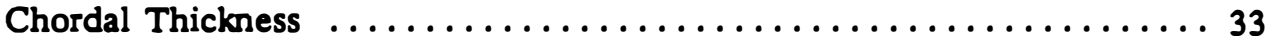

Fig 3-62

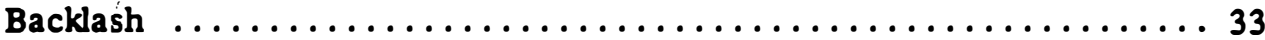

Fig 3-63

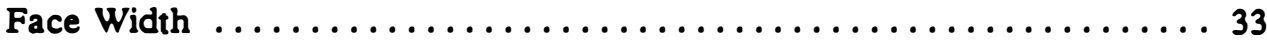

Fig 3-64

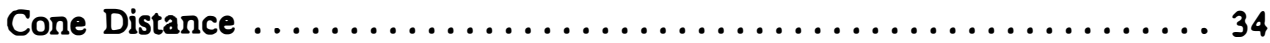

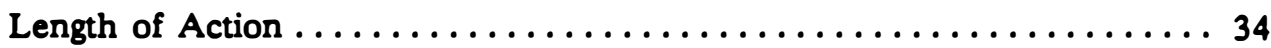

Fig 3-65

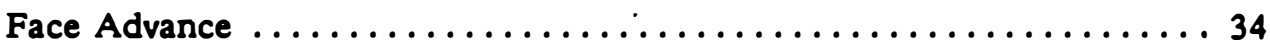

Fig 3-66

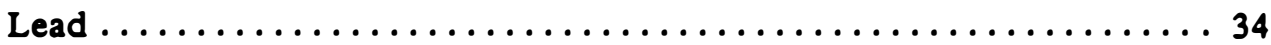

Fig 3-67

Fig 3-68

Fig 3-69

Fig 3-70

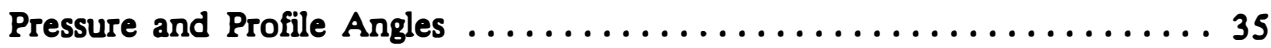

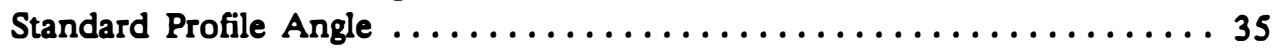

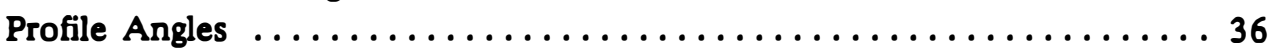

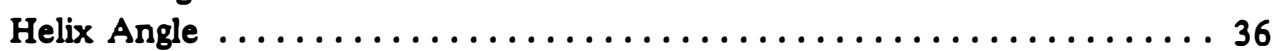

Fig 3-71

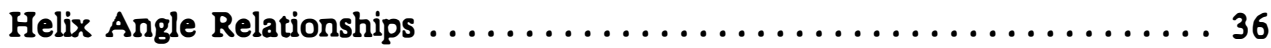

Fig 3-72

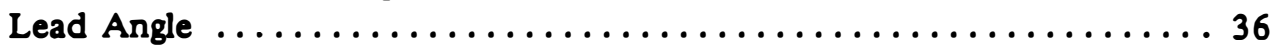

Fig 3-73

Lead Angle Relationships ........................ 37

Fig 3-74

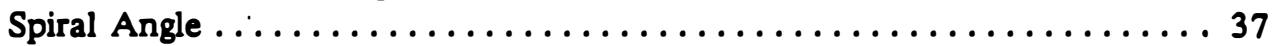

Fig 3-75

Fig 3-76

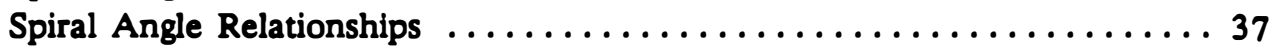

Fig 3-77

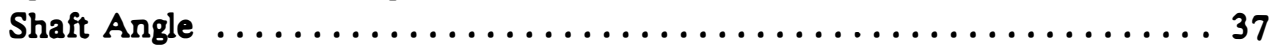

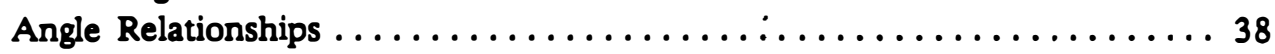

Fig 3-78

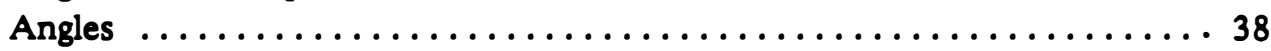

Fig 3-79

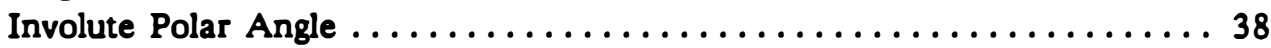

Fig 3-80

Involute Roll Angle $\ldots \ldots \ldots \ldots \ldots \ldots \ldots \ldots \ldots \ldots \ldots \ldots \ldots \ldots \ldots \ldots$

Fig 3-81

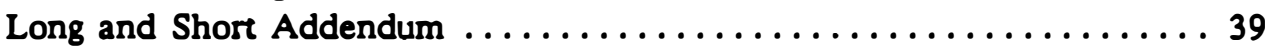

Fig 3-82

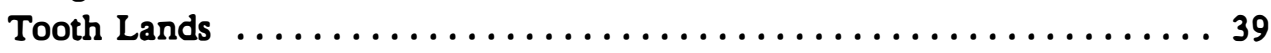

Fig 3-83

Tip Radius ................................ 40

Fig 3-84

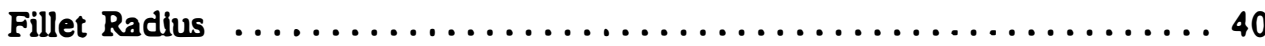

Fig 3-85

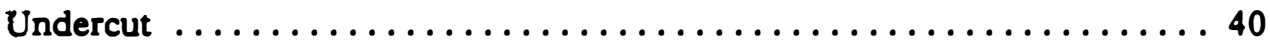

Fig 3-86

Fig 3-87

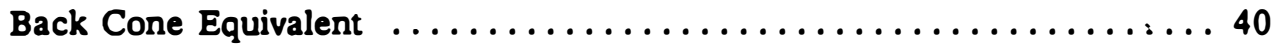

Fig 3-88

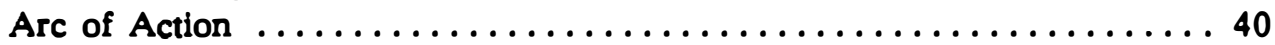

Apex to Back ............................. 41

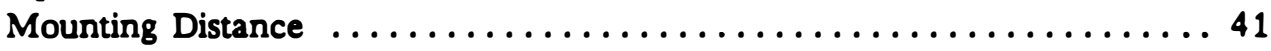

Fig 3-89

Tip Relief 


\section{Table Of Contents}

Section Title

Figures (cont)

Fig 3-90

Limit Diameter

Fig 3-91

Form Diameter

42

Fig 3-92

Crowned Gear 


\section{SCOPE}

This Standard establishes the definitions of terms, symbols and abbreviations which may be used to communicate the technology and specifications of external and internal gear teeth. It provides definitive meanings by the use of words and illustrations, for commonly used gearing terms. An appendix is provided to introduce those terms which are starting to come into accepted usage.

\section{TERMS AND SYMBOLS}

2.1 Terms. The terminology used in this Standard is intended for use in all AGMA documents and is summarized in Tables 2-1 and 2-2.

Many terms are listed in Table 2-1 more than once by re-stating alphabetically with re-arranged key words, to aid user look-up of related terms.

Table 2-1

Terms

\begin{tabular}{|c|c|c|c|}
\hline Terms & $\begin{array}{c}\text { Definition } \\
\text { Number }\end{array}$ & $\begin{array}{l}\text { Figure } \\
\text { Number }\end{array}$ & $\begin{array}{c}\text { Reference } \\
\text { Page }\end{array}$ \\
\hline action, arc of & 3.12 .13 & $3-86$ & 40 \\
\hline $\begin{array}{l}\text { action, length of } \\
\text { action, line of } \\
\text { action, plane of } \\
\text { action, surface of } \\
\text { action, path of } \\
\text { action, zone of }\end{array}$ & $\begin{array}{l}3.9 .41 \\
3.8 .16 \\
3.8 .19 \\
3.8 .18 \\
3.8 .15 \\
3.8 .20\end{array}$ & $\begin{array}{l}3-63 \\
3-38 \\
3-40 \\
3-40 \\
3-37,3-40 \\
3-41\end{array}$ & $\begin{array}{l}34 \\
27 \\
27 \\
27 \\
27 \\
28\end{array}$ \\
\hline $\begin{array}{l}\text { addendum } \\
\text { addendum, chordal } \\
\text { addendum, normal chordal } \\
\text { addendum angle } \\
\text { addendum circle }\end{array}$ & $\begin{array}{l}3.9 .11 \\
3.9 .31 \\
3.9 .32 \\
3.10 .23 \\
3.8 .12\end{array}$ & $\begin{array}{l}3-52 \\
3-59 \\
--5 \\
3-77 \\
3-36\end{array}$ & $\begin{array}{l}30 \\
33 \\
33 \\
38 \\
26\end{array}$ \\
\hline advance, face & 3.9 .42 & $3-64$ & 34 \\
\hline $\begin{array}{l}\text { angular bevel gears } \\
\text { angular pitch }\end{array}$ & $\begin{array}{l}3.2 .16 \\
3.11 .5\end{array}$ & $\begin{array}{l}3-12 \\
--\end{array}$ & $\begin{array}{l}19 \\
39\end{array}$ \\
\hline apex to back & 3.12 .24 & $3-87,3-88$ & 41 \\
\hline approach, arc of & 3.12 .14 & $3-86$ & 40 \\
\hline $\begin{array}{l}\text { arc of action } \\
\text { arc of approach } \\
\text { arc of recess }\end{array}$ & $\begin{array}{l}3.12 .13 \\
3.12 .14 \\
3.12 .15\end{array}$ & $\begin{array}{l}3-86 \\
3-86 \\
3-86\end{array}$ & $\begin{array}{l}40 \\
40 \\
41\end{array}$ \\
\hline axes, plane of & 3.6 .1 .1 & -- & 23 \\
\hline axial base pitch & 3.9 .10 & $3-51$ & 30 \\
\hline
\end{tabular}


Table 2-1 (cont)

Terms

\begin{tabular}{|c|c|c|c|}
\hline Terms & $\begin{array}{c}\text { Definition } \\
\text { Number }\end{array}$ & $\begin{array}{l}\text { Figure } \\
\text { Number }\end{array}$ & $\begin{array}{c}\text { Reference } \\
\text { Page }\end{array}$ \\
\hline $\begin{array}{l}\text { axial direction } \\
\text { axial pitch } \\
\text { axial plane } \\
\text { axial pressure angle } \\
\text { axial profile angle }\end{array}$ & $\begin{array}{l}3.7 .1 \\
3.9 .7 \\
3.6 .1 \\
3.10 .6 \\
3.10 .6\end{array}$ & $\begin{array}{l}3-31 \\
3-49 \\
3-27 \\
-\overline{3-68}\end{array}$ & $\begin{array}{l}25 \\
30 \\
23 \\
36 \\
36\end{array}$ \\
\hline axial thickness & 3.9.27 & $3-58$ & 32 \\
\hline $\begin{array}{l}\text { back angle } \\
\text { back cone } \\
\text { back cone distance }\end{array}$ & $\begin{array}{l}3.12 .22 \\
3.5 .6 \\
3.12 .21\end{array}$ & $\begin{array}{l}3-87 \\
3-26 \\
3-87\end{array}$ & $\begin{array}{l}41 \\
23 \\
41\end{array}$ \\
\hline backlash & 3.9 .33 & $3-60$ & 33 \\
\hline $\begin{array}{l}\text { base circle } \\
\text { base circular thickness } \\
\text { base cylinder } \\
\text { base diameter } \\
\text { base diameter, cone gear } \\
\text { base helix } \\
\text { base helix angle } \\
\text { base lead angle } \\
\text { base pitch } \\
\text { base pitch, axial } \\
\text { base pitch, normal }\end{array}$ & $\begin{array}{l}3.8 .5 \\
3.9 .28 \\
3.8 .6 \\
3.9 .22 \\
3.9 .23 \\
3.8 .23 \\
3.10 .10 \\
3.10 .14 \\
3.9 .8 \\
3.9 .10 \\
3.9 .9\end{array}$ & $\begin{array}{l}3-33,3-38 \\
3-59 \\
3-34 \\
3-56 \\
-- \\
3-43 \\
3-70 \\
3-72 \\
3-50,3-51 \\
3-51 \\
3-51\end{array}$ & $\begin{array}{l}26 \\
33 \\
26 \\
32 \\
32 \\
28 \\
36 \\
37 \\
30 \\
30 \\
30\end{array}$ \\
\hline basic rack & 3.1 .5 & $3-2$ & 17 \\
\hline $\begin{array}{l}\text { bevel gears } \\
\text { bevel gears, angular } \\
\text { bevel gears, Formate } \\
\text { bevel gears, skew } \\
\text { bevel gears, spiral } \\
\text { bevel gears, straight } \\
\text { bevel gears, Zerol }\end{array}$ & $\begin{array}{l}3.2 .14 \\
3.2 .16 \\
3.2 .21 \\
3.2 .22 \\
3.2 .19 \\
3.2 .18 \\
3.2 .20\end{array}$ & $\begin{array}{l}3-11 \\
3-12 \\
-- \\
3-14 \\
3-15 \\
3-14 \\
3-15\end{array}$ & $\begin{array}{l}19 \\
19 \\
20 \\
20 \\
20 \\
19 \\
20\end{array}$ \\
\hline bottom land & 3.12 .5 & 3-81 & 39 \\
\hline $\begin{array}{l}\text { center, gear } \\
\text { center distance } \\
\text { centers, line of } \\
\text { central plane }\end{array}$ & $\begin{array}{l}3.8 .9 \\
3.9 .1 \\
3.8 .10 \\
3.6 .7\end{array}$ & $\begin{array}{l}3-35 \\
3-46 \\
3-35 \\
3-30\end{array}$ & $\begin{array}{l}26 \\
29 \\
26 \\
25\end{array}$ \\
\hline
\end{tabular}


Table 2-1 (cont)

Terms

\begin{tabular}{|c|c|c|c|c|}
\hline Terms & $\begin{array}{c}\text { Definition } \\
\text { Number }\end{array}$ & $\begin{array}{l}\text { Figure } \\
\text { Number }\end{array}$ & & $\begin{array}{c}\text { Reference } \\
\text { Page }\end{array}$ \\
\hline $\begin{array}{l}\text { chordal addendum } \\
\text { chordal addendum, normal } \\
\text { chordal thickness } \\
\text { chordal thickness, normal }\end{array}$ & $\begin{array}{l}3.9 .31 \\
3.9 .32 \\
3.9 .29 \\
3.9 .30\end{array}$ & $\begin{array}{l}-- \\
-\overline{3-59} \\
3-57\end{array}$ & & $\begin{array}{l}33 \\
33 \\
33 \\
33\end{array}$ \\
\hline $\begin{array}{l}\text { circle, addendum } \\
\text { circle, base } \\
\text { circle, crown }\end{array}$ & $\begin{array}{l}3.8 .12 \\
3.8 .5 \\
3.5 .8\end{array}$ & $\begin{array}{l}3-36 \\
3-33 \\
3-26\end{array}$ & $\begin{array}{l}3-54 \\
3-38\end{array}$ & $\begin{array}{l}26 \\
26 \\
23\end{array}$ \\
\hline $\begin{array}{l}\text { circle, pitch } \\
\text { circle, pitch, standard (reference) } \\
\text { circle, root }\end{array}$ & $\begin{array}{l}3.8 .7 \\
3.9 .17 \\
3.8 .13\end{array}$ & $\begin{array}{l}3-35 \\
-\overline{3}-36\end{array}$ & $3-54$ & $\begin{array}{l}26 \\
31 \\
26\end{array}$ \\
\hline $\begin{array}{l}\text { circular pitch } \\
\text { circular pitch, normal } \\
\text { circular pitch, transverse }\end{array}$ & $\begin{array}{l}3.9 .4 \\
3.9 .6 \\
3.9 .5\end{array}$ & $\begin{array}{l}3-48 \\
3-49 \\
3-49\end{array}$ & & $\begin{array}{l}29 \\
29 \\
29\end{array}$ \\
\hline $\begin{array}{l}\text { circular thickness } \\
\text { circular thickness, base } \\
\text { circular thickness, normal } \\
\text { circular thickness, transverse }\end{array}$ & $\begin{array}{l}3.9 .24 \\
3.9 .28 \\
3.9 .26 \\
3.9 .25\end{array}$ & $\begin{array}{l}3-57 \\
3-59 \\
3-58 \\
3-58\end{array}$ & $3-59$ & $\begin{array}{l}32 \\
33 \\
32 \\
32\end{array}$ \\
\hline clearance & 3.9 .13 & $3-52$ & & 31 \\
\hline \multicolumn{5}{|l|}{. } \\
\hline $\begin{array}{l}\text { cone, back } \\
\text { cone, face (tip) } \\
\text { cone, front } \\
\text { cone, pitch } \\
\text { cone, root }\end{array}$ & $\begin{array}{l}3.5 .6 \\
3.5 .4 \\
3.5 .7 \\
3.4 .4 \\
3.5 .5\end{array}$ & $\begin{array}{l}3-26 \\
3-26 \\
3-26 \\
3-23 \\
3-26\end{array}$ & & $\begin{array}{l}23 \\
23 \\
23 \\
23 \\
23\end{array}$ \\
\hline $\begin{array}{l}\text { cone distance } \\
\text { cone distance, back } \\
\text { cone distance, inner } \\
\text { cone distance, mean } \\
\text { cone distance, outer } \\
\text { cone gear base diameter }\end{array}$ & $\begin{array}{l}3.9 .37 \\
3.12 .21 \\
3.9 .40 \\
3.9 .39 \\
3.9 .38 \\
3.9 .23\end{array}$ & $\begin{array}{l}3-62 \\
3-87 \\
3-62 \\
3-62 \\
3-62 \\
--\end{array}$ & & $\begin{array}{l}33 \\
41 \\
34 \\
34 \\
34 \\
32\end{array}$ \\
\hline $\begin{array}{l}\text { contact, line of } \\
\text { contact, path of } \\
\text { contact, point of }\end{array}$ & $\begin{array}{l}3.8 .17 \\
3.8 .21 \\
3.8 .14\end{array}$ & $\begin{array}{l}3-39 \\
3-42 \\
3-37\end{array}$ & $3-40$ & $\begin{array}{l}27 \\
28 \\
27\end{array}$ \\
\hline
\end{tabular}


Table 2-1 (cont)

Terms

\begin{tabular}{|c|c|c|c|}
\hline Terms & $\begin{array}{c}\text { Definition } \\
\text { Number }\end{array}$ & $\begin{array}{c}\text { Figure } \\
\text { Number }\end{array}$ & $\begin{array}{c}\text { Reference } \\
\text { Page }\end{array}$ \\
\hline $\begin{array}{l}\text { contact ratio } \\
\text { contact ratio, face } \\
\text { contact ratio, modified } \\
\text { contact ratio, total } \\
\text { contact ratio, transverse }\end{array}$ & $\begin{array}{l}3.12 .16 \\
3.12 .18 \\
3.12 .20 \\
3.12 .19 \\
3.12 .17\end{array}$ & $\begin{array}{l}-- \\
-- \\
-- \\
-- \\
--\end{array}$ & $\begin{array}{l}41 \\
41 \\
41 \\
41 \\
41\end{array}$ \\
\hline crossing point & 3.12 .26 & $3-88$ & 41 \\
\hline crossed axis gears & 3.2 .6 & $3-7$ & 18 \\
\hline $\begin{array}{l}\text { crown circle } \\
\text { crown gear } \\
\text { crowned teeth }\end{array}$ & $\begin{array}{l}3.5 .8 \\
3.2 .17 \\
3.12 .31\end{array}$ & $\begin{array}{l}3-26 \\
3-13 \\
3-92\end{array}$ & $\begin{array}{l}23 \\
19 \\
42\end{array}$ \\
\hline curve, fillet & 3.8 .3 & $3-32$ & 25 \\
\hline curvature, profile radius of & 3.12 .9 & $3-83$ & 40 \\
\hline $\begin{array}{l}\text { cylinder, base } \\
\text { cylinder, inside } \\
\text { cylinder, outside } \\
\text { cylinder, pitch } \\
\text { cylinder, root }\end{array}$ & $\begin{array}{l}3.8 .6 \\
3.5 .2 \\
3.5 .1 \\
3.4 .3 \\
3.5 .3\end{array}$ & $\begin{array}{l}3-34 \\
3-54 \\
3-25 \\
3-22 \\
3-25\end{array}$ & $\begin{array}{l}26 \\
23 \\
23 \\
23 \\
23\end{array}$ \\
\hline cylindrical worm & 3.2 .11 & $3-3,3-9$ & 19 \\
\hline $\begin{array}{l}\text { dedendum } \\
\text { dedendum angle }\end{array}$ & $\begin{array}{l}3.9 .12 \\
3.10 .24\end{array}$ & $\begin{array}{l}3-52 \\
3-77\end{array}$ & $\begin{array}{l}30 \\
38\end{array}$ \\
\hline $\begin{array}{l}\text { depth, whole } \\
\text { depth, working }\end{array}$ & $\begin{array}{l}3.9 .15 \\
3.9 .14\end{array}$ & $\begin{array}{l}3-52 \\
3-52\end{array}$ & $\begin{array}{l}31 \\
31\end{array}$ \\
\hline $\begin{array}{l}\text { diameter, base } \\
\text { diameter, base, cone gear } \\
\text { diameter, form } \\
\text { diameter, internal } \\
\text { diameter, limit } \\
\text { diameter, operating pitch } \\
\text { diameter, outside } \\
\text { diameter, pitch }\end{array}$ & $\begin{array}{l}3.9 .22 \\
3.9 .23 \\
3.12 .29 \\
3.9 .19 \\
3.12 .28 \\
3.9 .16 .1 \\
3.9 .18 .2 \\
3.9 .16\end{array}$ & $\begin{array}{l}3-56 \\
\overline{3}-91 \\
3-54 \\
3-90,3-91 \\
-\overline{3-26,3-53,3-55} \\
3-53\end{array}$ & $\begin{array}{l}32 \\
32 \\
42 \\
31 \\
42 \\
31 \\
31 \\
31\end{array}$ \\
\hline $\begin{array}{l}\text { diameter, root } \\
\text { diameter, standard pitch } \\
\text { diameter, throat }\end{array}$ & $\begin{array}{l}3.9 .18 .3 \\
3.9 .18 \\
3.9 .20\end{array}$ & $\begin{array}{l}3-53,3-54 \\
--55\end{array}$ & $\begin{array}{l}31 \\
31 \\
32\end{array}$ \\
\hline
\end{tabular}


Table 2-1 (cont)

Terms

\begin{tabular}{|c|c|c|c|}
\hline Terms & $\begin{array}{c}\text { Definition } \\
\text { Number }\end{array}$ & $\begin{array}{l}\text { Figure } \\
\text { Number } \\
\end{array}$ & $\begin{array}{c}\text { Reference } \\
\text { Page }\end{array}$ \\
\hline $\begin{array}{l}\text { diametral pitch } \\
\text { diametral pitch, normal }\end{array}$ & $\begin{array}{l}3.11 .3 \\
3.11 .4\end{array}$ & $\overline{-}-$ & $\begin{array}{l}39 \\
39\end{array}$ \\
\hline $\begin{array}{l}\text { direction, axial } \\
\text { direction, normal } \\
\text { direction, transverse }\end{array}$ & $\begin{array}{l}3.7 .1 \\
3.7 .3 \\
3.7 .2\end{array}$ & $\begin{array}{l}3-31 \\
3-31 \\
3-31\end{array}$ & $\begin{array}{l}25 \\
25 \\
25\end{array}$ \\
\hline $\begin{array}{l}\text { distance, back cone } \\
\text { distance, center } \\
\text { distance, cone } \\
\text { distance, inner cone } \\
\text { distance, mean cone } \\
\text { distance, mounting } \\
\text { distance, outer cone }\end{array}$ & $\begin{array}{l}3.12 .21 \\
3.9 .1 \\
3.9 .37 \\
3.9 .40 \\
3.9 .39 \\
3.12 .25 \\
3.9 .38\end{array}$ & $\begin{array}{l}3-87 \\
3-46 \\
3-62 \\
3-62 \\
3-62 \\
3-88 \\
3-62\end{array}$ & $\begin{array}{l}41 \\
29 \\
33 \\
34 \\
34 \\
41 \\
34\end{array}$ \\
\hline $\begin{array}{l}\text { double-enveloping wormgearing } \\
\text { double-helical gears }\end{array}$ & $\begin{array}{l}3.2 .13 \\
3.2 .8\end{array}$ & $\begin{array}{l}3-10 \\
3-8\end{array}$ & $\begin{array}{l}19 \\
18\end{array}$ \\
\hline effective face width & 3.9 .35 & $3-61$ & 33 \\
\hline enveloping (hourglass) worm & 3.2 .12 & $3-10$ & 19 \\
\hline equal-addendum teeth & 3.12 .3 & $3-80$ & 39 \\
\hline $\begin{array}{l}\text { equivalent number of teeth } \\
\text { equivalent pitch radius }\end{array}$ & $\begin{array}{l}3.12 .12 \\
3.12 .11\end{array}$ & $\overline{3-85}$ & $\begin{array}{l}40 \\
40\end{array}$ \\
\hline external gear & 3.3 .2 & $3-18$ & 21 \\
\hline $\begin{array}{l}\text { face advance } \\
\text { face angle } \\
\text { face cone } \\
\text { face contact ratio } \\
\text { face gears } \\
\text { face width } \\
\text { face width, effective }\end{array}$ & $\begin{array}{l}3.9 .42 \\
3.10 .21 \\
3.5 .4 \\
3.12 .18 \\
3.3 .1 \\
3.9 .34 \\
3.9 .35\end{array}$ & $\begin{array}{l}3-64 \\
3-76 \\
3-26 \\
--17 \\
3-17 \\
3-61 \\
3-61\end{array}$ & $\begin{array}{l}34 \\
38 \\
23 \\
41 \\
21 \\
33 \\
33\end{array}$ \\
\hline face width, total & 3.9 .36 & $3-61$ & 33 \\
\hline $\begin{array}{l}\text { fillet curve } \\
\text { fillet radius }\end{array}$ & $\begin{array}{l}3.8 .3 \\
3.12 .8\end{array}$ & $\begin{array}{l}3-32 \\
3-83\end{array}$ & $\begin{array}{l}25 \\
39\end{array}$ \\
\hline form diameter & 3.12 .29 & $3-91$ & 42 \\
\hline Formate bevel gears & 3.2 .21 & -- & 20 \\
\hline $\begin{array}{l}\text { front angle } \\
\text { front cone }\end{array}$ & $\begin{array}{l}3.12 .23 \\
3.5 .7\end{array}$ & $\begin{array}{l}3-87 \\
3-26\end{array}$ & $\begin{array}{l}41 \\
23\end{array}$ \\
\hline full-depth teeth & 3.12 .1 & -- & 39 \\
\hline
\end{tabular}


Table 2-1 (cont)

Terms

\begin{tabular}{|c|c|c|c|}
\hline Terms & $\begin{array}{c}\text { Definition } \\
\text { Number }\end{array}$ & $\begin{array}{l}\text { Figure } \\
\text { Number }\end{array}$ & $\begin{array}{c}\text { Reference } \\
\text { Page }\end{array}$ \\
\hline gear & 3.1 .2 & $3-1$ & 17 \\
\hline $\begin{array}{l}\text { gear center } \\
\text { gear ratio } \\
\text { gears }\end{array}$ & $\begin{array}{l}3.8 .9 \\
3.11 .2 \\
3.1 .1\end{array}$ & $\begin{array}{l}3-35 \\
\overline{3}-1\end{array}$ & $\begin{array}{l}26 \\
38 \\
17\end{array}$ \\
\hline generating rack & 3.1 .6 & -- & 17 \\
\hline heel & 3.8 .26 & $3-45$ & 28 \\
\hline $\begin{array}{l}\text { helical gear } \\
\text { helical gear, left-hand } \\
\text { helical gear, right-hand } \\
\text { helical gears, double- } \\
\text { helical gears, single- }\end{array}$ & $\begin{array}{l}3.2 .3 \\
3.3 .5 \\
3.3 .4 \\
3.2 .8 \\
3.2 .7\end{array}$ & $\begin{array}{l}3-5 \\
3-19 \\
3-19 \\
3-8 \\
3-8\end{array}$ & $\begin{array}{l}18 \\
21 \\
21 \\
18 \\
18\end{array}$ \\
\hline helical rack & 3.2 .4 & $3-8$ & 18 \\
\hline $\begin{array}{l}\text { helix, base } \\
\text { helix, normal } \\
\text { helix, outside } \\
\text { helix, pitch } \\
\text { helix angle } \\
\text { helix angle, base } \\
\text { helix angle, outside } \\
\text { helix angle, pitch }\end{array}$ & $\begin{array}{l}3.8 .23 \\
3.8 .24 \\
3.8 .25 \\
3.8 .22 \\
3.10 .7 \\
3.10 .10 \\
3.10 .9 \\
3.10 .8\end{array}$ & $\begin{array}{l}3-43 \\
3-44 \\
3-43 \\
3-43 \\
3-69 \\
3-70 \\
3-70 \\
3-70\end{array}$ & $\begin{array}{l}28 \\
28 \\
28 \\
28 \\
36 \\
36 \\
36 \\
36\end{array}$ \\
\hline herringbone gears & 3.2 .8 .1 & $3-8$ & 19 \\
\hline hypoid gears & 3.2 .23 & $3-16$ & 20 \\
\hline
\end{tabular}

inner cone distance

inner spiral angle

3.9 .40

3-62

34

3.10 .18

$3-74$

37

inside cylinder

3.5 .2

3-54

23

internal diameter

internal gear

3.9.19

3-54

3.3.3

3-18

31

involute polar angle

3.10 .25

3-78

3.10 .26

3-79

38

involute roll angle 
AGMA Gear Nomenclature, Definitions of Terms with Symbols

Table 2-1 (cont)

Terms

\begin{tabular}{|c|c|c|c|}
\hline Terms & $\begin{array}{c}\text { Definition } \\
\text { Number }\end{array}$ & $\begin{array}{l}\text { Figure } \\
\text { Number }\end{array}$ & $\begin{array}{c}\text { Reference } \\
\text { Page }\end{array}$ \\
\hline involute teeth & 3.8 .4 & $3-33$ & 25 \\
\hline $\begin{array}{l}\text { land, bottom } \\
\text { land, top }\end{array}$ & $\begin{array}{l}3.12 .5 \\
3.12 .6\end{array}$ & $\begin{array}{l}3-81 \\
3-81\end{array}$ & $\begin{array}{l}39 \\
39\end{array}$ \\
\hline $\begin{array}{l}\text { lead } \\
\text { lead angle } \\
\text { lead angle, base } \\
\text { lead angle, outside } \\
\text { lead angle, pitch }\end{array}$ & $\begin{array}{l}3.9 .43 \\
3.10 .11 \\
3.10 .14 \\
3.10 .13 \\
3.10 .12\end{array}$ & $\begin{array}{l}3-65 \\
3-71 \\
3-72 \\
3-72 \\
3-72\end{array}$ & $\begin{array}{l}34 \\
36 \\
37 \\
37 \\
37\end{array}$ \\
\hline $\begin{array}{l}\text { left-hand helical gear or worm } \\
\text { left-hand spiral bevel gear }\end{array}$ & $\begin{array}{l}3.3 .5 \\
3.3 .7\end{array}$ & $\begin{array}{l}3-19 \\
3-20\end{array}$ & $\begin{array}{l}21 \\
22\end{array}$ \\
\hline length of action & 3.9.41 & $3-63$ & 34 \\
\hline limit diameter & 3.12 .28 & $3-90$ & 42 \\
\hline $\begin{array}{l}\text { line, pitch } \\
\text { line of action } \\
\text { line of centers } \\
\text { line of contact }\end{array}$ & $\begin{array}{l}3.8 .8 \\
3.8 .16 \\
3.8 .10 \\
3.8 .17\end{array}$ & $\begin{array}{l}3-35 \\
3-38 \\
3-35 \\
3-39,3-40\end{array}$ & $\begin{array}{l}26 \\
27 \\
26 \\
27\end{array}$ \\
\hline long- and short-addendum teeth & 3.12 .4 & $3-80$ & 39 \\
\hline $\begin{array}{l}\text { mean cone distance } \\
\text { mean spiral angle }\end{array}$ & $\begin{array}{l}3.9 .39 \\
3.10 .16\end{array}$ & $\begin{array}{l}3-62 \\
3-74\end{array}$ & $\begin{array}{l}34 \\
37\end{array}$ \\
\hline miter gears & 3.2 .15 & $3-11$ & 19 \\
\hline modified contact ratio & $3.12: 20$ & -- & 41 \\
\hline $\begin{array}{l}\text { module (transverse) } \\
\text { module, normal }\end{array}$ & $\begin{array}{l}3.11 .6 \\
3.11 .7\end{array}$ & $\overline{-}$ & $\begin{array}{l}39 \\
39\end{array}$ \\
\hline mounting distance & 3.12 .25 & $3-88$ & 41 \\
\hline $\begin{array}{l}\text { normal base pitch } \\
\text { normal chordal addendum } \\
\text { normal chordal thickness } \\
\text { normal circular pitch } \\
\text { normal circular thickness } \\
\text { normal diametral pitch } \\
\text { normal direction } \\
\text { normal helix } \\
\text { normal module }\end{array}$ & $\begin{array}{l}3.9 .9 \\
3.9 .32 \\
3.9 .30 \\
3.9 .6 \\
3.9 .26 \\
3.11 .4 \\
3.7 .3 \\
3.8 .24 \\
3.11 .7\end{array}$ & $\begin{array}{l}3-51 \\
-- \\
3-57 \\
3-49 \\
3-49,3-58 \\
-- \\
3-31 \\
3-44 \\
--\end{array}$ & $\begin{array}{l}30 \\
33 \\
33 \\
29 \\
32 \\
39 \\
25 \\
28 \\
39\end{array}$ \\
\hline
\end{tabular}


Table 2-1 (cont)

Terms

\begin{tabular}{|c|c|c|c|}
\hline Terms & $\begin{array}{l}\text { Definition } \\
\text { Number }\end{array}$ & $\begin{array}{l}\text { Figure } \\
\text { Number }\end{array}$ & $\begin{array}{l}\text { Reference } \\
\text { Page }\end{array}$ \\
\hline $\begin{array}{l}\text { normal profile angle } \\
\text { normal plane } \\
\text { normal pressure angle }\end{array}$ & $\begin{array}{l}3.10 .5 \\
3.6 .6 \\
3.10 .5\end{array}$ & $\begin{array}{l}3-68 \\
3-29 \\
--\end{array}$ & $\begin{array}{l}36 \\
24 \\
36\end{array}$ \\
\hline $\begin{array}{l}\text { number of teeth or threads } \\
\text { number of teeth, equivalent }\end{array}$ & $\begin{array}{l}3.11 .1 \\
3.12 .12\end{array}$ & $\overrightarrow{-}$ & $\begin{array}{l}38 \\
40\end{array}$ \\
\hline offset & 3.9 .2 & $\begin{array}{l}3-16, \quad 3-17 \\
3-47\end{array}$ & 29 \\
\hline $\begin{array}{l}\text { operating pitch diameter } \\
\text { operating pressure angle }\end{array}$ & $\begin{array}{l}3.9 .16 .1 \\
3.10 .1 .1\end{array}$ & -- & $\begin{array}{l}31 \\
35\end{array}$ \\
\hline $\begin{array}{l}\text { outer cone distance } \\
\text { outer spiral angle }\end{array}$ & $\begin{array}{l}3.9 .38 \\
3.10 .17\end{array}$ & $\begin{array}{l}3-62 \\
3-74\end{array}$ & $\begin{array}{l}34 \\
37\end{array}$ \\
\hline $\begin{array}{l}\text { outside cylinder } \\
\text { outside diameter } \\
\text { outside helix } \\
\text { outside helix angle } \\
\text { outside lead angle }\end{array}$ & $\begin{array}{l}3.5 .1 \\
3.9 .18 .2 \\
3.8 .25 \\
3.10 .9 \\
3.10 .13\end{array}$ & $\begin{array}{ll}3-25 & \\
3-53, & 3-55 \\
3-43 & \\
3-70 & \\
3-72 & \end{array}$ & $\begin{array}{l}23 \\
31 \\
28 \\
36 \\
37\end{array}$ \\
\hline parallel axis gears & 3.2 .5 & $3-6$ & 18 \\
\hline $\begin{array}{l}\text { path of action } \\
\text { path of contact }\end{array}$ & $\begin{array}{l}3.8 .15 \\
3.8 .21\end{array}$ & $\begin{array}{l}3-37, \quad 3-40 \\
3-42\end{array}$ & $\begin{array}{l}27 \\
28\end{array}$ \\
\hline pinion & 3.1 .3 & $3-1$ & 17 \\
\hline $\begin{array}{l}\text { pitch } \\
\text { pitch, angular } \\
\text { pitch, axial } \\
\text { pitch, axial base } \\
\text { pitch, base } \\
\text { pitch, circular } \\
\text { pitch, diametral } \\
\text { pitch, normal base } \\
\text { pitch, normal circular } \\
\text { pitch, normal diametral } \\
\text { pitch, transverse circular }\end{array}$ & $\begin{array}{l}3.9 .3 \\
3.11 .5 \\
3.9 .7 \\
3.9 .10 \\
3.9 .8 \\
3.9 .4 \\
3.11 .3 \\
3.9 .9 \\
3.9 .6 \\
3.11 .4 \\
3.9 .5\end{array}$ & $\begin{array}{l}3-48 \\
-- \\
3-49 \\
3-51 \\
3-50, \quad 3-51 \\
3-48 \\
\overrightarrow{3-51} \\
3-49 \\
\overrightarrow{3-49}\end{array}$ & $\begin{array}{l}29 \\
39 \\
30 \\
30 \\
30 \\
29 \\
39 \\
30 \\
29 \\
39 \\
29\end{array}$ \\
\hline $\begin{array}{l}\text { pitch angle } \\
\text { pitch circle } \\
\text { pitch circle, standard (reference) } \\
\text { pitch cone } \\
\text { pitch cylinder } \\
\text { pitch diameter } \\
\text { pitch diameter, operating } \\
\text { pitch diameter, standard }\end{array}$ & $\begin{array}{l}3.10 .20 \\
3.8 .7 \\
3.9 .17 \\
3.4 .4 \\
3.4 .3 \\
3.9 .16 \\
3.9 .16 .1 \\
3.9 .18\end{array}$ & $\begin{array}{l}3-76, \quad 3-77 \\
3-35 \\
\overrightarrow{3}-23 \\
3-22 \\
3-53 \\
-- \\
--\end{array}$ & $\begin{array}{l}38 \\
26 \\
31 \\
23 \\
23 \\
31 \\
31 \\
31\end{array}$ \\
\hline $\begin{array}{l}\text { pitch helix } \\
\text { pitch helix angle } \\
\text { pitch lead angle }\end{array}$ & $\begin{array}{l}3.8 .22 \\
3.10 .8 \\
3.10 .12\end{array}$ & $\begin{array}{l}3-43 \\
3-70 \\
3-72\end{array}$ & $\begin{array}{l}28 \\
36 \\
37\end{array}$ \\
\hline
\end{tabular}


AGMA Gear Nomenclature, Definitions of Terms with Symbols

Table 2-1 (cont)

Terms

\begin{tabular}{lccc}
\hline \hline \multicolumn{1}{c}{ Terms } & $\begin{array}{c}\text { Definition } \\
\text { Number }\end{array}$ & $\begin{array}{l}\text { Figure } \\
\text { Number }\end{array}$ & $\begin{array}{c}\text { Reference } \\
\text { Page }\end{array}$ \\
\hline pitch line & 3.8 .8 & $3-35$ & 26 \\
pitch plane & $3.4 .2,3.6 .2$ & $3-24,3-27$ & 22 \\
pitch point & 3.8 .11 & $3-35$ & 26 \\
pitch radius, equivalent & 3.12 .11 & $3-85$ & 40 \\
pitch surfaces & 3.4 .1 & $3-22,3-23,3-24$ & 22
\end{tabular}

plane, axial

3.6 .1

3-27

23

plane, central

3.6 .7

3-30

plane, normal

3.6 .6

3-29

plane, pitch

3.4.2,

3.6 .2

3-24, 3-27

24

plane, tangent

3.6.5

3-39

22

3.6.4

$3-27,3-28$

24

plane, transverse

3.8.19

3-40

24

plane of action

3.6.1.1

$--$

27

3.6.3

3-28

23

plane of rotation

3.8.14

point of contact

3.12 .26

3-37

3-88

point, pitch

3.8.11

3-35

polar angle, involute

3.10 .25

3-78

pressure angle

pressure angle, axial

pressure angle, normal

pressure angle, operating

pressure angle, transverse

profile

profile angle

profile angle, axial

profile angle, normal

profile angle, standard

profile angle, transverse

profile radius of curvature
3.10 .1

3.10 .6

3.10 .5

3.10.1.1

3.10.4

3.8.2

3.10 .2

3.10 .6

3.10 .5

3.10.3

3.10.4

3.12 .9

3-83

3-66

3-68

3-68

$\overline{3}-\overline{68}$

35

36

36

35

36

3-32

3-66

3-68

3-68

3-67

3-68

25

35

36

36

35

36

40

rack

3.1 .4

3-1

17 
Table 2-1 (cont)

Terms

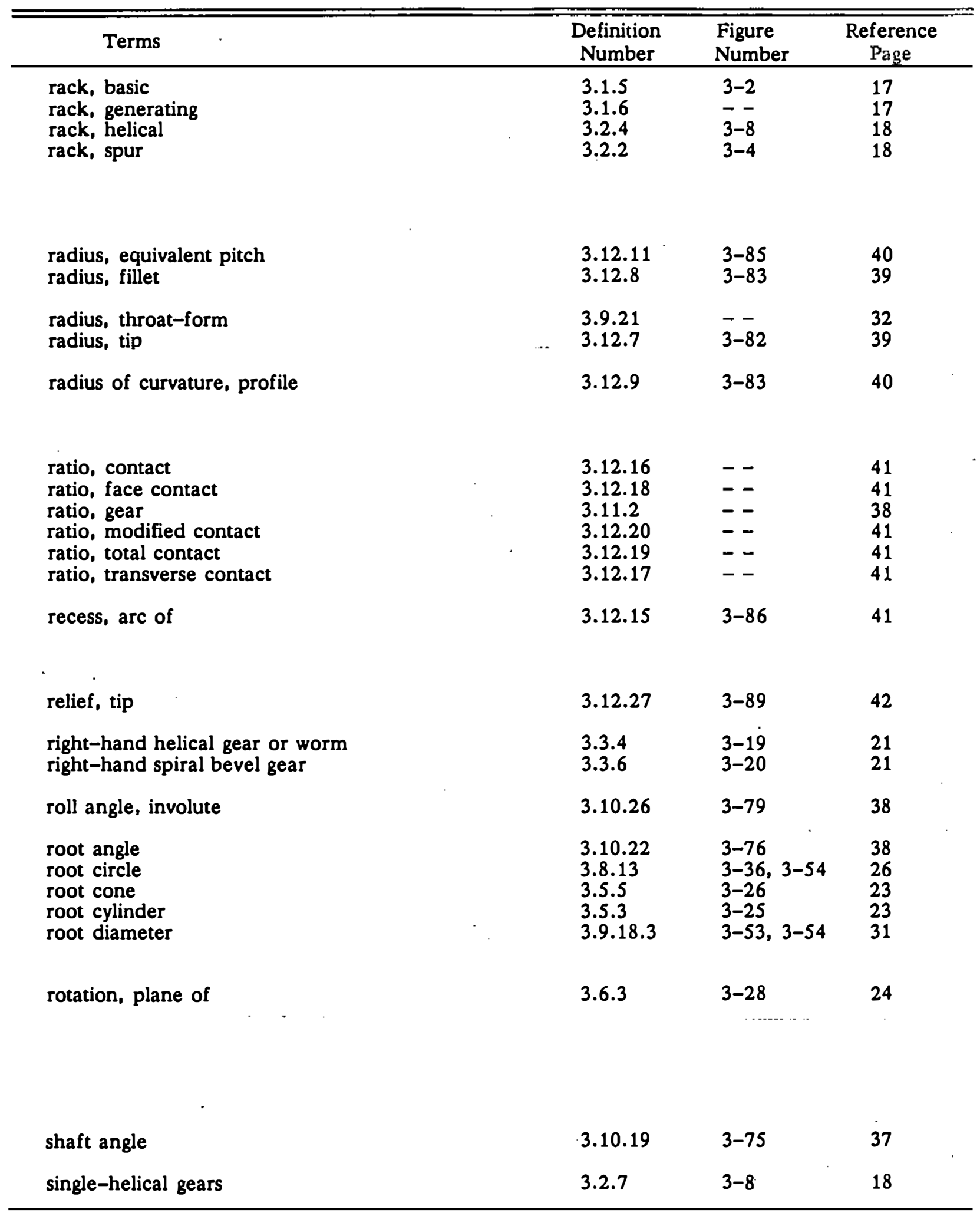


Table 2-1 (cont)

Terms

\begin{tabular}{|c|c|c|c|}
\hline Terms & $\begin{array}{c}\text { Definition } \\
\text { Number }\end{array}$ & $\begin{array}{l}\text { Figure } \\
\text { Number } \\
\end{array}$ & $\begin{array}{c}\text { Reference } \\
\text { Page }\end{array}$ \\
\hline skew bevel gears & 3.2 .22 & $3-14$ & 20 \\
\hline $\begin{array}{l}\text { spiral angle } \\
\text { spiral angle, inner } \\
\text { spiral angle, mean } \\
\text { spiral angle, outer } \\
\text { spiral bevel gear } \\
\text { spiral bevel gear, left-hand } \\
\text { spiral bevel gear, right-hand }\end{array}$ & $\begin{array}{l}3.10 .15 \\
3.10 .18 \\
3.10 .16 \\
3.10 .17 \\
3.2 .19 \\
3.3 .7 \\
3.3 .6\end{array}$ & $\begin{array}{l}3-73 \\
3-74 \\
3-74 \\
3-74 \\
3-15 \\
3-20 \\
3-20\end{array}$ & $\begin{array}{l}37 \\
37 \\
37 \\
37 \\
20 \\
22 \\
21\end{array}$ \\
\hline $\begin{array}{l}\text { spur gears } \\
\text { spur rack }\end{array}$ & $\begin{array}{l}3.2 .1 \\
3.2 .2\end{array}$ & $\begin{array}{l}3-4 \\
3-4\end{array}$ & $\begin{array}{l}17 \\
18\end{array}$ \\
\hline $\begin{array}{l}\text { standard (reference) pitch circle } \\
\text { standard pitch diameter } \\
\text { standard profile angles }\end{array}$ & $\begin{array}{l}3.9 .17 \\
3.9 .18 \\
3.10 .3\end{array}$ & $\overrightarrow{-} \overline{3}-67$ & $\begin{array}{l}31 \\
31 \\
35\end{array}$ \\
\hline start of active profile (SAP) & 3.12 .30 & $3-91$ & 42 \\
\hline straight bevel gears & 3.2 .18 & $3-14$ & 19 . \\
\hline stub teeth & 3.12 .2 & -- & 39 \\
\hline $\begin{array}{l}\text { surface, tooth } \\
\text { surface of action }\end{array}$ & $\begin{array}{l}3.8 .1 \\
3.8 .18\end{array}$ & $\begin{array}{l}3-32 \\
--\end{array}$ & $\begin{array}{l}25 \\
27\end{array}$ \\
\hline tangent plane & 3.6 .5 & $3-39$ & 24 \\
\hline $\begin{array}{l}\text { teeth, crowned } \\
\text { teeth, equal-addendum } \\
\text { teeth, equivalent number of } \\
\text { teeth, full-depth } \\
\text { teeth, involute } \\
\text { teeth, long- and short-addendum } \\
\text { teeth, number of } \\
\text { teeth, stub }\end{array}$ & $\begin{array}{l}3.12 .31 \\
3.12 .3 \\
3.12 .12 \\
3.12 .1 \\
3.8 .4 \\
3.12 .4 \\
3.11 .1 \\
3.12 .2\end{array}$ & $\begin{array}{l}3-92 \\
3-80 \\
-- \\
3-33 \\
3-80 \\
=-\end{array}$ & $\begin{array}{l}42 \\
39 \\
40 \\
39 \\
25 \\
39 \\
38 \\
39\end{array}$ \\
\hline $\begin{array}{l}\text { thickness, axial } \\
\text { thickness, base circular } \\
\text { thickness, chordal } \\
\text { thickness, circular }\end{array}$ & $\begin{array}{l}3.9 .27 \\
3.9 .28 \\
3.9 .29 \\
3.9 .24\end{array}$ & $\begin{array}{l}3-58 \\
3-59 \\
3-59 \\
3-57\end{array}$ & $\begin{array}{l}32 \\
33 \\
33 \\
32\end{array}$ \\
\hline
\end{tabular}


Table 2-1 (cont)

Terms

\begin{tabular}{|c|c|c|c|}
\hline Terms & $\begin{array}{c}\text { Definition } \\
\text { Number }\end{array}$ & $\begin{array}{l}\text { Figure } \\
\text { Number }\end{array}$ & $\begin{array}{c}\text { Reference } \\
\text { Page }\end{array}$ \\
\hline $\begin{array}{l}\text { thickness, normal chordal } \\
\text { thickness, normal circular } \\
\text { thickness, transverse circular }\end{array}$ & $\begin{array}{l}3.9 .30 \\
3.9 .26 \\
3.9 .25\end{array}$ & $\begin{array}{l}3-57 \\
3-58 \\
3-58,3-59\end{array}$ & $\begin{array}{l}33 \\
32 \\
32\end{array}$ \\
\hline threads, number of & 3.11 .1 & -- & 38 \\
\hline $\begin{array}{l}\text { throat diameter } \\
\text { throat-form radius }\end{array}$ & $\begin{array}{l}3.9 .20 \\
3.9 .21\end{array}$ & $3-55$ & $\begin{array}{l}32 \\
32\end{array}$ \\
\hline $\begin{array}{l}\text { tip radius } \\
\text { tip relief }\end{array}$ & $\begin{array}{l}3.12 .7 \\
3.12 .27\end{array}$ & $\begin{array}{l}3-82 \\
3-89\end{array}$ & $\begin{array}{l}39 \\
42\end{array}$ \\
\hline toe & 3.8 .27 & $3-45$ & 29 \\
\hline tooth surface & 3.8 .1 & $3-32$ & 25 \\
\hline top land & 3.12 .6 & $3-81$ & 39 \\
\hline $\begin{array}{l}\text { total contact ratio } \\
\text { total face width }\end{array}$ & $\begin{array}{l}3.12 .19 \\
3.9 .36\end{array}$ & $\overline{3-61}$ & $\begin{array}{l}41 \\
33\end{array}$ \\
\hline
\end{tabular}


Table 2-1 (cont)

Terms

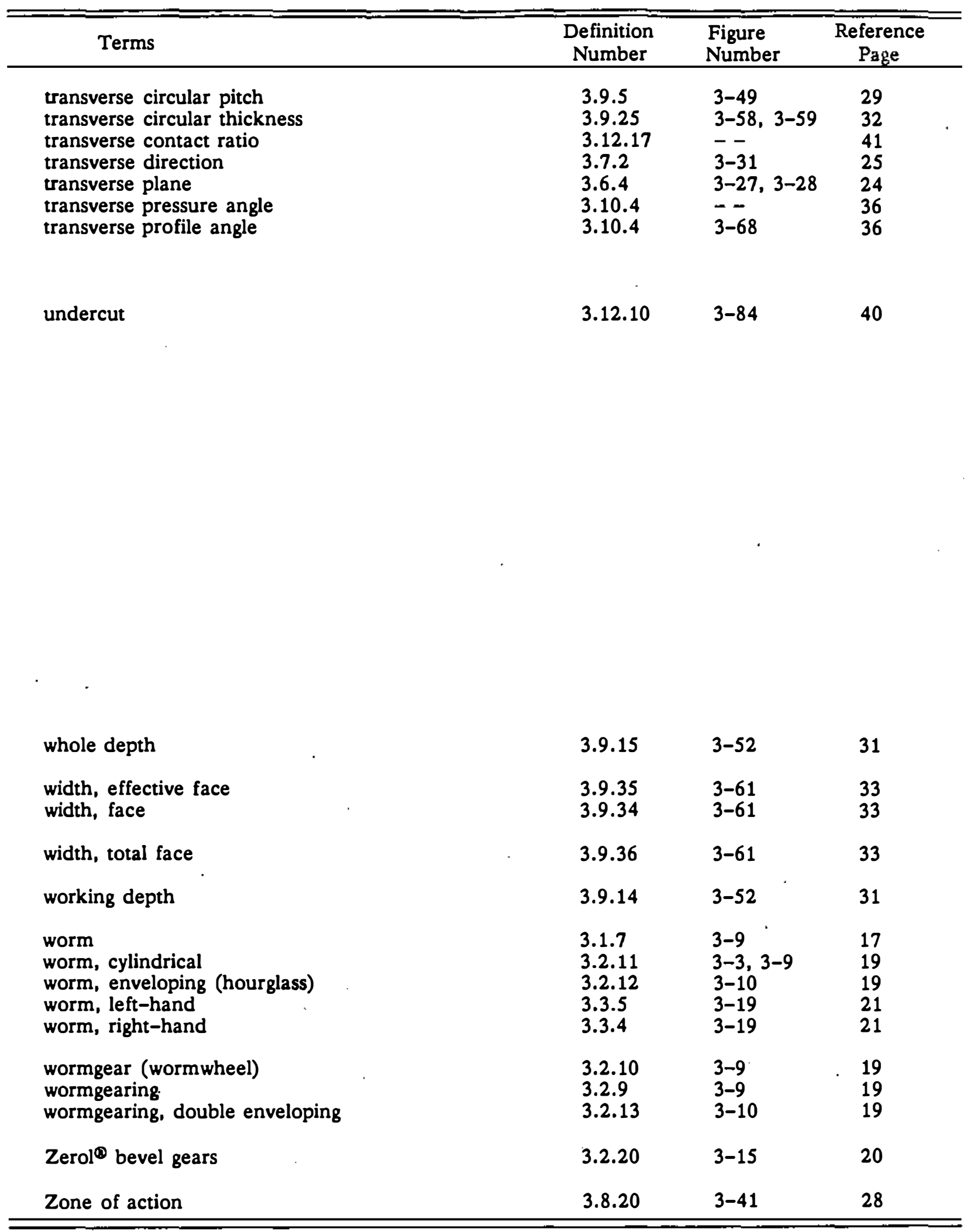


2.2 Symbols. The purpose of standard letter symbols for gear engineering is to establish a uniform practice in mathematical notation for equations and formulas dealing with toothed gearing. Such equations and corresponding calculations may be used in connection with design, application, manufacture, inspection, new methods, and new problems.

Letter symbols are not intended or suggested for use on working drawings, manufacturing records, or correspondence, where abbreviations would serve better. The principal use of standard letter symbols is in the mathematical formulas in published articles, papers, and books, to make understanding easier and confusion less likely.

NOTE: The symbols and definitions used in this Standard may differ from other AGMA standards. The user should not assume that familiar symbols can be used without a careful study of these definitions.

SI (metric) units of measure, where applicable, are shown in the text. Where equations require a different format or constant for use with SI units, a second expression is shown after the first, indented, in smaller type, and with " $M$ " included in the equation number.

Example:

$$
\begin{aligned}
P_{d}= & \frac{N}{D} \\
& P_{d}=\frac{25.4}{m}
\end{aligned}
$$

Symbols must be distinguished from abbreviations which are shortened forms of words often used on drawings and in tables, but not suitable for mathematical work For example, the symbol for circular pitch is $p$. whereas the abbreviation is $\mathrm{CP}$.

The system of symbols and subscripts presented here is generally consistent with other American National Standard letter symbols and follows the same general principles. It is not restricted to standardized gear terms but instead provides for extension to new problems and practices. A large number of terms and symbols illustrating the application of the system is contained in Table 2-2.

2.2.1 Subscripts. A subscript following the general symbol may be used to indicate a value applying to a particular gear or tool, or a value taken at a particular position or in a particular direction. For convenience and brevity, it is desirable to use a general symbol without a subscript when only one value of a given kind is involved. Thus, in a spur gear or a straight-tooth bevel gear, there is occasion to consider only one cross section of the teeth, namely, the transverse section, and it is convenient and natural to refer, for instance, simply to the circular pitch, $p$, and the pressure angle, $\phi$. In the case of gears with oblique teeth, on the other hand, it is usually necessary to be specific and to refer to the transverse pitch, $p_{t}$, and the transverse pressure angle, $\phi_{t}$, in order not to leave any doubt as to whether values are being given for the transverse plane or normal plane.

Table 2-2

Symbols

\begin{tabular}{clcl}
\hline \hline Symbols & \multicolumn{1}{c}{ Terms } & Symbols & \multicolumn{1}{c}{ Terms } \\
\hline$A$ & cone distance & $C$ & center distance \\
$A_{i}$ & inner cone distance & $c$ & clearance \\
$A_{m}$ & mean cone distance & $D$ & reference standard pitch diameter \\
$A_{0}$ & outer cone distance & $D_{b}$ & base diameter (of an involute gear) \\
$a$ & addendum & $D_{c}$ & datum circle \\
$a_{c}$ & chordal addendum & $D_{i}$ & internal diameter \\
$a_{n c}$ & normal chordal addendum & $D_{o}$ & outside diameter \\
$B$ & backlash & $D_{R}$ & root diameter \\
$b$ & dedendum & $d_{t}$ & throat diamter
\end{tabular}


Table 2-2 (cont)

Symbols

\begin{tabular}{|c|c|c|c|}
\hline Symbols & Terms & Symbols & Terms \\
\hline$d_{p}$ & operating pitch diamter & $r_{t}$ & throat-form radius \\
\hline$E$ & offset of axes & $r_{T}$ & tip or edge radius of tool \\
\hline$F$ & face width & $t$ & circular tooth thickness \\
\hline$F_{e}$ & effective or active face width & $t_{b}$ & base circular thickness \\
\hline$F_{t}$ & total face width & $t_{c}$ & chordal thickness \\
\hline$h_{k}$ & working depth & $t_{n}$ & normal circular thickness \\
\hline$h_{t}$ & whole depth (tooth depth) & $t_{n c}$ & normal chordal thickness \\
\hline$L$ & lead & ${ }^{t} T$ & tooth thickness tolerance \\
\hline$m$ & module & $t_{t}$ & transverse circular thickness \\
\hline$m_{c}$ & contact ratio & $t_{x}$ & axial thickness \\
\hline$m_{F}$ & face contact ratio & $v_{\text {ap }}$ & total accumulated pitch variation \\
\hline${ }_{m_{G}}^{m_{G}}$ & $\begin{array}{l}\text { gear ratio } \\
\text { normal module }\end{array}$ & $V_{\text {apk }}$ & $\begin{array}{l}\text { total accumulated pitch variation, } \\
\text { within a sector of } k \text { pitches }\end{array}$ \\
\hline$m_{0}$ & modified contact ratio & $V_{c q}$ & $\begin{array}{l}\text { total composite variation } \\
\text { (double flank) }\end{array}$ \\
\hline$m_{p}$ & $\begin{array}{l}\text { transverse contact ratio } \\
\text { total contact ratio }\end{array}$ & $V_{c q T}$ & $\begin{array}{l}\text { total composite tolerance } \\
\text { (double flank) }\end{array}$ \\
\hline$N$ & numbers of teeth or threads & $V_{p}$ & pitch variation \\
\hline $\mathcal{N}_{e}$ & equivalent number of teeth & $V_{p A}$ & allowable pitch variation \\
\hline$P_{d}$ & diametral pitch (transverse) & $V_{p n}$ & normal pitch variation \\
\hline$p_{n d}$ & $\begin{array}{l}\text { normal diametral pitch } \\
\text { circular pitch }\end{array}$ & $v_{q}$ & $\begin{array}{l}\text { tooth-to-tooth composite variation } \\
\text { (double flank) }\end{array}$ \\
\hline$p_{b}$ & $\begin{array}{l}\text { base pitch } \\
\text { true position pitch }\end{array}$ & $V_{q T}$ & $\begin{array}{l}\text { tooth-to-tooth composite tolerance } \\
\text { (double flank) }\end{array}$ \\
\hline$p_{m}$ & normal circular pitch & $V_{r}$ & radial runout \\
\hline$p_{N}^{n}$ & normal base pitch & $V_{r T}$ & radial runout tolerance \\
\hline$p_{t}$ & transverse circular pitch & $v_{s}$ & spacing variation \\
\hline$p_{x}$ & axial pitch & $v_{x}$ & index variation \\
\hline$p_{X}$ & axial base pitch & $v_{\phi}$ & profile variation \\
\hline$\ddot{Q}$ & Quality Number & $v_{\phi T}$ & profile tolerance \\
\hline$Q_{a}$ & arc of approach & $V_{\psi}$ & tooth alignment variation \\
\hline$Q_{F}$ & face advance & $V_{\psi T}$ & tooth alignment tolerance \\
\hline$Q_{r}$ & arc of recess & $z$ & length of action \\
\hline$Q_{t}$ & arc of action & $\alpha$ & addendum angle \\
\hline$R_{r}$ & test radius & $\Gamma$ & pitch angle \\
\hline$r_{f}$ & fillet radius, when constant & $\Gamma_{R}$ & root angle \\
\hline
\end{tabular}


Table 2-2 (cont)

Symbols

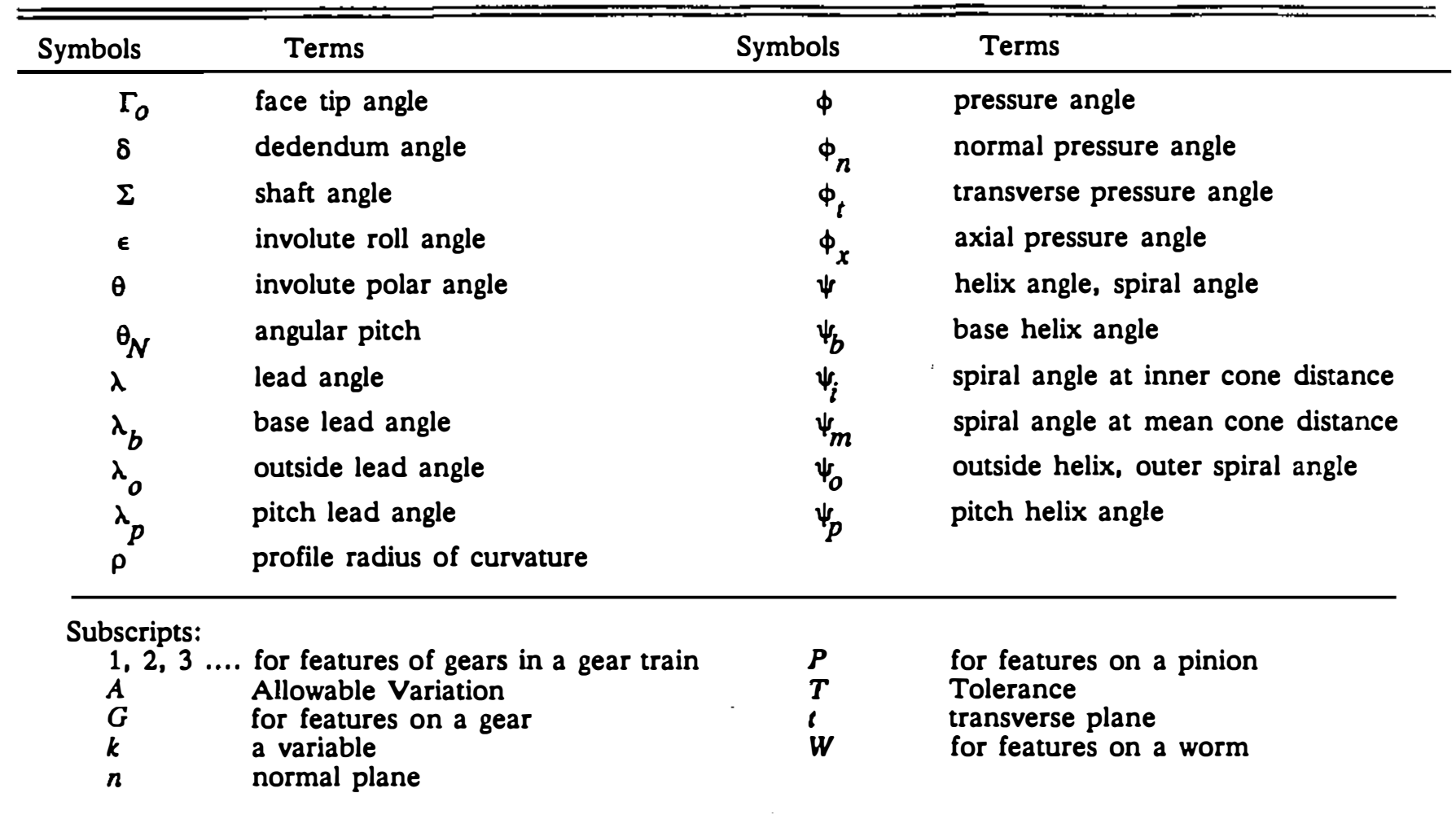

2.2.2 Typography. In accordance with the usual practice in published text, letter symbols, letter superscripts, and letter subscripts, whether upper or lower case, should be printed in italic type. An exception is Greek capital letters, which are always vertical. In manuscripts, italics are indicated by underlining each symbol to be italicized.

Numbers appearing as coefficients, subscripts, superscripts, or exponents should be printed in vertical Arabic numerals. Letter abbreviations should always be printed vertical and are not recommended for use in formulas. Trigonometric functions should be printed in lower-case vertical type. Standard mathematical notation should be followed.
To avoid confusion in reading symbols, and particularly superscripts and subscripts, it is important to select type faces that have italic forms and that make a clear distinction between upper and lower case. For this reason type faces with serifs are recommended.

2.3 Trade Names. The use of trade names, through consistent application for a given type of gear geometry, often become accepted as common nomenclature: Some terms, such as Zerol ${ }^{\circledR}$, have gained acceptance as being descriptive of a gear type. All trade names have not gained accepted usage." However, whenever used they should have a registered tradmark symbol, ๑.

\footnotetext{
- See trade name references in Appendix B.
} 


\section{GEOMETRIC DEFINITIONS}

There is an old Chinese proverb that states: The beginning of wisdom is to call things by their right nomes. Unfortunately, gearing terms and meanings vary in different offices, shops, textbooks, and even among gear authorities. Consequently, careful judgment was required in selecting terms and writing definitions for this nomenclature.

To obtain related continuity, the terms have been grouped in what may be called a textbook arrangement in preference to alphabetical order. Many of the definitions have been written in a way that makes them depend on one another, as a logical series. This arrangement leads to a more comprehensive understanding of the concepts and geometrical relations. It is efficient in thinking and requires fewer words than if each definition were complete in itself.

\subsection{General Designations.}

3.1.1 Gears. Gears are machine elements that transmit motion by means of successively engaging teeth (see Fig 3-1).

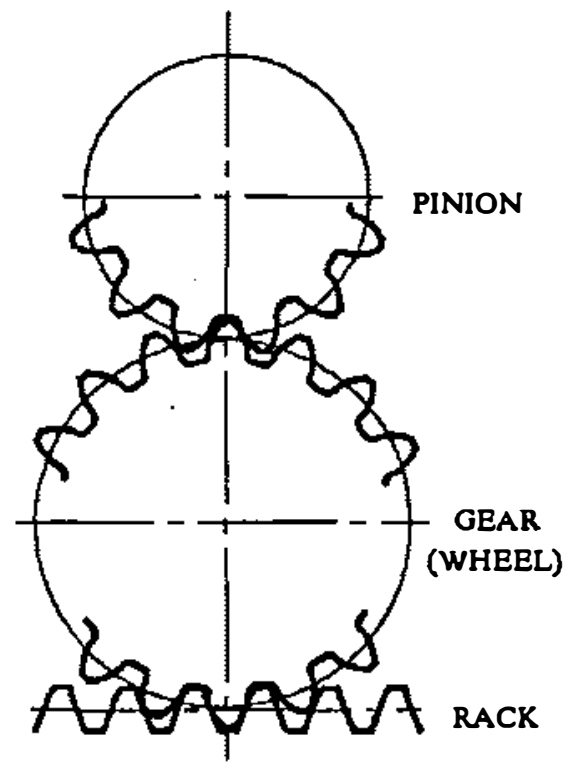

Fig 3-1 Gears

3.1.2 A Gear (Wheel) is a machine part with gear teeth. Of two gears that run together, the one with the larger number of teeth is called the gear. (Wheel per ISO 1122/1) (see Fig 3-1).
3.1.3 A Pinion is a machine part with gear teeth. Of two gears that run together, the one with the smaller number of teeth is called the pinion (see Fig 3-1).

3.1.4 A Rack is a gear with teeth spaced along a straight line, and suitable for straight-line motion. It can be regarded as part of a gear of infinitely large diameter (see Fig 3-1).

3.1.5 Basic Rack. For every pair of conjugate involute profiles, there is a basic rack. This basic rack is the profile of the conjugate gear of infinite pitch radius. The simplest way to define a conjugate gear-tooth system is to specify its basic rack (see Fig 3-2).

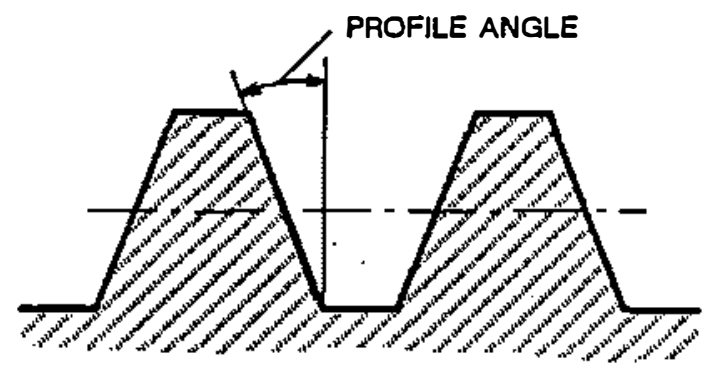

Fig 3-2 Basic Rack in Normal Plane

3.1.6 A Generating Rack is a rack outline used to indicate tooth details and dimensions for the design of a required generating tool, such as a hob or a gear-shaper cutter.

3.1.7 A Worm is a gear with one or more teeth in the form of screw threads (see Fig 3-3 and Fig 3-9).

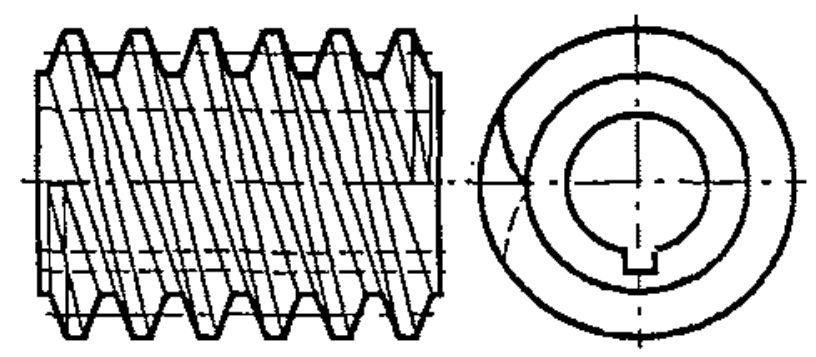

Fig 3-3 Worm

\subsection{Kinds of Gears.}

3.2.1 A Spur Gear has a cylindrical pitch surface and teeth that are parallel to the axis (see Fig $3-4)$. 
3.2.2 A Spur Rack has a plane pitch surface and straight teeth that are at right angles to the direction of motion (see Fig 3-4).

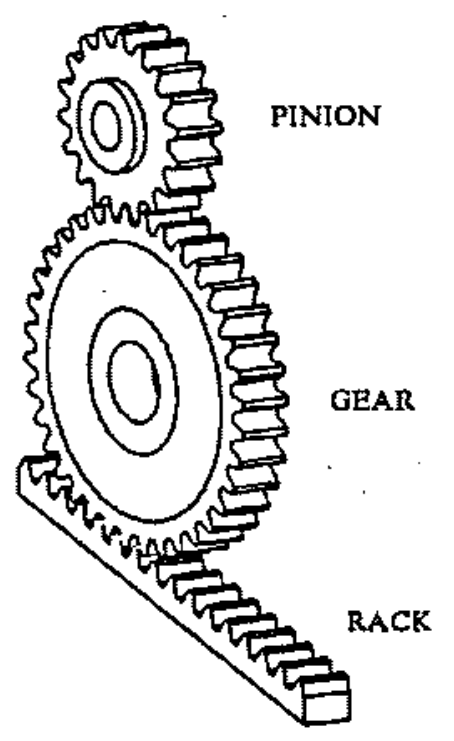

Fig 3-4 Spur Gears

3.2.3 A Helical Gear has a cylindrical pitch surface and teeth that are helical (see Fig 3-5).

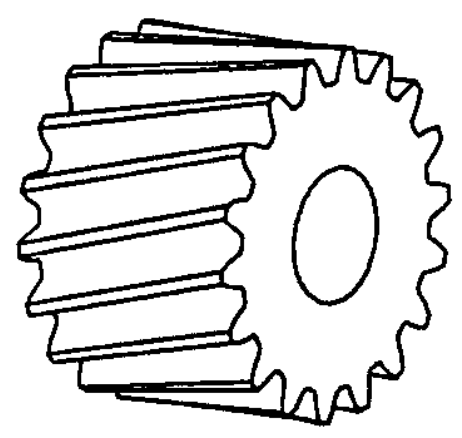

Fig 3-5 Helical Gear

3.2.4 A Helical Rack has a plane pitch surface and teeth that are oblique to the direction of motion (see Fig 3-8).

3.2.5 Parallel Axis Gears. Gears which operate on parallel axes. External helical gears on parallel axes have helices of opposite hands. If one of the members is an internal gear, the helices are of the same hand (see Fig 3-6).

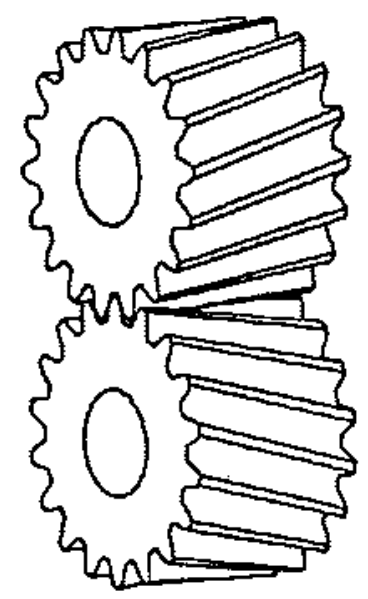

Fig 3-6 Parallel Helical Gears

3.2.6 Crossed Axis Gears are gears which: operate on crossed axes.

The term crossed helical gears has superseded the old term spiral gears. There is theoretically point contact between the teeth at any instant. They have teeth of the same or different helix angles, of the same or opposite hand, or the combination of spur and helical or other types can operate on crossed axes (see Fig 3-7).

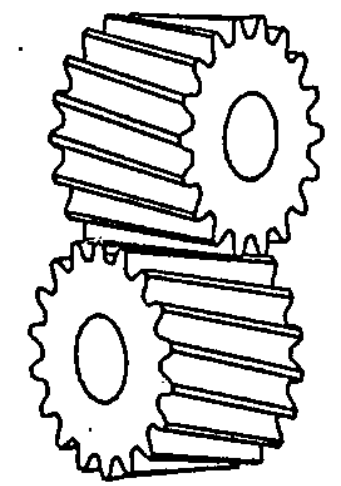

Fig 3-7 Crossed Helical Gears

3.2.7 Single-Helical Gears have teeth of only one hand on each gear (see Fig 3-8).

3.2.8 Double-Helical Gears have teeth of both right-hand and left-hand on each gear. The teeth are separated by a gap between the helices. Where there is no gap, they are known as herringbone (see Fig 3-8). 

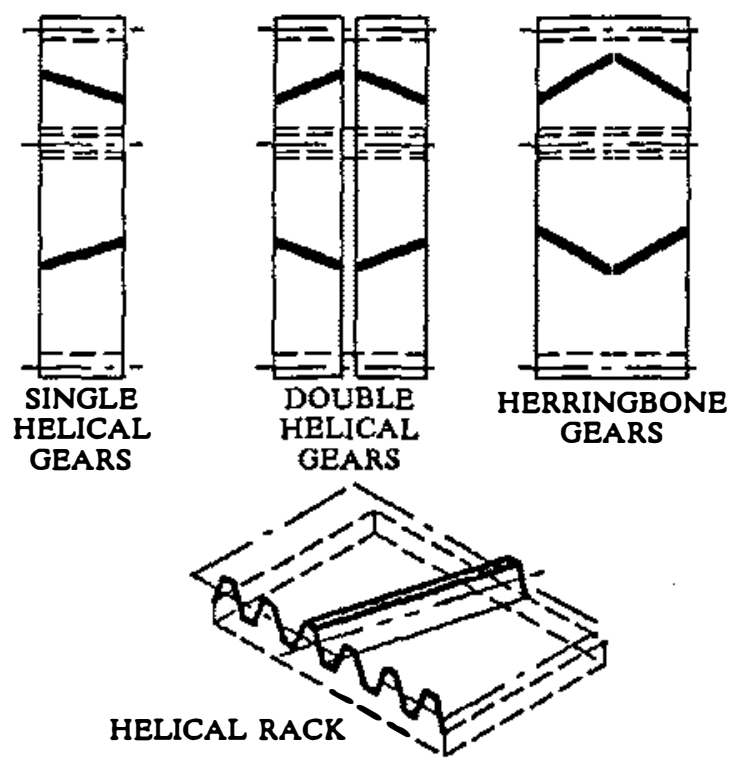

\section{Fig 3-8 Single \& Double Helical}

3.2.8.1 Herringbone Gears have teeth of both right-hand and left-hand on each gear. The teeth are continuous without a gap between the helices (see Fig 3-8).

3.2.9 Wormgearing includes worms and their mating gears. The axes are usually at right angles (see Fig 3-9).

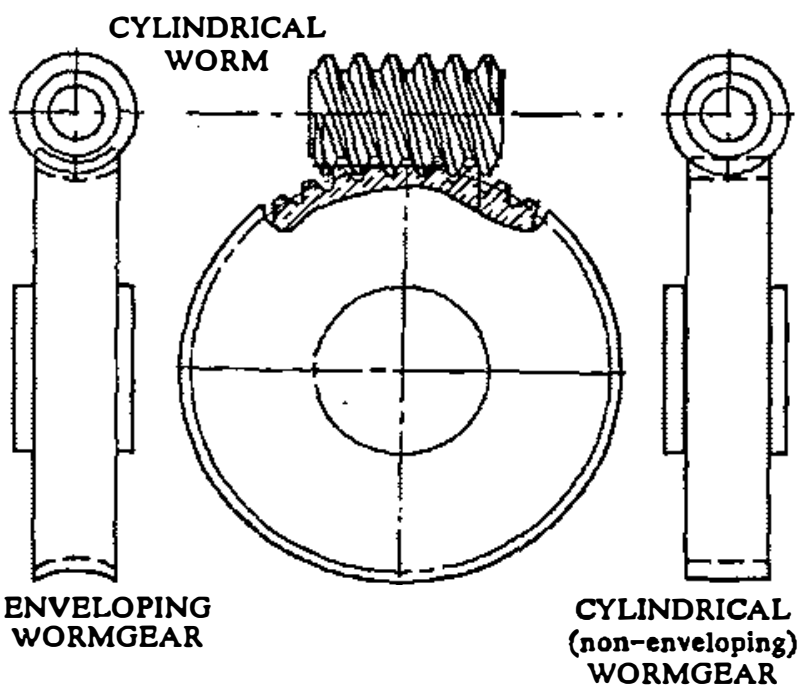

Fig 3-9 Wormgearing

3.2.10 A Wormgear (Wormwheel) is the mate to a worm. A wormgear that is completely conjugate to its worm has line contact and is said to be enveloping (see Fig 3-9). It is usually cut by a tool that is geometrically similar to the worm.
An involute spur gear or helical gear used with a cylindrical worm has only point contact.

3.2.11 A Cylindrical Worm has one or more teeth in the form of screw threads on a cylinder (see Fig 3-3 and Fig 3-9).

3.2.12 An Enveloping (Hourglass) Worm has one or more teeth and increases in diameter from its middle portion toward both ends, conforming to the curvature of the gear (see Fig 3-10).

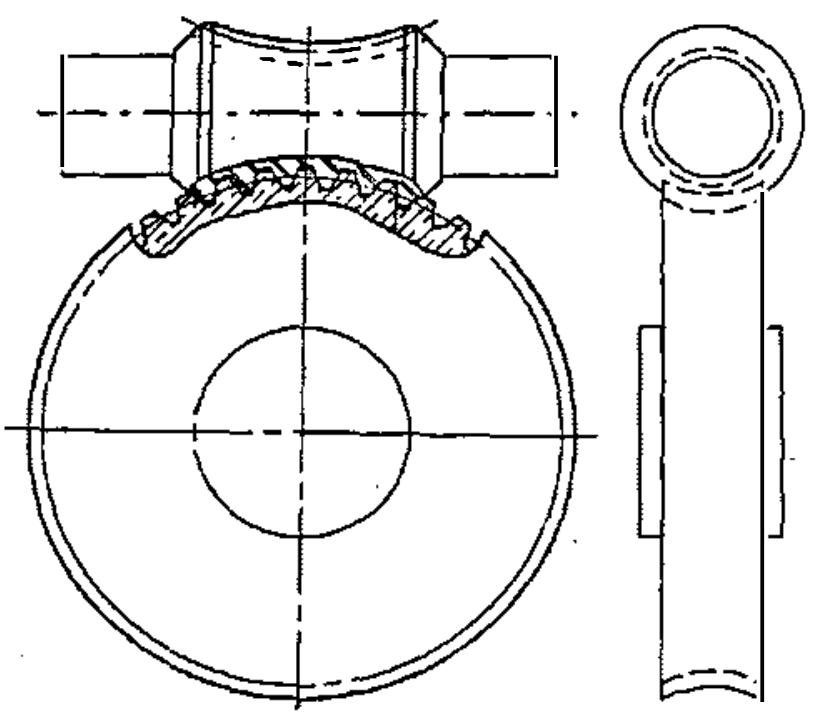

Fig 3-10 Double-Enveloping Wormgearing

3.2.13 Double-Enveloping Wormgearing comprises of enveloping (hourglass) worms mated with fully enveloping wormgears (see Fig 3-10).

3.2.14 Bevel Gears have conical pitch surfaces and operate on intersecting axes which are usually at right angles (see Fig 3-11).

3.2.15 Miter Gears are mating bevel gears with equal numbers of teeth and with axes at right angle (see Fig 3-11).

3.2.16 Angular Bcvel Gears are bevel gears in which the axes are not at right angles (see Fig 3-12).

3.2.17 A Crown Gear is a bevel gear with a plane pitch surface. The crown gear is analogous to the basic rack in spur gears (see Fig 3-13).

3.2.18 Straight Bevel Gears have straight tooth elements, which if extended, would pass through the point of intersection of their axes (see Fig 3-14). 

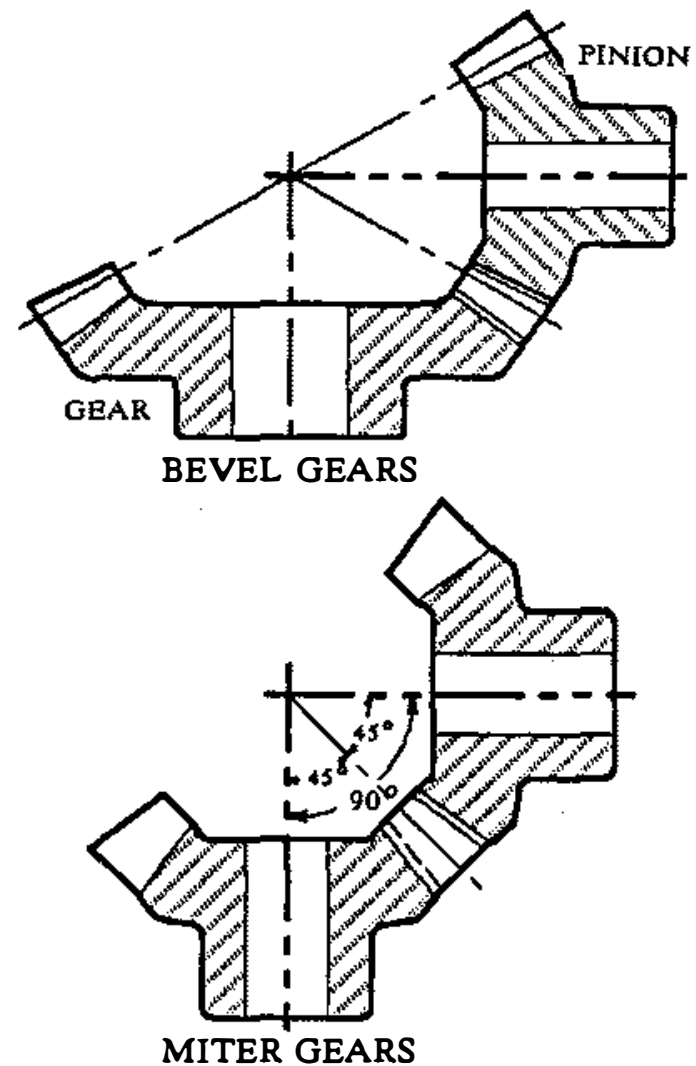

Fig 3-11 Bevel Gears

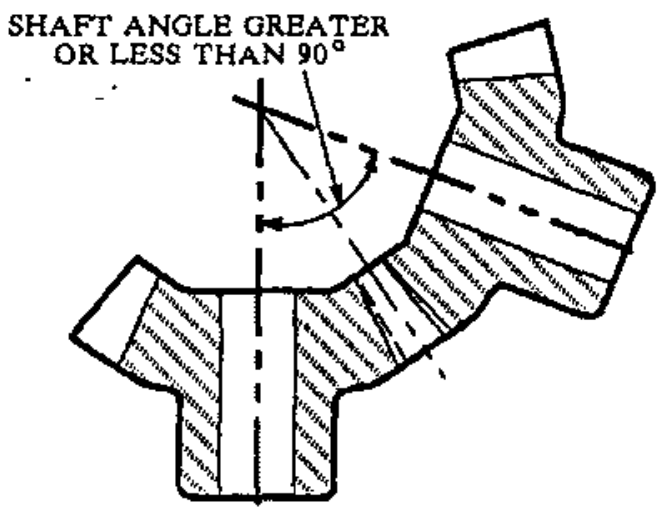

Fig 3-12 Angular Bevel Gears

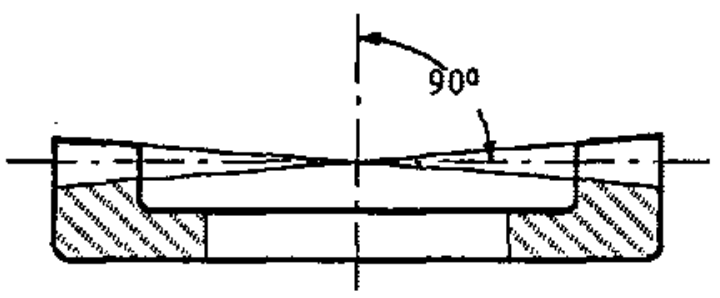

Fig 3-13 Crown Gear

3.2.19 Spiral Bevel Gears have teeth that are curved and oblique (see Fig 3-15).
3.2.20 Zerol ${ }^{\oplus}$ Bevel Gears have teeth that are curved but in the same general direction as straight teeth. They are spiral bevel gears of zero spiral angle (see Fig 3-15).

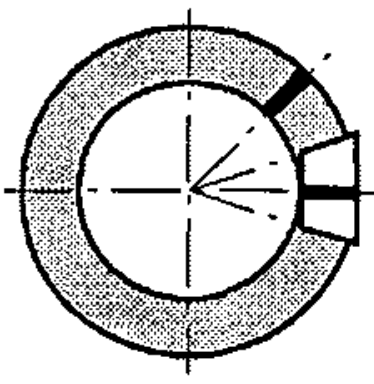

STRAIGHT BEVEL GEARS

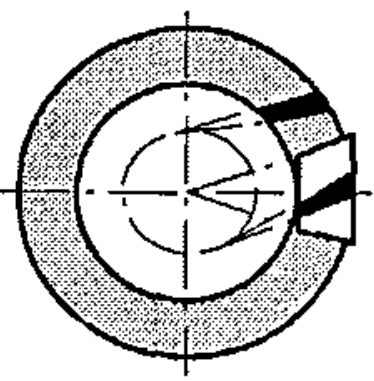

SKEW BEVEL GEARS
Fig 3-14 Straight Bevel

3.2.21 Formate Bevel Gears are bevel gears in which the gear member of the pair has nongenerated teeth, usually with straight tooth profiles, and in which the pinion member of the pair has generated teeth that are conjugate to the mating gear.
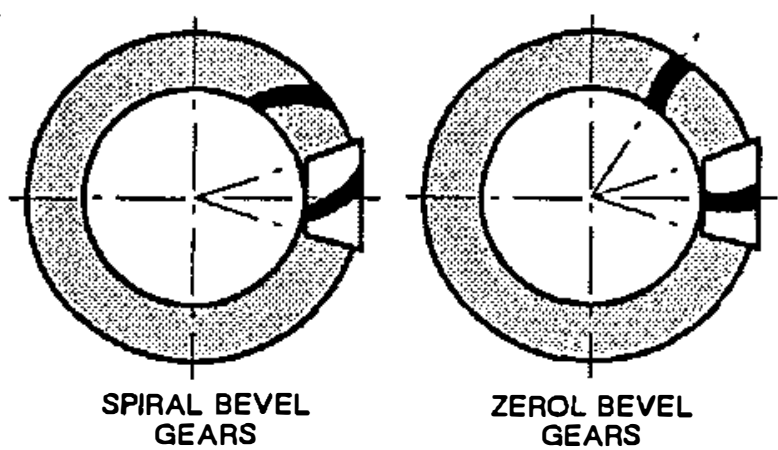

Fig 3-15 Spiral Bevel \& Zerol ${ }^{\circledR}$

3.2.22 Skew Bevel Gears are those for which the corresponding crown gear has teeth that are straight and oblique (see Fig 3-14).

3.2.23 Hypoid Gears are similar in general form to bevel gears, but operate on non-intersecting axes (see Fig 3-16).

Practically all hypoid gears have spiral teeth that are curved and oblique. The axes may be at right angles or otherwise. The tooth surfaces of a hypoid gear and pinion are both cut or generated by the same or similar tools.

In non-generated hypoid gears - like Formate bevel gears - the teeth of the gears are non-generated. 

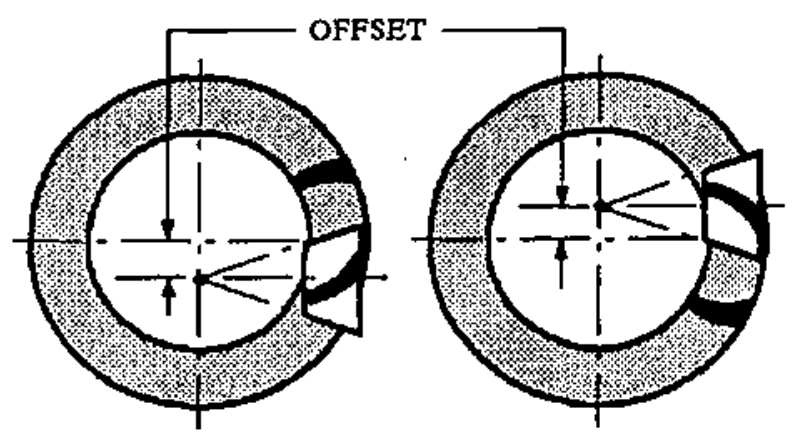

Fig 3-16 Hypoid Gears

3.2.24 Other Trade Name Gears include Beveloid ${ }^{\oplus}$, Helicon ${ }^{\oplus}$, Planoid ${ }^{\oplus}$, Spheroid, and Spiroid ${ }^{\oplus}$. It is beyond the scope of this Standard to define all trade name kinds of gears (see Appendix B).

\subsection{Tooth Orientation.}

3.3.1 Face Gears consist of a spur or helical pinion in combination with a conjugate gear of disk form, the axes being usually at right angles, either intersecting or non-intersecting (see Fig $3-17)$.

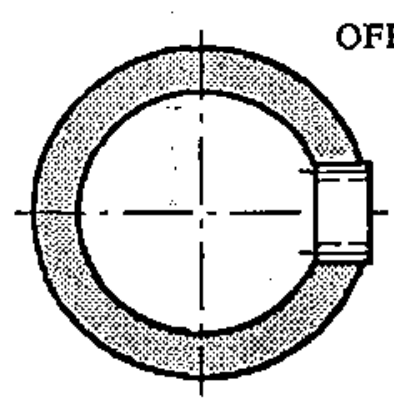

PINION ON CENTER

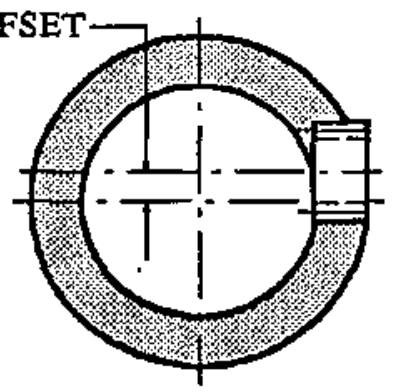

PINION OFF CENTER

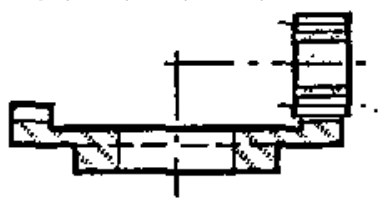

\section{Fig 3-17 Face Gears}

3.3.2 An External Gear is one with the teeth formed on the outer surface of a cylinder or cone (see Fig 3-18).

3.3.3 An Internal Gear is one with the teeth formed on the inner surface of a cylinder or cone (see Fig 3-18).

An internal gear can be meshed only with an external pinion.

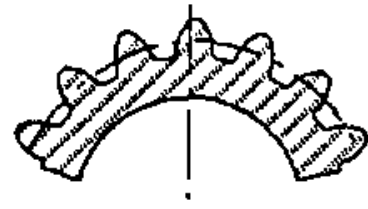

EXTERNAL GEAR

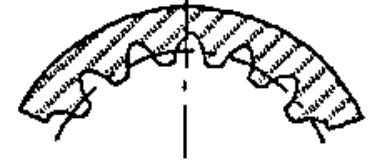

INTERNAL GEAR

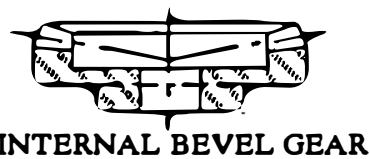

\section{Fig 3-18 External and Internal Gears}

\subsubsection{A Right-Hand Helical Gear or} Right-Hand Worm is one in which the teeth twist clockwise as they recede from an observer looking along the axis (see Fig 3-19).

The designations, right hand and left hand, are the same as in the long-established practice for screw threads, both external and internal.

Two external helical gears operating on parallel axes must be of opposite hand. An internal helical gear and its pinion must be of the same hand.
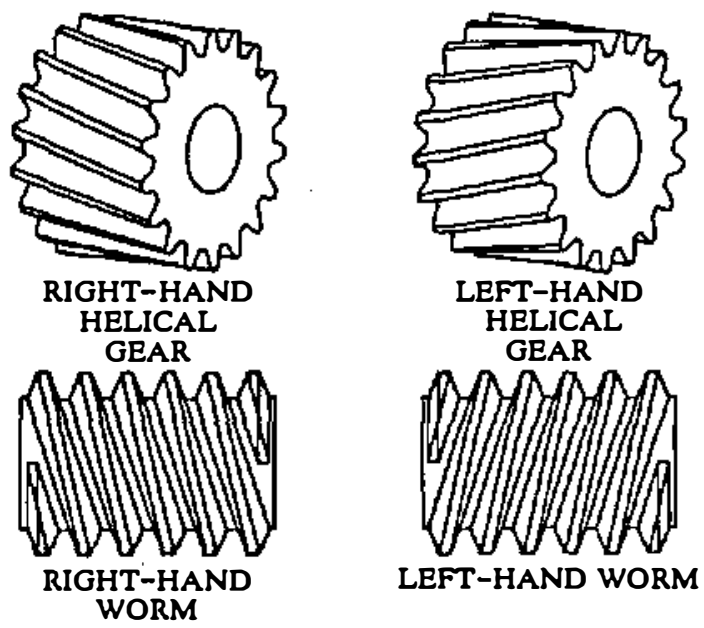

\section{Fig 3-19 Helical and Worm Hand}

3.3.5 A Left-Hand Helical Gear or LeftHand Worm is one in which the teeth twist counterclockwise as they recede from an observer looking along the axis (see Fig 3-19).

3.3.6 A Right-Hand Spiral Bevel Gear is one in which the outer half of a tooth is inclined in the clockwise direction from the axial plane through the midpoint of the tooth as viewed by an 
observer looking at the face of the gear (see Fig 3-20).
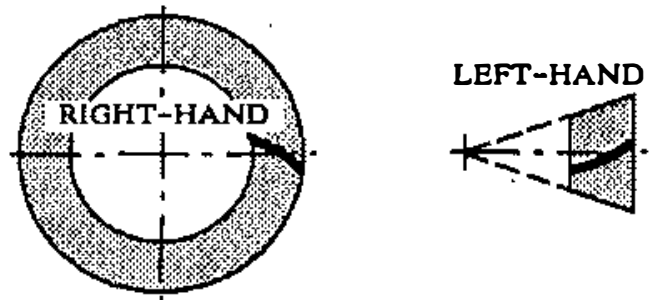

SPIRAL BEVEL GEARS

SPIRAL BEVEL PINIONS
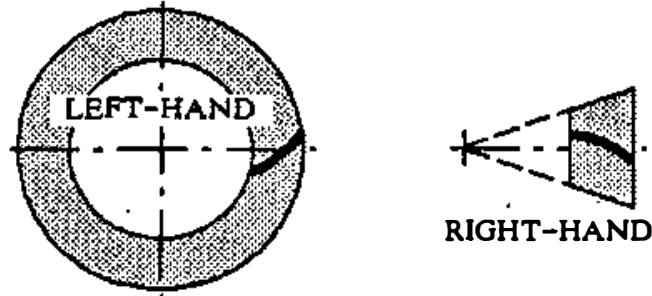

Fig 3-20 Spiral Bevel Hand

3.3.7 A Left-Hand Spiral Bevel Gear is one in which the outer half of a tooth is inclined in the counterclockwise direction from the axial plane through the midpoint of the tooth as viewed by an observer looking at the face of the gear (see Fig 3-20).

A spiral bevel gear and pinion are always of opposite hand, including the case when the gear is internal.

The designations right-hand and left-hand are applied similarly to spiral bevel gears, Zerol ${ }^{\oplus}$ bevel gears, skew bevel gears, hypoid gears, and oblique-tooth face gears (see Fig 3-21).
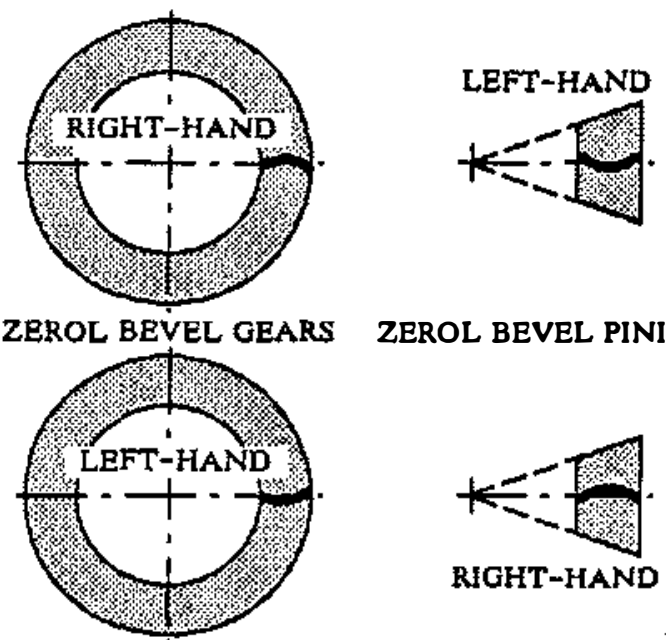

ZEROL BEVEL PINIONS

Fig 3-21 Zerol® Hand

In hypoid-gear design, the pinion and gear are practically always of opposite hand, and the spiral angle of the pinion is usually larger than that of the gear. The hypoid pinion is then larger in diameter than an equivalent bevel pinion.

\subsection{Pitch Surfaces.}

The pitch surface definitions are for gears having their ratio of angular velocities constant, and axes either parallel or intersecting - and, therefore, do not include crossed helical gears, wormgearing, hypoid gears, or offset face gears.

3.4.1 Pitch Surfaces are the imaginary planes, cylinders, or cones that roll together without slipping. For a constant-velocity ratio, the pitch cylinders and pitch cones are circular (see Figs 3-22, 3-23 and 3-24).

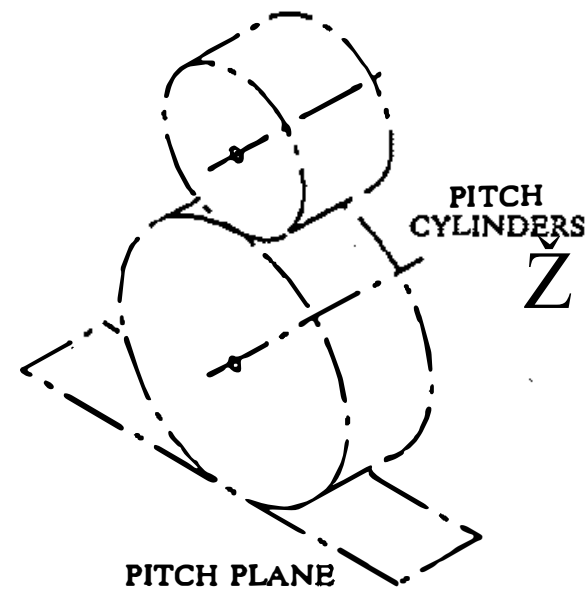

Fig 3-22 Pitch Surfaces

3.4.2 A Pitch Plane of a rack or in a crown gear is the imaginary surface that rolls without slipping with a pitch cylinder or pitch cone of another gear (see Fig 3-24). For a Pitch Plane of other gears, see 3.6.2.

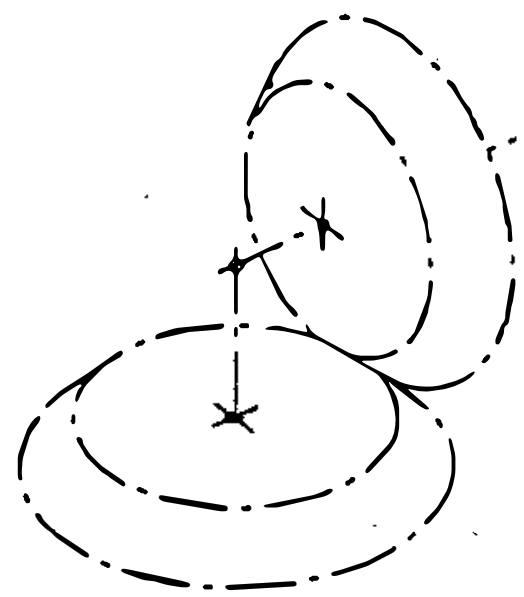

Fig 3-23 Pitch Cones 
3.4.3 A Pitch Cylinder is the imaginary cylinder in a spur or helical gear that rolls without slipping on a pitch plane or pitch cylinder of another gear (see Fig 3-22).

3.4.4 A Pitch Cone is the imaginary cone in a bevel gear that rolls without slipping on a pitch surface of another gear (see Fig 3-23).

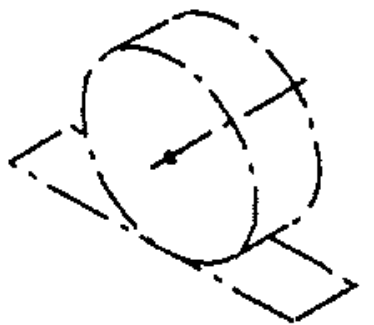

PITCH PLANE OF RACK

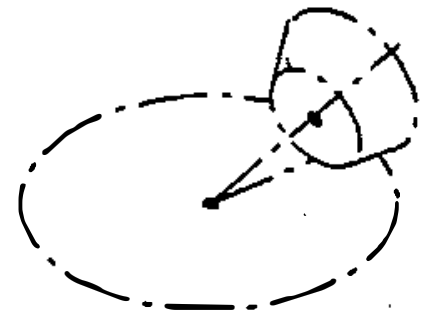

PITCH PLANE OF CROWN GEAR

\section{Fig 3-24 Pitch Planes}

\subsection{Boundary Surfaces.}

3.5.1 The Outside (Tip) Cylinder is the surface that coincides with the tops of the teeth of an external cylindrical gear (see Fig 3-25).

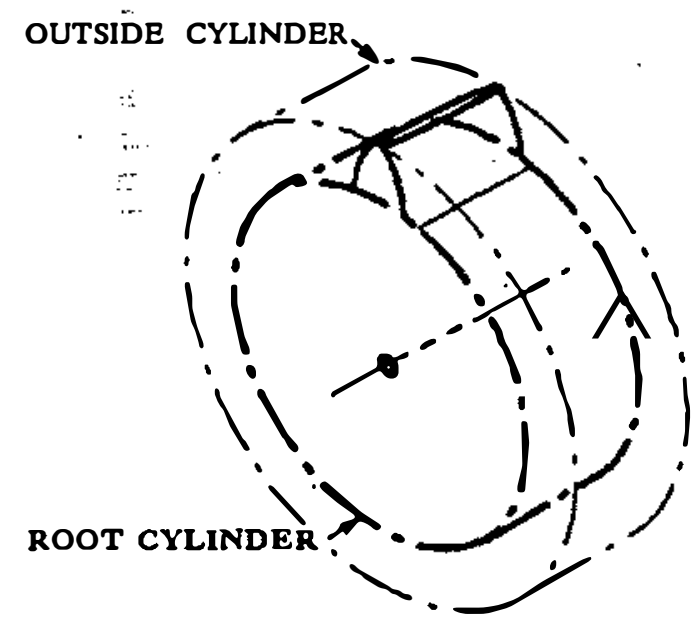

\section{Fig 3-25 Cylindrical Surfaces}

3.5.2 The Inside Cylinder is the surface that coincides with the tops of the teeth of an internal cylindrical gear (see Fig 3-54).

3.5.3 The Root Cylinder is the imaginary surface that coincides with the the bottoms of the tooth spaces in a cylindrical gear (see Fig 3-25).

3.5.4 The Face (Tip) Cone is the imaginary surface that coincides with the tops of the teeth of a bevel or hypoid gear (see Fig 3-26).
3.5.5 The Root Cone is the imaginary surface that coincides with the bottoms of the tooth spaces in a bevel or hypoid gear (see Fig 3-26).

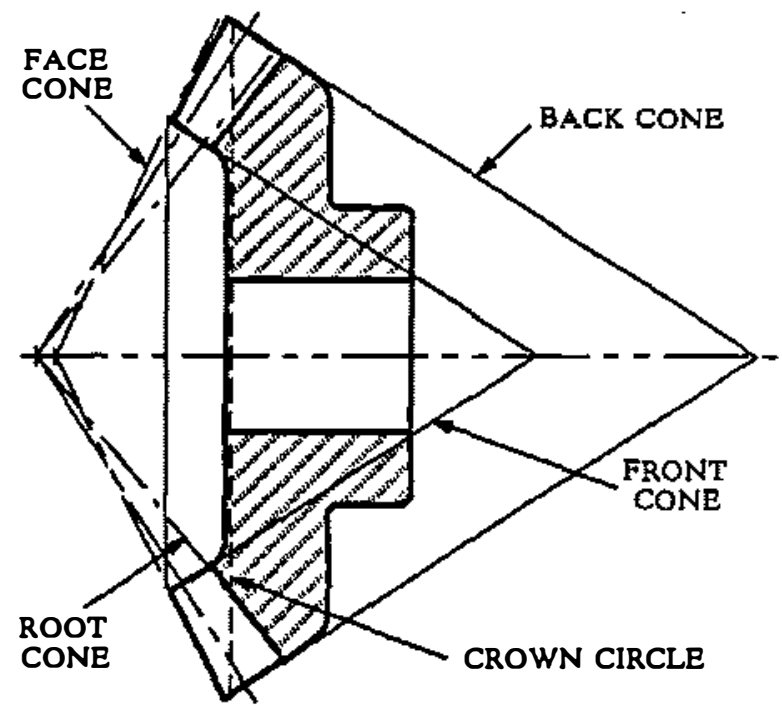

Fig 3-26 Conical Surfaces

3.5.6 The Back Cone of a bevel or hypoid gear is an imaginary cone tangent to the outer ends of the teeth, with its elements perpendicular to those of the pitch cone. The surface of the gear blank at the outer ends of the teeth is customarily formed to such a back cone (see Fig 3-26).

3.5.7 The Front Cone of a bevel or hypoid gear is an imaginary cone tangent to the inner ends of the teeth, with its elements perpendicular to those of the pitch cone. The surface of the gear blank at the inner ends of the teeth is customarily formed to such a front cone, but sometimes may be a plane on a pinion or a cylinder in a nearly flat gear (see Fig 3-26).

3.5.8 The Crown Circle in a bevel or hypoid gear is the circle of intersection of the back cone and face cone (see Fig 3-26).

\subsection{Principal Planes.}

3.6.1 An Axial Plane may be any plane containing the gear axis and a given point (see Fig 3-27).

3.6.1.1 The Plane of Axes of a pair of gears is the plane that contains the two axes.

3.6.2 The Pitch Plane of a pair of gears is the plane perpendicular to the axial plane and tangent to the pitch surfaces. A pitch plane in an individual gear may be any plane tangent to its pitch surface. The pitch plane of a rack or crown 
gear is the pitch surface (see Fig 3-27 and paragraph 3.4.2).

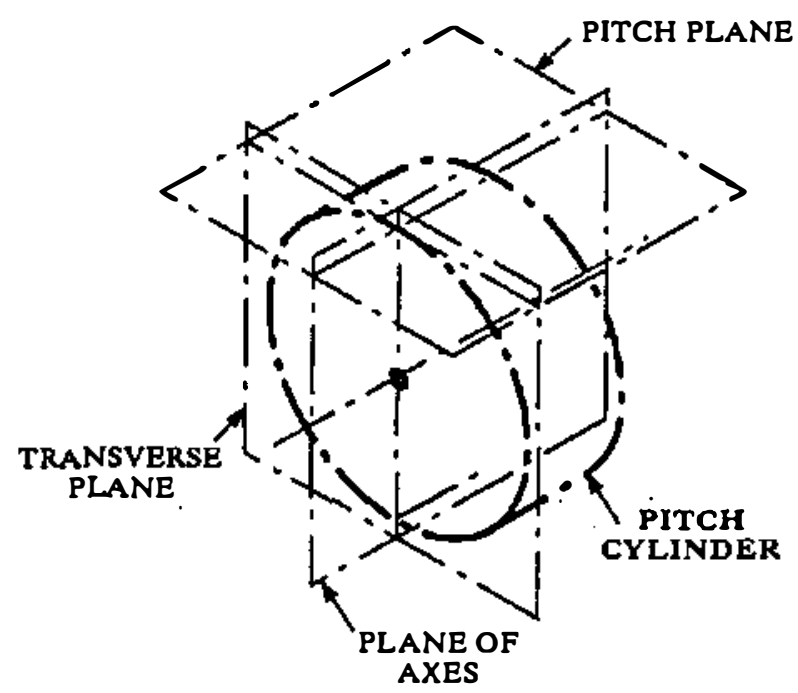

\section{Fig 3-27 Principal Reference Planes}

3.6.3 A Plane of Rotation is any plane perpendicular to a gear axis (see Fig 3-28).

3.6.4 A Transverse Plane is perpendicular to the axial plane and to the pitch plane. In gears with parallel axes, the transverse plane and plane of rotation coincide (see Figs 3-27 and 3-28).
3.6.5 A Tangent Plane is tangent to the tooth surfaces at a point or line contact (see Fig 3-39).
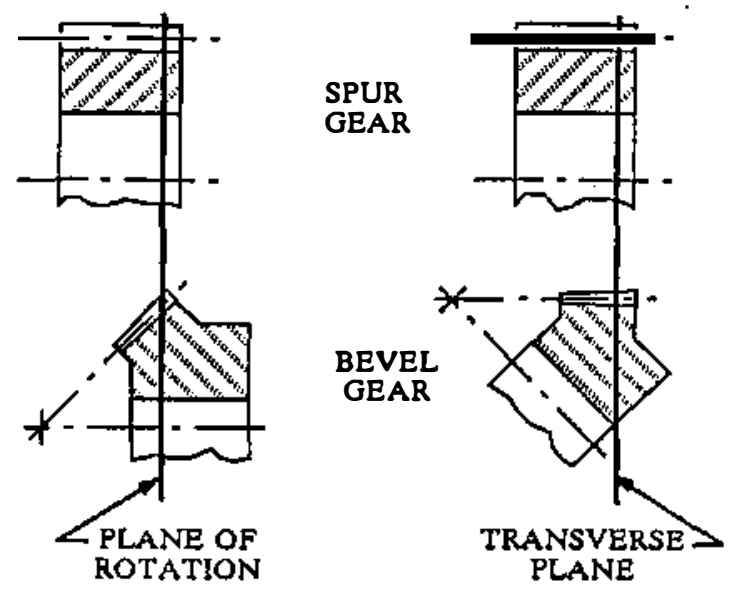

\section{Fig 3-28 Planes of Rotation}

3.6.6 A Normal Plane is normal to a tooth surface at a pitch point, and perpendicular to the pitch plane. In a helical rack, a normal plane is normal to all the teeth it intersects. In a helical gear, however, a plane can be normal to only one tooth at a point lying in the plane surface. At such a point, the normal plane contains the line normal to the tooth surface and is normal to the pitch surface (see Fig 3-29).

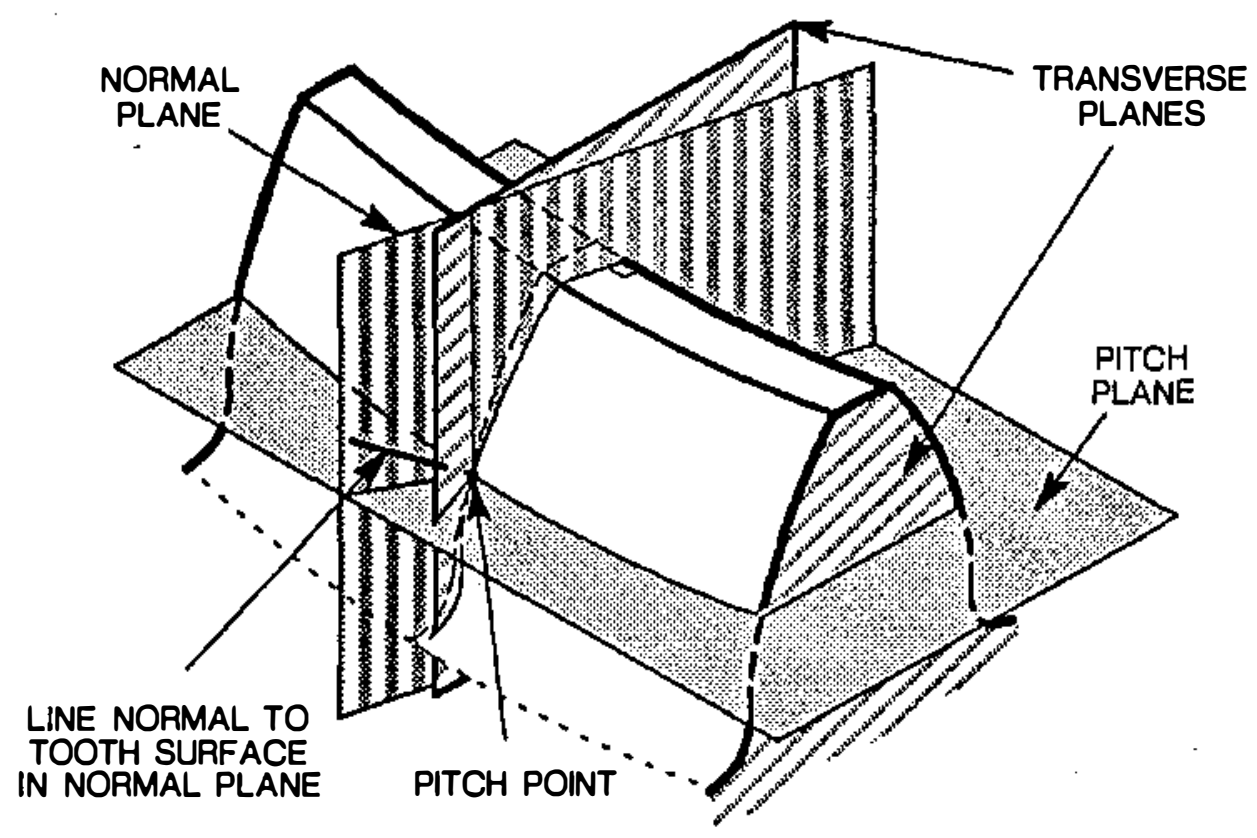

Fig 3-29 Planes at a Pitch Point on a Helical Tooth 
Important positions of a normal plane in tooth measurement and tool design of helical teeth and worm threads are:

(1) the plane normal to the pitch helix at side of tooth

(2) the plane normal to the pitch helix at center of tooth

(3) the plane normal to the pitch helix at center of space between two teeth

In a spiral bevel gear, one of the positions of a normal plane is at a mean point and the plane is normal to the tooth trace.

3.6.7 The Central Plane of a wormgear is perpendicular to the gear axis and contains the common perpendicular of the gear and worm axes. In the usual case with axes at right angles, it contains the worm axis (see Fig 3-30).

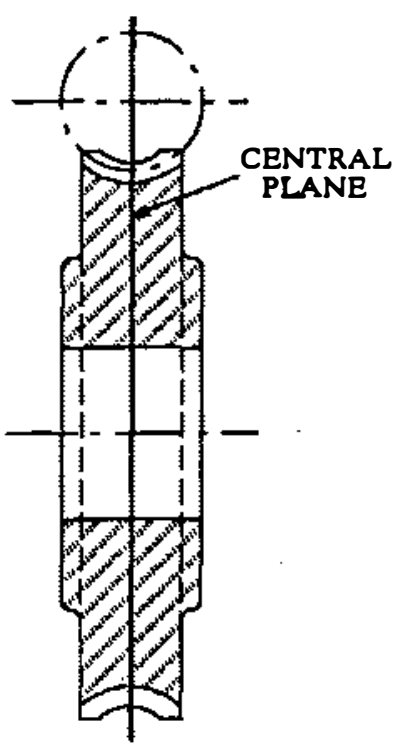

Fig 3-30 Central Plane

\subsection{Principal Directions.}

These are directions in the pitch plane, and correspond to the principal cross sections of a tooth.

3.7.1 The Axial Direction is a direction parallel to an axis (see Fig 3-31).

3.7.2 The Transverse Direction is the direction of the intersection of a transverse plane (see Fig 3-31).
3.7.3 The Normal Direction is the direction of the intersection of a normal plane (see Fig $3-31)$.

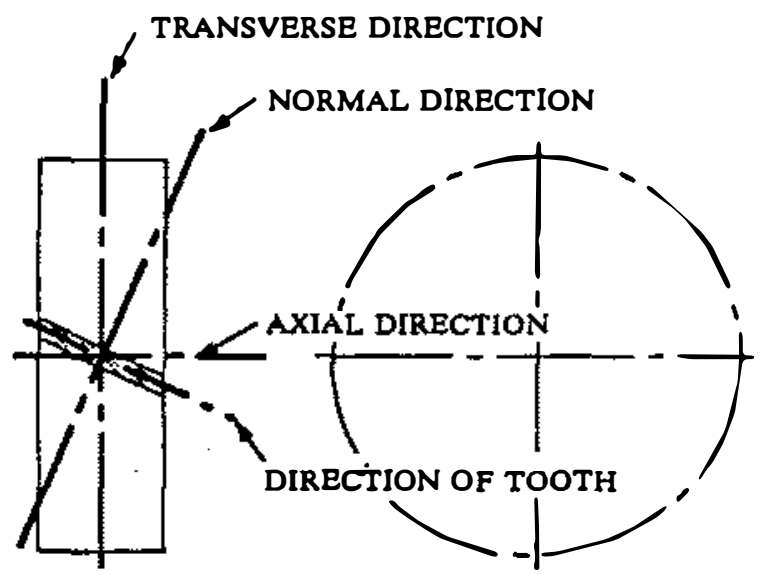

Fig 3-31 Principal Directions

\subsection{Elements of Gear Teeth.}

3.8.1 The Tooth Surface (Flank) forms the side of a gear tooth (see Fig 3-32).

3.8.2 A Profile is one side of a tooth in a cross section between the outside circle and the root circle. Usually a profile is the curve of intersection of a tooth surface and a plane or surface normal to the pitch surface, such as the transverse, normal, or axial plane (see Fig 3-32).

3.8.3 The Fillet Curve (Root Fillet) is the concave portion of the tooth profile where it joins the bottom of the tooth space (see Fig 3-32).

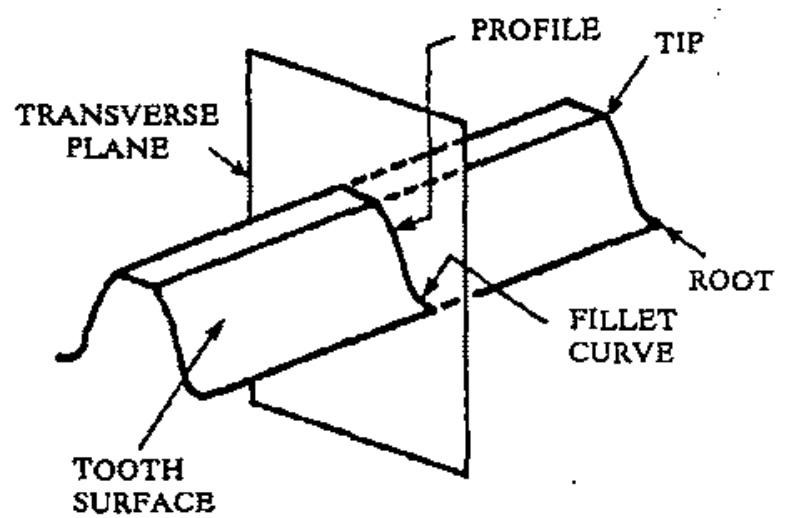

Fig 3-32 Profile (Spur Gear)

3.8.4 Involute Teeth of spur gears, helical gears, and worms are those in which the profile in a transverse plane (exclusive of the fillet curve) is the involute of a circle (see Fig 3-33). 
3.8.5 The Base Circle is the circle from which involute tooth profiles are derived (see Figs 3-33 and 3-38).

3.8.5.1 In Cone (double-enveloping) wormgearing, the term base circle is also used. The base circle is tangent to straight-line extensions of the worm tooth profiles in the central plane of the wormgear.

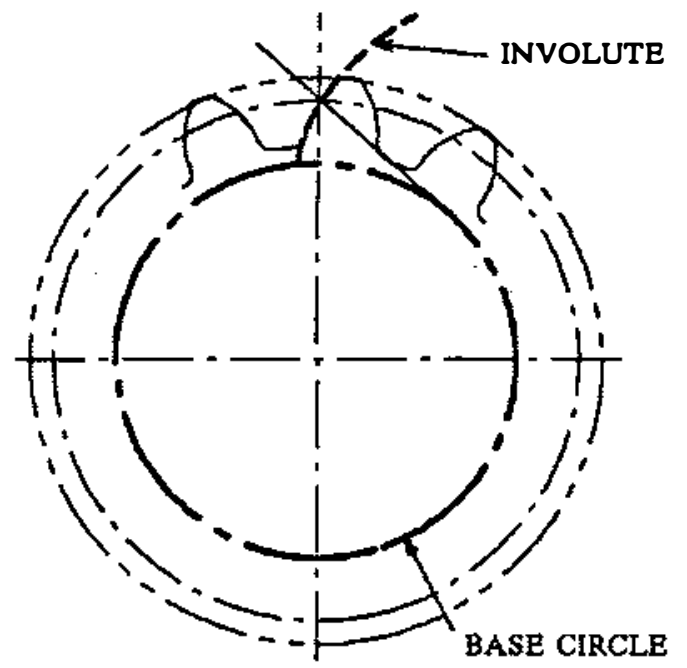

Fig 3-33 Involute Teeth

3.8.6 The Base Cylinder corresponds to the base circle, and is the cylinder from which involute tooth surfaces are developed (see Fig 3-34).

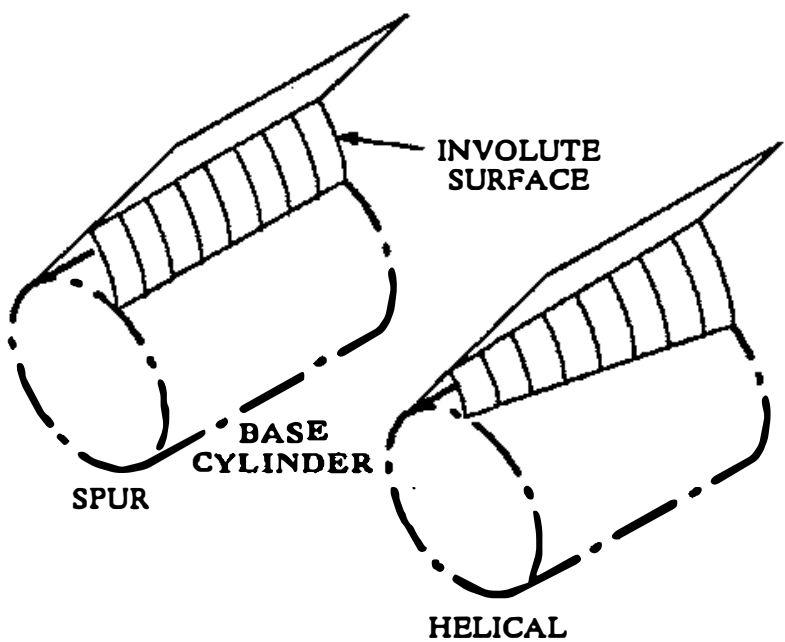

Fig 3-34 Base Cylinder

3.8.7 A Pitch Circle (operating) is the curve of intersection of a pitch surface of revolution and a plane of rotation. According to theory, it is the imaginary circle that rolls without slipping with a pitch circle of a mating gear (see Fig 3-35).
3.8.8 The Pitch Line corresponds, in the cross section of a rack, to the pitch circle (operating) in the cross section of a gear (see Fig 3-35).

3.8.9. A Gear Center is the center of the pitch circle (see Fig 3-35).

3.8.10 The Line of Centers connects the centers of the pitch circles of two engaging gears; it is also the common perpendicular of the axes in crossed helical gears and wormgears. When one of the gears is a rack, the line of centers is perpendicular to its pitch line (see Fig 3-35).

3.8.11 The Pitch Point is the point of tangency of two pitch circles (or of a pitch circle and pitch line) and is on the line of centers (see Fig 3-35).

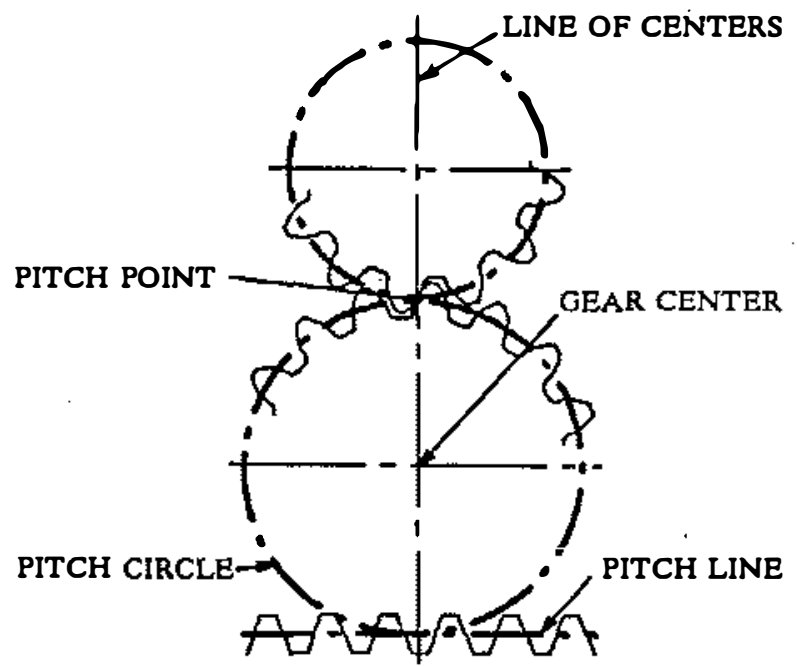

Fig 3-35 Pitch Circles and Line

3.8.12 The Addendum Circle coincides with the tops of the teeth and is concentric with the standard (reference) pitch circle and radially distant from it by the amount of the addendum (see Fig 3-36 and 3-52).

3.8.13 The Root Circle coincides with the bottoms of the tooth spaces (see Figs 3-36 and 3-54).

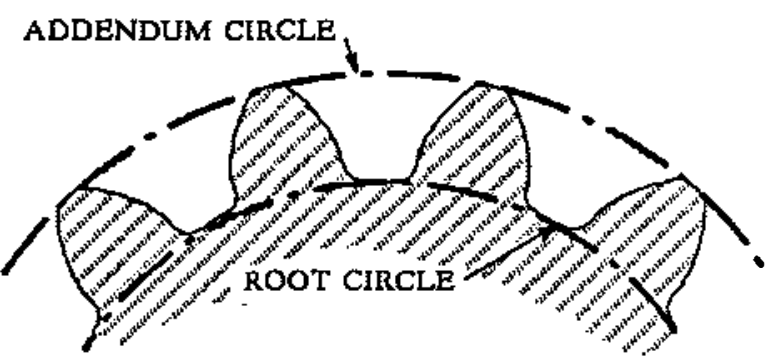

Fig 3-36 Root Circle 
3.8.14 A Point of Contact is any point at which two tooth profiles touch each other (see Fig 3-37).

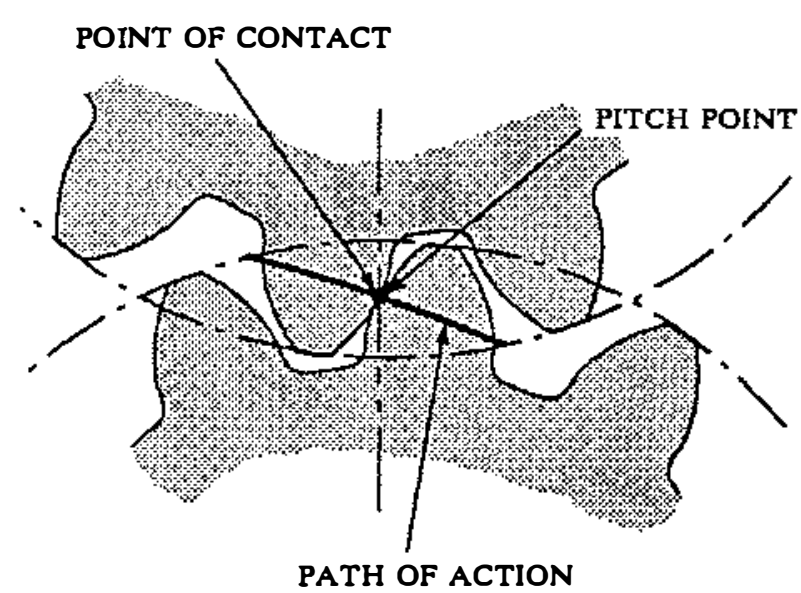

Fig 3-37 Path of Action

3.8.15 The Path of Action is the locus of successive contact points between a pair of gear teeth, during the phase of engagement. For conjugate gear teeth, the path of action passes through the pitch point. It is the trace of the surface of action in the plane of rotation (see Figs 3-37 and 3-40).

3.8.16 The Line of Action is the path of action for involute gears. It is the straight line passing through the pitch point and tangent to both base circles (see Fig 3-38).

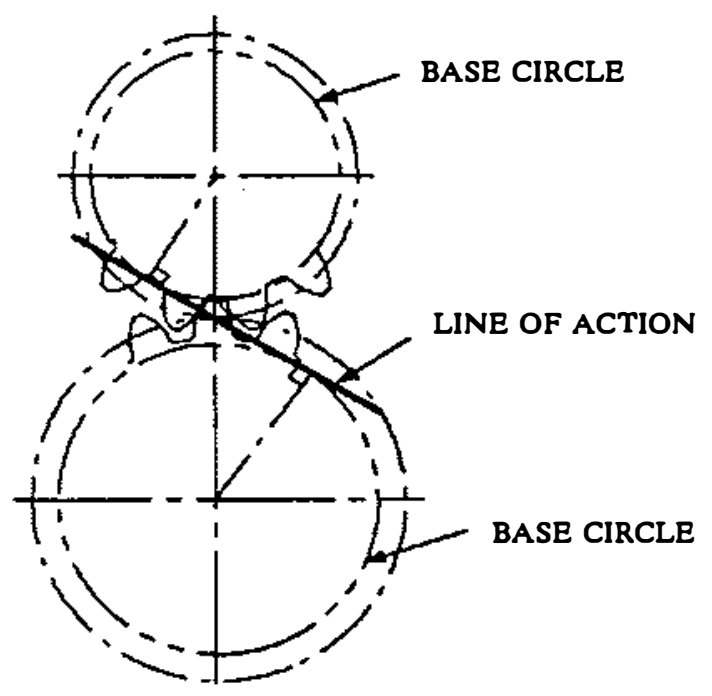

Fig 3-38 Line of Action
3.8.17 A Line of Contact is the line or curve along which two tooth surfaces are tangent to each other. (see Figs 3-39 and 3-40).

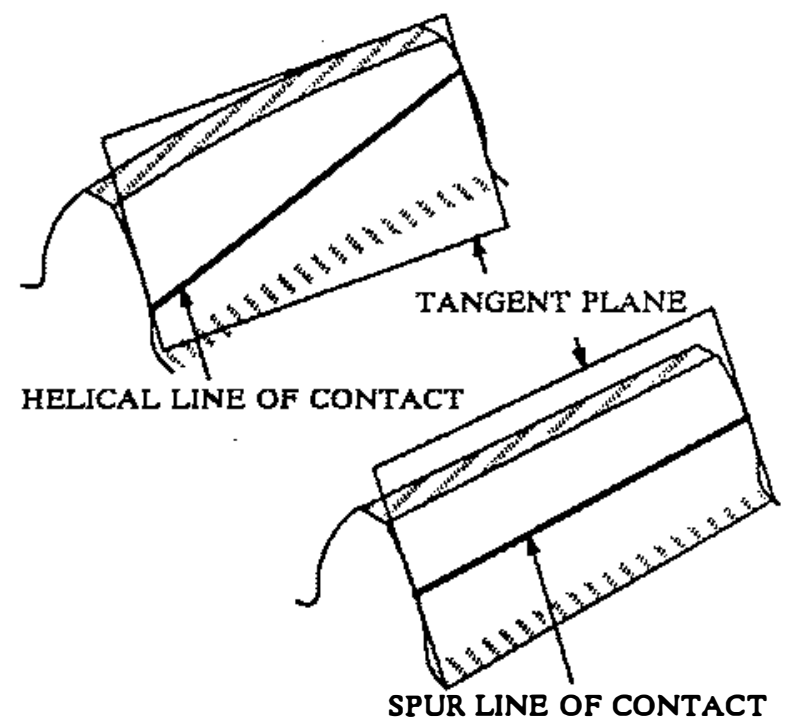

Fig 3-39 Line of Contact

3.8.18 The Surface of Action is the imaginary surface in which contact occurs between two engaging tooth surfaces. It is the summation of the paths of action in all sections of the engaging teeth.

3.8.19 The Plane of Action is the surface of action for involute, parallel-axis gears with either spur or helical teeth. It is tangent to the base cylinders (see Fig 3-40).

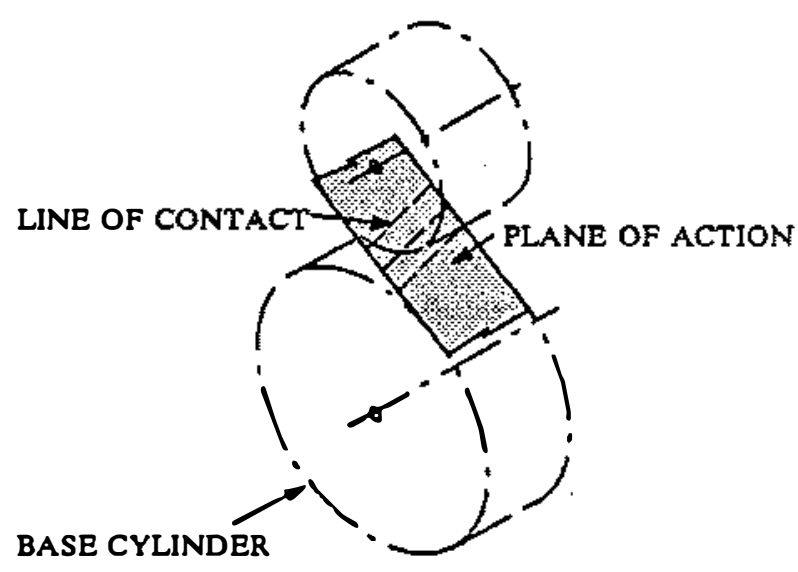

Fig 3-40 Plane of Action 
3.8.20 Zone of Action (Contact Zone) for involute, parallel-axis gears with either spur or helical teeth, is the rectangular area in the plane of action bounded by the length of action and the face width (see Fig 3-41).

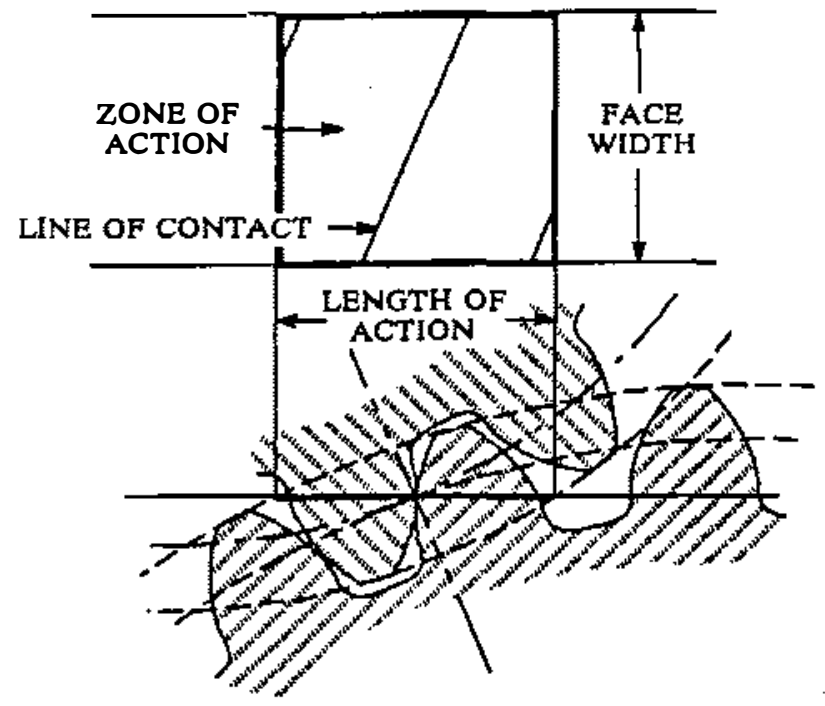

Fig 3-41 Zone of Action

3.8.21 The Path of Contact is the curve on either tooth surface along which theoretical single point contact occurs during the engagement of gears with crowned tooth surfaces or gears that normally engage with only single point contact (see Fig 3-42).

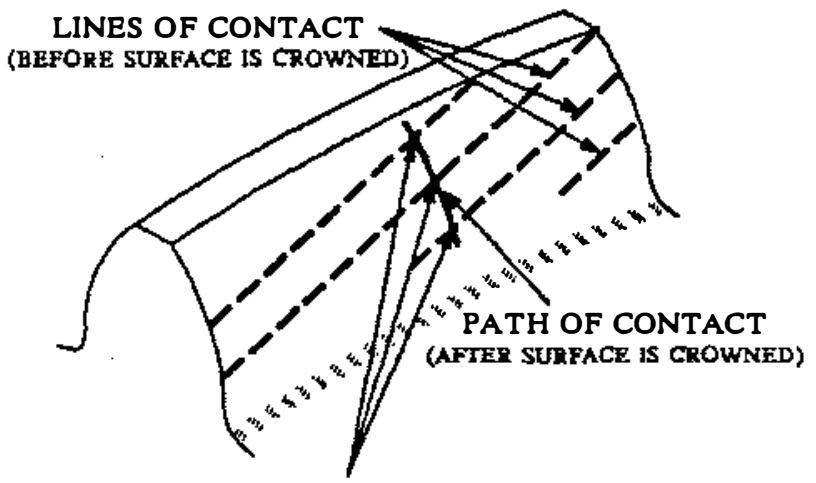

POINTS OF CONTACT

(AFTER SURPACE IS CROWNED)

Fig 3-42 Lines of Contact (helical gear)
3.8.22 The Pitch Helix is the intersection of the tooth surface and the pitch cylinder of a helical gear or cylindrical worm (see Fig 3-43).

3.8.23 The Base Helix of a helical, involute gear or involute worm lies on its base cylinder (see Fig 3-43).

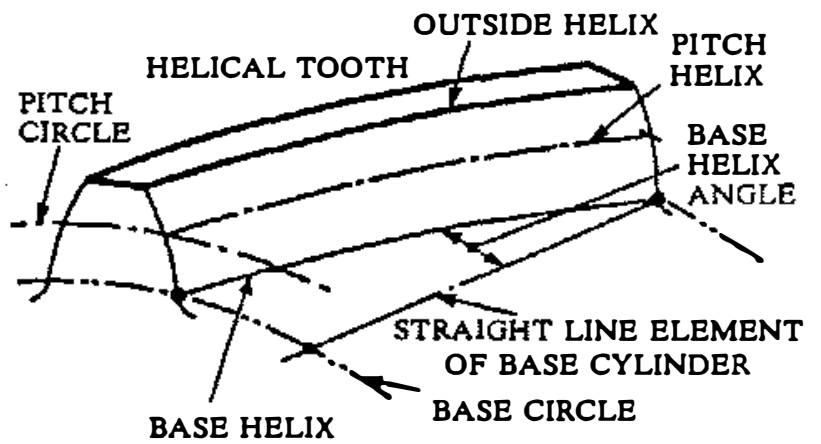

Fig 3-43 Tooth Helix

3.8.24 A Normal Helix is a helix on the pitch cylinder, normal to the pitch helix (see Fig 3-44).

3.8.25 The Outside (Tip) Helix is the intersection of the tooth surface and the outside cylinder of a helical gear or cylindrical worm (see Fig 3-43).

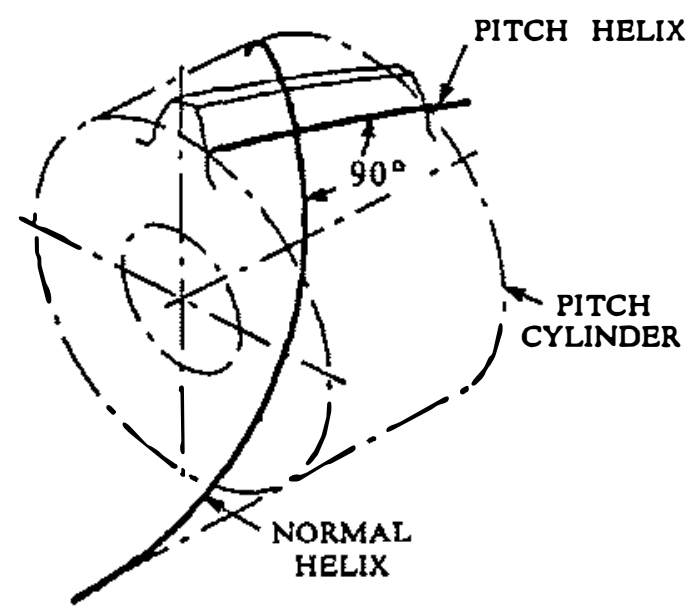

Fig 3-44 Normal Helix

3.8.26 The Heel of a tooth on a bevel gear or pinion is the portion of the tooth surface near its outer end (see Fig 3-45). 
3.8.27 The Toe of a tooth on a bevel gear or pinion is the portion of the tooth surface near its inner end (see Fig 3-45).

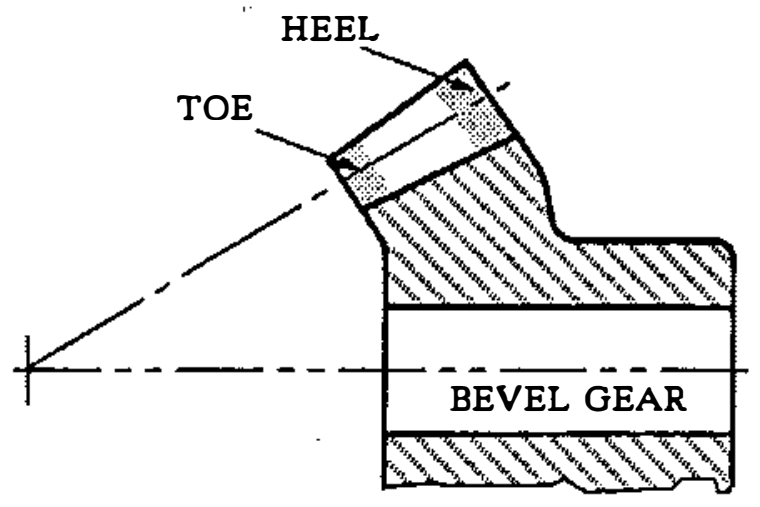

Fig 3-45 Heel and Toe

\subsection{Linear and Circular Dimensions.}

3.9.1 Center Distance (operating), $C$, is the shortest distance between non-intersecting axes. It is measured along the mutual perpendicular to the axes, called the line of centers. It applies to spur gears, parallel-axis or crossed-axis helical gears, and wormgearing (see Fig 3-46).

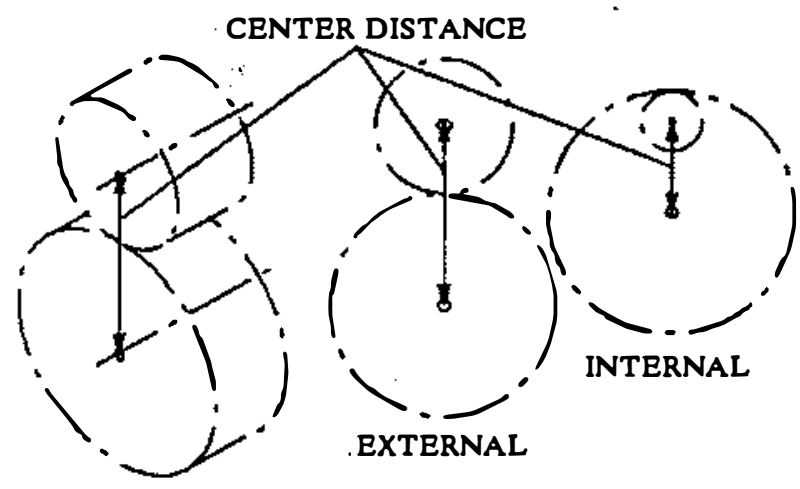

\section{Fig 3-46 Center Distance}

3.9.2 Off set, $E$, is the perpendicular distance between the axes of hypoid gears or offset face gears (see Figs 3-16, 3-17 and 3-47).

In Fig 3-47, for hypoid gears, (a) and (b) are referred to as having an offet below center, while those in (c) and (d) have an offset above center. In determining the direction of offset, it is customary to look at the gear with the pinion at the right. For below center of fset the pinion has a left hand spiral, and for above center offset the pinion has a right hand spiral.

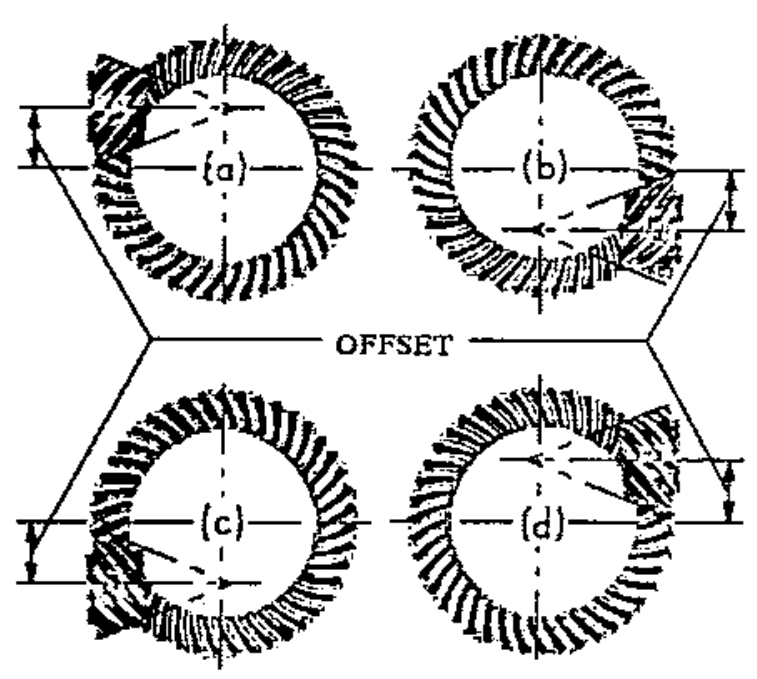

HYPOID GEARS

Fig 3-47 Offset

3.9.3 Pitch is the distance between a point on one tooth and the corresponding point on an adjacent tooth. It is a dimension measured along a line or curve in the transverse, normal, or axial directions. The use of the single word "pitch" without qualification may be confusing, and for this reason specific designations are preferred, e.g. transverse circular pitch, normal base pitch, axial pitch (see Fig 3-48).

3.9.4 Circular Pitch, $p$, is the arc distance along the pitch circle or pitch line between corresponding profiles of adjacent teeth (see Fig 3-48).
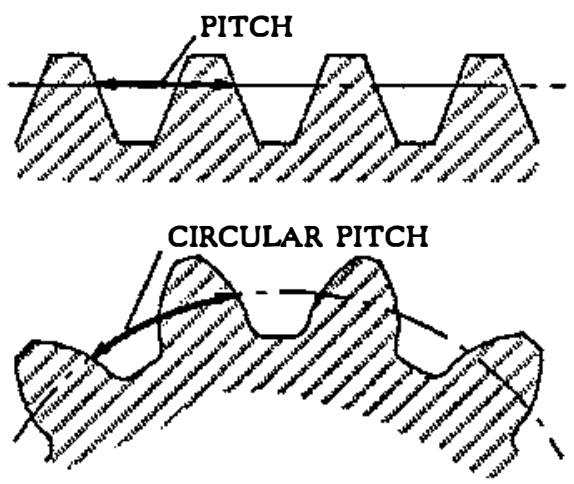

Fig 3-48 Pitch

3.9.5 Transverse Circular Pitch, $p_{t}$, is the circular pitch in the transverse plane (see Fig $3-49$ ).

3.9.6 Normal Circular Pitch, $p_{n}$, is the circular pitch in the normal plane, and also the length of the arc along the normal pitch helix between helical teeth or threads (see Fig 3-49). 


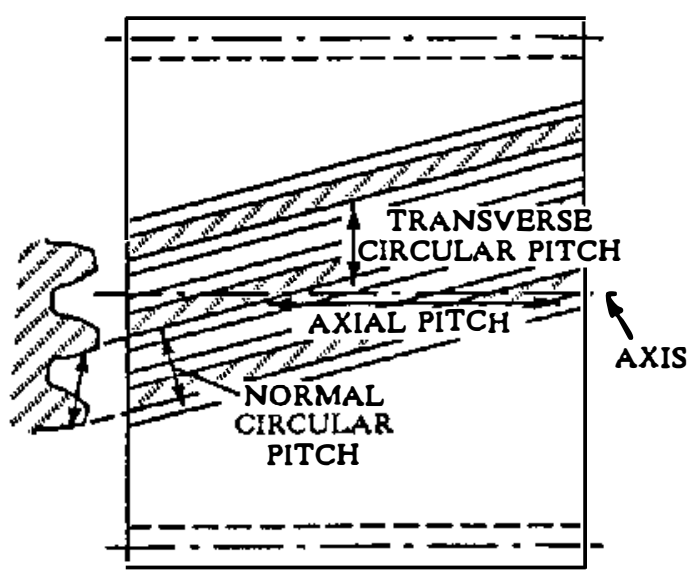

Fig 3-49 Tooth Pitch

3.9.7 Axial Pitch, $p_{x}$, is linear pitch in an axial plane and in a pitch surface. In helical gears and worms, axial pitch has the same value at all diameters. In gearing of other types, axial pitch may be confined to the pitch surface and may be a circular measurement (see Fig 3-49).

The term axial pitch is preferred to the term linear pitch. The axial pitch of a helical worm and the circular pitch of its wormgear are the same.

3.9.8 Base Pitch, $p_{b}$, in an involute gear is the pitch on the base circle or along the line of action. Corresponding sides of involute gear teeth are parallel curves, and the base pitch is the constant and fundamental distance between them along a common normal in a plane of rotation, transverse plane (see Figs 3-50 and 3-51).

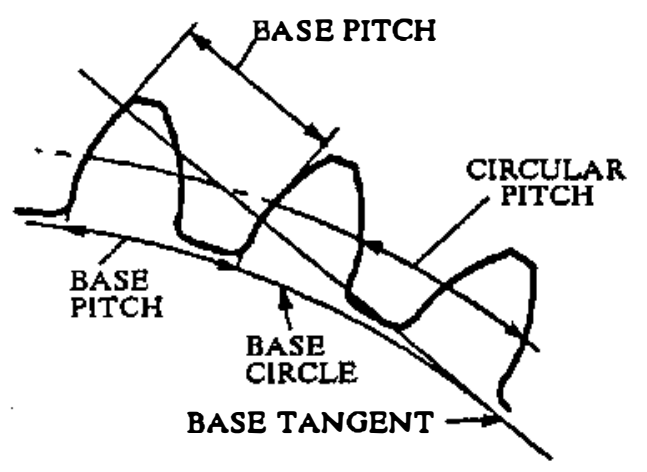

Fig 3-50 Principal Pitches

3.9.9 Normal Base Pitch, $p_{N}$, in an involute helical gear is the base pitch in the normal plane. It is the normal distance between parallel helical involute surfaces on the plane of action in the normal plane, or is the length of arc on the normal base helix. It is a constant distance in any helical involute gear (see Fig 3-51).

3.9.10 Axial Base Pitch, $p_{X}$, is the base pitch of helical involute tooth surfaces in an axial plane (see Fig 3-51).

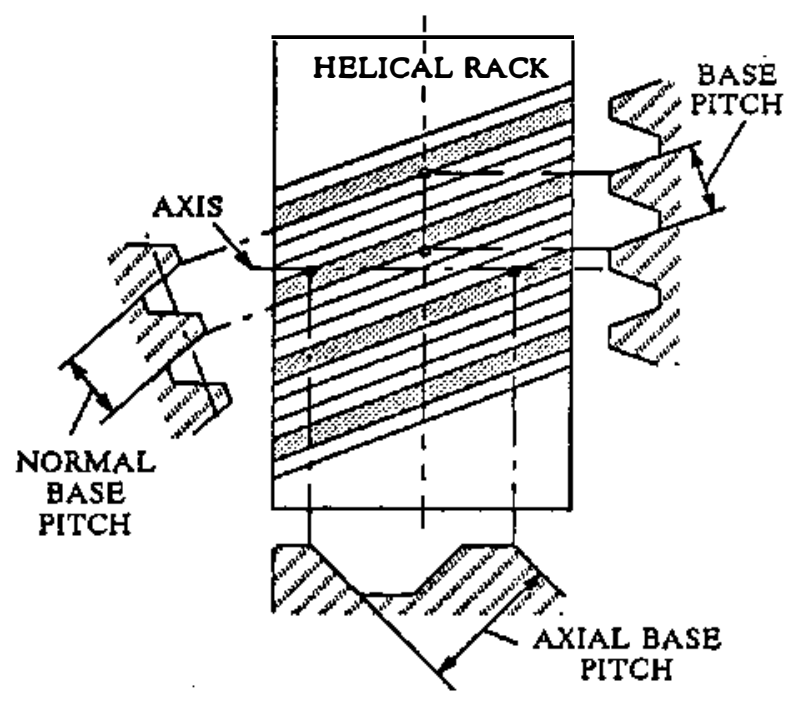

Fig 3-51 Base Pitch Relationships

3.9.11 Addendum, $a$, is the height by which a tooth projects beyond (outside for external, or inside for internal) the standard pitch circle or pitch line; also, the radial distance between the pitch circle and the addendum circle (see Fig 3-52).

3.9.12 Dedendum, $b$, is the depth of a tooth space below the standard (reference) pitch circle or pitch line; also, the radial distance between the pitch circle and the root circle (see Fig 3-52).

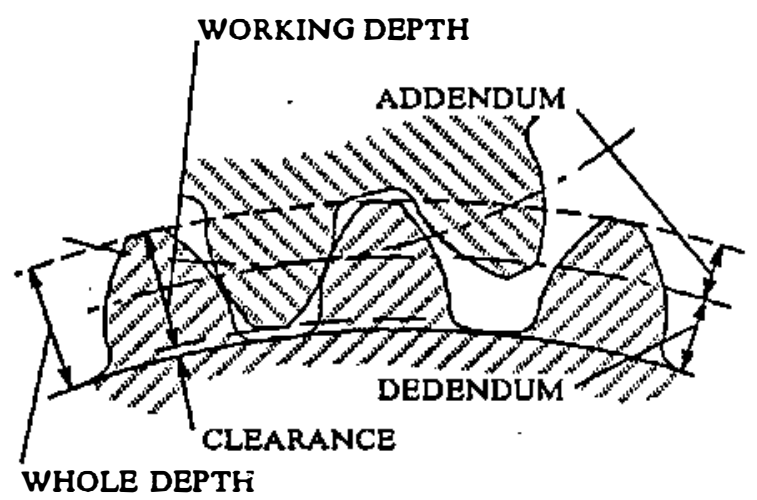

Fig 3-52 Principal Dimensions 
3.9.13 Clearance, $c_{1}$ is the distance between the root circle of a gear and the addendum circle of its mate (see Fig 3-52).

3.9.14 Working Depth, $h_{k}$, is the depth of engagement of two gears, that is, the sum of their operating addendums (see Fig 3-52).

3.9.15 Whole Depth, $h_{t}$, (Tooth Depth) is the total depth of a tooth space, equal to addendum plus dedendum, also equal to working depth plus clearance (see Fig 3-52).

3.9.16 Pitch Diameter is the diameter of a pitch circle (see Fig 3-53).

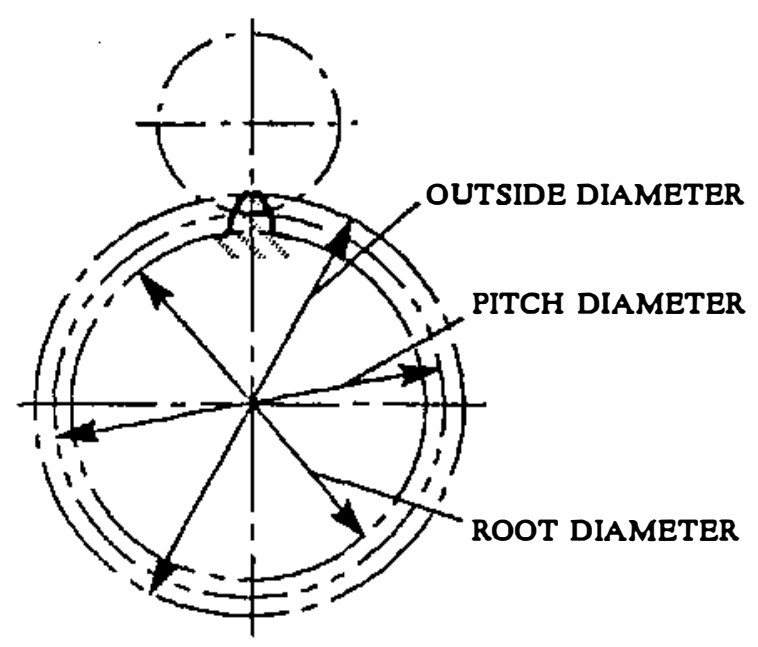

Fig 3-53 Diameters, External Gears

\subsubsection{Operating Pitch Diameters, $d_{P}$} and $d_{G}$, are the pitch diameters determined from the numbers of teeth and the center distance at which gears operate. Example for pinion:

$$
d_{P}=\frac{2 C}{m_{G}+1}=\frac{2 C}{\left(\frac{N_{C}}{N_{P}}\right)+1}
$$

\subsubsection{Standard (Reference) Pitch Circle.} The circle which intersects the involute at the point where the pressure angle is equal to the profile angle of the basic rack.

3.9.18 The Standard Pitch Diameter, $D$, is the diameter of the standard pitch circle. See also
3.9.1. In spur and helical gears, unless otherwise specified, the standard pitch diameter is related to the number of teeth and the standard transverse pitch. It is obtained as:

$$
\begin{gathered}
D=\frac{N}{P_{d}} \\
D=N m \\
D=\frac{N p}{\pi}
\end{gathered}
$$

3.9.18.1 A bevel gear pitch diameter is understood to be at the outer ends of the teeth unless otherwise specified.

3.9.18.2 Outside Diameter, $D_{0}$, is the diameter of the addendum (outside) circle (see Fig 3-53). In a bevel gear it is the diameter of the crown circle (see Fig 3-26). In a throated wormgear it is the maximum diameter of the blank (see Fig 3-55). The term applies to external gears (for internal gears, see 3.9.19).

3.9.18.3 Root Diameter, $D_{R}$ is the diameter of the root circle (see Figs $3-53$ and 3-54).

3.9.19 Internal Diameter, $D_{i}$, is the diameter of the addendum circle of an internal gear (see Fig 3-54).

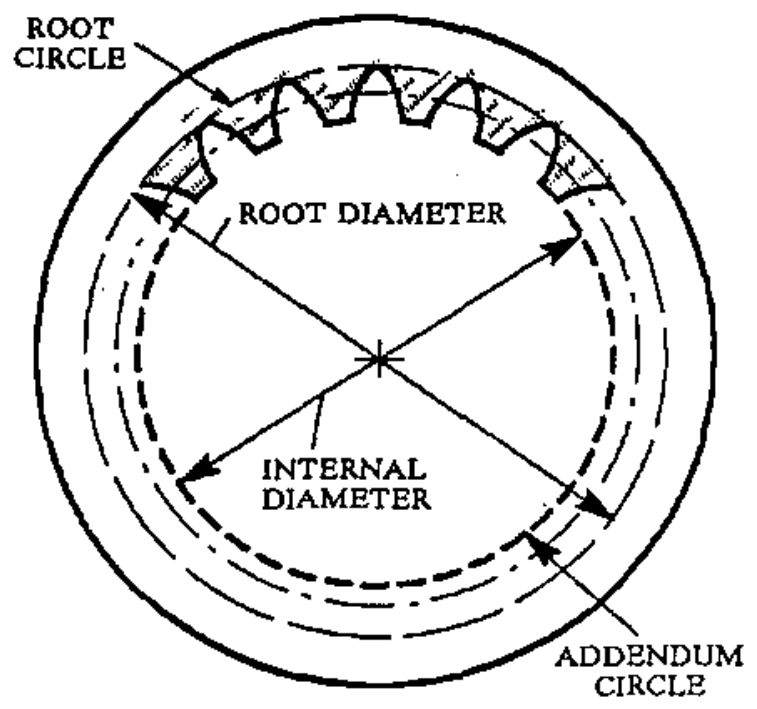

Fig 3-54 Diameters, Internal Gear 
3.9.20 Throat Diameter, $d_{t}$, is the diameter of the addendum circle at the central plane of a wormgear or of a double-enveloping wormgear (see Fig 3-55).

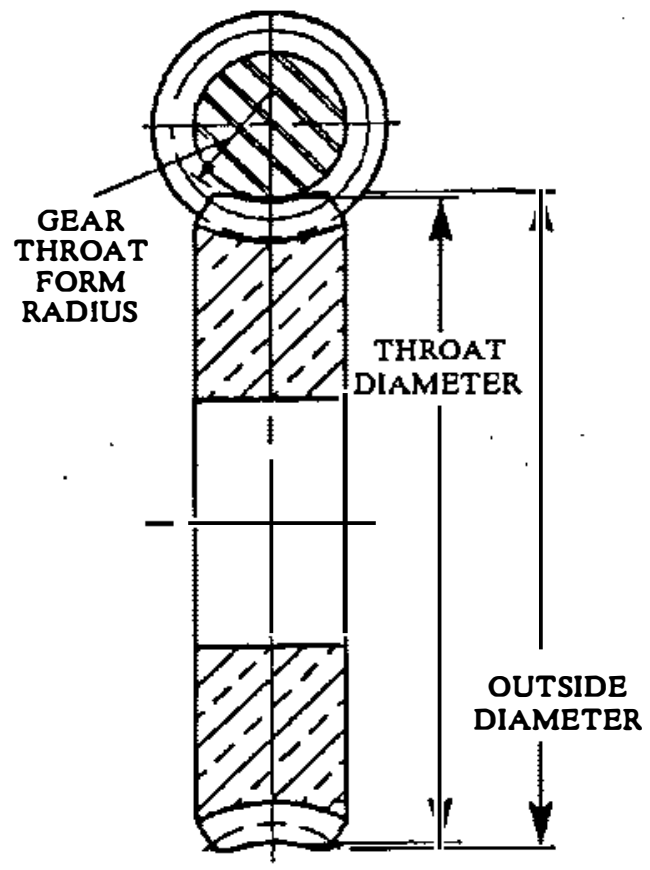

Fig 3-55 Wormgear Diameters

3.9.21 Throat-form Radius, $r_{t}$, is the radius of the throat surface of an enveloping wormgear or of a double-enveloping worm, in an axial plane (see Fig 3-55).

3.9.22 Base Diameter, $D_{b}$, is the diameter of the base circle of an involute gear (see Fig 3-56).

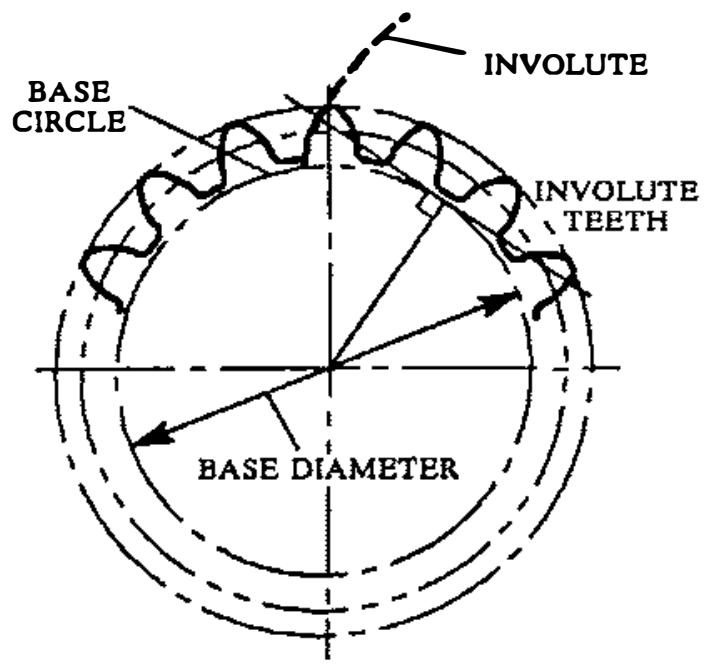

Fig 3-56 Base Diameter
3.9.23 Cone Gear Base Diameter, is the diameter of the base circle in a Cone ${ }^{\circledR}$ double-enveloping wormgear.

3.9.24 Circular Thickness, $t$, is the length of arc between the two sides of a gear tooth, on the specified datum circle (see Fig 3-57).

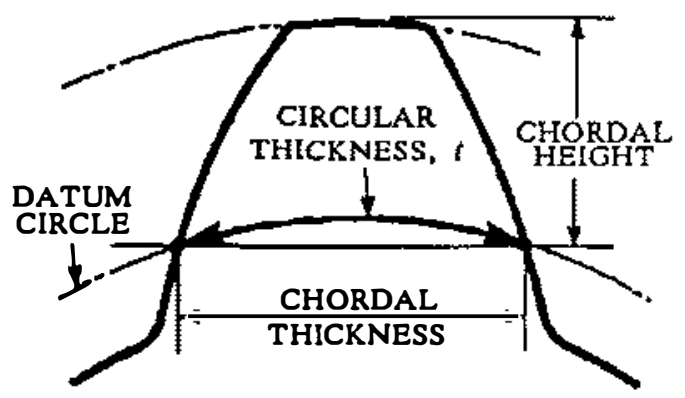

Fig 3-57 Tosth Thicliness

3.9.25 Transverse Circular Thickness, $t_{\ell}$, is the circular thickness in the transverse plane (see Figs 3-58 and 3-59).

3.9.26 Normal Circular Thickness, $t_{n}$, is the circular thickness in the normal plane. In a helical gear it may be considered as the length of arc along a normal helix (see Fig 3-58).

3.9.27 Axial Thickness, ${ }^{t}{ }_{x}$, in helical gears and worms is the tooth thickness in an axial cross section at the pitch line (see Fig 3-58).
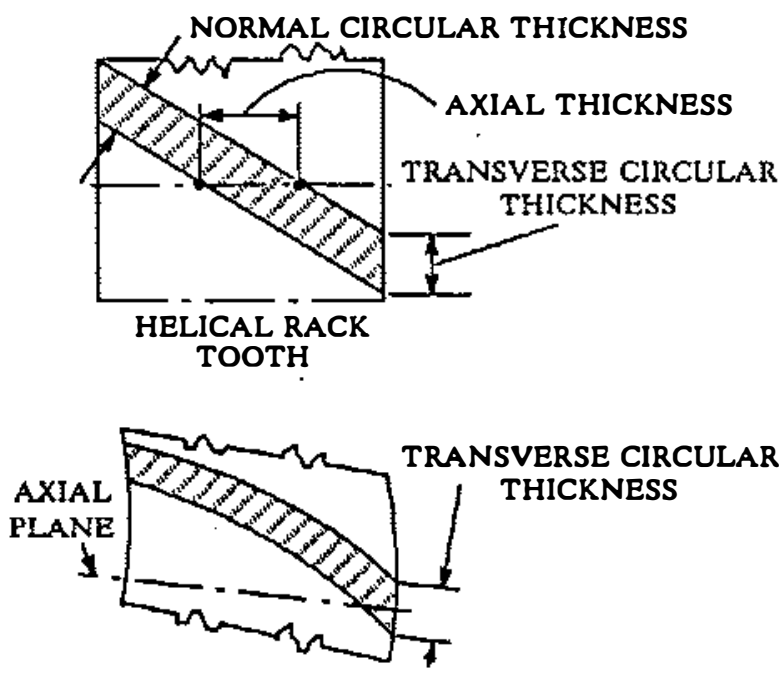

SPIRAL CROWN GEAR TOOTH

SECTIONS IN PITCH SURFACES

Fig 3-58 Thicleness Relationships 
3.9.28 Base Circular Thickness, $t_{b}$, in involute teeth is the length of arc on the base circle between the two involute curves forming the profile of a tooth (see Fig 3-59).

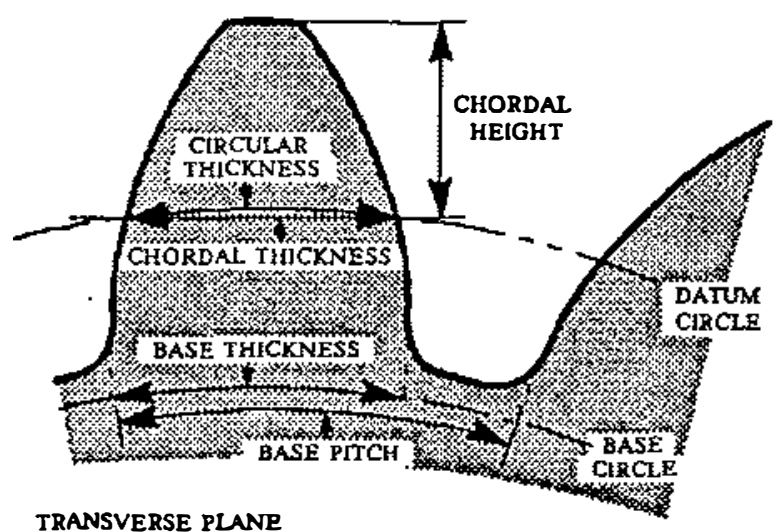

Fig 3-59 Chordal Thickness

3.9.29 Chordal Thickness, $t_{c}$, is the length of chord subtending a circular-thickness arc. Any convenient measuring diameter may be selected, not necessarily the pitch diameter (see Fig 3-59).

3.9.30 Normal Chordal Thickness, $t_{n c}$, is the chordal thickness in the plane normal to the pitch helix or the tooth trace at the center of the tooth. Any convenient measuring diameter may be selected, not necessarily the pitch diameter (see Fig 3-57).

\subsubsection{Chordal Addendum (Chordal} Height), $a_{c}$, is the height from the top of the tooth to the chord subtending the circular-thickness arc. Any convenient measuring diameter may be selected, not necessarily the pitch diameter (see Fig 3-59).

3.9.32 Normal Chordal Addendum, $a_{n c}$, is the chordal addendum in the plane normal to the pitch helix at the center of the tooth. Any convenient measuring diameter may be selected, not necessarily the pitch diameter.

3.9.33 Backlash, $B$, is the amount by which the width of a tooth space exceeds the thickness of the engaging tooth on the operating pitch circles (see Fig 3-60).

As actually indicated by measuring devices, backlash may be determined variously in the transverse, normal, or axial planes, and either in the direction of the pitch circles, or on the line of action. Such measurements may be converted to corresponding values on transverse pitch circles for general comparisons.

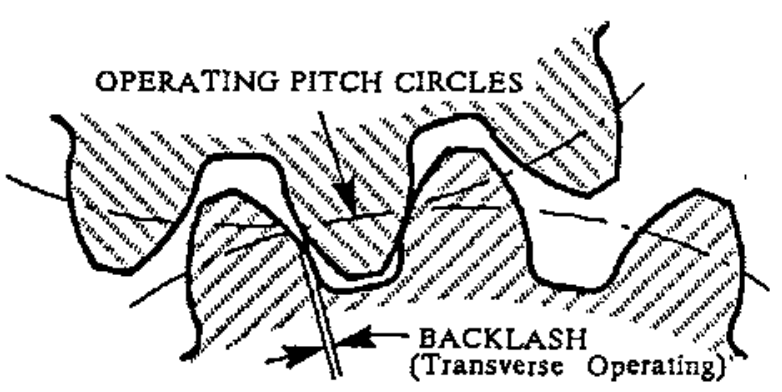

Fig 3-60 Backlash

3.9.34 Face Width, $F$, is the length of teeth in an axial plane (see Fig 3-61).

3.9.35 Effective Face Width, $F_{e}$, is the portion that may actually come into contact with mating teeth, as occasionally one member of a pair of gears may have a greater face width than the other (see Fig 3-61).

3.9.36 Total Face Width, $F_{t}$, is the actual dimension of a gear blank including the portion that exceeds the effective face width, or as in double-helical gears where the total face width includes any distance or gap separating right-hand and left-hand helices (see Fig 3-61).

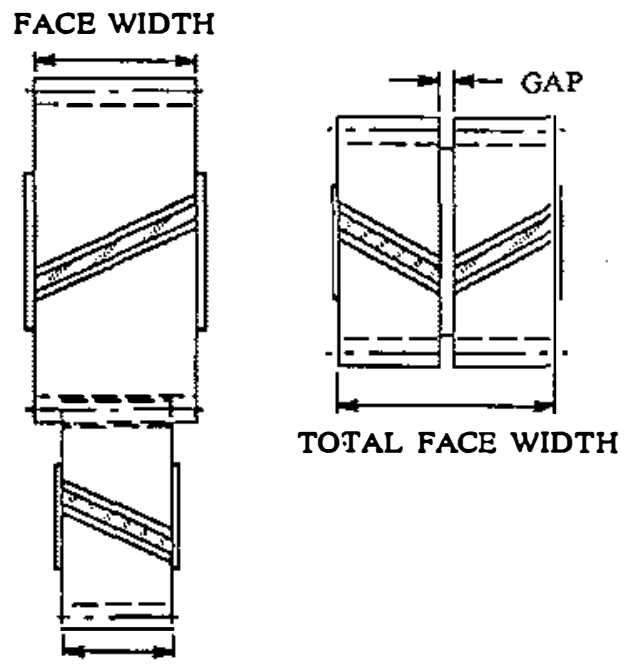

EFFECTIVE FACE WIDTH

\section{Fig 3-61 Face Width}

3.9.37 Cone Distance, $A$, in a bevel gear is the general term for the distance along an element of the pitch cone from the apex to any given position in the teeth (see Fig 3-62). 
3.9.38 Outer Cone Distance, $A_{o}$, in bevel gears is the distance from the apex of the pitch cone to the outer ends of the teeth. When not otherwise specified, the short term cone distance is assumed to be outer cone distance. It is customary to give the diametral pitch, tooth thickness, addendum, and dedendum in bevel gears at the outer cone distance (see Fig 3-62).

3.9.39 Mean Cone Distance, $A_{m}$, in bevel gears is the distance from the apex of the pitch cone to the middle of the face width (see Fig $3-62)$.

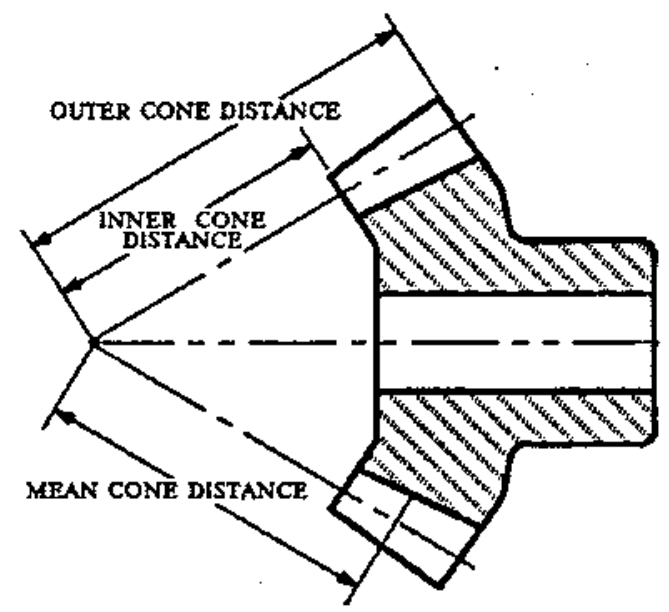

Fig 3-62 Cone Distance

3.9.40 Inner Cone Distance, $A_{i}$, in bevel gears is the distance from the apex of the pitch cone to the inner ends of the teeth, where dimensions for allowable widths of tools and cutters are determined (see Fig 3-62).

3.9.41 Length of Action, 2 , is the distance on an involute line of action through which the point of contact moves during the action of the tooth profile (see Fig 3-63).

3.9.42 Face Advance, $Q_{F}$, is the distance on a pitch circle through which a helical or spiral tooth moves from the position at which contact begins at one end of the tooth trace on the pitch surface to the position where contact ceases at the other end (see Fig 3-64).

3.9.43 Lead, $L$, is the axial advance of a helix for one complete turn, as in the threads of cylindrical worms and the teeth of helical gears (see Fig 3-65).

$L=p \times N$

(Eq 3.4)

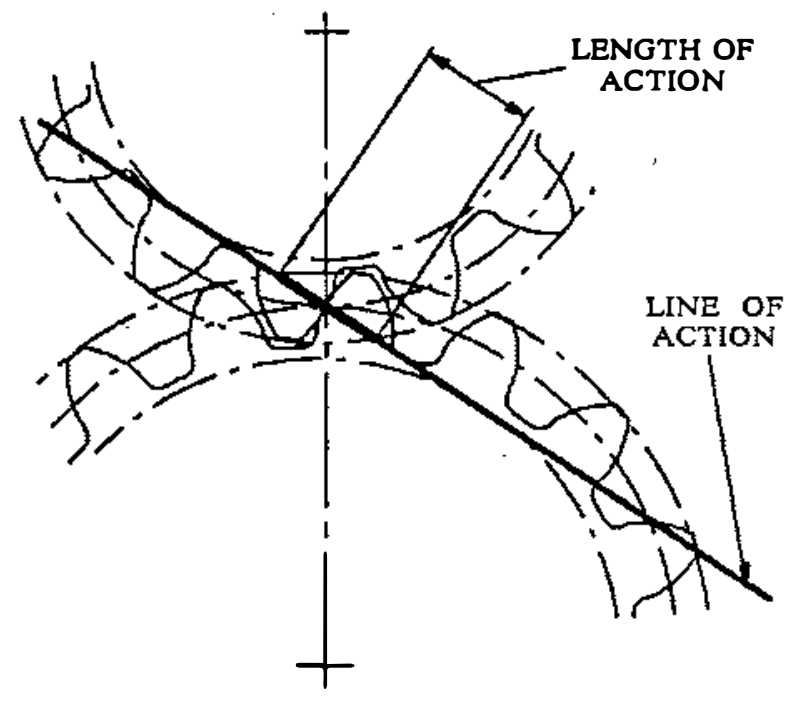

Fig 3-63 Length of Action

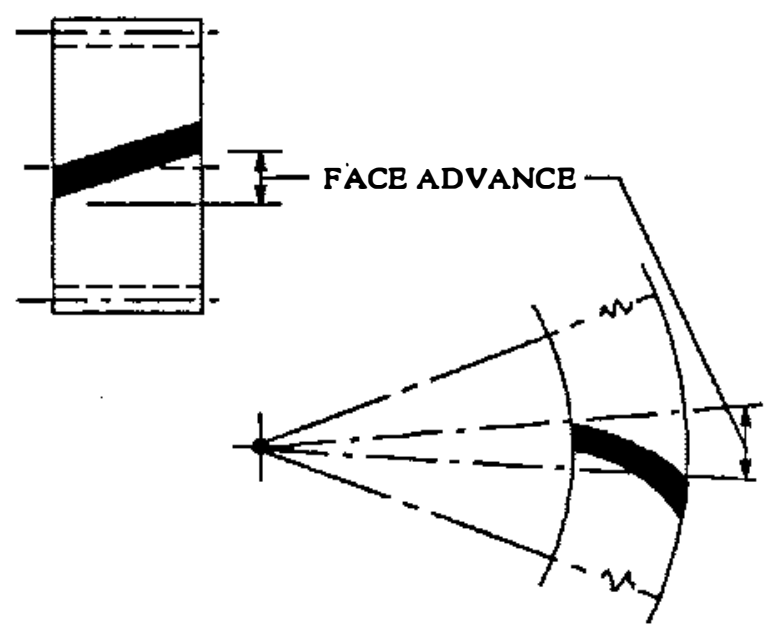

Fig 3-64 Face Advance

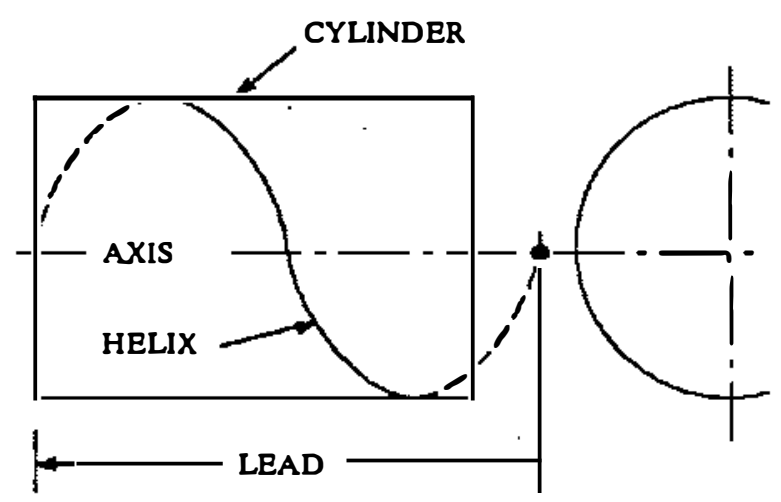

Fig 3-65 Lead 


\subsection{Angular Dimensions.}

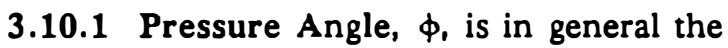
angle at a pitch point between the line of pressure which is nornal to the tooth surface, and the plane tangent to the pitch surface. The pressure angle gives the direction of the normal to the tooth profile (see Fig 3-66). The pressure angle is equal to the profile angle at the standard pitch circle and can be termed the "standard" pressure angle at that point.

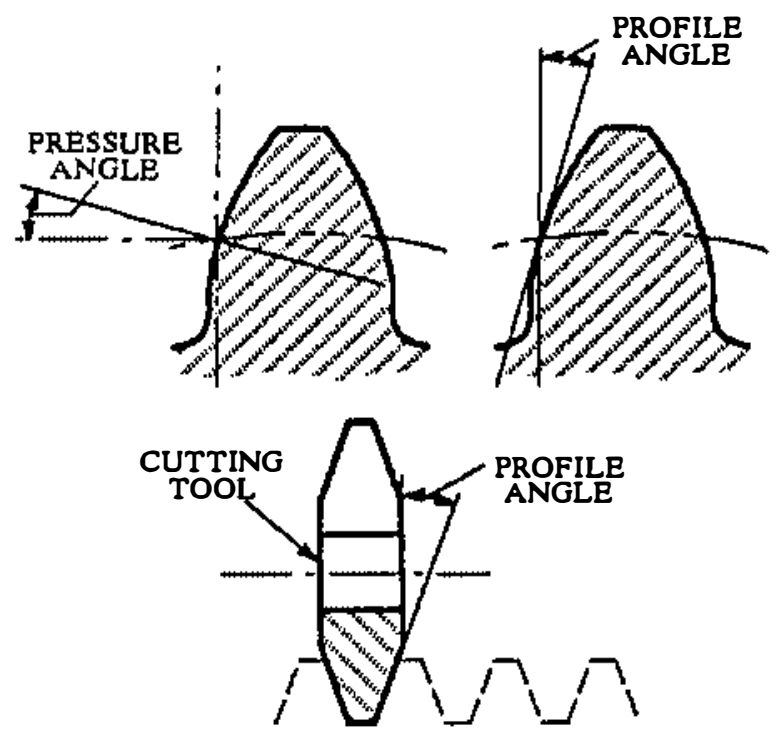

\section{Fig 3-66 Pressure and Profile Angles}

\subsubsection{The Operating Pressure Angle} is determined by the base circles of two gears and the center distance at which the gears operate. Various other pressure angles may be considered in gear calculations.

3.10.2 Profile Angle is in general the angle at a specified pitch point between a line tangent to a tooth surface and the line normal to the pitch surface (which is a radial line of a pitch circle). This definition is applicable to every type of gear for which a pitch surface can be defined. The profile angle gives the direction of the tangent to a tooth profile (see Fig 3-66).

In spur gears and straight bevel gears, tooth profiles are considered only in a transverse plane, and the general terms profile angle and pressure angle are customarily used rather than transverse profile angle and transverse pressure angle. In helical teeth, the profiles may be considered in different planes, and in specifications it is essential to use terms that indicate the direction of the plane in which the profile angle or the pressure angle lies, such as transverse profile angle, normal pressure angle, axial profile angle.

3.10.3 Standard Profile Angles are established in connection with standard proportions of gear teeth and standard gear-cutting tools. Involute gears operate together correctly after a change of center distance, and gears designed for a changed center distance can be generated correctly by standard tools. A change of center distance is accomplished by changes in operating values for pitch diameter, circular pitch, diametral pitch, pressure angle, and tooth thicknesses or backlash. The same involute gear may be used under conditions that change its operating pitch diameter and pressure angle. Unless there is a good reason for doing otherwise, it is practical to consider that the pitch and the profile angle of a single gear correspond to the pitch and the profile angle of the hob or cutter used to generate its teeth.

In tools and gages for cutting, grinding, and gaging gear teeth, the profile angle is the angle between a cutting edge or a cutting surface, and some principal direction such as that of a shank, an axis, or a plane of rotation (see Fig 3-67).

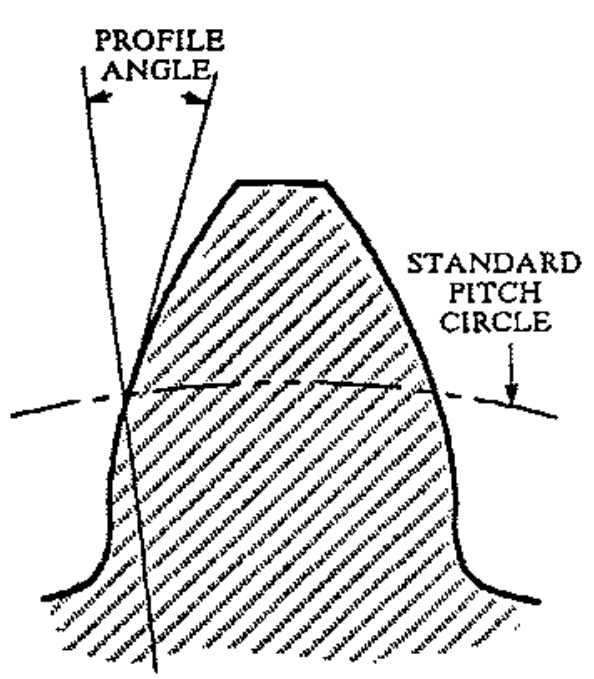

Fig 3-67 Standard Profile Angle 
3.10.4 Transverse Pressure Angle and Transverse Profile Angle, $\phi_{t}$, are the pressure angle and the profile angle in a transverse plane (see Fig 3-68).

3.10.5 Normal Pressure Angle and Normal Profile Angle, $\phi_{n}$, are the pressure and profile angle in a normal plane of a helical or a spiral tooth. In a spiral bevel gear, unless otherwise specified, profile angle means normal profile angle at the mean cone distance (see Fig 3-68).

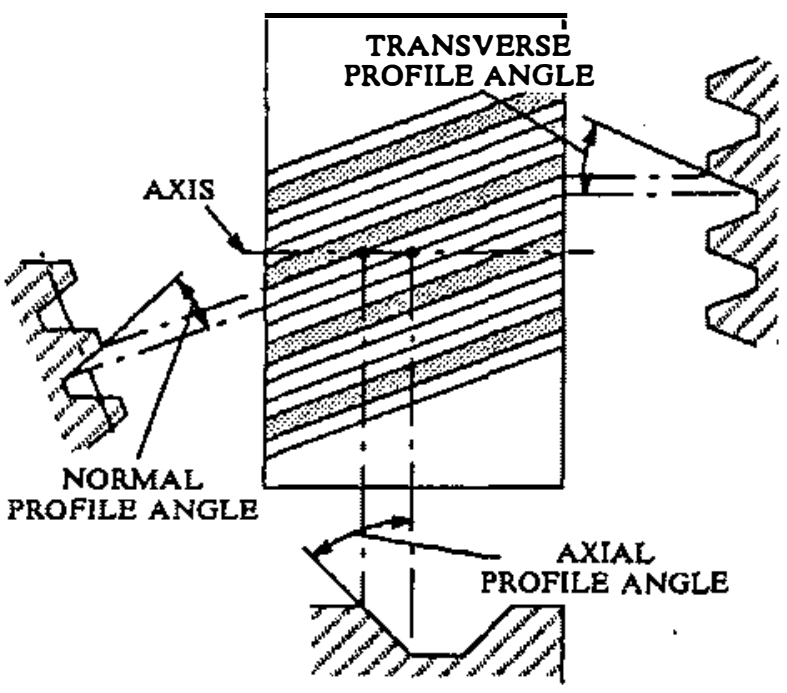

Fig 3-68 Profile Angles

\subsubsection{Axial Pressure Angle and Axial} Profile Angle, $\phi_{x}$, are the pressure angle and the profile angle in an axial plane of a helical gear or a worm, or of a spiral bevel gear (see Fig 3-68).

3.10.7 Helix Angle, $\psi$, is the angle between any helix and an element of its cylinder. In helical gears and worms, it is at the standard pitch circle unless otherwise specified (see 3.9.8 and Fig 3-69).

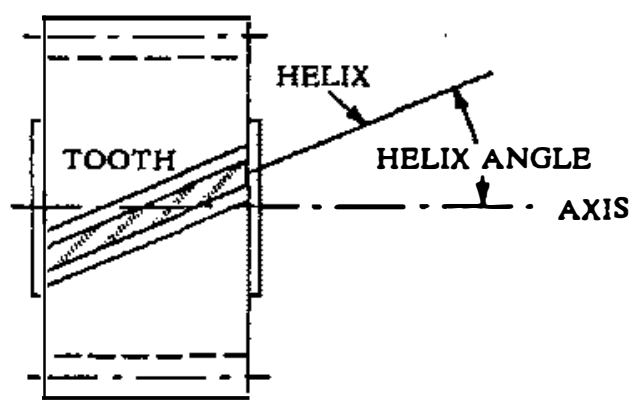

Fig 3-69 Helix Angle
3.10.8 Pitch Helix Angle, $\psi_{p}$, is the helix angle on the standard pitch cylinder (see Fig 3-70).

3.10.9 Outside Helix Angle, $\psi_{0}$, is the helix angle on the outside cylinder (see Fig 3-70).

3.10.10 Base Helix Angle, $\psi_{b}$, is the helix angle on the base cylinder of involute helical teeth or threads (see Fig 3-70).

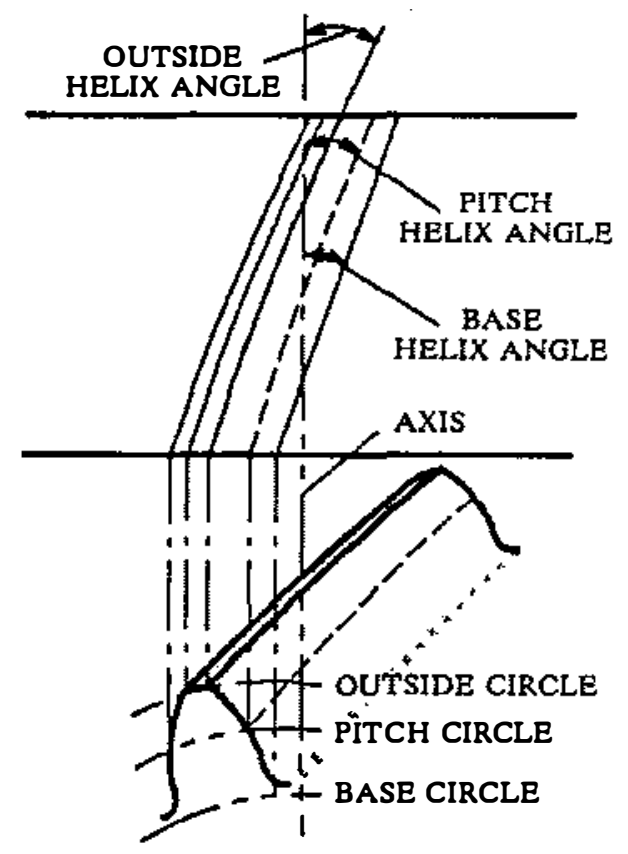

Fig 3-70 Helix Angle Relationships

3.10.11 Lead Angle, $\lambda$, is the angle between any helix and a plane of rotation. It is the complement of the helix angle, and is used for convenience in worms and hobs. It is understood to be at the standard pitch diameter unless otherwise specified (see Fig 3-71).

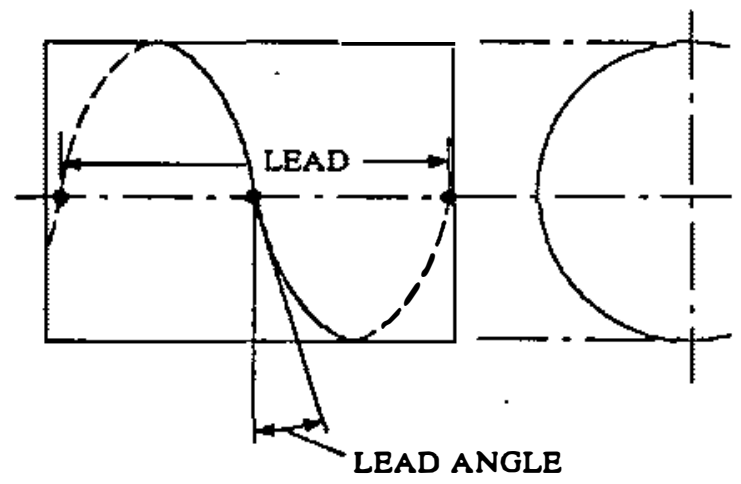

Fig 3-71 Lead Angle 
3.10.12 Pitch Lead Angle, $\lambda_{p}$, is the lead angle on the pitch cylinder (see Fig 3-72).

3.10.13 Outside Lead Angle, $\lambda_{o}$, is the lead angle on the outside cylinder (see Fig 3-72).

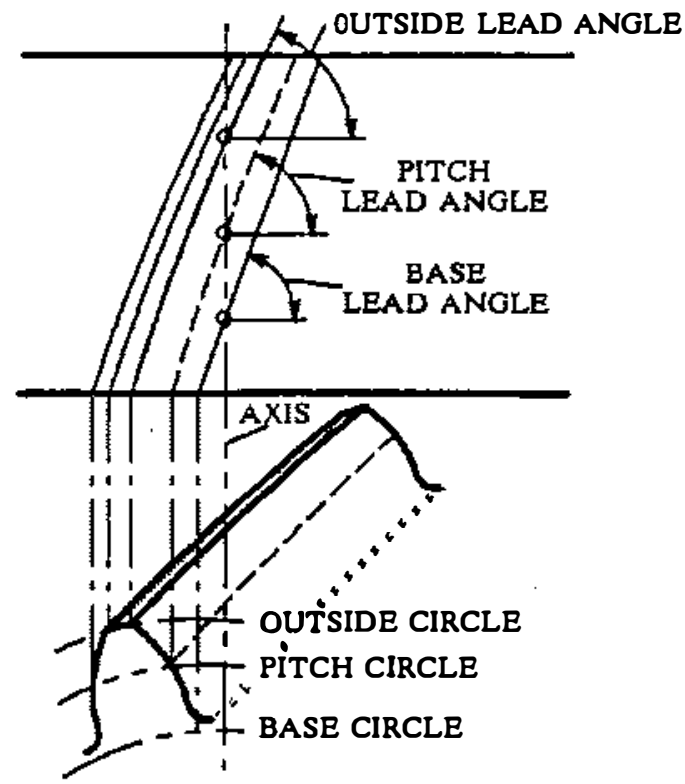

Fig 3-72 Lead Angle Relationships

3.10.14 Base Lead Angle, $\lambda_{b}$, is the lead angle on the base cylinder (see Fig 3-72).

3.10.15 Spiral Angle, $\psi_{1}$ in a spiral bevel gear is the angle between the tooth trace and an element of the pitch cone, and corresponds to the helix angle in helical teeth. Unless otherwise specified, the spiral angle is understood to be at the mean cone distance (see Fig 3-62 and Fig 3-73).

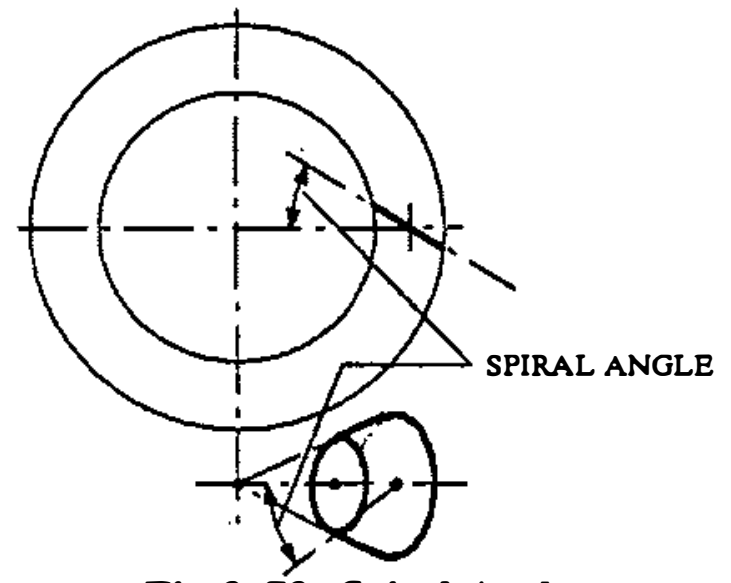

Fig 3-73 Spiral Angle

3.10.16 Mean Spiral Angle, $\Psi_{m}$, is the specific designation for the spiral angle at the mean cone distance in a bevel gear (see Fig 3-74).
3.10.17 Outer Spiral Angle, $\psi_{0}$, is the spiral angle of a bevel gear at the outer cone distance, where the tooth thickness is customarily measured (see Fig 3-74).

3.10.18 Inner Spiral Angle, $\psi_{i}$, is the spiral angle of a bevel gear at the inner cone distance, where the allowable point width of cutting tools usually must be determined (see Fig 3-74).

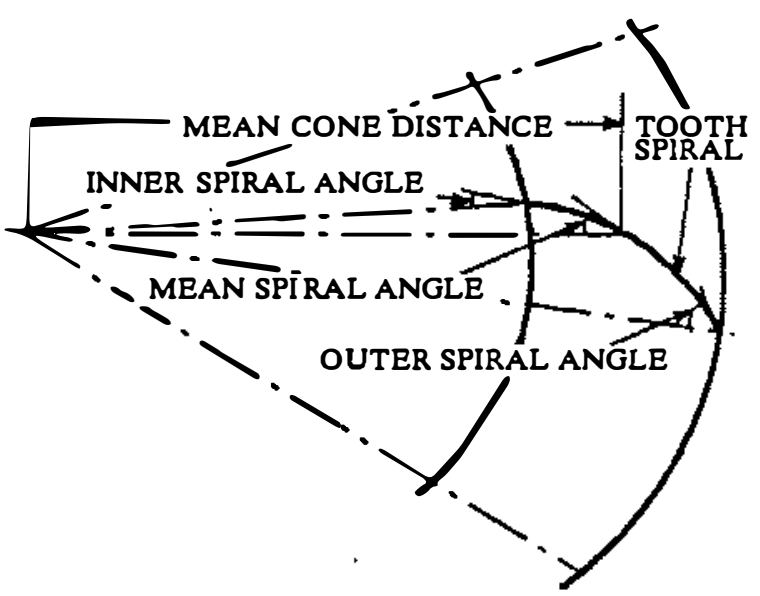

\section{Fig 3-74 Spiral Angle Relationships}

3.10.19 Shaft Angle, $\Sigma$, is the angle between the axes of two non-parallel gear shafts. In a pair of crossed helical gears, the shaft angle lies between the oppositely rotating portions of two shafts. This applies also in the case of wormgearing. In bevel gears, the shaft angle is the sum of the two pitch angles. In hypoid gears, the shaft angle is given when starting a design, and it does not have a fixed relation to the pitch angles and spiral angles (see Fig 3-75).

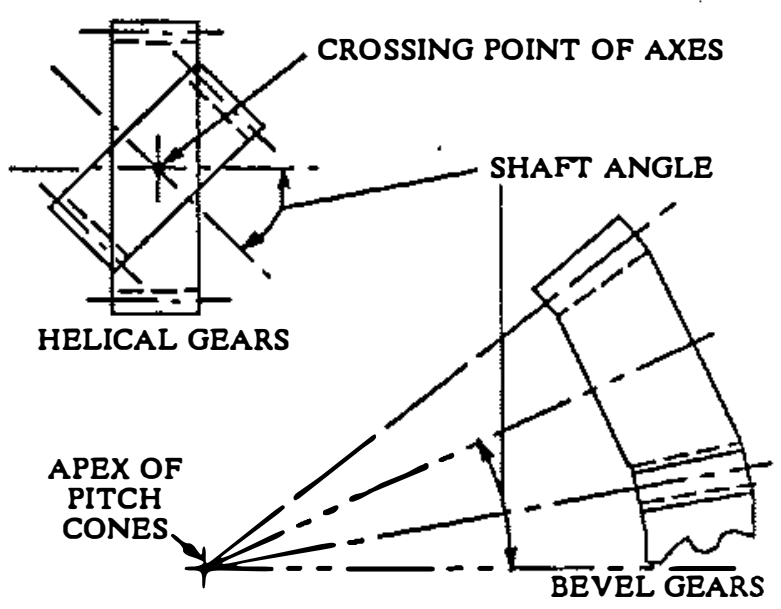

Fig 3-75 Shaft Angle 
3.10.20 Pitch Angle, $\Gamma$, in bevel gears, is the angle between an element of a pitch cone and its axis. In external and internal bevel gears, the pitch angles are respectively less than and greater than 90 degrees (see Figs 3-76 and 3-77).

3.10.21 Face (Tip) Angle, $\Gamma_{o}$, in a bevel or hypoid gear, is the angle between an element of the face cone and its axis (see Fig 3-76).

3.10.22 Root Angle, $\Gamma_{R}$, in a bevel or hypoid gear, is the angle between an element of the root cone and its axis (see Fig 3-76).

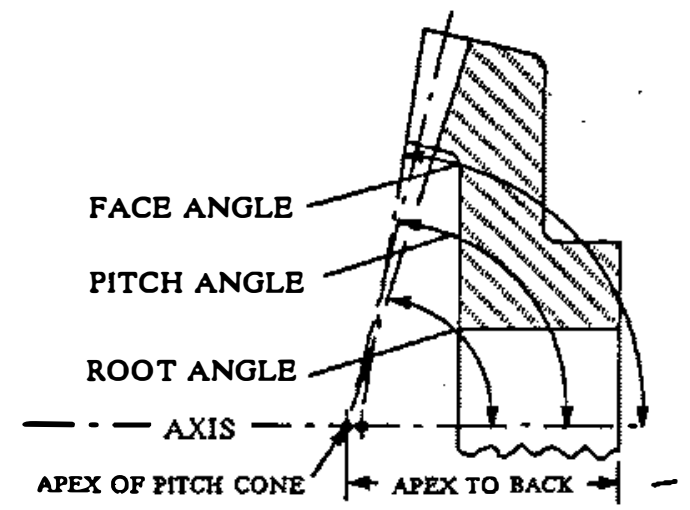

Fig 3-76 Angle Relationships

3.10.23 Addendum Angle, $\alpha$, in a bevel gear, is the angle between elements of the face cone and pitch cone (see Fig 3-77).

3.10.24 Dedendum Angle, $\delta$, in a bevel gear, is the angle between elements of the root cone and pitch cone (see Fig 3-77).

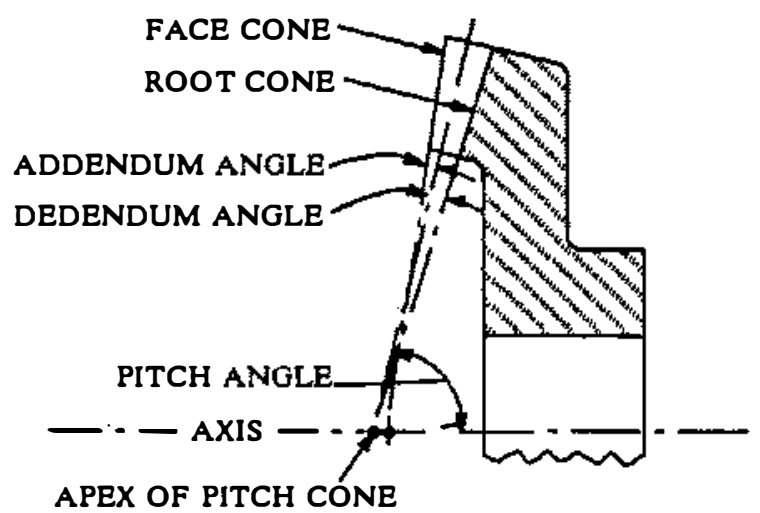

Fig 3-77 Angles

3.10.25 Involute Polar Angle, $\theta$, is the angle between a radius vector to a point, $P$, on an involute curve and a radial line to the intersection,
$A$, of the curve with the base circle (see Fig 3-78).

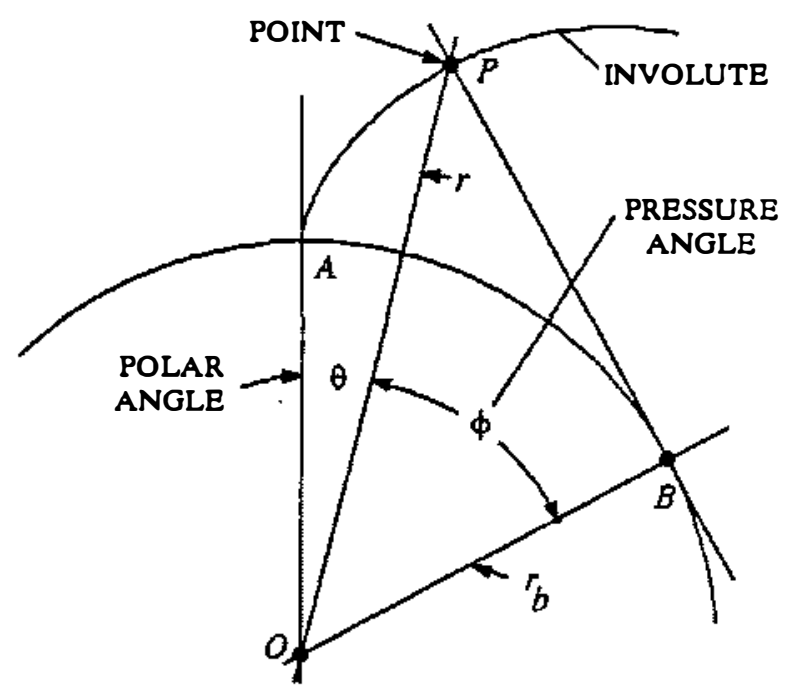

Fig 3-78 Involute Polar Angle

3.10.26 Involute Roll Angle, $\epsilon$, is the angle whose arc on the base circle of radius unity equals the tangent of the pressure angle at a selected point on the involute (see Fig 3-79).

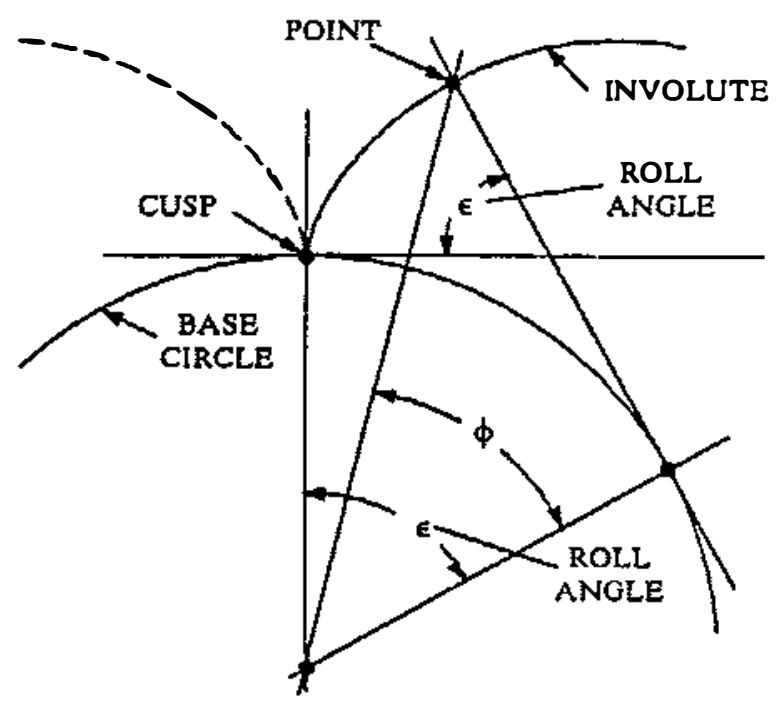

Fig 3-79 Involute Roll Angle

\subsection{Numbers and Ratios.}

3.11.1 Number of Teeth or Threads, $N$, is the number of teeth contained in the whole circumference of the pitch circle.

3.11.2 Gear Ratio, $m_{G}$, is the ratio of the larger to the smaller number of teeth in a pair of gears. 
$m_{G}=\frac{N_{G}}{N_{P}}$

3.11.3 Diametral Pitch (Transverse), $P_{d}$. is the ratio of the number of teeth to the standard pitch diameter in inches.

$$
\begin{aligned}
P_{d} & =\frac{N}{D} \\
P_{d} & =\frac{25.4}{m} \\
P_{d} & =\frac{\pi}{P}
\end{aligned}
$$

3.11.4 Normal Diametral Pitch, $P_{n d}$, is the value of diametral pitch in a normal plane of a helical gear or worm.

$$
P_{n d}=\frac{P_{d}}{\cos \psi}
$$

3.11.5 Angular Pitch, ${ }^{\theta} N$, is the angle subtended by the circular pitch, usually expressed in radians.

$\theta_{N}=\frac{360}{N}$ degree or $\frac{2 \pi}{N}$ radian

3.11.6 Module (Transverse), $m$, is the ratio of the pitch diameter in millimeters to the number of teeth.

$$
\begin{aligned}
m & =\frac{D}{N} \\
m & =\frac{25.4}{\therefore P_{d}}
\end{aligned}
$$

3.11.7 Normal Module, $m_{n}$, is the value of the module in a normal plane of a helical gear or worm.

$m_{n}=m \cos \psi$.

\subsection{Miscellaneous Terms and Dimensions.}

3.12.1 Full-Depth Teeth are those in which the working depth equals 2.000 divided by the normal diametral pitch.

3.12.2 Stub Teeth are those in which the working depth is less than 2.000 divided by the normal diametral pitch.

3.12.3 Equal-Addendum Teeth are those in which two engaging gears have equal addendums (see Fig 3-80).
3.12.4 Long- and Short-Addendum Teeth are those in which the addendums of two engaging gears are unequal (see Fig 3-80). For additional information, see Appendix B, under Addendum Modification.

3.12.5 Bottom Land is the surface at the bottom of a tooth space adjoining the fillet (see Fig 3-81).

3.12.6 Top Land is the surface of the top of a tooth (see Fig 3-81).

3.12.7 Tip Radius, $r_{T}$, is the radius of the circular arc used to join a side-cutting edge and an end-cutting edge in gear-cutting tools. Edge Radius is an alternate term (see Fig 3-82).
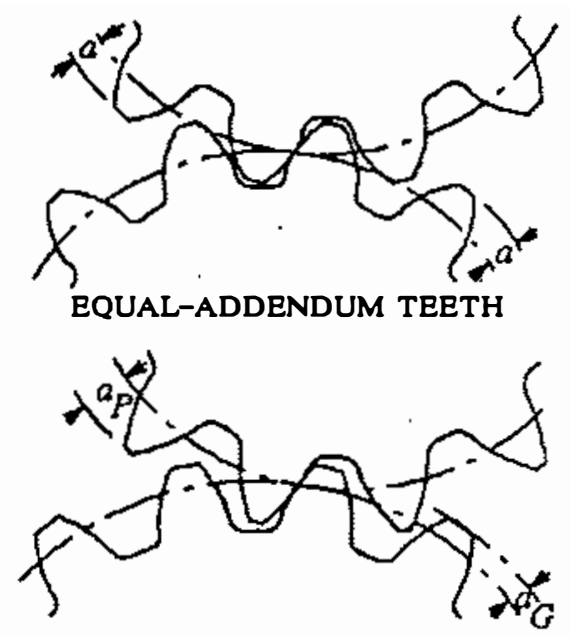

LONG- AND SHORT-ADDENDUM TEETH

Fig 3-80 Long and Short Addendum

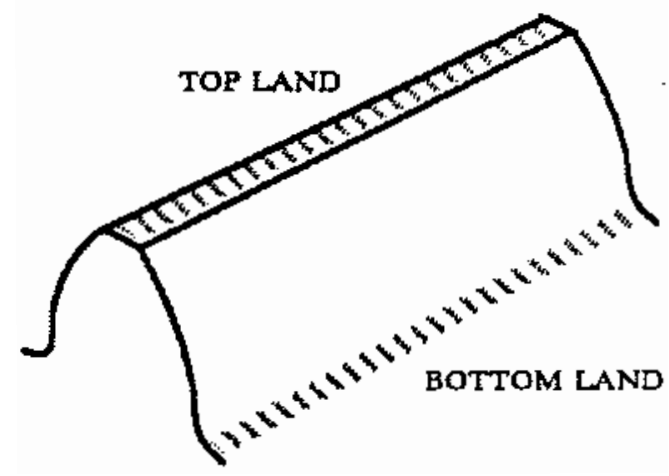

Fig 3-81 Tooth Lands

3.12.8 Fillet Radius, $r_{f}$, is the radius of a circular arc approximating the root fillet curve. In generated teeth, the fillet curve has a varying radius of curvature, $\rho_{f}$ (see Fig 3-83). 


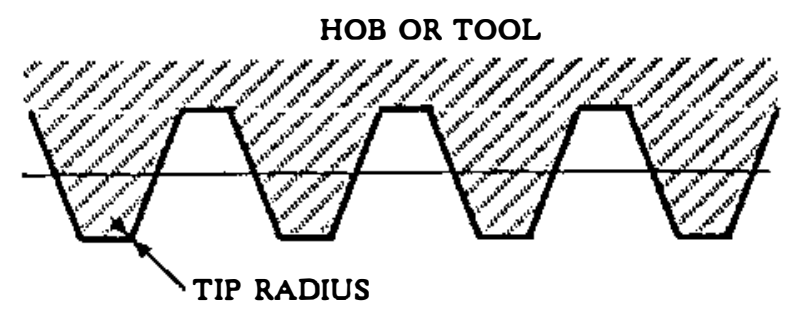

Fig 3-82 Tip Radius

3.12.9 Profile Radius of Curvature, $\rho$, is the radius of curvature of a tooth profile, usually at the pitch point or a point of contact (see Fig 3-83).

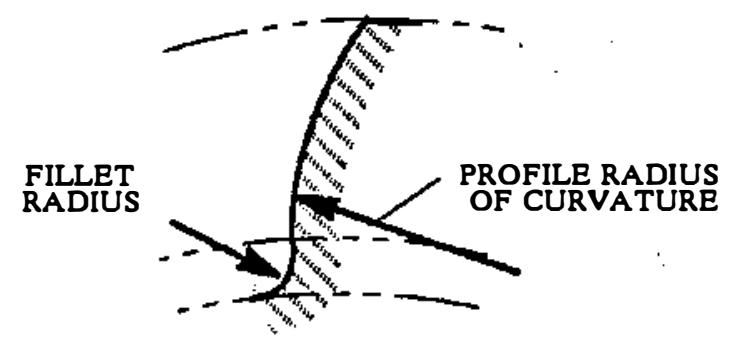

Fig 3-83 Fillet Radius

3.12.10 Undercut is a condition in generated gear teeth when any part of the fillet curve lies inside of a line drawn tangent to the working profile at its point of juncture with the fillet (see Fig 3-84). Undercut may be deliberately introduced to facilitate finishing operations. With undercut the fillet curve intersects the working profile. Without undercut the fillet curve and the working profile have a common tangent.

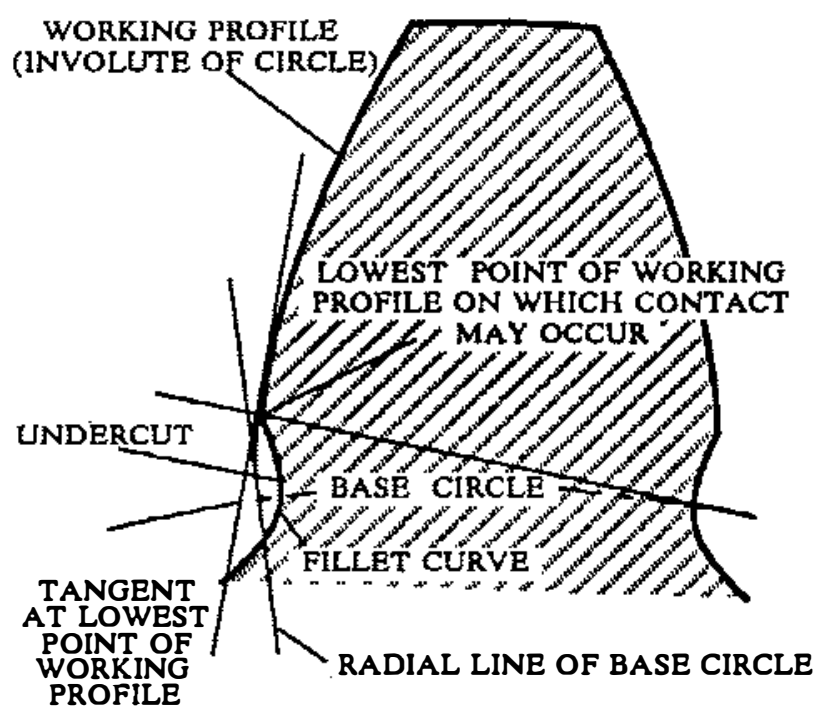

Fig 3-84 Undercut
3.12.11 Equivalent Pitch Radius is the radius of the pitch circle in a cross section of gear teeth in any plane other than a plane of rotation. It is properly the radius of curvature of the pitch surface in the given cross section. Examples of such sections are the transverse section of bevel gear teeth and the normal section of helical teeth (see Fig 3-85).

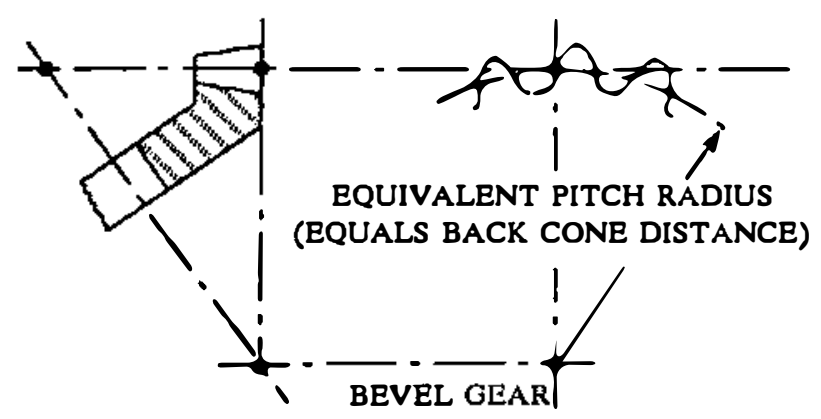

Fig 3-85 Back Cone Equivalent

3.12.12 Equivalent Number of Teeth, $N_{e}$, is the number of teeth contained in the whole circumference of a pitch circle corresponding to an equivalent pitch radius.

3.12.13 Arc of Action, $Q_{t}$, is the arc of the pitch circle through which a tooth profile moves from the beginning to the end of contact with a mating profile (see Fig 3-86).
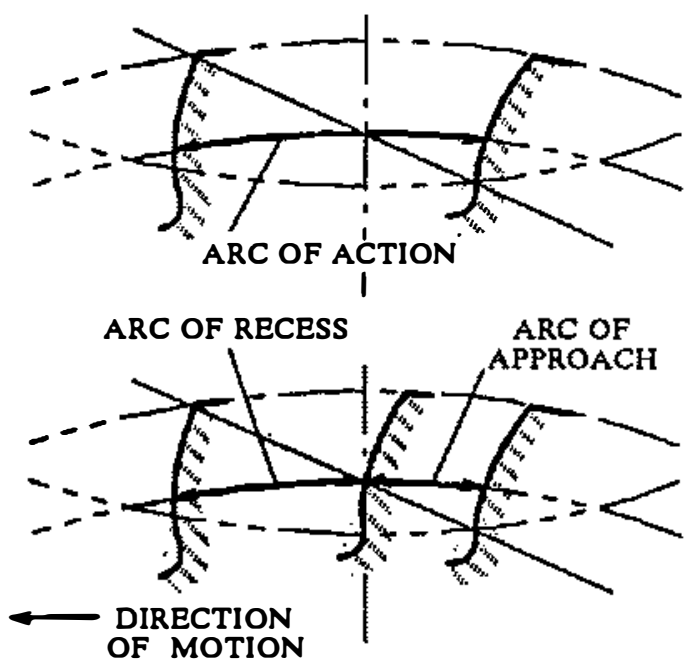

Fig 3-86 Arc of Action

3.12.14 Arc of Approach, $Q_{a}$, is the arc of the pitch circle through which a tooth profile moves from its beginning of contact until the point 
of contact arrives at the pitch point (see Fig $3-86)$.

3.12.15 Arc of Recess, $Q_{r}$, is the arc of the pitch circle through which a tooth profile moves from contact at the pitch point until contact ends (see Fig 3-86).

3.12.16 Contact Ratio, $m_{c}$, in general is the number of angular pitches through which a tooth surface rotates from the beginning to the end of contact.

3.12.17 Transverse Contact Ratio, $m_{p}$, is the contact ratio in a transverse plane. It is the ratio of the angle of action to the angular pitch. For involute gears it is most directly obtained as the ratio of the length of action to the base pitch.

3.12.18 Face Contact Ratio, $m_{F}$, is the contact ratio in an axial plane, or the ratio of the face width to the axial pitch. For bevel and hypoid gears it is the ratio of face advance to circular pitch.

3.12.19 Total Contact Ratio, $m_{t}$, is the sum of the transverse contact ratio and the face contact ratio. It is calculated by the following formula:

$m_{t}=m_{p}+m_{F}$

3.12.20 Modified Contact Ratio, $m_{0}$, is the contact ratio of modified tooth surfaces. It is the contact ratio within the boundaries of an ellipse tangent to the extremities of the zone of action, and can be calculated by:

$$
m_{o}=\sqrt{m_{p}^{2}+m_{F}^{2}}
$$

3.12.21 Back Cone Distance in a bevel gear is the distance along an element of the back cone from its apex to the pitch circle (see Fig 3-87).

3.12.22 Back Angle, in a bevel gear, is the angle between an element of the back cone and a plane of rotation, and usually is equal to the pitch angle (see Fig 3-87).

3.12.23 Front Angle, in a bevel gear, is the angle between an element of the front cone and a plane of rotation, and usually equals the pitch angle (see Fig 3-87).

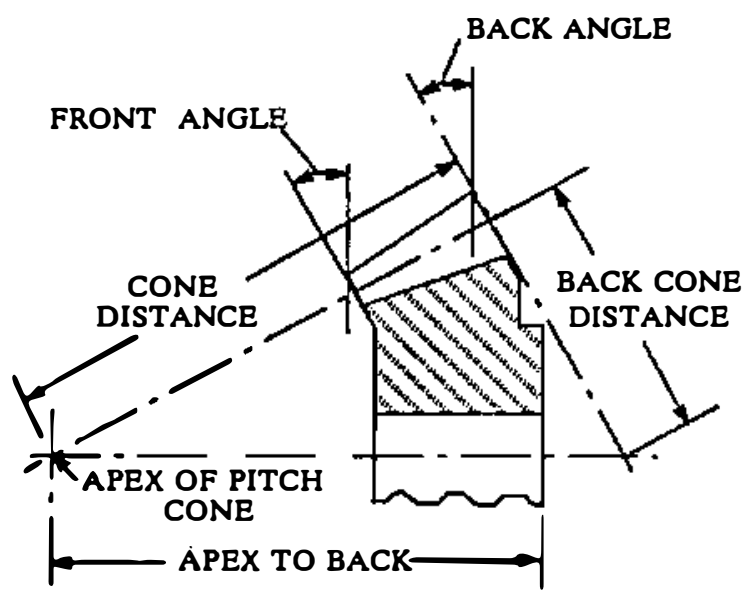

Fig 3-87 Apex to Back

3.12.24 Apex to Back, in a bevel gear or hypoid gear, is the distance in the direction of the axis from the apex of the pitch cone to a locating surface at the back of the blank (see Figs 3-87 and 3-88).

3.12.25 Mounting Distance, for assembling bevel gears or hypoid gears, is the distance from the crossing point of the axes to a locating surface of a gear, which may be at either back or front (see Fig 3-88).

3.12.26 Crossing Point is the point of intersection of bevel gear axes; also the apparent point of intersection of the axes in hypoid gears, crossed helical gears, wormgears, and offset face gears, when projected to a plane parallel to both axes (see Fig 3-88).

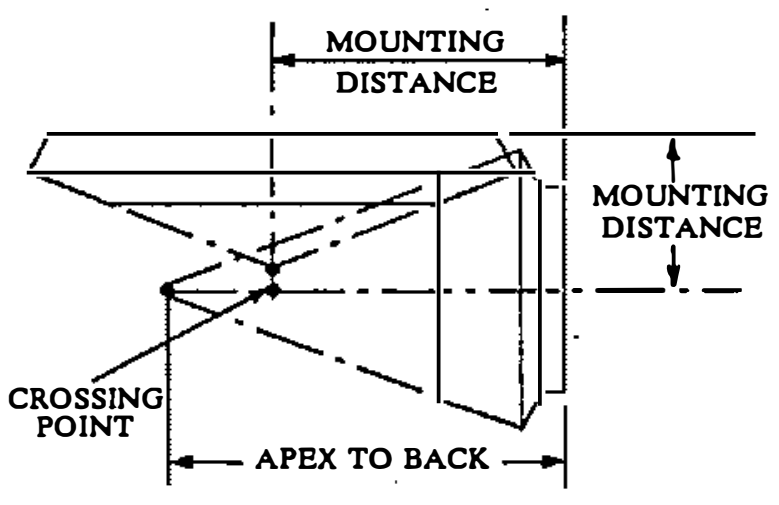

HYPOID GEAR AND PINION

Fig 3-88 Mounting Distance 
3.12.27 Tip Relief is an arbitrary modification of a tooth profile whereby a small amount of material is removed near the tip of the gear tooth (see Fig 3-89).

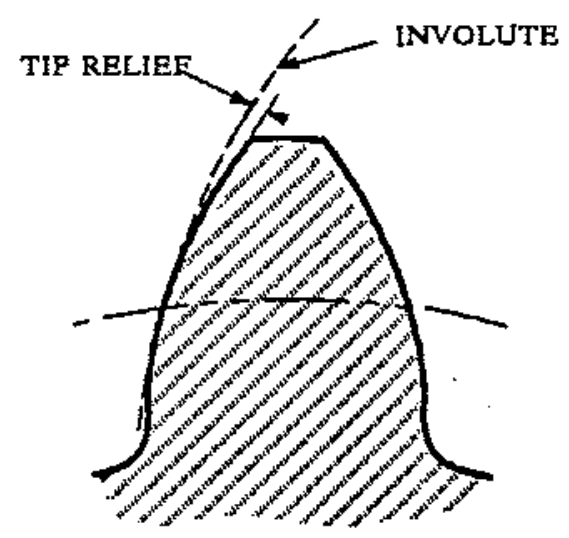

Fig 3-89 Tip Relief

3.12.28 Limit Diameter is the diameter on a gear at which the line of action intersects the maximum (or minimum for internal pinion) addendum circle of the mating gear. This is sometimes referred to as the start (start of active profile, SAP) or end of contact or profile (see Figs 3-90 and 3-91).

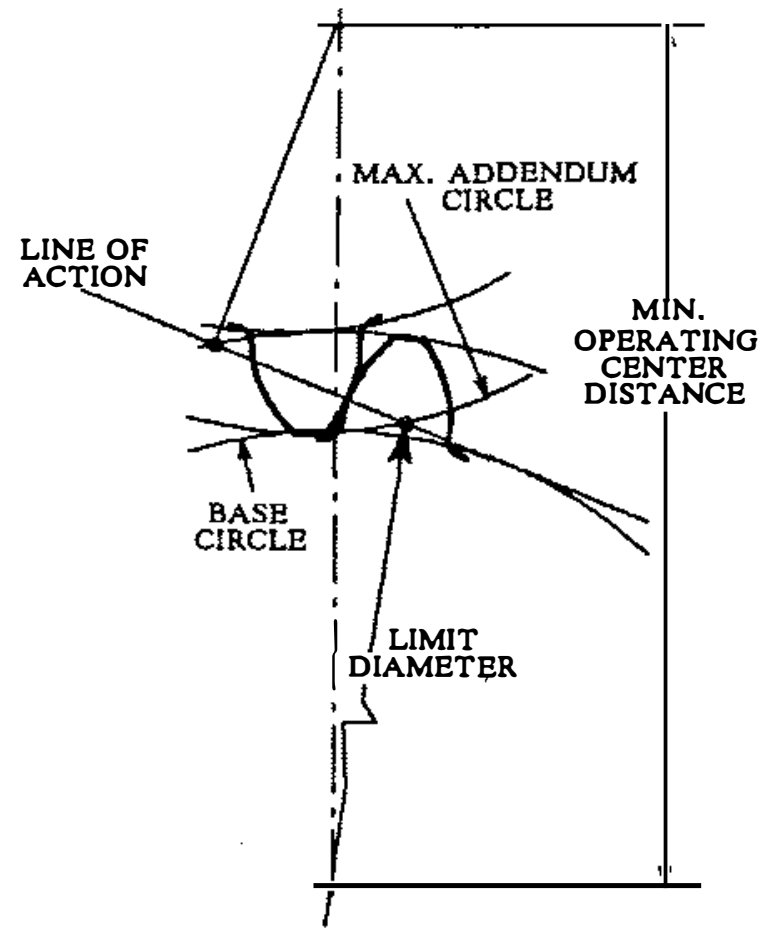

Fig 3-90 Limit Diameter
3.12.29 Form Diameter is the diameter of a circle at which the trochoid produced by the tooling intersects, or joins, the involute or specified profile. This diameter cannot be less than the base circle diameter (see Fig 3-91).

3.12.30 The Start of Active Profile (SAP) is the intersection of the limit diameter and the involute profile (see Fig 3-91).

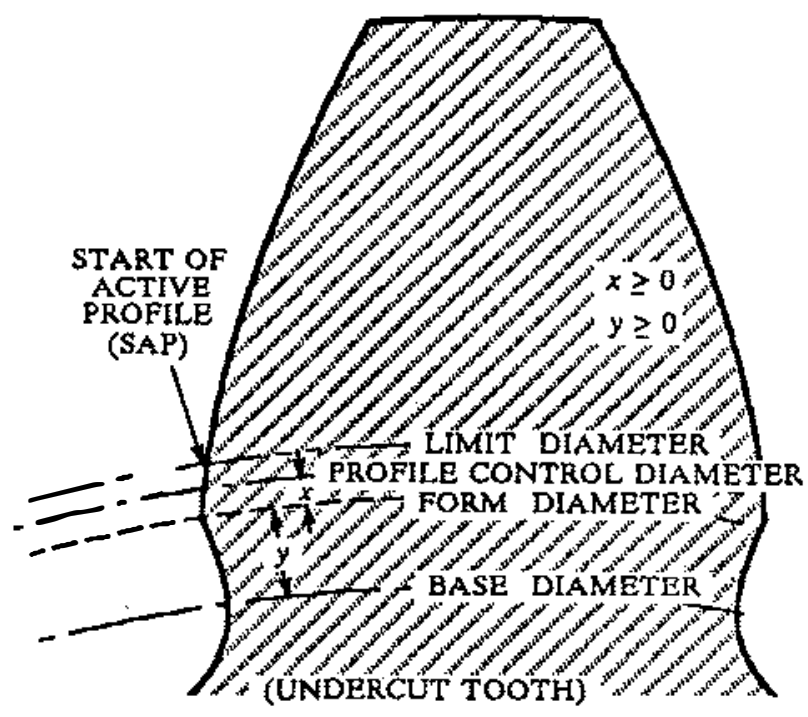

Fig 3-91 Form Diameter

3.12.31 Crowned Teeth have surfaces modified in the lengthwise direction to produce localized contact or to prevent contact at their ends (see Fig 3-92). Crowning can be applied to all types of teeth.

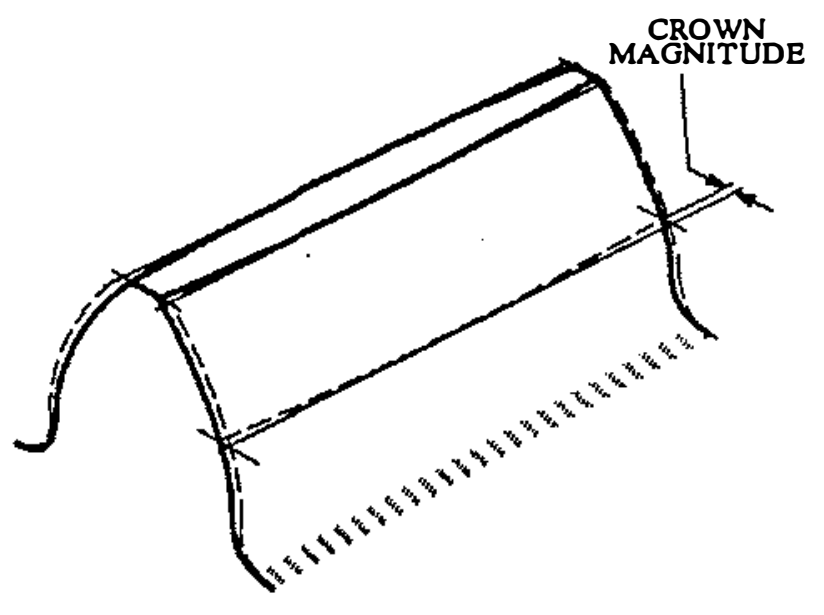

Fig 3-92 Crowned Gear 


\section{Glossary of Additional Terms}

[This Appendix is provided for informational purposes only and should not be construed as a part of ANSI/AGMA 1012-F90, Gear Nomenclature, Definitions of Terms with Symbols.]

B1. Purpose. This Appendix is intended to be a reference for terms in new or revised AGMA literature, and hopefully, its influence will be felt in circles outside of AGMA.

Terms in this section are arranged alphabetically. Some definitions are intentionally brief, but references to other AGMA Standards are included for those who wish more information, or a more detailed definition.

Addendum Modification. Gear teeth may have modified addenda in order to avoid undercut, to balance the bending stresses in the pinion and gear, or to vary the relative amounts of approach and recess action. For external gears with increased addendum, there is a corresponding reduction in dedendum; i.e., the teeth are moved outward from the center of the gear. This "profile shift", as it is sometimes called, is expressed in terms of an addendum modification coefficient, $x$, where $x$ is the proportionate distance (in terms of unity normal diametral pitch) by which the datum line of the generating rack (e.g., hob) and the generating pitch circle of the gear are separated.

For external and internal gears, $x$ is positive when the reference generating rack is shifted outward from the center of the gear. This results in increased addendum (and increased tooth thickness) for external gears, and decreased addendum (and decreased tooth thickness) for internal gears. The sum of the addendum modification coefficients, $\Sigma x$, is given by:

$\Sigma x=x_{2} \pm x_{1}$

where

$x_{1}=$ addendum modification coefficient, pinion

$x_{2}=$ addendum modification coefficient, gear

and where the upper sign $(+)$ is used for external gears and the lower sign $(-)$ is used for internal gears.

Gear pairs with modified addenda may operate on the same standard center distance as unmodified gears if the addendum modification coefficients are chosen as follows: external gears: $x_{2}=-x_{1}$, internal gears: $x_{2}=x_{1}$. In either case, $\Sigma x=0$, and the gear pair may operate on standard centers, (i.e., $C=C_{s}$ ). Alternatively, if: $\Sigma x>0$, then $C>C_{s} ; \Sigma x<0$, then $C<C_{s}$. The addendum modification coefficients are selected such that their sum results in zero backlash:

$\Sigma x=\frac{C_{s} P_{n}\left(\operatorname{inv} \phi_{t}-\operatorname{inv} \phi_{s}\right)}{\tan \phi_{s}}$

where

$C_{S}=$ standard center distance

$P_{n}=$ normal diametral pitch

$\phi_{t}=$ operating transverse pressure angle

$\phi_{S}=$ standard transverse pressure angle

The small adjustments (radial shifting) of the generating rack to thin the teeth for backlash are considered independently of $x_{1}, x_{2}$ by specifying the amount the pinion and gear teeth are thinned for backlash, $\Delta s_{n 1}$ and $\Delta s_{n 2}$, where $\Delta s_{n 1}$ is the pinion tooth thinning for backlash and $\Delta s_{n 2}$ is the gear tooth thinning for backlash. This way the outside diameters are independent of tooth thinning for backlash and are based solely on the addendum modification coefficients $x_{1}$ and $x_{2}$.

Adjusted Number of Teeth. This number, $N_{i}$, represents an editorial device for tabular convenience to allow use of spur gear tables in a regular progression for an infinite combination of helical gears.

$N_{i}=\frac{N}{\cos \psi}$

Backlash, Minimum. Minimum backlash is the minimum transverse backlash at the operating pitch circle allowable when the gear tooth with the greatest allowable functional tooth thickness is in mesh with the pinion tooth having its greatest allowable functional tooth thickness, at the tightest allowable center distance, under static conditions (from ANSI/AGMA 2002-B88).

Backlash Variation. Difference between the maximum and minimum backlash occurring in a whole revolution of the larger of a pair of mating gears. 
Appendix B

Gear Failure Modes and Prevention 


\section{GEAR FAILURE MODES AND PREVENTIONS}

GEARTECH has observed all of the gear failure modes discussed in wind turbine gearboxes here. Some failure modes are widespread in the wind turbine industry, such as micropitting, abrasive wear and polishing wear, while others such as electrical discharge damage are rare. All these failures should be considered when designing a gearbox for a wind turbine.

Failure modes are described in detail and methods for failure prevention are presented. It is important to note that a method for preventing one failure mode could actually facilitate another failure mode. Therefore it is important to consider side effects when prescribing a remedy for a particular failure mode.

\section{Overload}

When a gear tooth is overloaded either because it is under-designed or because the local load is too high it may fail by plastically deforming or fracturing. If it fractures the failure may be a ductile fracture that is preceded by appreciable plastic deformation, a brittle fracture with little prior plastic deformation, or a mixed-mode fracture exhibiting both ductile and brittle characteristics.

Fatigue failures usually culminate in a fracture when the fatigue cracks grow to a point where the remaining tooth section can no longer support the load. In this sense the remaining material is overloaded; however, the fracture occurs in a secondary failure mode that is caused by the primary mode of fatigue cracking.

Gear tooth fractures without prior fatigue cracking are infrequent, but they may result from shock loads. Shock loads may be generated by the driving or driven equipment. They may also occur when large, foreign objects enter the gear mesh or when the gear teeth are suddenly misaligned and jam together following failure of a bearing or shaft.

Fractures are classified as brittle or ductile, depending on their macroscopic and microscopic characteristics:

\begin{tabular}{l|l|l}
\hline \multicolumn{1}{c|}{$\begin{array}{c}\text { Characteristic of } \\
\text { Fracture Surface }\end{array}$} & \multicolumn{1}{c}{\begin{tabular}{c}
\multicolumn{1}{c}{ Brittle } \\
Fracture
\end{tabular}} & \multicolumn{1}{c}{$\begin{array}{c}\text { Ductile } \\
\text { Fracture }\end{array}$} \\
\hline light reflection & $\begin{array}{l}\text { bright } \\
\text { shiny }\end{array}$ & $\begin{array}{l}\text { gray (dark) } \\
\text { dull }\end{array}$ \\
\hline texture & $\begin{array}{l}\text { crystalline } \\
\text { grainy } \\
\text { rough } \\
\text { coarse } \\
\text { granular }\end{array}$ & $\begin{array}{l}\text { silky } \\
\text { matte } \\
\text { smooth } \\
\text { fine } \\
\text { fibrous (stringy) }\end{array}$ \\
\hline orientation & $\begin{array}{l}\text { flat } \\
\text { square }\end{array}$ & slant or flat \\
\hline pattern & $\begin{array}{l}\text { radial ridges } \\
\text { chevrons }\end{array}$ & shear lips \\
\hline plastic deformation(necking or distortion) & negligible & appreciable \\
\hline microscopic features & cleavage (facets) & dimples (shear) \\
\hline \hline
\end{tabular}




\section{Brittle Fracture}

Brittle fractures are characterized by rapid crack propagation without appreciable gross plastic deformation. Brittle fractures have a bright, granular appearance. The fracture surface is generally flat and perpendicular to the direction of the maximum tensile stress (see Figure B1). Radial ridges or a chevron pattern may be present on the fracture surface and point toward the origin of the crack. On a microscopic level, brittle fractures typically consist of transgranular cleavage facets or intergranular facets.

Material toughness, material flaws, and tensile stress levels are the three primary factors that control the susceptibility of gear teeth to brittle fracture. Brittle fracturing occurs when a combination of tensile stress and flaw size creates a critical stress intensity for a particular gear tooth material toughness.

The toughness of a gear material depends on a number of factors, the most important being temperature, loading rate, and constraint (state of stress) at the location of flaws. Many structural steels and low-alloy steels have a transition temperature where the fracture mode changes from ductile to brittle as temperature decreases. The transition temperature is influenced by the loading rate and constraint. The ductile-tobrittle transition can be demonstrated quite readily by the Charpy V-notch impact test. Many materials, such as aluminum, titanium and many high-strength, quenched and tempered steels, do not exhibit a transition temperature behavior. For low and medium strength steels the transition temperature is of primary importance. Gears made from these steels should not be put into service at temperatures below their transition temperature.

The compliance of shafts and couplings in a drive system helps to cushion shock loads and reduce the loading rate during impact. Gear drives with close-coupled shafts and rigid couplings have less resistance to overloads. If drive systems with low compliance must be used in applications where overloads are expected, the gears should be large enough to absorb the overloads with reasonable stress levels. Otherwise the gears should be isolated from impact loads by using load-limiting couplings that employ slip clutches or shear devices. However, load-limiting couplings cannot be used in critical applications such as hoists where slip or shear devices could result in the load being dropped.

Notches create stress concentrations that elevate the stress locally ahead of the notch. Adjacent material at lower stress constrains and limits plastic deformation. For wide face gears (i.e., thick plates), triaxial tensile stresses develop at the notch. These reduce the ductility of the material by decreasing the shear stresses.

The toughness of a material depends on its elemental composition, heat treatment, and mechanical processing. Many alloying elements increase the hardenability of steel while decreasing its toughness. Exceptions are nickel and molybdenum, which increase hardenability while improving toughness. Diesburg and Smith [9] tested the impact fracture resistance of carburized steels and found the following:

- High-hardenability steels have greater fracture resistance than low-hardenability steels.

- High nickel content does not guarantee good fracture resistance, but nickel and molybdenum in the right combination results in high fracture resistance.

- High chromium and high manganese contents tend to give low fracture resistance.

Toughness can be optimized by keeping the carbon, phosphorus and sulfur content as low as possible.

The microstructure of steel depends on its initial microstructure, hardenability, and heat treatment. Generally, the highest toughness is obtained with tempered martensite. Microstructures consisting of 
ferrite, pearlite, or bainite have lower fracture toughness. For maximum toughness, a steel should have sufficient hardenability so that its heat-treated microstructure consists primarily of tempered martensite. Embrittlement must be avoided by selecting a steel in which the desired hardness will be achieved without tempering in the range of $250^{\circ}-400^{\circ} \mathrm{C}\left(482^{\circ}-752^{\circ} \mathrm{F}\right)$.

Most material properties are improved when the grain size is both uniform and fine. This is especially true for toughness: fine-grained steel has increased toughness and a decreased ductile-to-brittle transition temperature. The grain size is influenced by steel making practices, alloying elements, mechanical treatments and heat treatments. Steels containing nickel and molybdenum resist grain coarsening during austenitizing better than plain carbon steels. Aluminum, vanadium or columbium are alloyed with steel to produce fine grain size.

Brittle fractures initiate at flaws, which cause stress concentrations. The flaw may be a notch, crack, surface tear, porosity or surface or subsurface inclusion. Flaw size may be small initially, but it can initiate a fatigue crack which may grow until a critical size is reached, at which point the crack may extend in a fast, brittle fracture. The critical flaw size is not constant. Rather, it depends on the geometry of the part, shape and orientation of the flaw, applied stress and the fracture toughness of the material at the service temperature and loading rate.

The root fillets of gear teeth are especially vulnerable to brittle fracture because the tooth bending stresses are highest in these regions. Critical gears should be made of clean materials and magnetic-particle inspected to ensure that the gear tooth root fillets are free of flaws.

Gear tooth geometry should be designed in a way to minimize the tensile bending stress in the root fillets. The gear teeth should be cut with full-fillet tools to obtain large root fillets that have minimum stress concentrations. If the gears are to be finished by shaving or grinding, they should be cut by protuberance tools so that the teeth can be finished without notching the root fillets. Case hardening by carburizing or nitriding is especially beneficial because these hardening processes induce compressive residual stresses which reduce the net tensile bending stresses. Also, shot peening can be used to obtain compressive residual strésses.

Following are some methods for preventing brittle fracture:

- Use materials with high cleanliness.

- Use materials and heat treatments that give high toughness.

- Do not use gears made from low and medium strength steels at service temperatures below their transition temperature.

- Reduce loading rates by using compliant shafts and couplings. Protect gears from impact loads by using load-limiting couplings.

- Use steels with high nickel content. For carburized gears, nickel and molybdenum in the right combination gives maximum toughness. Do not use steels with high chromium and manganese content. Keep the carbon, phosphorus, and sulfur content as low as possible.

- Use steel with sufficient hardenability to obtain a microstructure of primarily tempered martensite. Avoid embrittlement by using steel in which the desired hardness will be achieved without tempering in the range of $250^{\circ}-400^{\circ} \mathrm{C}\left(482^{\circ}-752^{\circ} \mathrm{F}\right)$. 
- Use fine-grained steel. Nickel and molybdenum steels resist grain coarsening during austenitizing.

- Eliminate flaws, especially in the root fillets of gear teeth. Use clean materials. Use magneticparticle inspection to detect flaws.

- Reduce tensile bending stresses by optimizing gear tooth geometry.

- Use case hardening and/or shot peening to obtain compressive residual stresses.

\section{Ductile Fracture}

Ductile fractures are characterized by tearing of metal accompanied by gross plastic deformation. Ductile fractures have a gray, fibrous appearance. The fracture surface may have a flat or slant orientation to the direction of the maximum tensile stress. The fracture surface may terminate with a shear lip that extends along the nonworking side of the gear tooth. Microscopically, ductile fractures are characterized by numerous dimples that are formed by the nucleation and growth of microvoids.

Gear tooth failures that occur solely by ductile fracture are relatively infrequent because most fractures occur as a consequence of a preexisting flaw which tends to promote brittle behavior. Factors that promote ductile rather than brittle fracture are:

- High material toughness.

- High temperature.

- Slow loading rate.

- No significant material flaws.

- Low tensile stress.

- High shear stress.

Under these conditions, gear teeth yield when the bending stresses exceed the yield strength of the material and subsequently shear of $f$ with significant plastic deformation prior to fracture (see Figure B2).

\section{Mixed-Mode Fracture}

A local area of a fracture surface may exhibit both ductile and brittle characteristics (see Figure B3). Under these conditions, the fracture is termed mixed-mode. This is not to be confused with a fracture surface having features that suggest successive crack propagation by different mechanisms.

\section{Plastic Deformation}

Plastic deformation is permanent deformation that occurs when the stress exceeds the yield strength of the material (see Figure B4). It may occur at the surface or subsurface of the active flanks of the gear teeth due to high contact stress, or at the root fillets of the gear teeth due to high bending stress.

\section{Hot Flow}

Hot flow is plastic deformation that occurs at a temperature higher than the recrystallization temperature. 


\section{Indentation}

The active flanks of gear teeth may be damaged by indentations caused by foreign material trapped between mating teeth (see Figure B5). Depending on the number and size of the indentations, the damage may or may not initiate failure of the gear teeth. If plastic deformation associated with the indentations causes raised areas on the tooth surface it creates stress concentrations which may lead to subsequent Hertzian fatigue.

For gear teeth subjected to contact stresses greater than 1.8 times the tensile yield strength of the material, local subsurface yielding may occur. The subsurface plastic deformation causes shallow grooves (Brinelling) on the surfaces of the active flanks of the gear teeth along the lines of contact between mating teeth. The high contact stress may be the result of high loads or gear tooth impact (tooth hammer) caused by resonant vibration.

\section{Rippling}

Rippling is periodic, wavelike deformation of the active gear tooth surfaces. The peaks of the waves run perpendicular to the direction of sliding. The peaks are wavy along the length of the tooth, creating a fish scale appearance (see Figure B6). Rippling usually occurs under high contact stress and boundarylubricated conditions.

\section{Tip-To-Root Interference}

Plastic deformation and abrasive wear may occur on the tooth tips of one gear and in the roots of the mating gear teeth due to tip-to-root interference (see Figure B7). The interference may be caused by geometric errors in the profiles of the gear teeth, engagement below the form diameter, inadequate tip or root relief, spacing errors, or insufficient center distance.

\section{Bending Fatigue}

Fatigue is a progressive failure consisting of three distinct stages - crack initiation, crack propagation, and fracture.

Most of the fatigue life is occupied by the first two stages until the crack grows to critical size, at which time sudden fracture occurs. The fracture may be ductile, brittle or mixed-mode (see Figure B8), depending upon the toughness of the material and the magnitude of the applied stress (see discussion in section on overload).

During the first stage the peak bending stress is less than the yield strength of the material and no gross yielding of the gear teeth occurs. However, local plastic deformation may occur in regions of stress concentration or in areas of structural discontinuity, such as surface notches, grain boundaries, or inclusions (see Figure B9). Cyclic plastic deformation normally occurs on slip planes that coincide with the direction of maximum shear stress. The cyclic slip continues within these grains, usually near the surface where stress is highest, until microcracks are initiated. The cracks grow in the planes of maximum shear stress and coalesce across several grains until they form a major crack.

In the second propagation stage the crack turns and grows across grain boundaries (transgranular) in a direction approximately perpendicular to the maximum tensile stress. During the propagation phase, the plastic deformation is confined to a small zone at the leading edge of the crack, and the surfaces of the fatigue crack usually appear smooth without signs of gross plastic deformation. 
Under the scanning electron microscope, ripples called fatigue striations may be seen on a fatigue-cracked surface. These are thought to be associated with alternating blunting and sharpening of the crack tip and correspond to the advance of the crack during each stress cycle. The orientation of the striations is at $90^{\circ}$ to the crack advance.

If the crack propagates intermittently, it may leave a pattern of macroscopically visible "beach marks" (see Figure B8). These marks correspond to various positions of the crack front where the crack stopped because the stress decreased. Beach marks are helpful to the failure analyst because they aid in locating the origins of fatigue cracks. The origin is usually on the concave side of the curved beach marks and is often surrounded by several concentric beach marks. Beach marks, however, may not be present, especially if the fatigue crack grows without interruption under cyclic loads that do not vary in magnitude. The presence of beach marks is a strong indication that the crack was a result of fatigue, but it is not absolute proof, because other failure modes sometimes leave beach marks (for example, stress corrosion under changing environment).

If there are multiple crack origins, each producing separate crack propagation zones, ratchet marks may be formed. These are caused when adjacent cracks propagating on different crystallographic planes join together, forming a step. Ratchet marks are often present on fatigue crack surfaces of gear teeth because the stress concentration in the root fillet frequently initiates multiple fatigue cracks.

\section{High-Cycle Fatigue}

High-cycle fatigue is defined as fatigue where the cyclic stress is less than the yield strength of the material and the number of cycles to failure is greater than 10,000. Most gear teeth fail by high-cycle fatigue rather than low-cycle fatigue. A large fraction of the life is spent initiating rather than propagating cracks.

\section{Root Fillet Cracks}

Although bending fatigue cracks may occur elsewhere, they usually initiate in the root fillets on the tensile side of the teeth (see Figure B9). The geometry of the root fillets may cause significant stress concentrations, which, combined with a high bending moment, result in high bending stress.

\section{Profile Cracks}

Fatigue cracks may initiate on the active surface of the gear tooth if there are stress concentrations caused by macropits or material flaws (see Figure B10).

\section{Tooth End Cracks}

Fatigue cracks may initiate at an end of the gear tooth if the load is concentrated at the tooth end. Stress concentrations or material flaws at the ends of the teeth may also be responsible for tooth end cracks.

High-cycle fatigue life can be extended by maximizing the ultimate tensile strength of the material and ensuring that the microstructure of the surface of the gear teeth is optimum. Kem [10] recommends the following methods to increase the high-cycle bending fatigue life of carburized gears:

- Eliminate bainite, pearlite and network carbides from the case microstructure.

- Eliminate microcracks, especially near the surface of the root fillets. 
- Ensure maximum residual compressive stress in the case by using a steel with the lowest possible carbon content.

- Eliminate defects on the surfaces of the root fillets.

There are several geometric variables (for example, diameter, face width, number of teeth, pressure angles and addendum modification) that may be optimized to lower the bending stress and increase bending fatigue life. Gear tooth geometry should be designed to minimize the tensile bending stress in the root fillets. The gear teeth should be cut with full-fillet tools to obtain large radius root fillets with minimum stress concentrations. If the gear teeth are to be finished by shaving or grinding, they should be cut by protuberance tools so they can be finished without notching the root fillets.

Case hardening by carburizing or nitriding is especially beneficial because these hardening processes induce compressive residual stresses that reduce net tensile bending stresses. Shot peening can also be used to obtain compressive residual stresses. For carburized gears there are optimum values of case hardness, case depth and core hardness [11] which give the proper balance of residual stresses and fatigue strength to maximize gear tooth resistance to bending fatigue.

The following are methods for preventing high-cycle bending fatigue:

- Use clean steel that is properly heat-treated by carburizing.

- Use case hardening and/or shot peening to obtain compressive residual stresses. For carburized gears, maximize residual compressive stress in the case by using a steel with the lowest possible carbon content.

- For case hardened gears specify optimum values of case hardness, case depth and core hardness to maximize resistance to bending fatigue.

- Use steel with sufficient hardenability to obtain a microstructure of primarily tempered martensite in the gear tooth root fillets. Avoid embrittlement by using a steel in which the desired hardness will be achieved without tempering in the range of $250^{\circ}-400^{\circ} \mathrm{C}\left(482^{\circ}-752^{\circ} \mathrm{F}\right)$. For carburized gears, make sure that the microstructure of the case is free of bainite, pearlite, network carbides and microcracks.

- Use fine grain steel. Nickel and molybdenum steels resist grain coarsening during austenitizing.

- Ensure that the surfaces of the root fillets are relatively free from notches, tool marks, cracks, nonmetallic inclusions, decarburizing, corrosion, intergranular oxidation, or other defects.

- Reduce bending stresses by reducing loads or optimizing gear geometry, especially the shape of the root fillet.

\section{Hertzian Fatigue}

Hertzian fatigue is the consequence of repeated contact stresses that cause surface or subsurface cracks and detachment of fragments of material from the gear tooth surface. 


\section{Macropitting}

Macropitting is a fatigue phenomenon [12] that may occur when a fatigue crack initiates either at the surface of the active flank of the gear tooth or at a small depth below the surface. The crack usually propagates for a short distance in a direction roughly parallel to the tooth surface before tuming or branching to the surface. When the cracks have grown to where they separate a piece of the surface material, a pit is formed. The edges of a pit are usually sharp and angular. Cracks may be found near the boundary of the pit and fatigue beach marks may be evident on the crater bottom (see Figure B11).

There is no endurance limit for Hertzian fatigue, and macropitting occurs even at low stresses if the gears are operated long enough. Because there is no endurance limit, gear teeth must be designed for a suitable finite lifetime.

Based on the nature and severity of the damage, macropitting can be categorized as nonprogressive, progressive, spall, or flake.

\section{Progressive Macropitting}

Progressive macropitting normally consists of pits significantly larger than $1 \mathrm{~mm}$ in diameter. Macropitting of this type may continue at an increasing rate until a significant portion of the tooth surface has pits of various shapes and sizes.

\section{Spall Macropitting}

Spall macropitting is progressive macropitting that occurs when pits coalesce and form irregular craters that cover a significant area of the tooth surface.

\section{Flake Macropitting}

Flake macropitting consists of pits that are relatively shallow but large in area. The fatigue crack extends from the origin in a fan-shaped manner until thin flakes of material break out and form a triangular crater (see Figure B12).

To extend the macropitting life of a gearset, the designer must keep the contact stress low and the material strength and lubricant specific film thickness high. There are several geomeric variables, such as diameter, face width, number of teeth, pressure angle, and so on, that can be optimized to lower the contact stress. Material alloys and heat treatment are selected to obtain hard tooth surfaces with high strength. Maximum macropitting resistance is obtained with carburized gear teeth because they have hard surfaces, and carburizing induces beneficial compressive residual stresses that effectively lower the load stresses. The drawback to using carburized gear teeth is that they are relatively expensive to produce because they must be finished by grinding. High lubricant specific film thickness is obtained by using smooth tooth surfaces and an adequate supply of cool, clean, and dry lubricant that has high viscosity and a high pressure-viscosity coefficient.

Macropitting may initiate at the surface or at a subsurface defect, such as a nonmetallic inclusion. With gear teeth, pits are most often the surface-initiated type because the lubricant film thickness is usually low, resulting in a relatively high degree of metal-to-metal contact. The interaction between asperities or contact at defects (such as nicks or furrows) creates surface-initiated cracks rather than subsurface-initiated cracks. For high-speed gears with smooth surface finishes, the film thickness is greater and subsurfaceinitiated macropitting rather than surface-initiated macropitting may predominate. In these cases, macropitting usually starts at a subsurface inclusion which acts as a point of stress concentration. Cleaner 
steels, such as those produced by vacuum melting, prolong the macropitting life by reducing the number of inclusions.

At present, the influence that lubricant additives have on macropitting is unresolved. However, contamination from water in the lubricant is believed to promote macropitting, and abrasive particles in the lubricant promote macropitting by indenting the tooth surfaces, causing stress concentrations and/or disrupting the lubricant film.

Following are some methods for preventing macropitting:

- $\quad$ Reduce contact stresses by reducing loads or optimizing gear geometry.

- Use clean steel that is properly heat treated to high hardness, preferably by carburizing.

- Use smooth tooth surfaces produced by careful grinding or honing.

- Use an adequate amount of cool, clean, and dry lubricant of adequate viscosity.

\section{Micropitting}

Micropitting gives the gear tooth a frosted, matte, or gray stained [13] appearance (see Figures B13 and 14). Under magnification, the surface appears to be covered by very fine pits (normally less than $20 \mu \mathrm{m}$ deep). Metallurgical sections through the micropits show fatigue cracks that are inclined to the surface at an angle of less than 45 degrees. The cracks may extend deeper than the visible micropits.

Micropitting may occur more frequently on surface-hardened gear teeth, although it may also occur on through-hardened gear teeth. It may occur anywhere on the active profile of the gear tooth.

In many cases, micropitting is not destructive to the gear tooth surface. It sometimes occurs only in patches and it may stop after the tribological conditions have improved by running-in. The micropits may actually be removed by mild polishing wear during run-in, in which case the micropitting is said to "heal." However, there have been examples [13], [14] and [15] where micropitting has escalated into macropitting, leading to the destruction of the gear teeth.

The specific film thickness is the most important parameter that influences micropitting. Damage seems to occur most readily on gear teeth with rough surfaces, especially when they are lubricated with lowviscosity lubricants. Gears finished with special grinding wheels to a mirror-like finish [16] have effectively eliminated micropitting. Slow-speed gears are prone to micropitting because their film thickness is low.

To prevent micropitting, the specific film thickness should be maximized by using smooth gear tooth surfaces, high-viscosity lubricants, and high speeds. Experiments [14] have shown that flame-hardened and induction-hardened gears have less resistance to micropitting than carburized gears of the same hardness. This is probably due to the lower carbon content of the surface layers of the flame-hardened and induction-hardened gears.

Following are some methods for preventing micropitting:

- Use smooth tooth surfaces produced by careful grinding or honing.

- Use an adequate amount of cool, clean, and dry lubricant of the highest viscosity permissible. 
- Use high speeds if possible.

- Use carburized steel with proper carbon content in the surface layers.

\section{Wear}

Wear is damage to a gear tooth surface that involves removal or displacement of material due to mechanical, chemical, or electrical action.

\section{Adhesion}

Adhesive wear is caused by the transfer of material from one tooth surface to another due to microwelding and tearing. It is confined to surface films and oxide layers on the tooth surface. Adhesive wear can be categorized as mild or moderate. Severe adhesive wear is termed scuffing (see section on scuffing).

\section{Mild Adhesive Wear}

Mild adhesive wear typically occurs during run-in and usually subsides after run-in has smoothed the tooth surfaces by removing minor imperfections through local wear. To the unaided eye, the tooth surface appears undamaged and the original machining marks are visible. Microscopically, smooth microplateaus can be seen between the machining furrows.

\section{Moderate Adhesive Wear}

Adhesive wear is classified as moderate if it removes some or all of the original machining marks from the active surface of the tooth. Under certain conditions, adhesive wear may cause continuous removal of surface films and oxide layers and result in excessive wear.

When new gear units are first operated, the contact between the gear teeth is not optimum because of unavoidable manufacturing inaccuracies. If the tribological conditions are favorable, mild adhesive wear occurs during run-in and usually subsides with time, resulting in a satisfactory lifetime for the gears. The wear that occurs during run-in is beneficial if it creates smooth tooth surfaces (thereby increasing the specific film thickness) and if it increases the area of contact by removing minor imperfections through local wear. To ensure that the wear rate remains under control, new gearsets should be run-in by being operated for at least the first 10 hours at one-half load.

The amount of wear considered tolerable depends on the expected lifetime for the gears and requirements for control of noise and vibration. Wear is considered excessive when the tooth profiles wear to the extent that high dynamic loads occur, or the tooth thickness is reduced to the extent that bending fatigue becomes possible.

Many gears, because of practical limits on lubricant viscosity, speed, and temperature, must operate under boundary-lubricated conditions in which some wear is inevitable. Highly loaded, slow speed $(<0.5 \mathrm{~m} / \mathrm{s})$, boundary-lubricated gears are especially prone to excessive wear. Tests with slow-speed gears [14] have shown that nitrided gears have good wear resistance, whereas carburized and through-hardened gears have similar but lower wear resistance. Reference [14] concluded that lubricant viscosity has the greatest effect on slow speed adhesive wear, and that high viscosity lubricants reduce the wear rate significantly. They also found that sulfur-phosphonus additives can be detrimental with slow speed $(<0.05 \mathrm{~m} / \mathrm{s})$ gears, giving very high wear rates. 
Some gear units operate under ideal conditions with smooth tooth surfaces, high pitchline speed and high lubricant film thickness. For example, steam turbine gears that operated almost continuously at $150 \mathrm{~m} / \mathrm{s}$ pitchline speed still had the original machining marks on their teeth even after 20 years of service. Most gears, however, operate between the boundary and full film lubrication regimes under elastohydrodynamic (EHD) conditions.

In the EHD regime, with the proper type and viscosity of lubricant, the wear rate usually reduces during run-in and adhesive wear virtually ceases once the run-in is completed. If the lubricant is properly maintained (kept cool, clean, and dry) the gearset should not suffer an adhesive wear failure.

Following are methods for preventing adhesive wear:

- Use smooth tooth surfaces.

- If possible, run-in new gearsets by operating the first 10 hours at one-half load.

- Use high speeds if possible. Otherwise, recognize that highly loaded slow speed gears are boundary lubricated and are especially prone to excessive wear. For these conditions, use nitrided gears and the highest permissible lubricant viscosity.

- For very slow speed gears $(<0.05 \mathrm{~m} / \mathrm{s})$, avoid using lubricants with sulfur-phosphorus additives.

- Use an adequate amount of cool, clean, and dry lubricant of the highest viscosity permissible.

\section{Abrasion}

Abrasive wear is usually caused by contamination of the lubricant by hard, sharp-edged particles. Common contaminants are sand, scale, rust, machining chips, grinding dust, weld splatter, or wear debris.

Abrasion dive to loose contaminants is called three-body abrasion. Two-body abrasion occurs when embedded particles or asperities on one gear tooth abrade the opposing tooth surface.

Abrasive wear causes scratches or gouges on the tooth surface that are oriented in the direction of sliding. Under magnification, the scratches appear as parallel furrows that are smooth and clean.

Based on the severity of the damage, abrasive wear can be categorized as mild, moderate, or severe.

\section{Mild Abrasive Wear}

Abrasive wear is classified as mild if it consists of fine scratches that are not numerous or deep enough to remove significant amounts of material from the tooth surface.

\section{Moderate Abrasive Wear}

Abrasive wear is classified as moderate if remnants of the original machining marks are visible on the tooth surface.

\section{Severe Abrasive Wear}

Severe abrasive wear removes all of the original machining marks from the active surface of the tooth. There may be wear steps at the ends of the active face and in the dedendum. The tooth thickness may 
be reduced significantly, and in some instances the tooth tip may be reduced to a sharp edge (see Figure B15).

Contamination enters gearboxes by being built-in, internally. generated, ingested through breathers and seals, or inadvertently added during maintenance.

To remove built-in contamination, the gearbox lubricant should be drained and flushed before start up and again after the first 50 hours of operation, refilled with the recommended lubricant, and fitted with a new oil filter.

Internally generated particles are usually wear debris from gears, bearings or other components with origins in Hertzian fatigue pitting or adhesive and abrasive wear. The wear particles may be abrasive because they become work-hardened when they are trapped between the gear teeth. Internally generated wear debris can be minimized by using accurate, surface hardened gear teeth (with high pitting resistance), smooth tooth surfaces, and high viscosity lubricants.

Breather vents are used on gearboxes to vent the internal pressure that may occur when air enters through seals or when the air within the gearbox expands (or contracts) during the normal heating and cooling of the gear unit. The breather vent should be located in a clean, nonpressurized area and have a filter to prevent ingress of airbome contaminants. In especially harsh environments, the gearbox can sometimes be completely sealed and the pressure variation can be accommodated by an expansion chamber with a flexible diaphragm.

All maintenance procedures that involve opening any part of the gearbox or lubrication system should be carefully performed in a clean environment to prevent contamination of the gearbox.

Unless the tooth surfaces of a surface-hardened gear are smoothly finished, they will act like files if the mating gear is appreciably softer. This is the reason that a worm pinion is polished after grinding before it is run with a bronze worm wheel.

The lubrication system should be carefully maintained and monitored to ensure that the gears receive an adequate amount of cool, clean, and dry lubricant. For circulating-oil systems, fine filtration helps remove contamination. Filters as fine as $3 \mu \mathrm{m}$ have significantly increased gear life. For circulating-oil systems, the lubricant may have to be changed or processed to remove water. With oil-bath gearboxes the lubricant should be changed frequently to remove contamination. Under normal operating conditions the lubricant should be changed at least every 2500 operating hours or every 6 months, whichever occurs first. For critical gearboxes, a regular program of lubricant monitoring can help prevent gear failure by showing when maintenance is required. Lubricant monitoring should include spectrographic and ferrographic analysis of contamination, along with analysis of acidity, viscosity, and water content. Used filter elements should be examined for wear debris and contaminants.

Following are some methods for preventing abrasive wear:

- Remove built-in contamination from new gearboxes by draining and flushing the lubricant before start up and again after the first 50 hours of operation. Refill with the recommended lubricant and install a new filter.

- Minimize internally generated wear debris by using surface-hardened gear teeth, smooth tooth surfaces, and high viscosity lubricants. 
- Minimize ingested contamination by maintaining oil-tight seals and using filtered breather vents located in clean, nonpressurized areas.

- Minimize contamination that is added during maintenance by using good housekeeping procedures.

- For circulating-oil systems, use fine filtration. Change or process the lubricant to remove water.

- For oil-bath systems, change the lubricant at least every 2500 hours or every 6 months.

- Monitor the lubricant with spectrographic and ferrographic analysis, along with analyses of acidity, viscosity, and water content.

\section{Corrosion}

Corrosion is the chemical or electrochemical reaction between the surface of a gear and its environment. The tooth surfaces may appear stained or rusty and there may be reddish-brown deposits of rust (see Figure B16). If the loose corrosion products are removed, rough irregular etch pits may be revealed. Corrosion commonly attacks the entire tooth surface and may proceed intergranularly by preferentially attacking the grain boundaries of the tooth surfaces.

Identification of metal corrosion products is proof of corrosion. For example, the identification of $\alpha-\mathrm{Fe}_{2} \mathrm{O}_{3}$ $\mathrm{H}_{2} \mathrm{O}$ by X-Ray diffraction on pitted steel is evidence of rusting.

Etch pits from corrosion on the active flanks of gear teeth cause stress concentrations that may initiate macropitting. Etch pits on the root fillets of gear teeth may cause bending fatigue cracks. Water reduces fatigue life:by causing hydrogen embrittlement, which accelerates fatigue crack growth. The particles of rust are hard and may cause abrasive wear of the gear teeth.

Corrosion is often caused by contaminants in the lubricant such as acid or water. Overly reactive, antiscuff additives can also cause corrosion, especially at high temperatures. Corrosive wear caused by contamination or formation of acids in the lubricant can be minimized by monitoring the lubricant acidity, viscosity and water content, and by changing the lubricant when required.

At times, gear tooth surfaces are chemically attacked during processing in the factory, (e.g., when copper plating is stripped from the gear after carburizing, or when acid-etch is used to inspect for grinding temper). To avoid this type of damage, proper processing procedures must be carefully followed.

Gearboxes not properly protected during storage can become corroded. If the gearbox must be stored for more than one month, special precautions are required to prevent rusting of the components [23]. Condensation occurs when humid air is cooled below its dew point and the air-water mixture releases water which collects in the form of droplets on exposed surfaces. It occurs with atmospheric air at high relative humidity where there are frequent, wide temperature changes. Gearboxes should be stored indoors where the humidity is controlled and the temperature changes are minimized. For long-term storage, it is best to completely fill the gearbox with oil and plug the breather vent. This minimizes the air space above the oil level and minimizes the amount of condensation. Where this is not practical all exposed metal parts, both inside and outside, should be sprayed with a heavy-duty rust preventative. If stored outdoors, the gearbox should be raised off the ground and completely enclosed by a protective covering such as a tarpaulin. Do not use plastic as a cover because it tends to accumulate condensation on its underside. The gear shafts should be rotated at weekly intervals to distribute oil to the gears and bearings. 


\section{Fretting Corrosion}

Fretting corrosion is the deterioration of contacting gear tooth surfaces caused by corrosion and minute vibratory motion. It occurs most often in joints that are bolted, keyed or press-fitted, and in splines or couplings; however, it may occur in gears under specific conditions where the gears are not rotating and are subjected to vibration, such as during shipping (see Figure B17).

Fretting occurs between contacting surfaces that are pressed together and subjected to cyclic, relative motion of extremely small amplitude. Under these conditions, the lubricant is squeezed from between the surfaces and the motion of the surfaces is too small to replenish the lubricant. The natural, oxide films that normally protect the surfaces are disrupted, permitting metal-to-metal contact and causing adhesion of the surface asperities. The relative motion breaks the welded asperities and generates extremely small wear particles that oxidize to form iron-oxide powder $\left(\alpha-\mathrm{Fe}_{2} \mathrm{O}_{3}\right)$, which has the fineness and reddish-brown color of cocoa. The wear debris is hard and abrasive, and is in fact of the same composition as jewelers' rouge. Fretting corrosion tends to be self aggravating because the wear debris builds a dam that prevents fresh lubricant from reaching the contact area.

Fretting corrosion is sometimes responsible for initiating fatigue cracks, which, if they are in high stress areas, may propagate to failure.

\section{Polishing}

Polishing is fine-scale abrasive wear that causes gear teeth to have a bright, mirror-like finish. The gear tooth surface may be smooth or wavy with local bumps. Under magnification, the surface appears to be covered by fine scratches that are oriented in the direction of sliding.

For gearsets with surface hardened pinions and through-hardened gears, polishing is more likely to occur on the pinion rather than the gear. Polishing is promoted by chemically active lubricants that are contaminated with a fine abrasive.

Based on the severity of the damage, polishing can be categorized as mild, moderate, or severe.

\section{Mild Polishing}

Polishing is classified as mild if it is confined to the peaks of the surface asperities. Mild polishing typically occurs during run-in and ceases before the original machining marks are removed from the tooth surface.

\section{Moderate Polishing}

Polishing is classified as moderate if remnants of the original machining marks are visible on the tooth surface.

\section{Severe Polishing}

Severe polishing removes all of the original machining marks from the active surface of the tooth. The polished surface may be wavy and there may be wear steps at the ends of the active face and in the dedendum (see Figure B18).

If the antiscuff additives in the lubricant are too chemically reactive and a fine abrasive is present the gear teeth may polish to a bright, mirror-like finish. Although the polished gear teeth may look good, polishing 
wear is undesirable because it generally reduces gear accuracy by wearing the tooth profiles away from their ideal form. Antiscuff additives used in lubricants to prevent scuffing, such as sulfur and phosphorus, will be covered when scuffing is discussed. They function by forming iron-sulfide and iron-phosphate films on areas of the gear teeth where high temperatures occur. Ideally, the additives should react only at temperatures where there is a danger of welding. If the rate of reaction is too high and there is a continuous removal of the surface films through wear caused by very fine abrasives in the lubricant, polishing wear may be excessive [24].

Polishing wear can be prevented by using less chemically active additives and clean oil. As an alternative to sulfur-phosphorus additives, antiscuff lubricants are available with dispersions of potassium borate [25] that deposit antiscuff films without chemically reacting with the metal. The abrasives in the lubricant should be removed by using fine filtration or through frequent oil changes.

Following are methods for preventing polishing wear:

- Use less chemically active antiscuff additives such as borate.

- Remove abrasives from the lubricant by using fine filtration or through frequent oil changes.

\section{Electric Discharge}

Gear teeth may be damaged if faulty insulation, induction effects or improper grounding allows electric current to pass through the gear mesh. Electric discharge damage is caused by electric arc discharge across the oil film between the active flanks of the mating gear teeth. The electric current may originate from electric motors, electric clutches or instrumentation, or it may result from accumulation of static charge and subsequent discharge. The damage may occur during electric welding on or near the gearbox if the path to ground is not properly made around the gears rather than through them.

An electric arc produces temperatures high enough to locally melt the gear tooth surface. Microscopically, the damage appears as small, hemispherical craters. The edges of the craters are smooth and may be surrounded by burned or fused metal in the form of rounded particles that were once molten. A metallurgical section taken transversely through the craters and acid etched may reveal austenitized and rehardened areas in white, bordered by tempered areas in black. Sometimes microcracks are found near the craters.

The overall damage to the gear teeth is proportional to the number and size of the points of arcing. Depending on its extent, electric discharge damage may be destructive to the gear teeth. Because of associated microcracking, it may also lead to subsequent Hertzian fatigue or bending fatigue. If arc burns are found on the gears, all associated bearings should be examined for similar damage.

Electric discharge damage can be prevented by providing adequate electrical insulation or grounding and by ensuring that proper welding procedures are enforced.

\section{Scuffing}

Scuffing is severe adhesive wear that causes transfer of metal from one tooth surface to another due to welding and tearing. The scuffed areas appear to have a rough or matte texture. The damage typically occurs in the addendum or dedendum of the tooth in narrow or broad bands that are oriented in the direction of sliding. Scuffing may occur in localized patches if it is caused by load concentrations. Under magnification, the scuffed surface appears rough, tom, and plastically deformed. Scuffing is not a fatigue phenomenon and it may occur instantaneously. 
Based on the severity of the damage, scuffing can be categorized as mild, moderate, or severe.

\section{Mild Scuffing}

Scuffing is classified as mild if it occurs only on small areas of the teeth and is confined to the peaks of the surface asperities. Generally, mild scuffing is nonprogressive.

\section{Moderate Scuffing}

Moderate scuffing occurs in patches that cover significant portions of the teeth. If the operating conditions do not change, moderate scuffing may be progressive.

\section{Severe Scuffing}

Severe scuffing occurs on significant portions of the gear tooth (for example, the entire addendum, the entire dedendum, or both). In some cases the surface material may be plastically deformed and displaced over the tip of the tooth or into the root of the tooth. Unless corrective measures are taken, severe scuffing is usually progressive (see Figure B19).

Scuffing may occur in gear teeth when they operate in the boundary lubrication regime. If the lubricant film is insufficient to prevent significant metal-to-metal contact, the oxide layers that normally protect the gear tooth surfaces may be broken through and the bare metal surfaces may weld together. The sliding that occurs between gear teeth results in tearing of the welded junctions, metal transfer and sometimes catastrophic damage.

In contrast to pitting and bending fatigue, which only occur after a period of running time, scuffing may occur immediately upon start-up. In fact, gears are most vulnerable to scuffing when they are new and their tooth surfaces have not yet been smoothed by running-in. For this reason, it is wise to run-in new gears under one-half load for at least 10 hours to reduce the surface roughness of the teeth before applying full load. The gear teeth can be coated with iron-manganese phosphate or plated with copper or silver to protect them from scuffing during the critical running-in period.

The basic mechanism of scuffing is not clearly understood, but there is general agreement that it is caused by intense frictional heating generated by the combination of high sliding velocity and intense surface pressure. Blok's [27] critical temperature theory is believed to be the best criterion for predicting scuffing. It states that scuffing will occur in gear teeth that are sliding under boundary-lubricated conditions when the maximum contact temperature of the gear teeth reaches a critical magnitude. For mineral oils without antiscuff additives, each combination of oil and gear tooth material has a critical scuffing temperature that is constant, regardless of the operating conditions [28]. Critical scuffing temperatures are not constant for synthetic lubricants and lubricants with antiscuff additives and must be determined from tests which closely simulate the operating conditions of the gears.

Today, most antiscuff additives are sulfur-phosphorus compounds which form boundary-lubricating films by chemically reacting with the metal surfaces of the gear teeth at local points of high temperature. Antiscuff films help prevent scuffing by forming solid films on the gear tooth surfaces and inhibiting true metal-to-metal contact. The films of iron-sulfide and iron-phosphate have high melting points, allowing them to remain as solids on the gear tooth surfaces even at high contact temperatures. The rate of reaction of the antiscuff additives is greatest where the gear tooth contact temperatures are highest. Because of the rubbing action of the gear teeth, the surface films are repeatedly scraped off and reformed. In effect, scuffing is prevented by substituting mild corrosion in its place. Occasionally, antiscuff additives (for example, sulfur) are too chemically active, causing polishing wear and necessitating a change to less 
aggressive additives. Lubricants with antiscuff additives of potassium borate do not cause polishing wear because they deposit glass-like boundary films without reacting with the metal.

For mineral oils without antiscuff additives the critical scuffing temperature increases with increasing viscosity and ranges from $150^{\circ} \mathrm{C}-300^{\circ} \mathrm{C}\left(302^{\circ}-572^{\circ} \mathrm{F}\right)$. The increased scuffing resistance of high viscosity lubricants is believed to result from differences in chemical composition rather than increases in viscosity. However, a viscosity increase also helps to reduce the risk of scuffing by increasing the lubricant film thickness and reducing the contact temperature generated by metal-to-metal contact.

According to Blok, scuffing is controlled by the total contact temperature Tc, which consists of the sum of the gear bulk temperature $\mathrm{Tb}$ and the flash temperature Tf:

$$
\mathrm{Tc}=\mathrm{Tb}+\mathrm{Tf}
$$

The bulk temperature is the equilibrium temperature of the surface of the gear teeth before they enter the meshing zone. The flash temperature is the local and instantaneous temperature rise that occurs on the gear teeth due to the frictional heating as they pass through the meshing zone.

Anything that reduces either the bulk temperature or the flash temperature will reduce the total contact temperature and lessen the risk of scuffing. Higher viscosity lubricants or smoother tooth surfaces help by increasing the specific film thickness, which in tum reduces the frictional heat and, therefore, the flash temperature. Also, the lubricant performs the important function of removing heat from the gear teeth. The lubricant must be supplied to the gear teeth in such a way that it removes heat rapidly and maintains a low bulk temperature. A heat exchanger can be used with a circulating-oil system to cool the lubricant before it is sprayed at the gears.

The gear designer can maximize scuffing resistance by optimizing the gear geometry so that the gear teeth are as small as possible and are consistent with bending strength requirements to reduce the temperature rise caused by sliding. The amount of sliding is proportional to the distance from the pitch point. It is zero when the gear teeth contact at the pitch point and is largest at the ends of the path of action. Addendum modification can be used to balance and minimize the temperature rise that occurs in the addendum and dedendum of the gear teeth. The temperature rise may also be reduced by modifying the tooth profiles with slight tip and/or root relief to ease the load at the start and end of the engagement path, where the sliding velocities are the greatest. Also, the gear teeth should be accurate and held rigidly in good alignment to minimize the tooth loading and, therefore, the temperature rise.

Gear materials should be chosen with their scuffing resistance in mind. Nitrided steels, such as Nitralloy $135 \mathrm{M}$, are generally found to have the highest resistance to scuffing, whereas stainless steels are liable to scuff even under near-zero loads. The thin oxide layer on stainless steel is hard and brittle and breaks up easily under sliding loads. This exposes the bare metal and promotes scuffing. Like stainless steel, anodized aluminum has a low scuffing resistance. Hardness does not seem to be a reliable indication of scuffing resistance.

Following are some methods for preventing scuffing:

- Use smooth tooth surfaces produced by careful grinding or honing.

- Protect the gear teeth during the critical run-in period by coating them with iron-manganese phosphate or plating them with copper or silver. Run-in new gearsets by operating the first 10 hours at one-half load. 
- Use high viscosity lubricants with antiscuff additives such as sulfur, phosphorus, or borate.

- Cool the gear teeth by supplying an adequate amount of cool lubricant. For circulating-oil systems, use a heat exchanger to cool the lubricant.

- Optimize the gear tooth geometry by using small teeth, addendum modification, and profile modification.

- Use accurate gear teeth, rigid gear mountings, and good helix alignment.

- Use nitrided steels for maximum scuffing resistance. Do not use stainless steel or aluminum for gears if there is a risk of scuffing. 


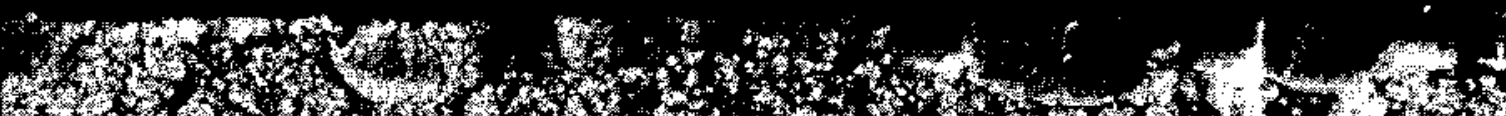

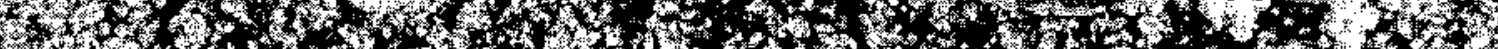
-

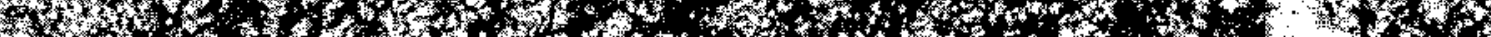

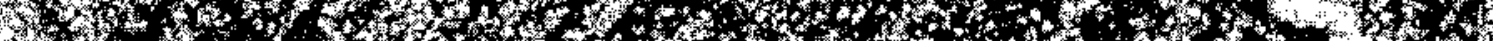

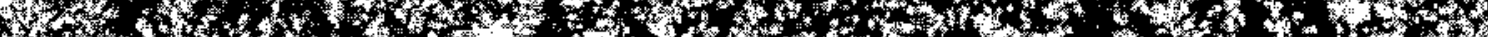

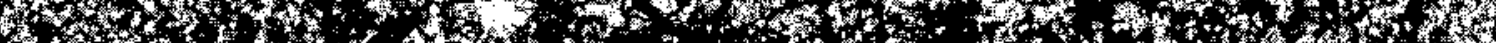

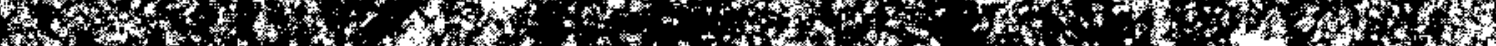

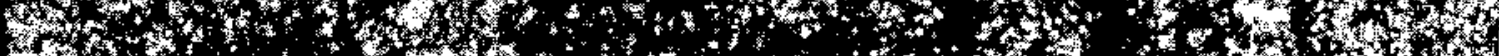

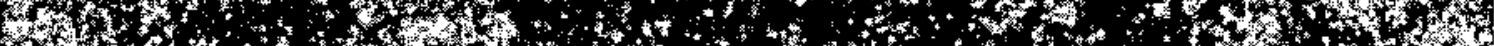

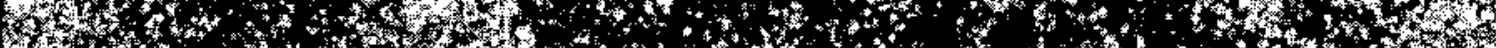

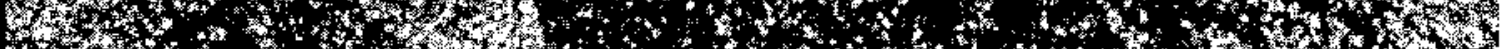

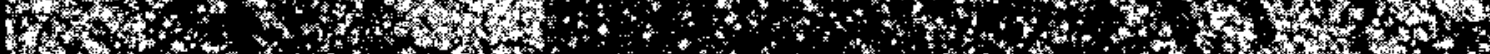

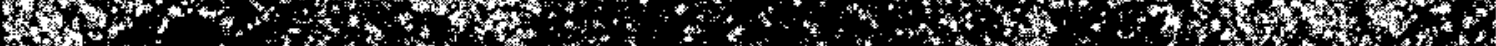
20

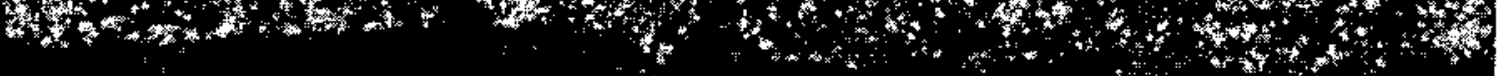

Figure B1 Brittle fracture due to overload

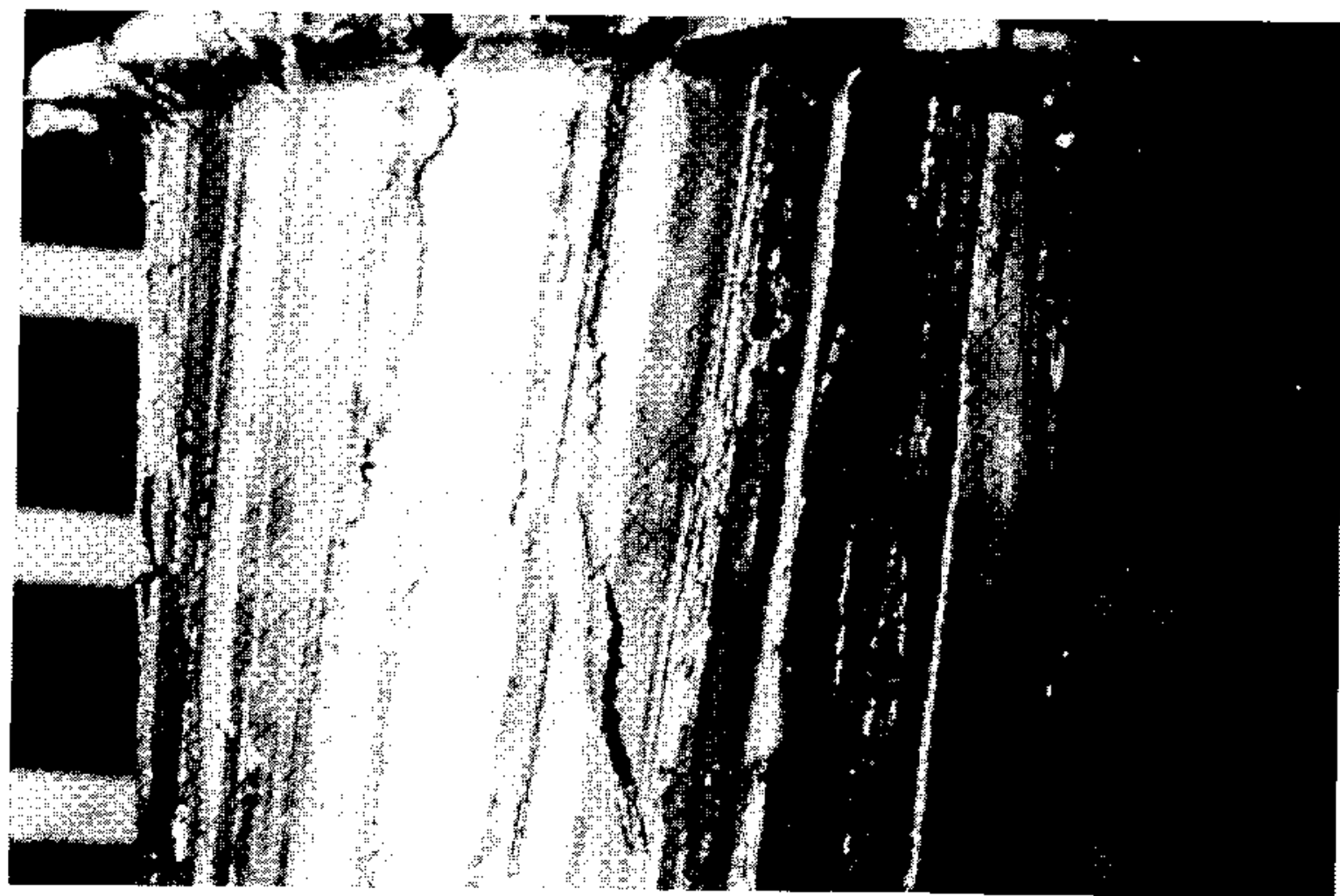

Figure B2 Ductile fracture with significant plastic deformation 


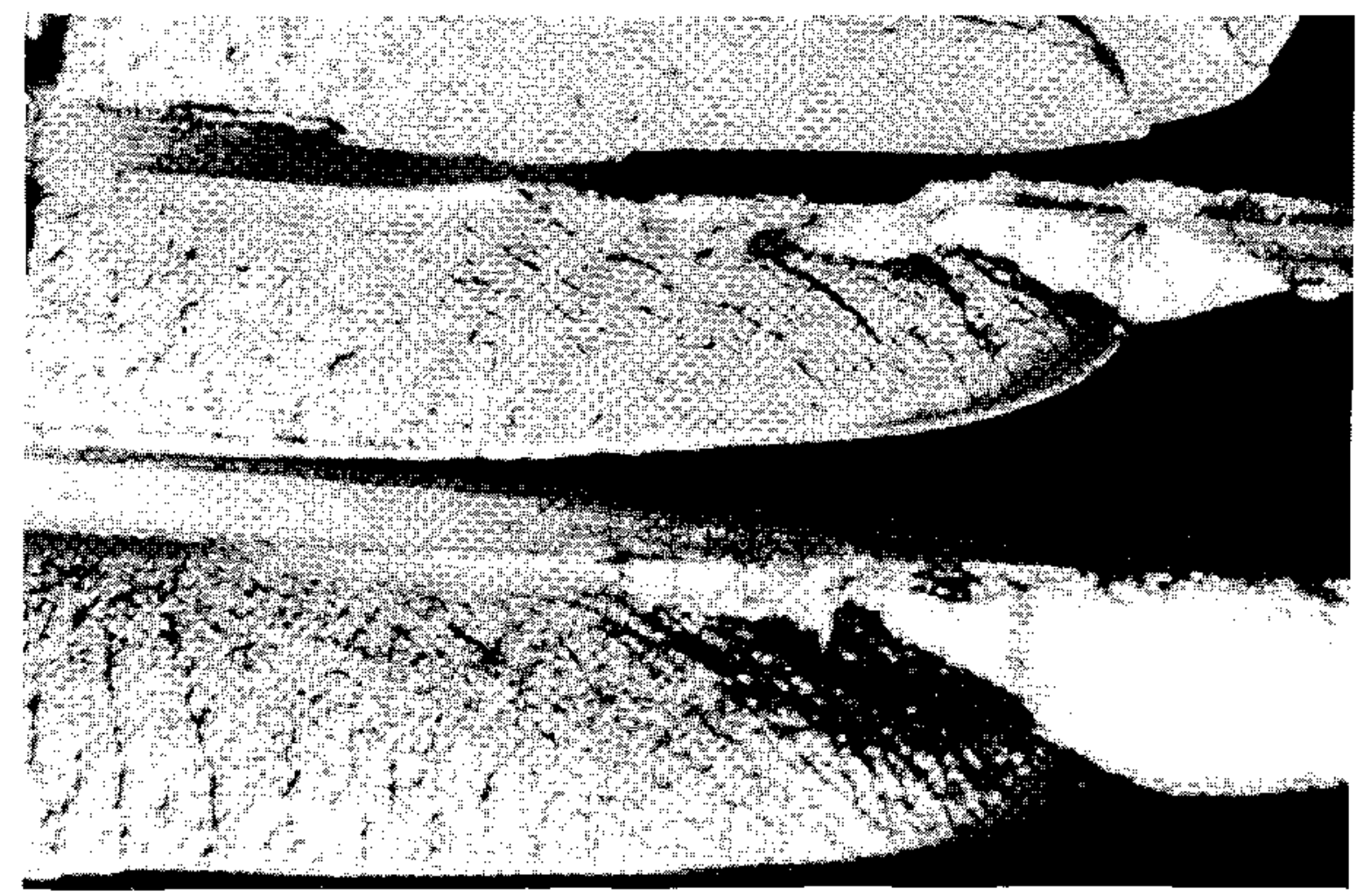

Figure B3 Mixed-mode fracture showing brittle and ductile fractures

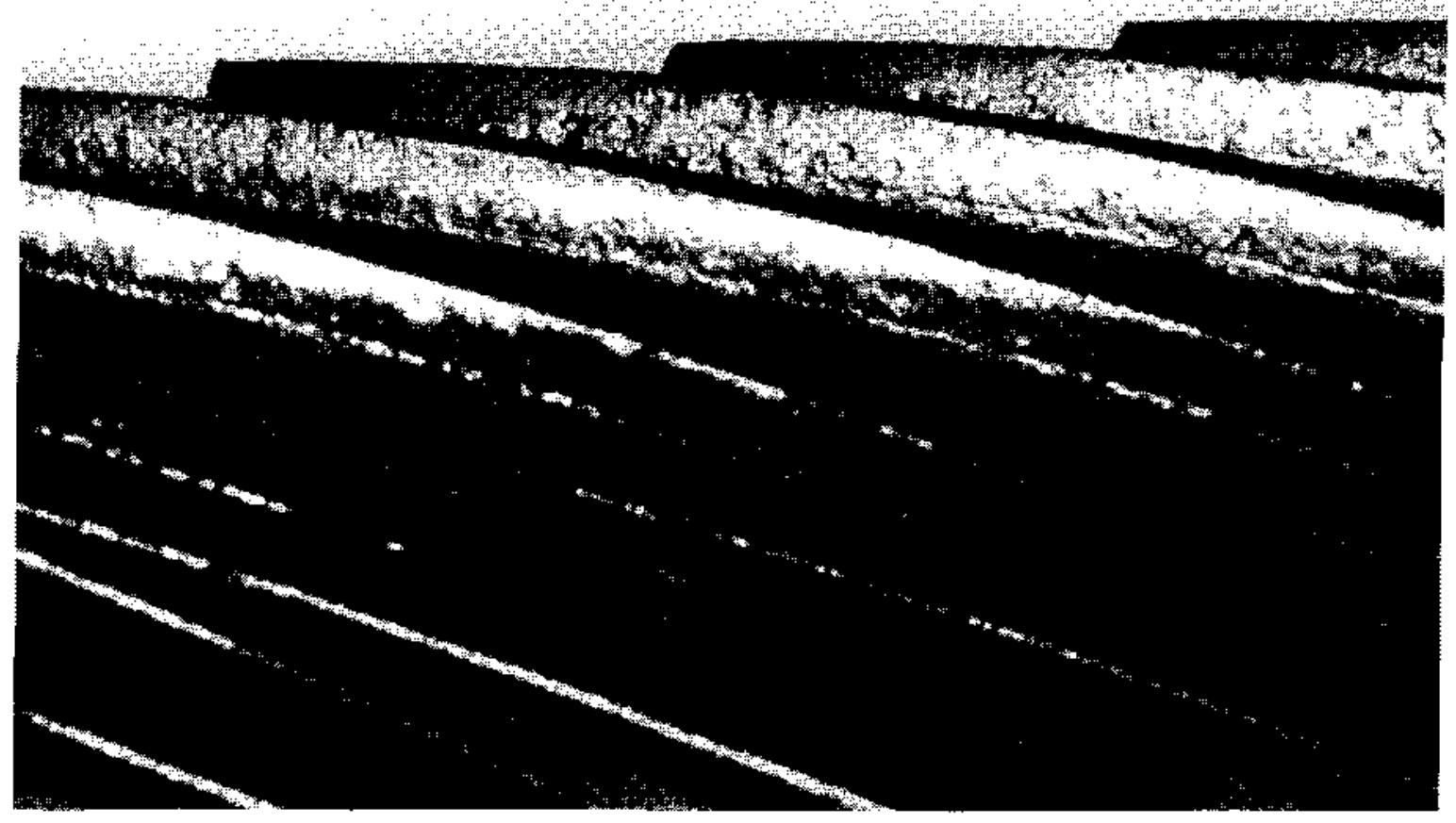

Figure B4 Plastic deformation 


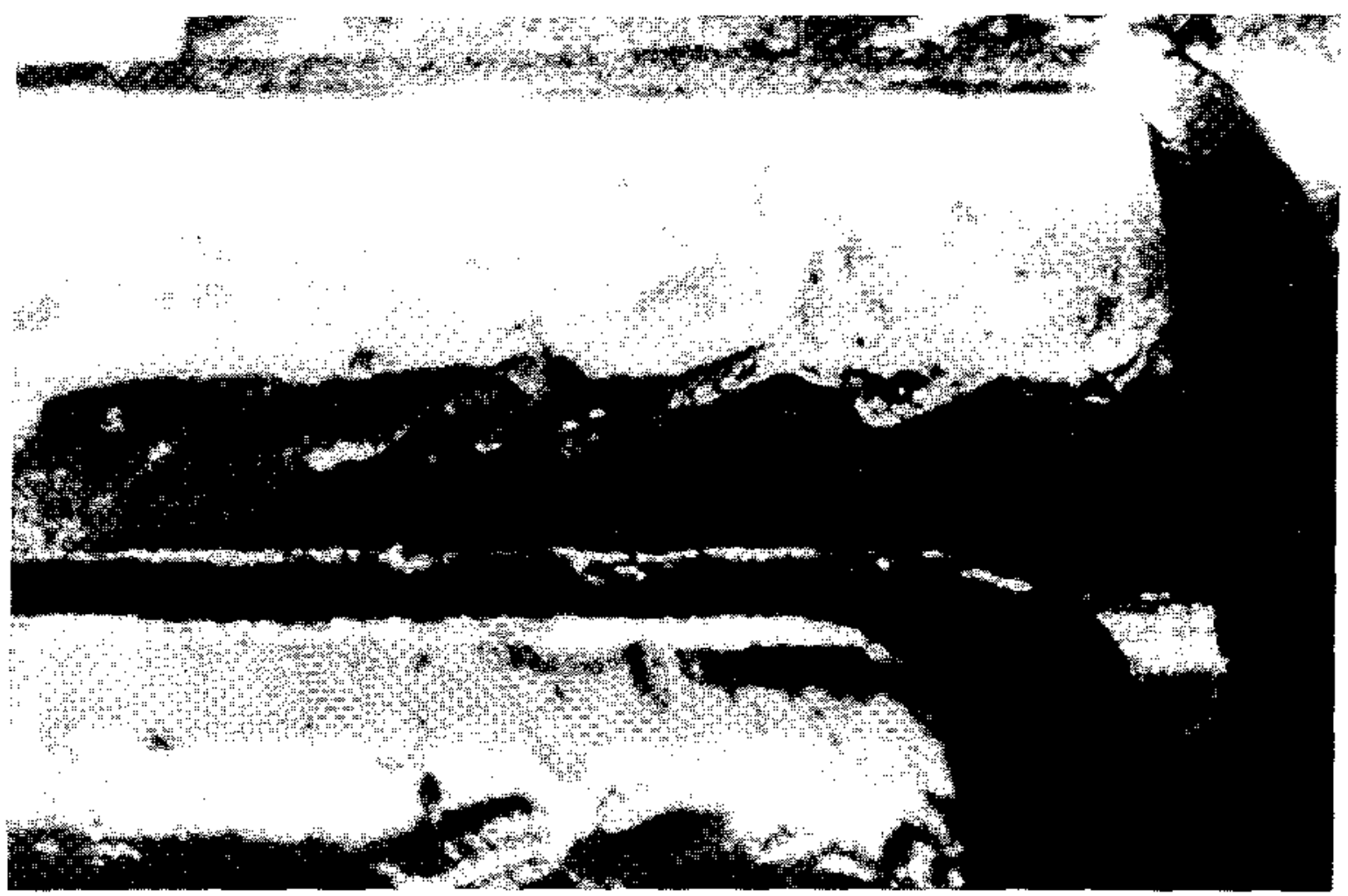

Figure B5 Indentation caused by debris running through the mish

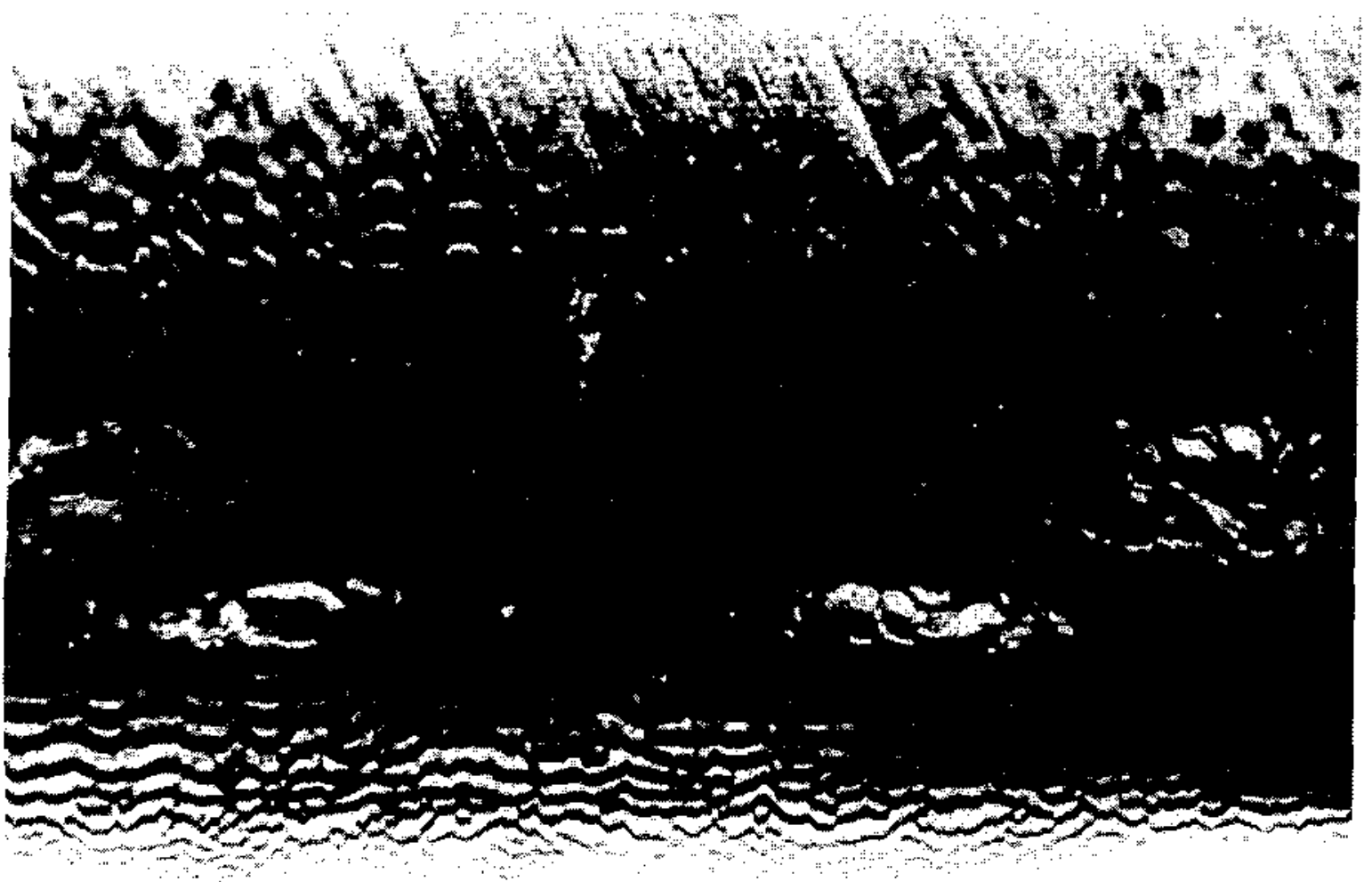

Figure B6 Rippling due to boundary lubrication conditions 


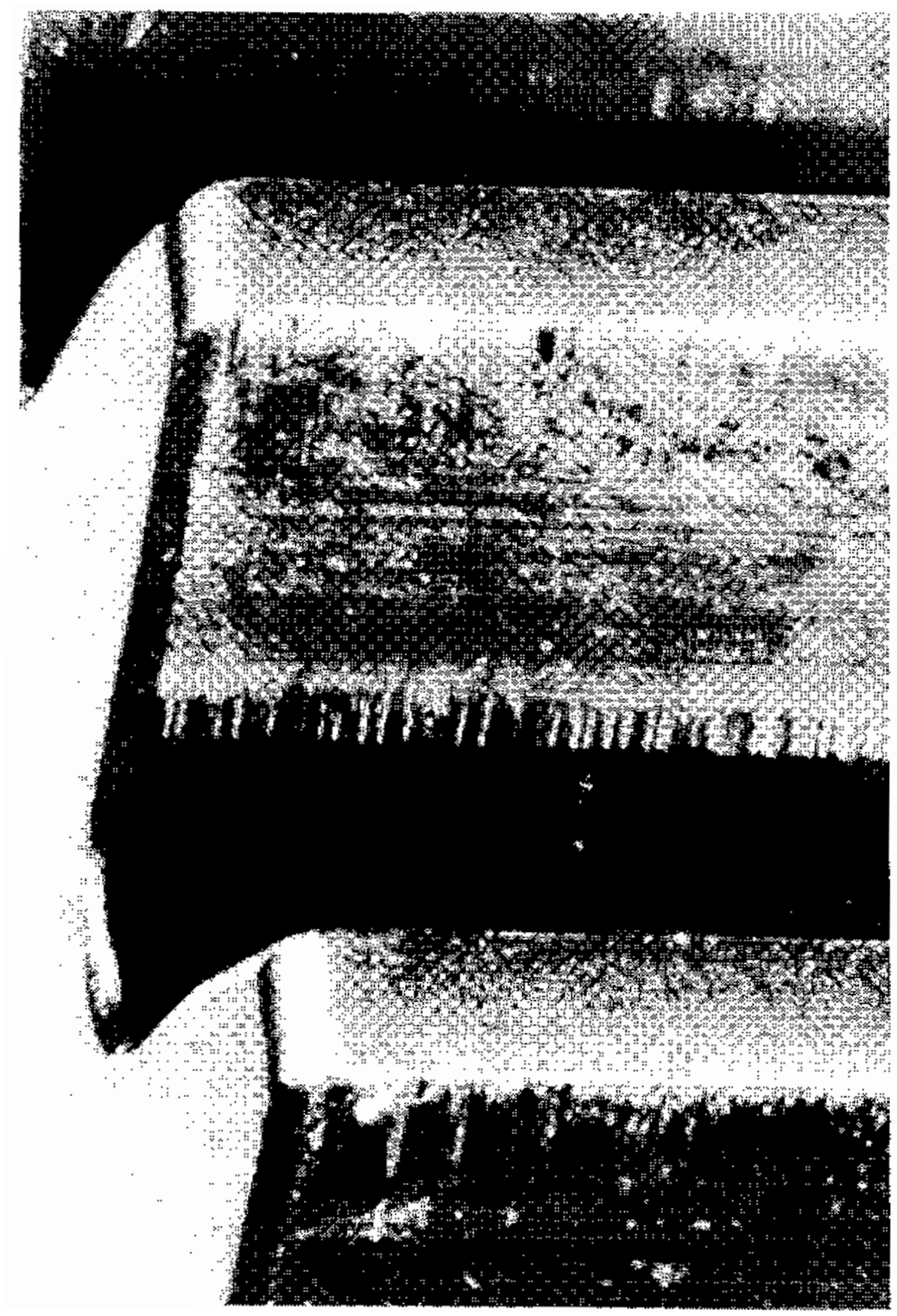

Figure B7 Tip-to-root interference due to inadequate profile modification 


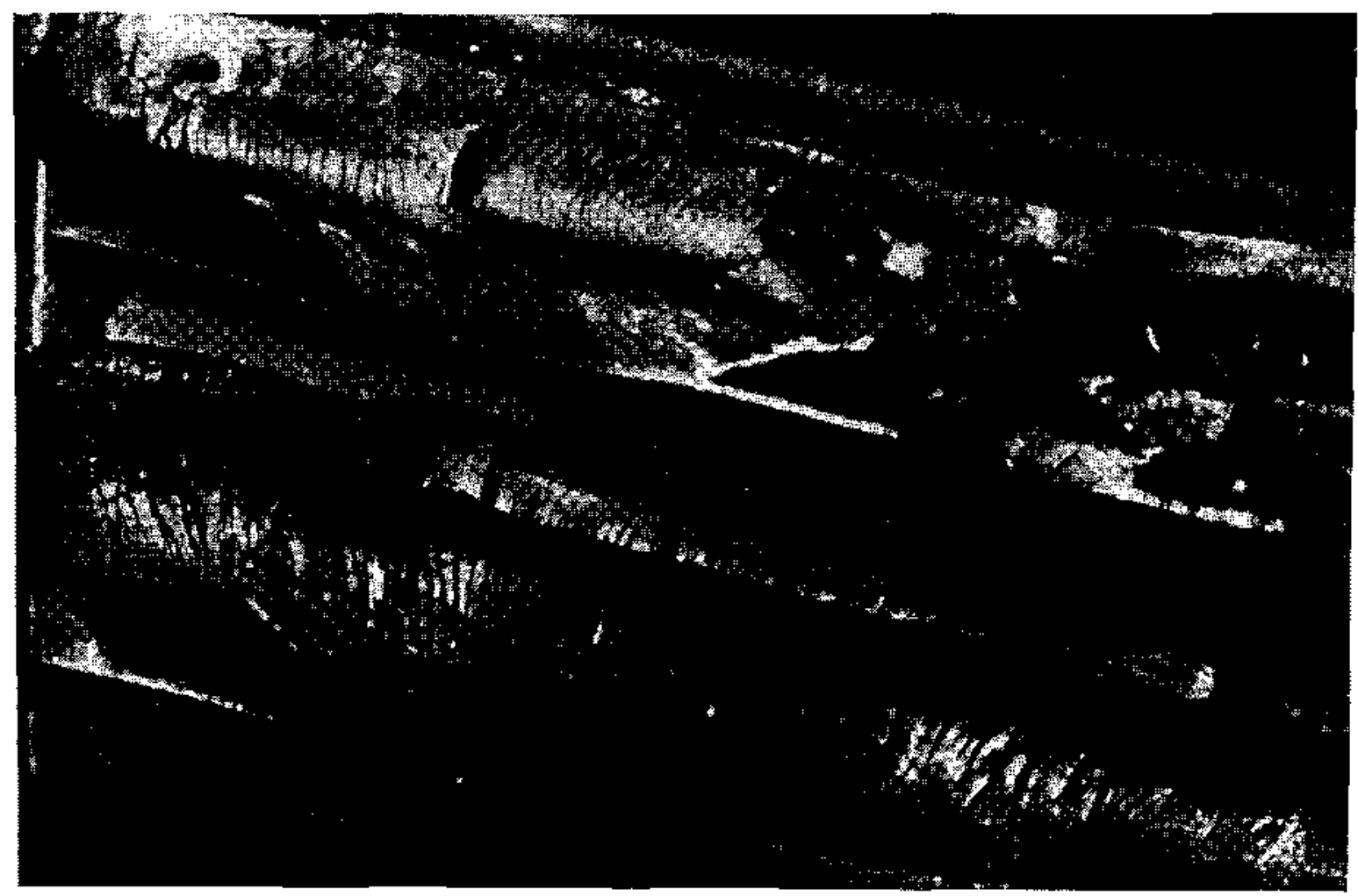

Figure B8 Bending fatigue due to a manufacturing defect

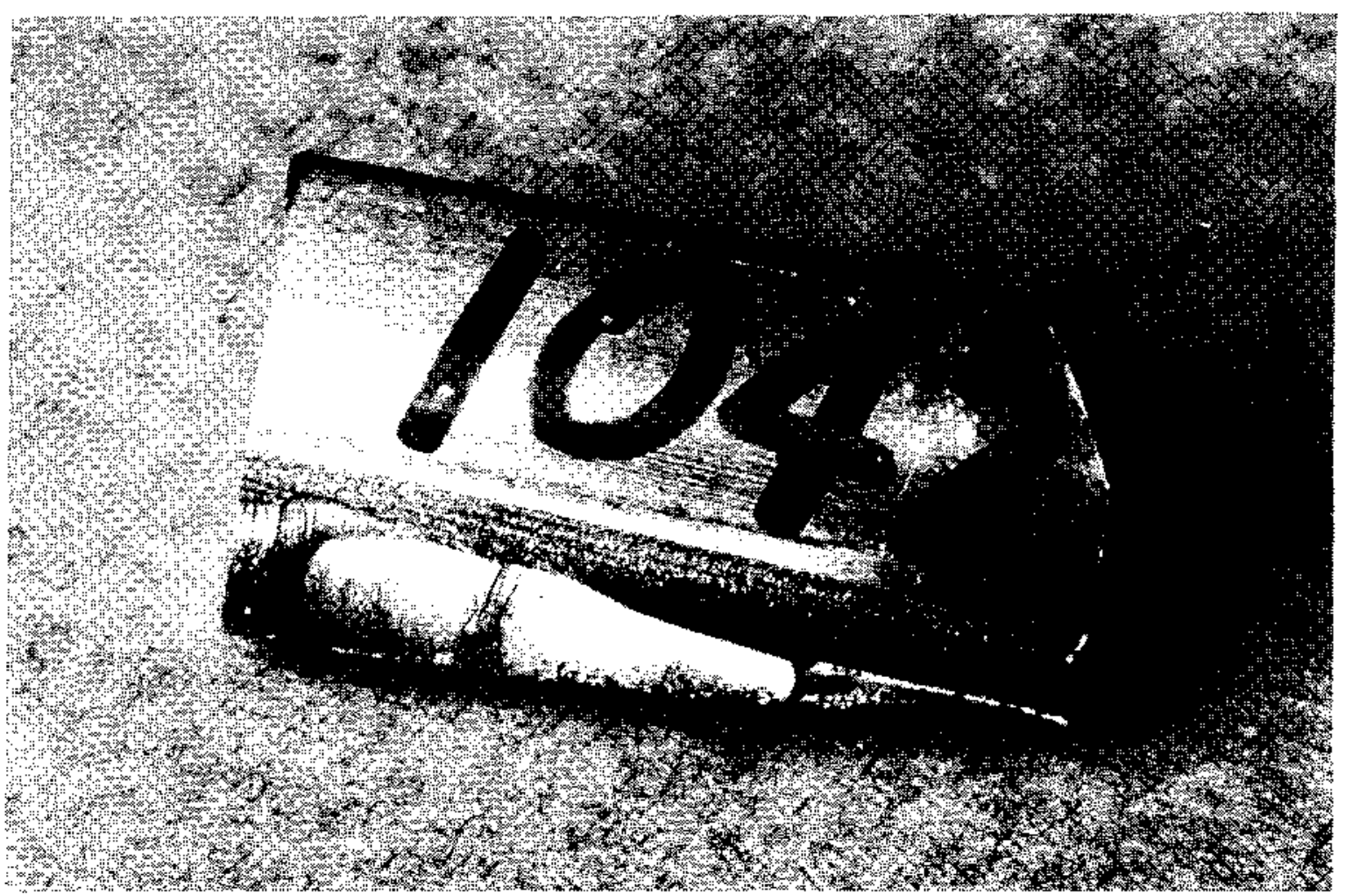

Figure B9 Bending fatigue root fillet crack due to material defect 


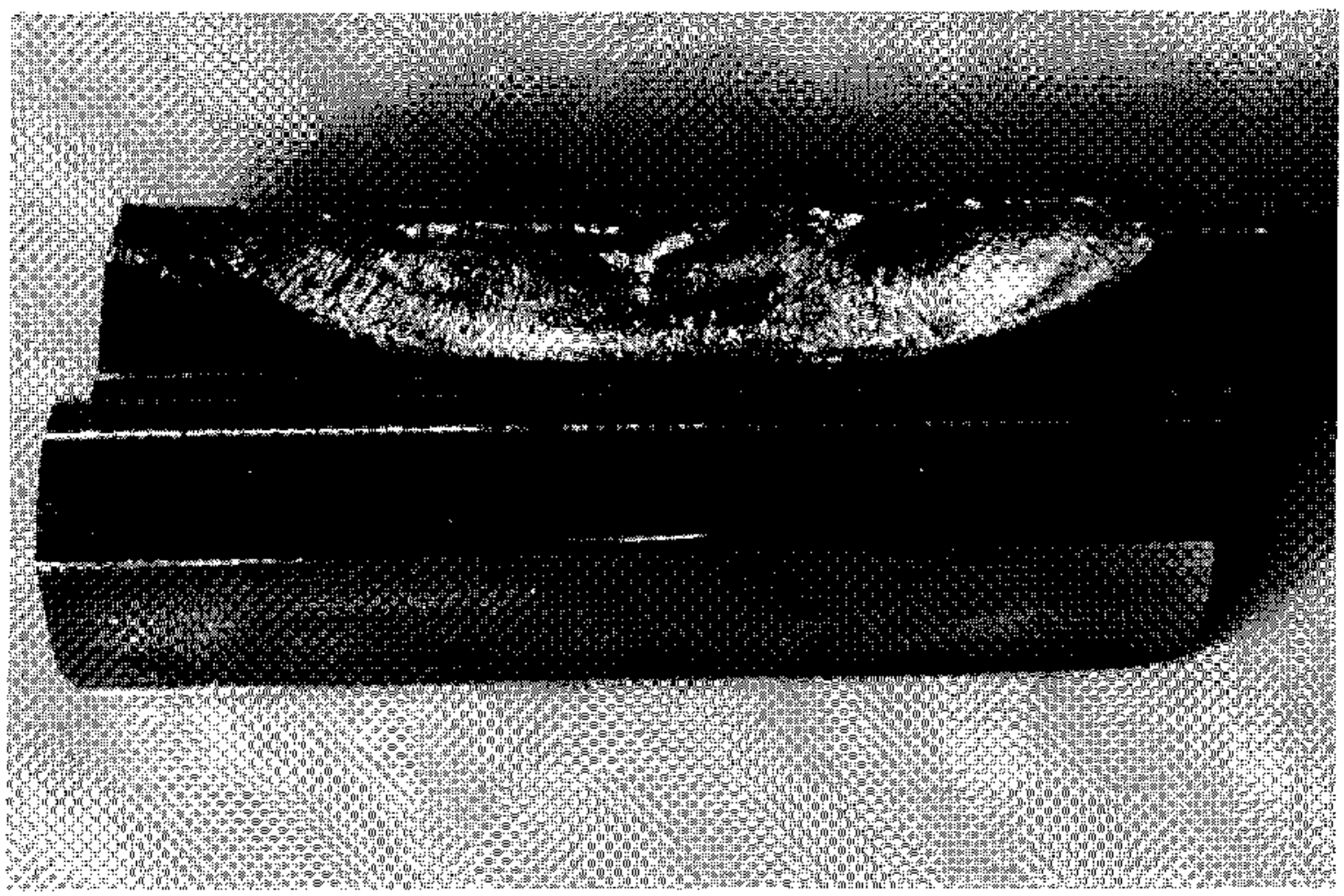

Figure B10 Bending fatigue crack on profile near pirchline

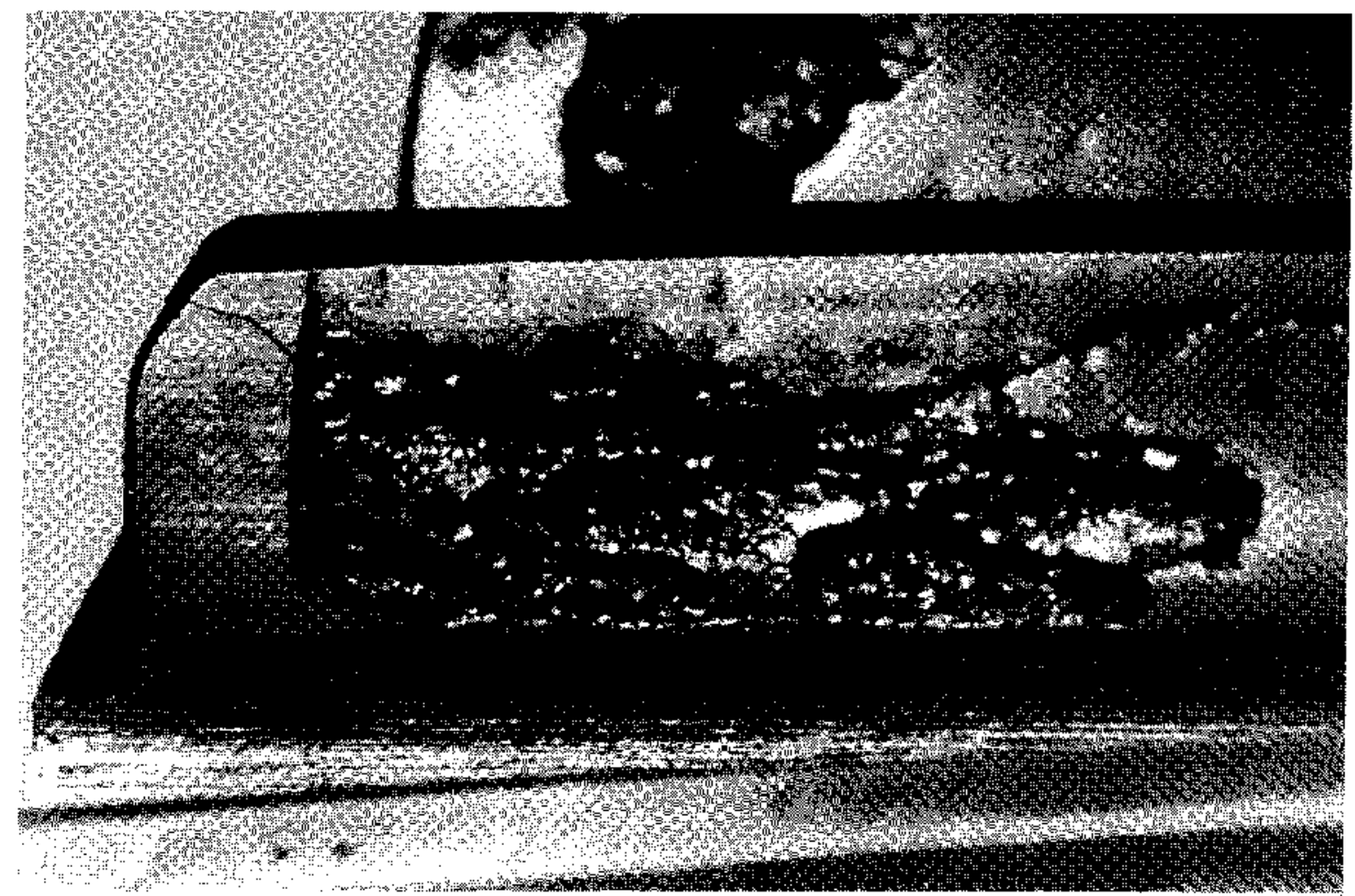

Figure B11 Macropits due to gear tooth misalignment 


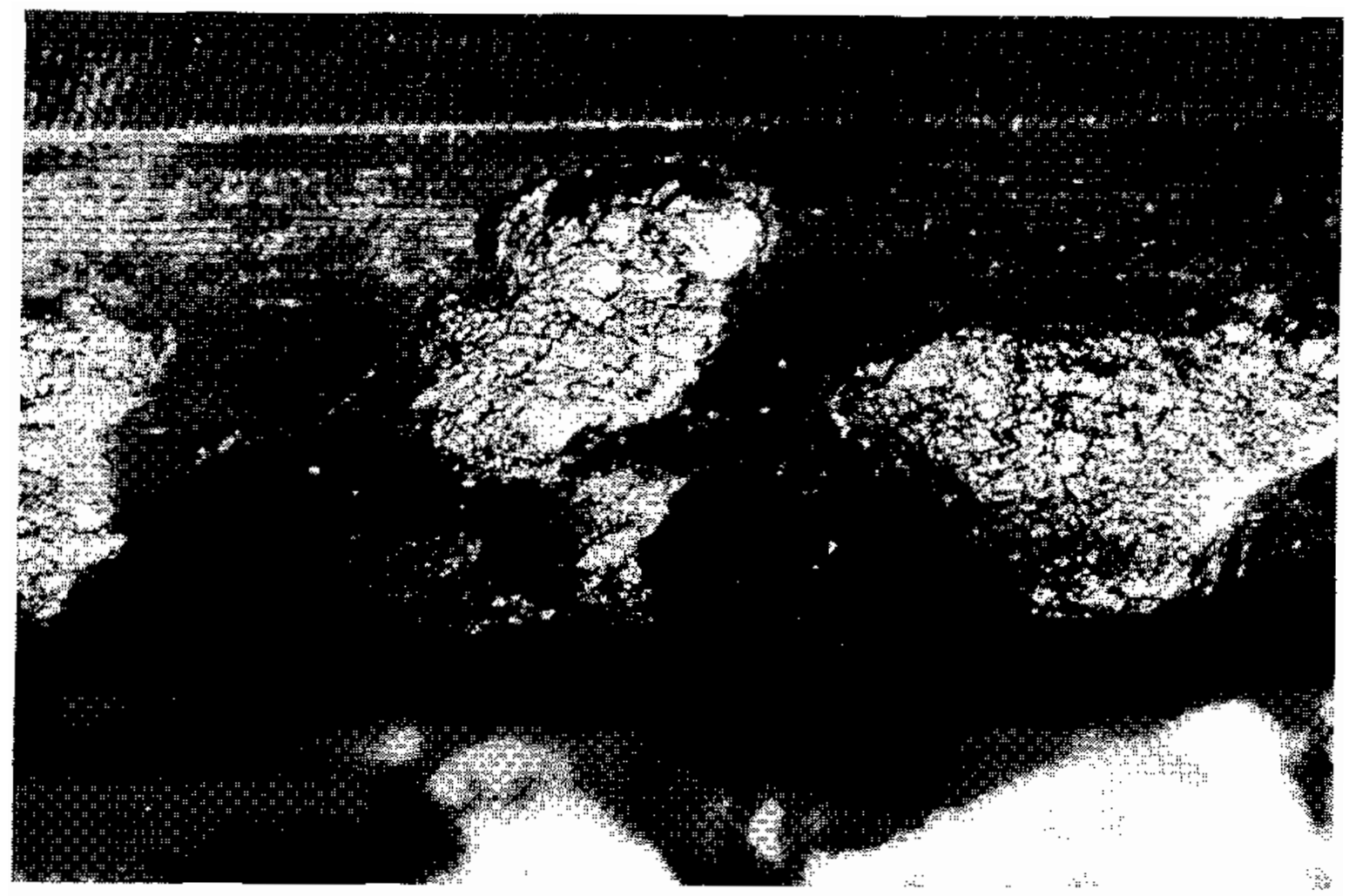

Figure B12 Characteristic triangular-shaped flake macroplts

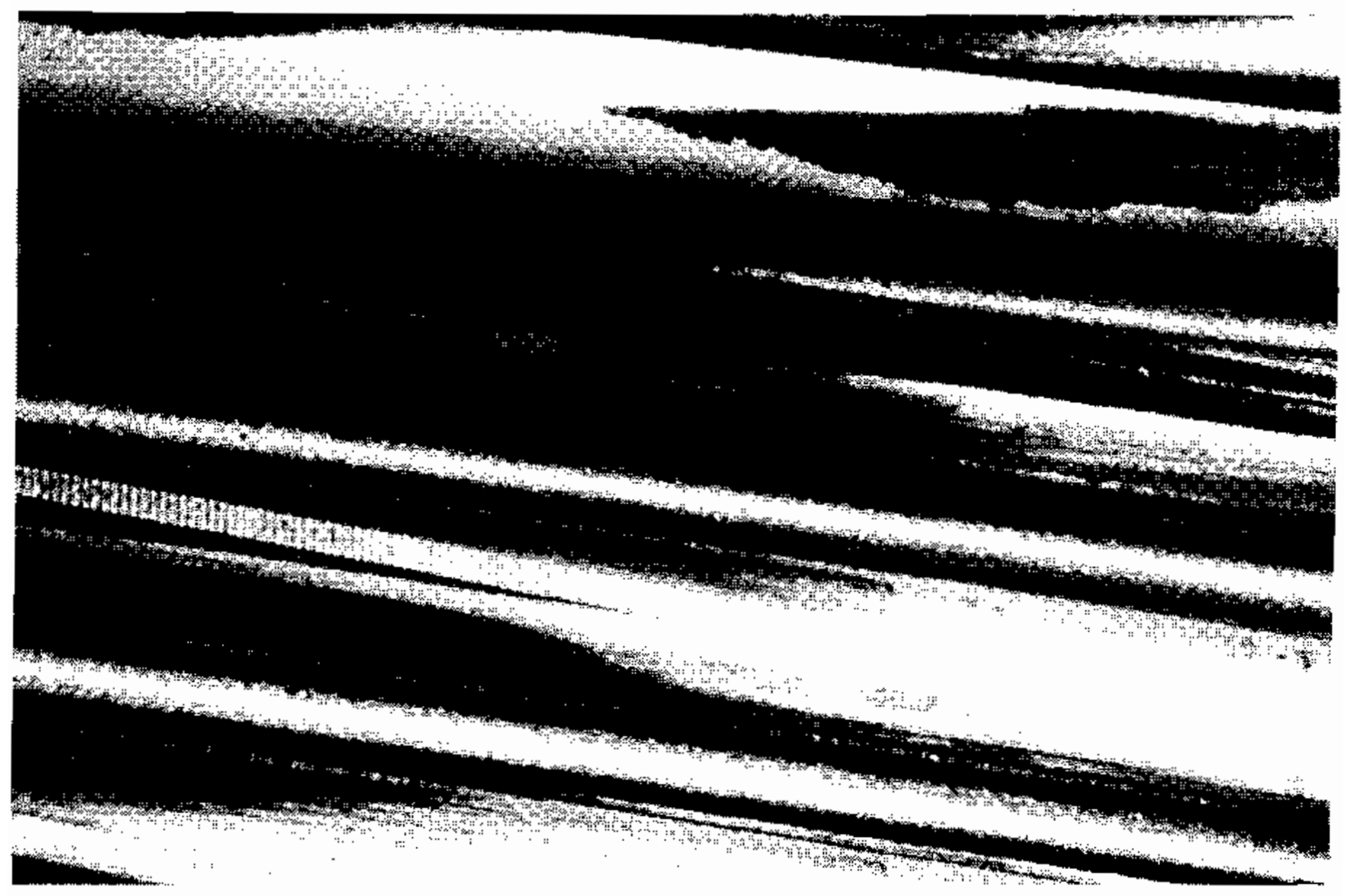

Figure B13 Micropitting due to inadequate lubricant viscosity 


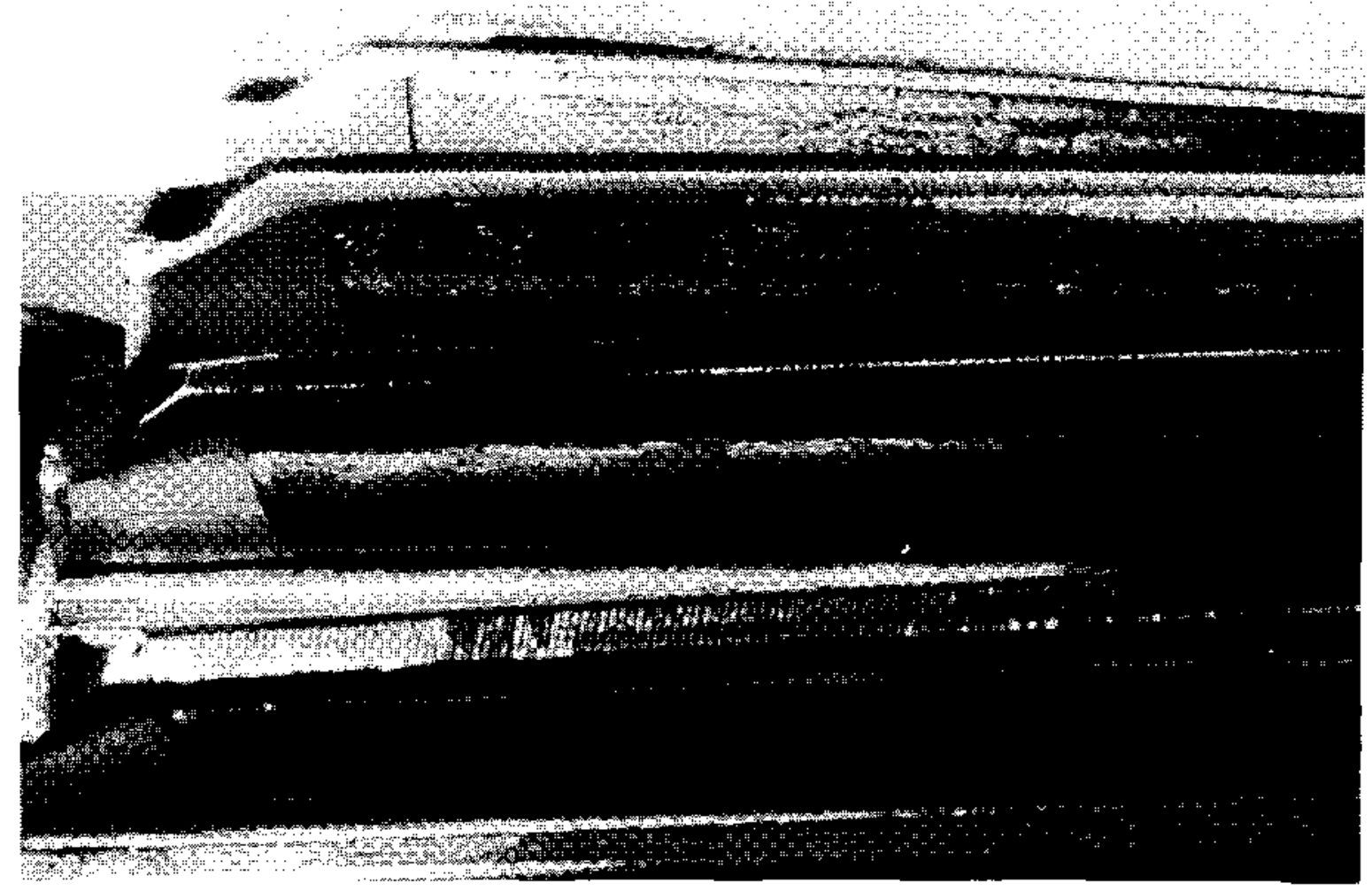

Figure B14 Typical patchy micropitting

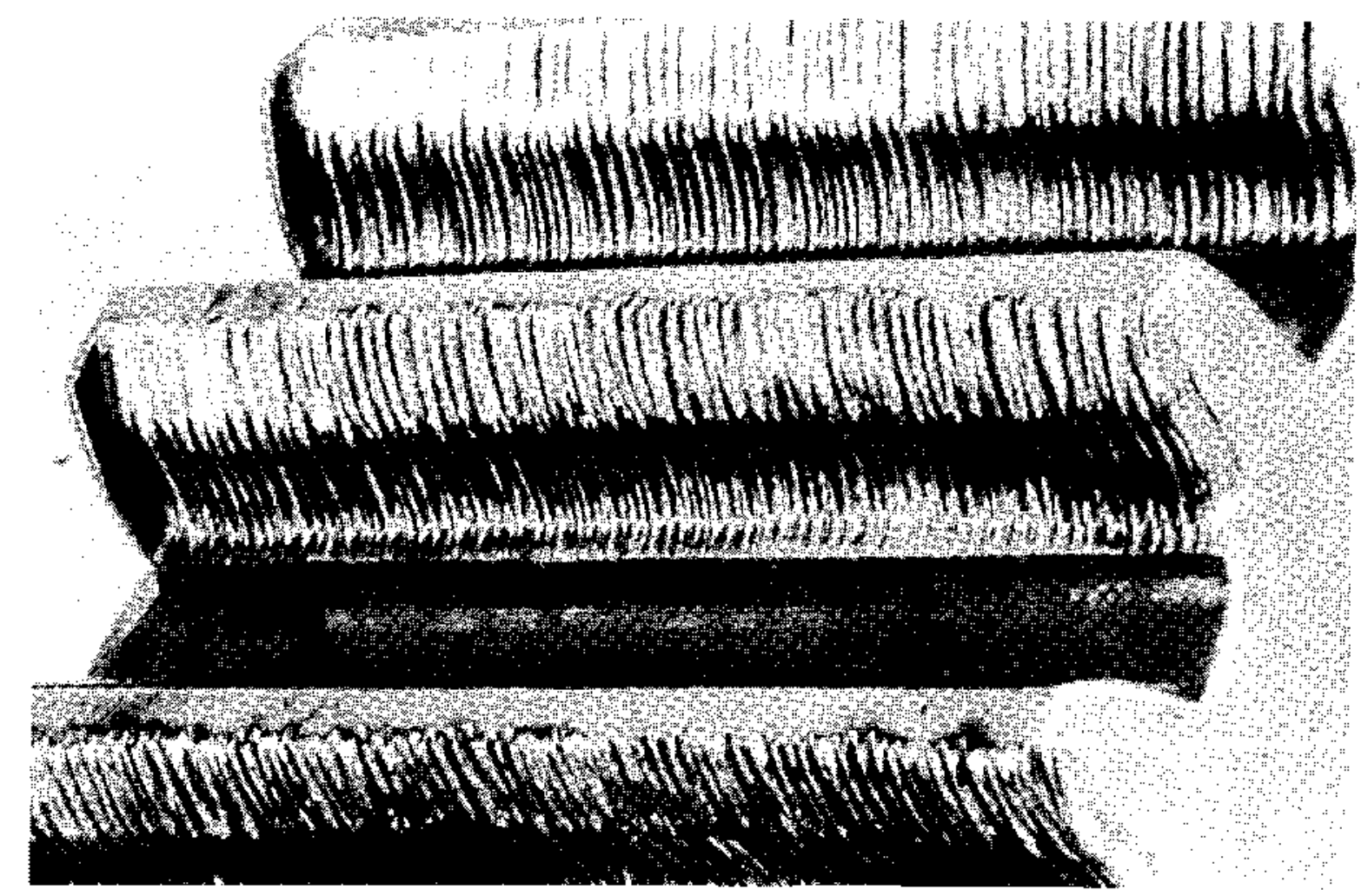

Figure B15 Severe abrasive wear 


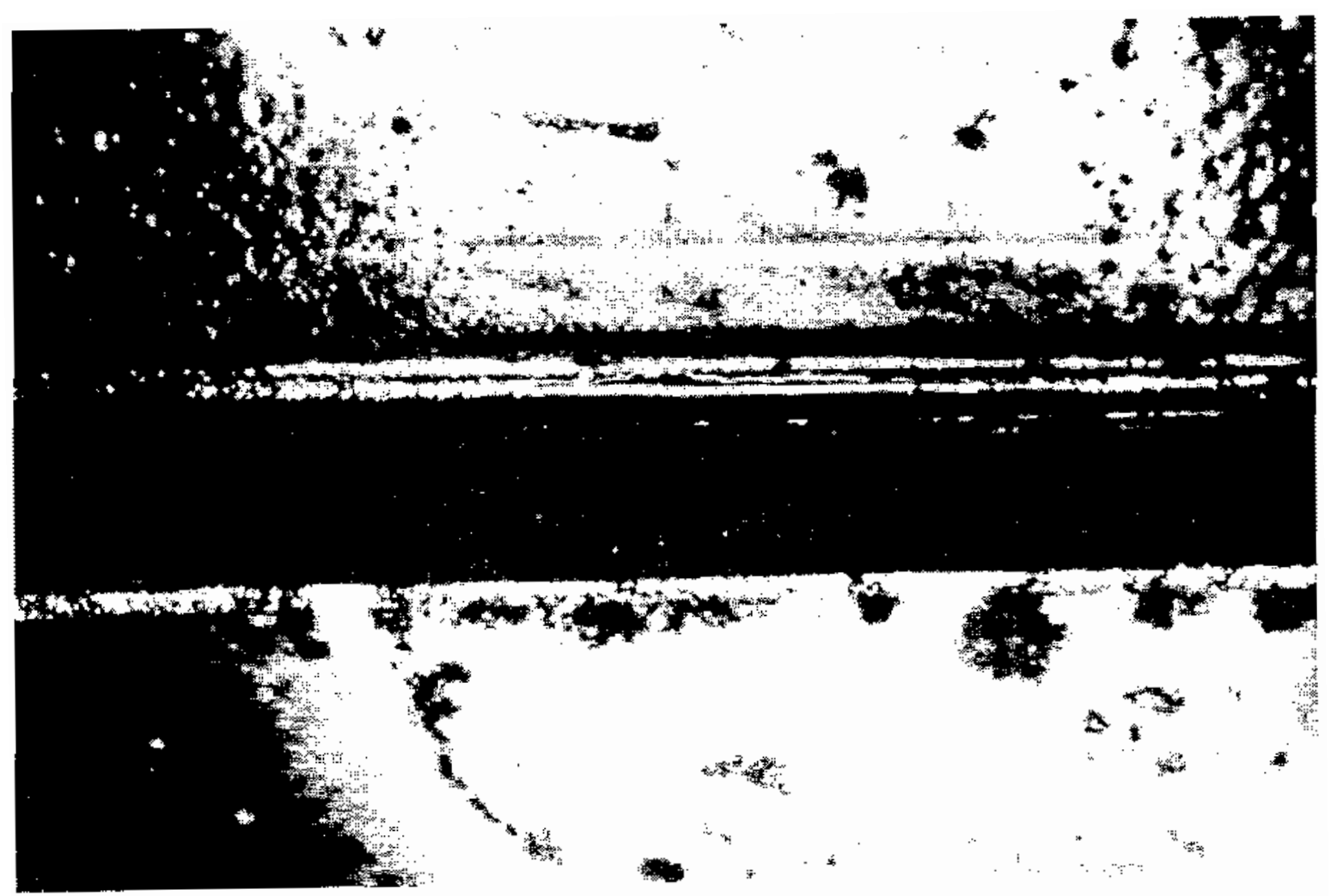

Figure B16 Corrosion in the form of rust deposits

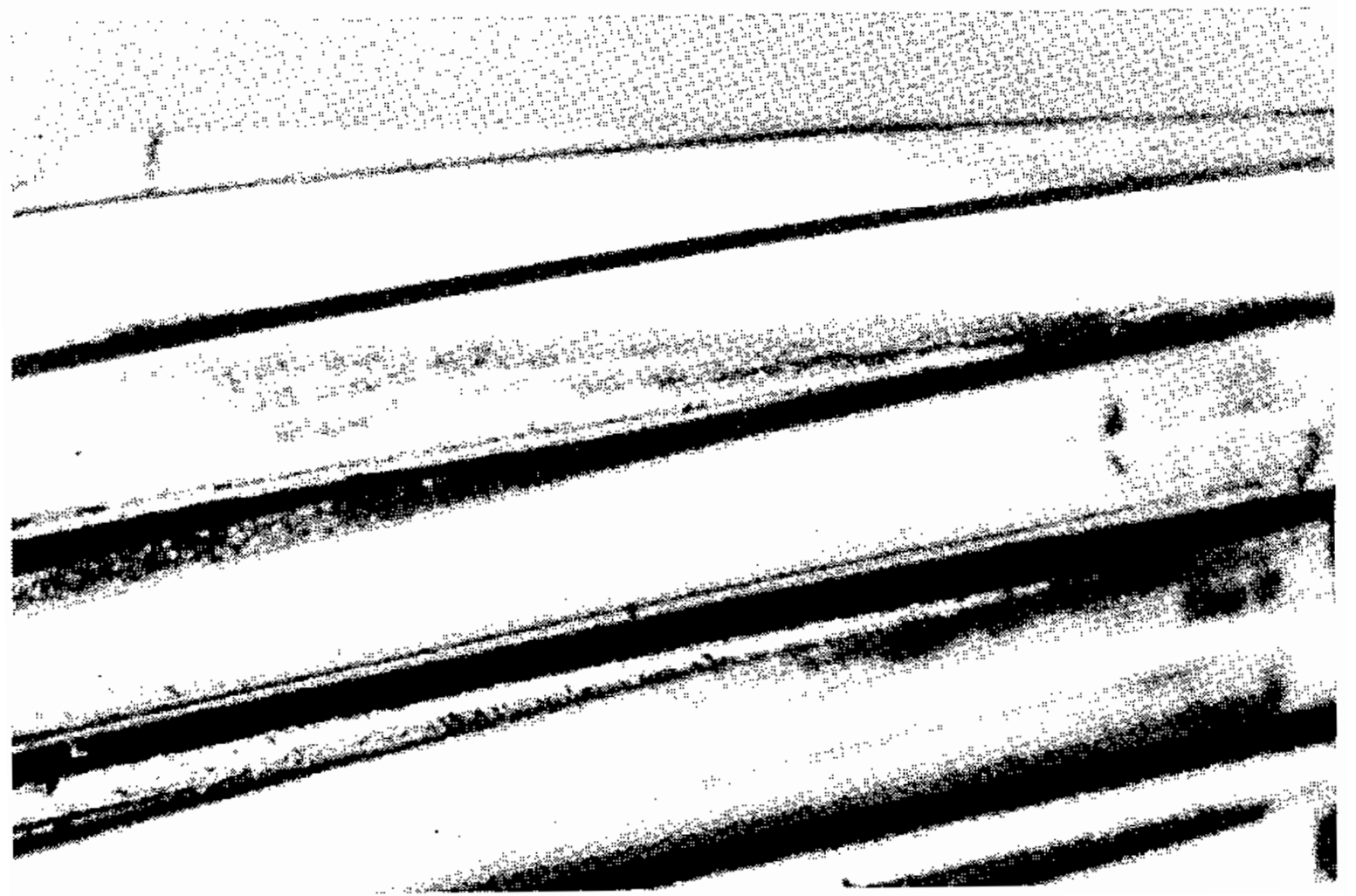

Figure B17 Fretting corrosion due to vibration of a parked turbine 


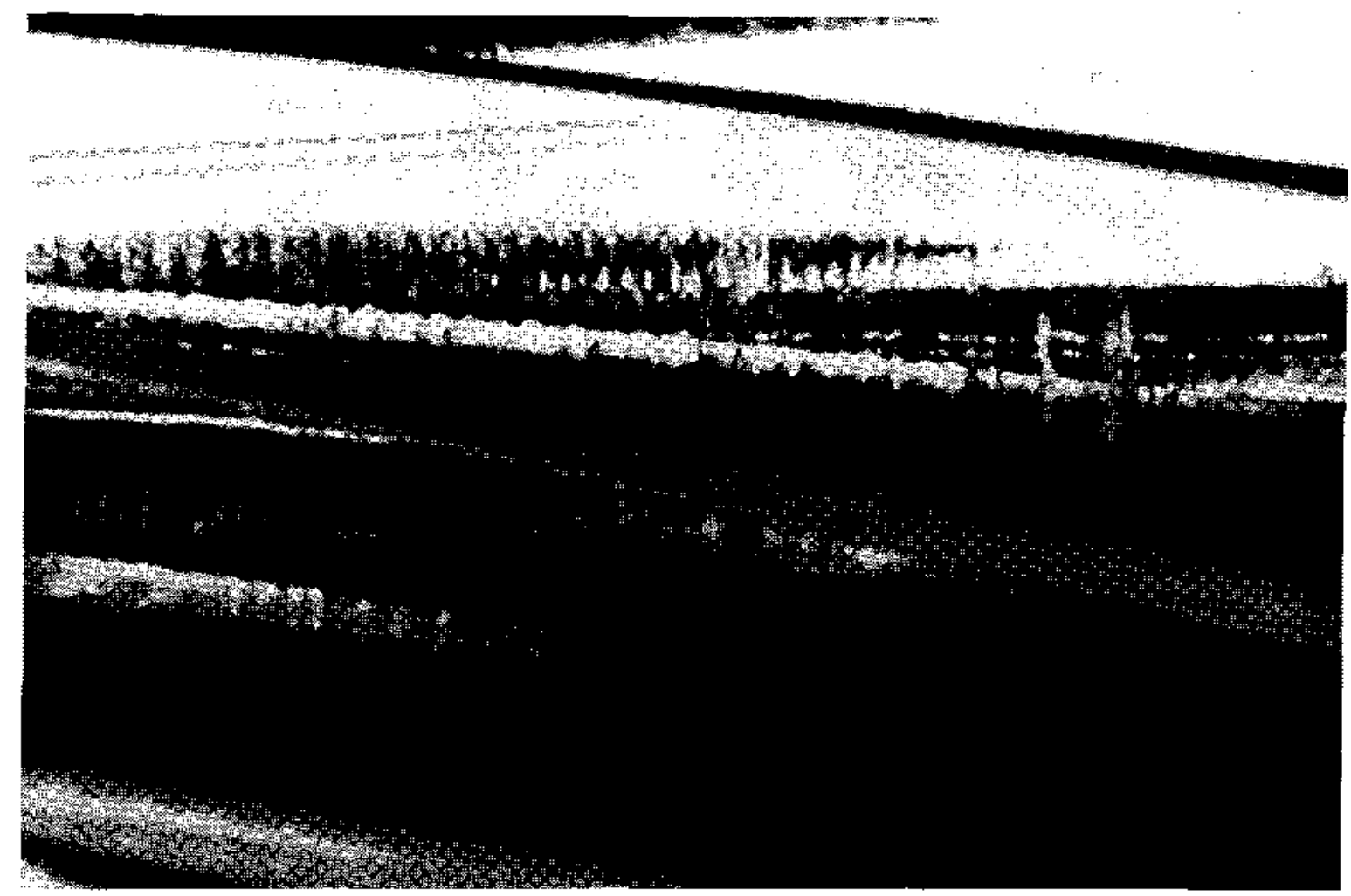

Figure B18 Severe polishing wear that has removed original grinding marks

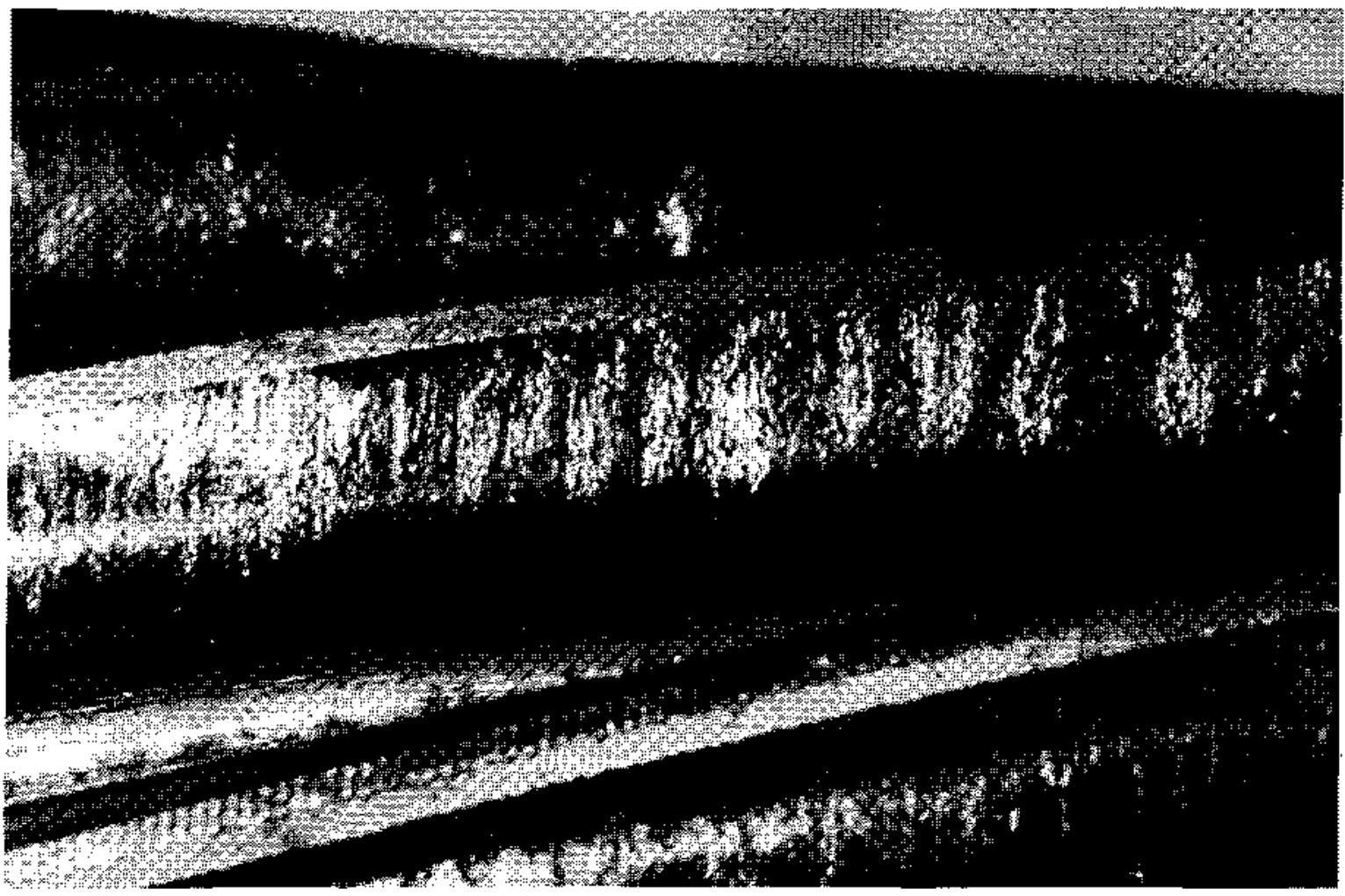

Figure B19 Severe scuffing 


\section{REFERENCES}

1. Dudley, D.W. (1984). "Handbook of Practical Gear Design." McGraw-Hill.

2. ANSI/AGMA 110.04. (1980). "Nomenclature of Gear Tooth Failure Modes."

3. Shipley, E.E. (December 1967). "Gear Failures." Machine Design; pp. 152-162.

4. Dudley, D.W. (1980). "Gear Wear." Wear Control Handbook ASME; pp. 755-830.

5. Ku, P.M. (1975). "Gear Failure Modes - Importance of Lubrication and Mechanics." ASLE Trans., Vol. 19, No. 3; pp. 239-249.

6. Wulpi, D.J. (1966). "How Components Fail", ASM.

7. Metals Handbook, "Failure Analysis and Prevention" (Failures of Gears), Vol. 10, 8th ed.; pp. 507-524.

8. Godf rey, D. (February 1987). "Recognition and Solution of Some Common Wear Problems Related to Lubrication and Hydraulic Fluids." Lubrication Engineering; pp. 111-114.

9. Diesburg, D.E. and Smith, Y.E. (1979). "Fracture Resistance in Carburizing Steels." Metal Progress, Parts I, II and III.

10. Kern, R.F. and Suess, M.E. (1979). "Steel Selection A Guide for Improving Performance and Profits." John Wiley.

11. Parrish, G. (1980). "The Influence of Microstructure on the Properties of Case-Carburized Components." ASM.

12. Littman, W.E. (1970). "The Mechanism of Contact Fatigue", Interdisciplinary Approach to the Lubrication of Concentrated Contacts, NASA SP-237; pp. 309-377.

13. Ueno, T., et. al. (1980). "Surface Durability of Case-Carburized Gears On a Phenomenon of Grey Staining of Tooth Surface." ASME Pap. No. 80-C2/DET-27; pp 1-8.

14. Winter, H. and Weiss, T. (1980). "Some Factors Influencing the Pitting, Micropitting (Frosted Areas) and Slow Speed Wear of Surface Hardened Gears." ASME Pap. No. 80-C2/DET-89; pp. 1-7.

15. Shipley, E.E. (1982). "Failure Analysis of Coarse-Pitch, Hardened and Ground Gears." AGMA Pap. No. P229.26; pp. 1-24.

16. Tanaka, S., et. al. (1984). "Appreciable Increases in Surface Durability of Gear Pairs with Mirror-Like Finish." ASME Paper No. 84-DET-223; pp. 1-8.

17. Sharma, V.K., Walter, G.H., and Breen, D.H. "An Analytical Approach for Establishing Case Depth Requirements in Carburized Gears." ASME pap. No. 77-DET-152; pp. 1-11.

18. Pedersen, R. and Rice, S.L. (1961). "Case Crushing of Carburized and Hardened Gears", Trans. SAE, Vol. 69; pp. 370-380. 
19. Mudd, G.C. (1969-70). "A Numerical Means of Predicting the Fatigue Performance of NitrideHardened Gears." Proc. Inst. Mech. Engrs., Vol. 184, Part 30, pap. 12; pp. 95-104.

20. Kron, H.O. (June 1977). "Gear Tooth Sub-Surface Stress Analysis." Unabridged Text of Lectures, Vol. 1, World Congress on Gearing, Paris, France; pp. 185-202.

21. Sandberg, E. (August 1981). "A Calculation Method for Subsurface Fatigue." Proc. of International Symposium on Gearing and Power Transmissions, Tokyo, Vol. 1; pp. 429-434.

22. Drago, R.J. (1988). "Fundamentals of Gear Design." Butterworths.

23. Lynwander, P. (1983). "Gear Drive Systems." Marcel Dekker.

24. Milburn, A., Errichello, R., and Godfrey, D. (October 1990). "Polishing Wear." AGMA Pap. No. 90 FTM 5.

25. Adams, J.H. and Godfrey, D. (January 1981). "Borate Gear Lubricant-EP Film Analysis and Performance." Lubrication Engineering, Vol. 37, No. 1; pp. 16-21.

26. Hunt, J.B., Ryde-Weller, A.J., and Ashmead, F.A.H. (1981). "Cavitation Between Meshing Gear Teeth." Wear, Vol. 71; pp. 65-78.

27. Blok, H. (June 1977). "Les Temperatures de Surface dans Les Conditions de Graissage Sons Pression Extreme." World Petroleum Congress, Paris.

28. Blok, H. (1970). "The Postulate About the Constancy of Scoring Temperature." Interdisciplinary Approach to the Lubrication of Concentrated Contacts, NASA SP-237; pp. 153-248. 
Appendix C

Introduction to Gear Failure Analysis 


\section{INTRODUCTION TO GEAR FAILURE ANALYSIS}

Gearbox failure analysis is a systematic investigation that identifies gearbox failure modes, diagnoses failure mechanisms, locates the origins of failures, and determines their causes. Once the cause of a failure is known, its remedy may become obvious.

Procedures for gearbox failure analysis will vary depending on a number of factors, including, when and where the inspection is to be performed, the nature of the failure, and time constraints. Even though a customer may elect not to follow the recommendations of fered, a failure analyst should prescribe a specific course of action which outlines the suggested thoroughness of the on-site inspection and the most appropriate metallurgical and laboratory tests to be conducted.

Timing is important. Ideally the failure analyst should visit the site and inspect the failed components as soon as possible after the failure has occurred. If the failure analysis cannot be performed for some time, the failed components should be stored to preserve the evidence.

Ideally, gearboxes should be disassembled and inspected at a well equipped repair or gear shop, but failure analysts don't always have control over where the inspection occurs. If the facilities are determined not to be sufficient the inspection should either be moved to a more appropriate facility or the equipment necessary for analysis should be imported.

The nature of the failure can affect how a gearbox failure analysis is performed. For example, if the gears are damaged but remain capable of operation, a decision must be made whether to shut down and disassemble the gearbox or to continue operating. If continued use of the gearbox is judged as imperative, the gears should be examined with magnetic particle inspection to ensure that there are no cracks. If a damaged gearbox is put back into service, a monitoring system should be prescribed and overseen by the failure analyst. The gears should be periodically inspected and their condition should be documented to determine if the damage is progressive. Gears should be visually inspected through inspection ports, although care should be taken not to contaminate the gear unit when the ports are open. If there is a magnetic plug it should be inspected and the wear debris collected for detailed examination. It is best to drain the lubricant, flush the lubricant system, and replace the lubricant. Samples of the used lubricant should be taken for analysis of properties, wear debris and contaminants. Oil filters should be examined for wear debris and contaminants.

There of ten are situations where shutting down gearbox equipment is extremely costly and the amount of time available for inspection is therefore very limited. It is critical in these instances to carefully plan the failure analysis inspection. It may be helpful to have more than one failure analyst present so that tasks can be divided and time optimized.

A gearbox failure analysis begins with the making of preparations for field work and then proceeds to the actual analysis and followup office work. The major steps of an analysis are described as follows:

\section{Interview the Contact Person}

Before visiting the site of the failure the analyst should interview the contact person by telephone. It is important at this point for the analyst to take responsibility for managing the inspection, including scheduling, ensuring that the contact person understands the responsibilities expected of them, and making sure the facilities for a proper analysis are sufficient. 
The analyst should determine if the contact person has authority to supervise and control personnel, equipment and working conditions at the site. If not, the analyst should make it clear that such control is necessary for performing a failure analysis. Also, ask that arrangements be made so that work can be done safely and in an undisturbed manner. Check to see if safety equipment will be provided or if you need to bring your own and whether any existing union or work rules will influence your investigation. Ensure that no work is performed on the failed gearbox or components. Disassembly should not proceed, nothing should be cleaned, and bolts should not be loosened. Well-meaning technicians who clean the exterior of a gearbox may destroy evidence. Ideally, you should witness any disassembly work. Ask to have a skilled technician assigned to disassemble the gearbox or component under the analyst's direction and designated pace.

The following form, "Requirements for Site Inspection," explains what is needed for a failure inspection.

The forms, "Gearbox Failure Inspection Data" and "Bearing Failure Inspection Data," list the minimum required data for a gearbox failure inspection. They have been tailored for wind turbine gearboxes, but can be modified for other applications. 


\section{REQUIREMENTS FOR SITE INSPECTION}

To: From: Date:

Re:

In order to complete our site inspection we require the following items:

$\square$ Drawings of Failed Parts

$\longleftarrow$ Identification Numbers of Failed Parts

$\square$ Completed Form: Failure Inspection Data

$\square$ Rolling Cart (waist high)

$\square$ Dedicated Technician for Disassembly

$\longleftarrow$ Inspection Table for Viewing Failed Parts

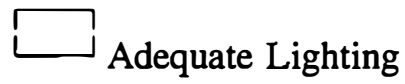

$\square$ Solvent Tank

$\sqcup^{\circ}$ Cleaning Rags

$\square$ Access to Hand Tools

$\square$ Dial Indicator with Magnetic Base

$\left[\_\right.$Overhead Hoist and Hydraulic Press

$\square$ Electric Outlet with Capacity for $1000-$ W Light

$\square$ Extension Cords

Comments: 


\section{GEARBOX FAILURE INSPECTION DATA}

To:

From:

Date:

Re:

In order to best prepare for a site inspection, the following information is needed.

Manufacturer:

Gearbox Serial Number:

Site/Project:

Wind Turbine Pad Number:

Installation Date:

Removed from Service Date:

Gearbox Runtime Hours:

Number of Brake Stops:

Lubricant Type:

Comments: 


\section{BEARING FAILURE INSPECTION DATA}

To: From:

Date:

Re:

In order to best prepare for a site inspection, the following information is needed.

Manufacturer:

Catalogue Number:

Bearing Position:

Site/Project:

Wind Turbine Pad Number:

Installation Date:

Removed From Service Date:

Bearing Runtime Hours:

Number of Brake Stops:

Lubricant Type:

Comments: 
An organized failure analyst should carry a tool kit that includes the following items:

Notebook

Pens and pencils

Calculator

Flashlight (MINI-MAGLITE)

Headlight

Batteries

Magnifying glass (10X)

Pocket microscope (30X)

Mirror

Tape measure

Ruler

Feeler gauges

Calipers for measuring internal and external diameters

Vernier calipers for tooth span measurements

Micrometer

Tweezers

Oilstone

Scotchbrite pad

Files

Scriber

Felt tip paint marker

Duct tape

Magnet

Tags and wire

Plastic baggies

Temperature sticks

Rags

Lubricant sampling equipment should include the following:

Suction pump

Plastic tubing

Sample bottles and labels

Plastic spatula

Equipment for recording gear contact patterns should include the following:

Prussian blue marking compound

DYKEM

Scotch tape

Brushes

Knife

Plain paper (11 x 17 white)

Recommended photographic equipment is listed later in this handbook in Appendix D: "Gear Failure Photography." 


\section{Organize Documentation}

Documentation should be addressed with an organized notebook and file folder system containing all the documentation and forms pertinent to the failure analysis. GEARTECH uses a detailed failure inspection form. This form is tailored to wind turbine gearboxes, but can be adapted to other applications.

\section{Manage Personnel, Equipment, and Working Conditions}

Before commencing with the analysis it is important to get acquainted with the technician who will be working with you and explain your objectives. Make it clear that the work must be done at your pace. Inspect the areas where you will be working to ensure that they are adequate and safe. For example, confirm that working elecrical outlets and adequate lighting are available.

The analyst should confirm that all requested equipment is available and review all safety and shop rules with the technician. Review any documentary evidence that was not previously available. Review assembly drawings with the technician performing the disassembly to plan the disassembly and resolve any problems. Confirm that the necessary tools for disassembly are available. The analyst should also review the service history of the gearbox (see the inspection form for minimum required data).

\section{Interview Witnesses}

Interview any personnel involved in the design, installation, operation, maintenance, and failure of the gearbox. It is best to interview personnel individually to avoid influence from other peoples' opinions. Encourage the person to tell you everything they know about the gearbox, even if they feel it may not be important. Allow them to explain things in their own words and do not ask leading questions. When they feel that they have told you everything they know, ask the more specific questions you may have.

After completion of the interviews and when you are satisfied that all is in order, begin inspection of the gearbox using a detailed inspection form.

Prior to disassembly, inspect the exterior of the gearbox thoroughly. This inspection helps the analyst remember to record important data that could be lost once the disassembly begins. For example, seals and keyways can be damaged during disassembly, and if their condition is not recorded prior to disassembly it will be impossible to determine when the damage occurred. If you are working with a team of analysts, one person should monitor the inspection to ensure that all items are completed in the proper order.

Following inspection of the external condition of the gearbox, inspection of internal components can begin. The visual examination is a detailed inspection of both the failed and undamaged components of the gearbox. All surfaces should be examined, particularly the functional surfaces of gear teeth and bearings. The initial examination should be done without cleaning the parts in order to check for signs of corrosion, contamination, and overheating. Evidence of any such problems should be documented before the parts are cleaned.

Following the initial visual examination, hand wash the components with solvents and reexamine them. The examination should be as thorough as possible and is often the most important phase of the investigation. It is imperative to allot sufficient time for this visual examination so that no clues to the cause of the failure are missed. A low-power magnifying glass and pocket microscope are invaluable tools for this visual examination. 


\section{Document Important Features}

All important features should be documented by writing, sketching, and photographing. It is very helpful to identify each component with unique numbers or letters and mark each gear tooth and bearing roller with identifying numbers so that the components can be clearly identified in written descriptions and their accompanying sketches and photographs. It is especially important to mark bearings carefully since gearboxes often employ more than one of the exact same kind of bearing. It is also important to mark the inboard and outboard sides of the bearings because many bearings are symmetrical and their relative position in the gearbox may be lost if they are not marked.

It is best to write down descriptions and make sketches of all the components before taking photographs. This will determine which components are the most important to photograph.

Be sure to write down all your observations and concentrate on the collection of evidence, not determination of the cause of the failure. Save that judgement for when you are back in the office and have all the collected data in front of you.

Develop a standard system for recording your descriptions. Use consistent nomenclature and describe parts in the same sequence. When describing a bearing, for example, the analyst may start with the same part of the bearing and work through the various other parts in the same order for each bearing. This helps to avoid missing any evidence.

\section{Take Gear Tooth Contact Patterns}

Taking contact patterns is an important initial step of the gearbox inspection. Gear tooth alignment is checked by recording contact patterns. For no-load tests, the contact patterns are obtained by painting one gear with marking compound (Prussian blue) prior to testing. The gear teeth are rolled through mesh, and the compound transfers to the unpainted gear, marking the extent of the contact pattern. A permanent record of the contact pattern is made by lifting the transferred pattern from the gear with Scotch tape and fixing the tape to a clear sheet of white paper.

For loaded tests, contact patterns are obtained by painting several teeth on one or both gears with machinists' layout lacquer (DYKEM) prior to testing. The gears are run under load for a sufficient time to wear off the DYKEM and establish the contact patterns. Records of the contact patterns are obtained by photography.

While performing the failure analysis, you will begin to formulate hypotheses regarding the cause of the failure. With these hypotheses in mind you should decide what samples should be taken for laboratory testing and take whatever samples are permitted. Each situation will be different, and it may not be possible to take samples at the time of the failure analysis, but it is usually possible to take specimens of wear debris and oil samples. If there are broken parts from gears and bearings, ask for permission to take them. If this is not possible, try to ensure that the gearbox and its components are well preserved for future analyses.

\section{Select Specimens for Laboratory Tests}

Take oil samples whether the lubricant is suspected as a cause of the failure or not. It is a quick and inexpensive procedure and the samples can be used as a baseline for future analysis. The effectiveness of lubricant analysis depends on proper sampling techniques and it is important that the same procedures be followed so consistent samples can be obtained. The sampling should be representative of the operating lubricant. Always use clean, plastic sample bottles, and keep all sampling equipment 
scrupulously clean. Prior to sampling, fill out the label by recording the date, sample point and time, type of oil if known, and an identification code for the gearbox, such as the serial number. After the sample is taken and the outside of the bottle is cleaned attach the label.

To take samples from the gearbox drain valve, discard any oil that may have been stagnant in the drain valve. Do this by tuming on the valve, capturing the oil to be discarded in a separate bottle, and taking the sample to be analyzed in a fresh bottle without touching the valve. Take a sample at the start of the drain, at the middle and at the end to obtain a representative sample and avoid stratification.

It is usually a good idea to take samples from the oil source (oil drum or reservoir) as well to determine a baseline for testing. This may also uncover problems with the source oil, such as excessive water content from improper storage.

To sample from the reservoir, use a manual suction pump to draw the oil sample into the sample bottle. Take samples from the top, middle and near the bottom of the reservoir. Use a sampling rod and attach the sampling tube to the rod with plastic ties. Position the sampling tube a few inches from the bottom of the rod to prevent the end of the tube from touching the sides and bottom of the reservoir. Take onethird of the sample with the rod touching the bottom of the reservoir. Take the next one-third with the rod raised mid-height in the oil, and take the final third just below the top surface of the oil.

If you use one lab regularly you may want to prepare an addressed shipping container with written instructions so the samples can be mailed directly from the inspection site. This avoids having to carry oil samples back to your office and may speed the analysis.

\section{Perform Nondestructive Tests}

Nondestructive tests are usually performed in the laboratory, but with the proper equipment they can be conducted in the field. This kind of equipment tends to be expensive, and it may be difficult to transport with all the other equipment suggested in this paper. Three of the more important utensils are a portable hardness tester, portable magnetic particle tester, and portable surface roughness tester. One inexpensive altemative to hardness testing utilizes calibrated hand files to estimate surface hardness. This test requires skill and should only be performed by an experienced technician.

Before leaving the site, methodically review all of your notes and specimens. Make sure you have completed all sections of the inspection form and written descriptions and sketches of all components. Review your photography log to make sure that you have photographs of all pertinent components. Check to be sure you have packed all the specimens you will take back to your office and confirm that specimens to be mailed from the site are correctly packaged and addressed. Take the time to thank all the personnel that assisted you in the inspection.

\section{Review Field Data}

The data obtained from the field inspection of the failure, including written descriptions, sketches and photographs must be analyzed and collated in order to identify the failure mode, diagnose the failure mechanism, and locate the origin of the failure. Many failure modes may be present and it is up to the failure analyst to identify which is the primary mode of failure and which secondary failure modes may have resulted as a consequence. It is sometimes helpful to list all the failure modes that are not evident in order to narrow the possibilities.

In many cases the cause of failure is not disclosed by visual examination alone and it is necessary to perform calculations and laboratory tests to confirm or disprove the hypothesis for the probable cause of 
failure. Each failure mode has distinct characteristics that help identify it. The failure analyst must be intimately familiar with the characteristics of each and the mechanisms by which each failure mode progresses in order to reconstruct the sequence of events that led to the failure. The goal is to identify the primary mode of failure and its origin. With this information the failure analyst can use his or her experience or reference literature to list all possible causes of failure and their influencing factors. Then, through elimination, a hypothesis is formed for the probable cause of failure.

\section{Determine Geometry of Gears}

In order to calculate the load capacity of a gearset it is necessary to know the geometry of the gear teeth. It is very helpful to have engineering drawings of the gears. Otherwise, the following data should be obtained through an inspection of the gears and gear housing:

- Number of teeth in each gear.

- Outside diameter of each gear.

- Face width of each gear.

- Gear housing center distance for each gearset.

- Whole depth of teeth in each gear.

- Thickness of teeth in each gear obtained by span measurement.

- Thickness of teeth in each gear measured at the topland on teeth.

\section{Audit Design of Gears}

The contact stress, bending stress, and contact temperature should be calculated for each gear based on the best estimate of the transmitted loads. The calculated values should be compared with AGMAallowable values to determine the risks of macropitting, bending fatigue, and scuffmg.

\section{Order and Organize Specimens for Laboratory Analysis}

If the primary failure mode is one that is influenced by the geometric quality or metallurgical quality of the gears, it may be necessary to perform tests to determine if there are any geometric or metallurgical defects that may have contributed to the failure. Geometric quality may be questioned if the contact patterns on the gear teeth show misalignment or interference, in which case the gears should be inspected for accuracy on special gear inspection machines (generally available only at gear shops). If the gear tooth contact patterns indicate that the gear teeth were well aligned and the load capacity calculations show that the failure is not predicted, there may be metallurgical defects and the gear tooth metallurgy should be inspected at a laboratory. The failure analyst should specify what tests are required and visit the laboratory to witness the tests.

\section{Examine Specimens Microscopically}

Microscopic examination may be necessary to disclose problems like cracking or macropitting, or to find the origin of a fatigue crack. Light microscopes and scanning electron microscopes (SEM) are ideal for these purposes. An SEM equipped with an energy dispersive X-ray (EDX) is especially useful for identifying corrosion, contamination, and lubricant films. 


\section{Perform Nondestructive Tests}

Nondestructive tests should be performed prior to destructive tests. The nondestructive tests may check for surface hardness, surface roughness, magnetic particle inspection, acid etch inspection and gear tooth accuracy.

\section{Perform Destructive Tests}

For case hardened gears it is generally necessary to section the gear teeth to inspect their subsurface microstructure. If the gear teeth are to be inspected in an SEM they must be cut into sections small enough to fit the loading stage of the microscope. Destructive tests may be used to survey for microhardness, microstructure (using various acid etches), grain size and nonmetallic inclusions. SEM microscopy may also be used.

\section{Evaluate All Data}

After all inspections and tests are complete the failure analyst must evaluate all data. The data may include:

- Documentary evidence.

- Service history.

- Statements from witnesses.

- Written descriptions, sketches, and photographs.

- Contact patterns of gears.

- Laboratory data from oil tests.

- Laboratory data from material tests.

- Geometry of gears.

- Calculations of load capacity of gears.

\section{Form Preliminary Conclusions}

During the course of the investigation it is customary for the analyst to form one or more hypotheses for the probable cause of failure. After all the evidence is gathered it must be evaluated to determine if it supports or disproves the hypotheses.

\section{Test Conclusions}

Evidence factors should be judged in terms of their probability as causes of the failure. When all the evidence is reviewed it may be necessary to modify the initial hypotheses. The process of weighing the evidence for or against the hypotheses may be repeated a number of times. During this evaluation certain hypotheses may be modified or abandoned and new lines of investigation may be charted. 
After the hypotheses have been tested repeatedly against the evidence the failure analyst can reach a conclusion as to the probable cause of failure. In addition, the analyst may identify secondary factors which contributed to the failure.

\section{Form Recommendations}

Based on the findings of the investigation, the failure analyst may make recommendations for repair of the equipment or suggest changes for the design or operation of the equipment in order to prevent future failures.

\section{Write Report}

The failure analysis report should describe all the relevant facts found by the analyst, the various inspections and tests conducted, the weighing of the evidence, the conclusions reached, and any recommendations.

A good report presents the facts as concisely and clearly as possible while minimizing the possibility for misinterpretation. Because the reader is primarily interested in the conclusions of the investigation, these should be listed at the beginning of the report. The main body of the report should present the engineering arguments upon which the conclusions are based. There is no need to lead the reader through all the alternatives and scenarios which the failure analyst considered. Only relevant facts and the details should be presented in a logical order. Data should be presented as succinctly as possible, preferably in tables or in figures and not in lengthy blocks of text. Good photographs are especially helpful for portraying the characteristics of a failure analysis. Lengthy data, complex tabulations, calculations, or test results should be relegated to an appendix. 
Appendix D

Gear Failure Photography 


\section{GEAR FAILURE PHOTOGRAPHY}

Photography is essential to gear failure analysis. It not only provides a fast, convenient way to accurately document the appearance of gear failures, but also is an effective diagnostic tool because the magnification obtained through photographic enlargement and slide projection can disclose evidence that might otherwise have been missed.

GEARTECH has generally found it necessary to do its own gear photography. On several occasions professionals engaged to assist in an analysis have failed to provide satisfactory, detailed photographs. By personally composing photographs through the camera viewfinder, however, a failure analyst or analyst's assistant can capture the necessary detail.

Gear teeth are difficult to photograph properly, especially when they are highly polished, because light reflecting from shiny surfaces causes "hot spots" in the photograph that obliterate details. Cameramounted flashguns are especially problematic because the light they send is reflected off shiny surfaces and back into the lens. Some improvement may be obtained by using an extension cord and holding the flashgun to the side or at an angle, so that reflected light is directed away from the lens. But there is no sure way to determine where to place the flashgun.

The basic problem with flashguns is that the light source is too small. They emit essentially a point source of very harsh light. Adding diffusers to the flash helps soften the flash, but the lighting is still too harsh because it originates from a single point. White cards can be used to bounce light from a flashgun, which in effect increases the number of light sources. Still, the results with this method are not predictable.

A ring flash is better suited for gear photography than are flashguns. A ring flash surrounds the lens with a ring of even light that is relatively soft. The ring flash eliminates hot spots from reflective surfaces in most cases, with the exception of mirror-like surfaces such as bearing raceways. In some cases, however, a ring flash can produce photographs that appear unnatural because they are "flat." This results from a lack of shadows. GEARTECH has found that photographs of pits in gear teeth often do not appear realistic if they are taken with a ring flash.

The performance of a flash can be improved immensely by directing it into an umbrella that reflects the light back to the subject. In effect, the source of the light is increased to the size of the umbrella and the light is diffused and softened. However, a major disadvantage with flash photography is that you cannot preview the lighting by looking through the viewfinder, so you do not know for sure how the photograph will look. The solution to this problem is to substitute the flash with a tungsten lamp. With the light from the tungsten lamp reflected from the umbrella, you can compose the photograph through the viewfinder and see exactly what it will show. Shadows are easily controlled by moving the umbrella or subject, and fill light can be added by using white cards. The umbrella and tungsten lamp eliminate hot spots by providing soft, even illumination, resulting in photographs that are realistic and pleasing. The only disadvantage with the tungsten lamp is its hot operating temperature, which can make close working conditions uncomfortable.

There are a multitude of ways to obtain good photographs and a huge array of photographic equipment to choose from. What follows is a description of equipment and techniques that GEARTECH has used for field and studio photography of gear failures. It is a proven system that has the following features:

- All equipment is lightweight and readily portable (easily carried onboard aircraft). 
- All equipment is robust enough to withstand the rigors of industrial environments.

- The technique is easily learned and reliable enough to produce good photographs consistently.

Following is a list of photographic equipment used in gear failure analysis:

Camera: Pentax SP 1000, 35 mm SLR

Tripod: Benbo Trekker 35 with pan-ballhead

Normal lens: Takumar $55 \mathrm{~mm}$

Wide angle lens: Tamron $35 \mathrm{~mm}$

Macro lens: Tamron SP $90 \mathrm{~mm} \mathrm{F/2.5}$ with extension tube

Tungsten lamp: Lowel Tota-Light, $1000 \mathrm{~W}$

Umbrella: Photek Goodliter Stowaway

Light Stand: Photoflex Litestand

Color Slide Film: Kodak Ektachrome 320T professional, ISO 320

Color Print Film: Fujicolor Reala, ISO 100

Grey Card: Kodak $8 \times 10$ gray card

Color Card: Jobo

Filters: No. $80 \mathrm{~A}$ and skylight

Ring flash: Sunpak auto DX 8R

Flashgun: Vivitar 283 with SB-4 power supply and flash cord

Cable release

\section{Camera}

Most of the features of newer, computerized cameras are not necessary or do not work well for photographing gears. GEARTECH has found that auto-focus cameras are not suited to macrophotography because the light reflected from the shiny surfaces of gear teeth tends to confuse the computer.

Almost any manual, 35-mm single lens reflex (SLR) camera body with quality lenses can be used for photographing gears, so there is no need to buy an expensive camera body. GEARTECH uses a manual Pentax SP 1000 SLR camera body that is an early version of the Pentax K-1000.

\section{Tripod}

For general photography the best illumination is ambient lighting, which usually requires relatively long exposure times. In closeup macrophotography the lens must be stopped down to maintain the depth of field, which also necessitates longer exposures. In these cases a good tripod is necessary to avoid camerashake. An excellent tripod is the Benbo Trekker 35 with a pan-ballhead. It is compact and weighs less than 5 pounds. The tripod is unique because its legs can be positioned at any angle and it features a special monorail the allows you to raise, lower, extend, retract, twist or angle the camera without changing the tripod position. Such flexibility is especially important for macrophotography because the working distances between the camera, umbrella, lamp and subject are small and the camera itself is usually the easiest item to adjust. The tripod works on uneven terrain because each leg can be individually adjusted. This feature is especially important for photographing gears on site, where there may be limited space and no flat surfaces.

\section{Lenses}

GEARTECH has found that three lenses are sufficient for most gear failure analysis work. A normal 55$\mathrm{mm}$ lens is sufficient for most photographs of large gears and gearboxes. When there is not enough room 
to back away from the subject to include everything in the photograph a 35-mm wide-angle lens works well. For close-up photographs of individual gear teeth a 90-mm macro lens works well.

\section{Macro Lens}

Macro lenses are optically corrected for shooting at close range. Fixed focal length macro lenses have the best image quality. Macro zoom lenses can focus closer than nonmacro zoom lenses, but zoom lenses are not specifically designed for close-up work and their image quality is not as good as a fixed focal length macro lens.

Fixed focal lengths vary from about $50 \mathrm{~mm}$ to $200 \mathrm{~mm}$. Longer focal lengths allow extra working distance between the lens and the subject. GEARTECH uses a Tamron SP $90 \mathrm{~mm}$ F/2.5 macro lens. The $90-\mathrm{mm}$ focal length gives a minimum working distance of about $215 \mathrm{~mm}$ from the end of the lens to the subject (about $125 \mathrm{~mm}$ with an extension tube).

The degree of magnification with macro lenses is specified as a magnification ratio, which is the ratio between the size of the subject's image on film and its real size. Most macro lenses have a magnification ratio of $1: 2$, which gives a film image that is one half the real size. With an extension tube, the magnification ratio is increased to $1: 1$, giving a film image the same size as the subject.

\section{Macrophotography}

There are several advantages of using a macro lense and tungsten lighting. Tungsten lighting reflected from an umbrella gives soft, dispersed light that eliminates "hot spots" or bright reflections from shiny gear teeth. With tungsten lighting you view the subject through the lens and see exactly what the photograph will show. Adjusting the angle of the light, camera, or subject allows you to get just the right amount of shadow or highlighting to enhance important gear features.

A good lightịng system includes the Lowel Tota-Light, a 1000-W Tungsten lamp and a Photek, Goodliter Stowaway umbrella. The light and umbrella are mounted on a Photoflex Litestand. All the lighting equipment was chosen for its compactness. Total weight for the lamp, umbrella, and stand is only 6 pounds.

For most gear tooth photographs, GEARTECH uses the macro lens without the extension tube. A $4 \times$ 6 -inch print is about twice the actual size of the subject. This level of magnification can show features that are not apparent in visual inspections of gears. For extreme close-ups the extension tube can be added. It is best to reserve this tool for only those features of the subject that are especially interesting. The extension tube reduces the working distance and the amount of light reaching the film. With less light, of course, larger lens apertures are required and less depth of field is obtained.

There are some disadvantages to macrophotography. These include small working distances, shallow depth of field and difficulty in focusing sharply.

\section{Films for Macrophotography}

For color slides GEARTECH uses Kodak Ektachrome 320T professional film. It is balanced for tungsten light; this eliminates the need for a lens filter. If you use daylight-balanced film in tungsten light you will need to add a No. $80 \mathrm{~A}$ filter to the camera lens to keep the pictures from coming out too orange. There are, however, disadvantages to doing this. They include: 
- A requirement of two aperture stops to compensate for lens effect on the exposure, which means less depth of field for the same shutter speed.

- The filter creates a dim, blue image in the viewfinder.

- There is a slight loss of image quality when filters are used.

- Daylight-balanced film with a No. 80A filter does not reproduce colors as well as a film originally balanced for tungsten light.

Unfortunately, GEARTECH is not aware of a tungsten-balanced film for color prints. In its place a daylight-balanced Fujicolor Reala with a No. 80A filter works best.

\section{Whole Component Photography}

For overall photos of an entire gearbox or other large equipment, GEARTECH uses a normal $55 \mathrm{~mm}$ lens or a $35 \mathrm{~mm}$ wide angle lens. Again, ambient lighting provides the best illumination whenever possible because it allows composition through the lens while viewing exactly what the photograph will show and avoiding problems associated with flash photography, such as "hot spots" or overly dark backgrounds. Many industrial sites have fluorescent lights; these create problems for most color films. However, Fujicolor Reala film gives excellent color reproduction even with fluorescent lighting. The film speed is ISO 100 , which is relatively slow and requires longer exposures with a tripod.

\section{Exposure}

Through-the-lens camera metering and a grey card should give the proper exposure. For macrophotography with the tungsten light, a No. 80A filter, and Fujicolor Reala (ISO 100) film, the exposure is usually about $\mathrm{f} / 11$ with a shutter speed of 1 second. When using Kodak Ektachrome 320T slide film without the No. 80A filter, the exposure is usually about $f / 16$ and a quarter second.

GEARTECH always brackets the exposures to ensure that at least one good exposure of each subject is taken. For color print film it is best to bracket the base exposure by one stop. For example, if the base aperture is $f / 11$, we also shoot the subject at $f / 16$ and $f / 8$. Because color-slide film is more sensitive to the aperture setting, it is best to bracket by only one-half stop.

\section{Ring Flash}

It may not be practical to use tungsten light in cramped quarters, for shooting photographs through small inspection ports, or in areas where electric power is not available. In these cases GEARTECH uses a Sunpak ring flash with a battery pack. The ring flash surrounds the lens with light and produces soft illumination that eliminates most "hot spots." However, it does not provide results as good as those from the tungsten lamp because ring lighting lacks shadows and creates "flat" photos.

\section{Flash Photography}

Flash photography is necessary for stop-action photography. It should be used, for example, when photographing a gear hanging from a swaying hoist. Flash photography also works well for picturing the interior of a gearbox through the inspection port because the light bouncing off the interior surfaces of the housing provides soft lighting. GEARTECH uses a Vivitar 283 flashgun for photographing components that are not shiny. Nevertheless, to avoid hot spots, it is best to use an extension cord and hold the flash somewhat above and to the side at about a 45 degree angle to the film plane. The flash 
can be mounted on a bracket attached to the camera or held in one hand. It may be easiest to hold the flash in the left hand while pressing the back of the left wrist against the left temple and holding the camera in the right hand. This maintains a consistent flash-to-camera distance. When photographing at closer range, set the aperture properly for distance, look through the viewfinder, rock back and forth slightly to get a precise focus and trip the shutter just as the subject becomes sharp. For shiny components it is best to use the ring flash rather that the flashgun to avoid hot spots.

\section{Documentation}

GEARTECH starts every roll of film by writing the film roll number and date on a color card and photographing the card on the first frame. This permits identification of any exposed roll of film. When the film is processed, ask the photo laboratory to include a print of the color card. By comparing the actual color card to the laboratory's print of the color card, the laboratory can correct its processing in order to produce the correct colors.

GEARTECH records each photograph on a log sheet and includes a brief description of the subject, aperture setting, shutter speed, type of film and lighting. The log sheet helps to identify the best camera settings for future photographs and correlates the photographs with separate written descriptions of gear failures.

It is a good idea to type a list of instructions for each photographic process when first starting in gear failure analysis photography. Put the instructions on a laminated card and keep it in your camera bag for quick reference. It is also a good idea to make a list of all your camera equipment and put it on a laminated card. 


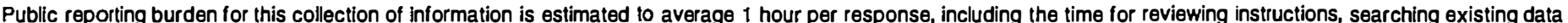

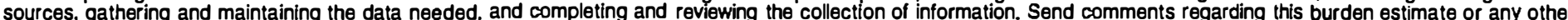

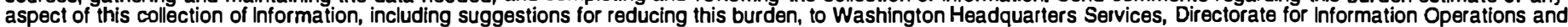

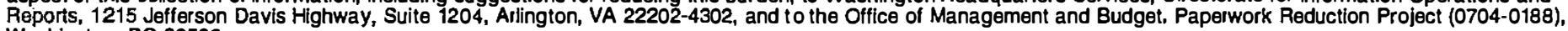
Washington, DC 20503.

\begin{tabular}{|l|l|l}
\hline 1. & $\begin{array}{c}\text { 2. REPORT DATE } \\
\text { September } 1994\end{array}$ & $\begin{array}{l}\text { 3. REPORT TYPE AND DATES COVERED } \\
\text { Subcontract Report, April 1993 June 1994 }\end{array}$
\end{tabular}

4. TITLE AND SUBTITLE

Application Requirements for Wind Turbine Gearboxes

6. AUTHOR(S)

R. Errichello, J. Muller

7. PERFORMING ORGANIZATION NAME(S) AND ADDRESS(ES)

\section{GEARTECH}

Albany, California
5. FUNDING NUMBERS

C: AAO-3-13247-01

TA: WE437410
9. SPONSORING/MONITORING AGENCY NAME(S) AND ADDRESS(ES)

National Renewable Energy Laboratory

1617 Cole Blvd.

Golden, CO $80401-3393$
8. PERFORMING ORGANIZATION REPORT NUMBER

11. SUPPLEMENTARY NOTES

NREL Technical Monitor: W. Musial

12a. DISTRIBUTION/AVAILABILITY STATEMENT

12b. DISTRIBUTION CODE

UC-1210

13. ABSTRACT (Maximum 200 words)

This report is a technical guide which documents the wind turbine gearbox experience of the GEARTECH consulting firm. The report provides a reference on wind turbine gearbox applications for the gear industry, wind turbine designers, and wind turbine operators. This report will assist in selecting, designing, manufacturing, procuring, operating, and maintaining gearboxes for use on wind turbines.
14. SUBJECT TERMS
wind turbine gearbox
18. SECURITY CLASSIFICATION OF THIS PAGE Unclassified
19. SECURITY CLASSIFICATION OF ABSTRACT Unclassified

10. SPONSORING/MONITORING AGENCY REPORT NUMBER

TP-442-7076

DE94011883
15. NUMBER OF PAGES 167

16. PRICE CODE A08

20. LIMITATION OF ABSTRACT UL 